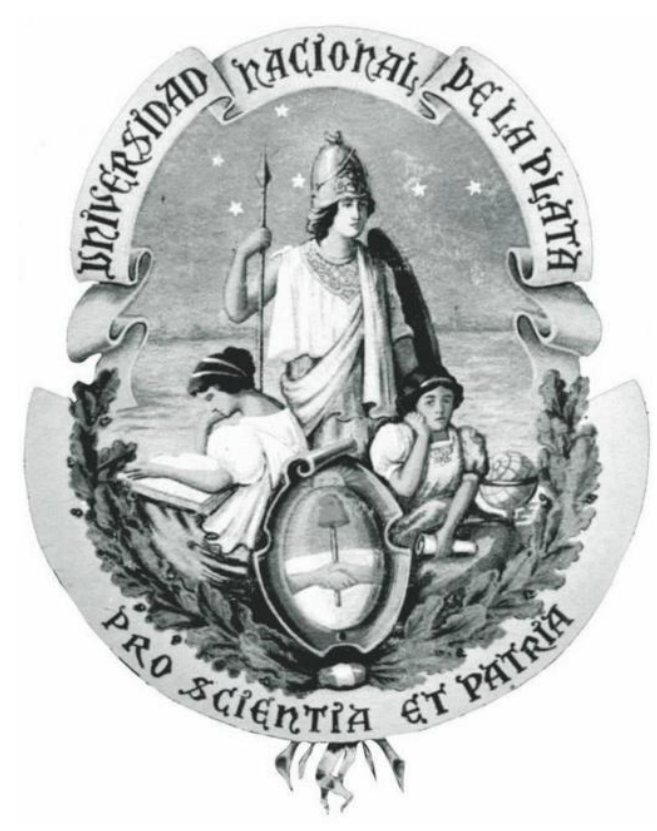

\title{
PALEOAMBIENTES Y VERTEBRADOS ASOCIADOS CON LOS PRIMATES DEL MIOCENO MEDIO DE LA VENTA, COLOMBIA
}

Trabajo de Tesis Doctoral

Manuscrito final de tesis para acceder al título de Doctor en Ciencias Naturales

Tesista: Yaneth Muñoz Saba

Director: Marcelo F. Tejedor

Directora: Adriana Magdalena Candela

Carrera del Doctorado en Ciencias Naturales

Facultad de Ciencias Naturales y Museo (FCNyM)

Universidad Nacional de La Plata (UNLP) 
Nota de aceptación:

Jurado No. 1

Jurado No. 2

Jurado No. 3

La Plata, Argentina, 2018 


\section{DEDICATORIA}

A mis maestros cuyas enseñanzas están plasmadas en esta investigación.

Luis Norberto Parra-Sánchez

In Memoriam

Jorge Hernández Camacho - "E1 Mono Hernández"

Michael Alberico

Thomas van der Hammen

Hermann Duque Caro

A mi amiga!! Por su eterna amistad.

Sandra Isabel Saavedra Sandoval 


\section{AGRADECIMIENTOS}

Agradezco a la Facultad de Ciencias Naturales y Museo (FCNyM) de la Universidad Nacional de La Plata (UNLP), Argentina, enmarcada en cada uno de sus docentes que compartieron su conocimiento conmigo; a la Universidad Nacional de Colombia (UNC), mi alma máter, por su apoyo para la realización de este doctorado, específicamente a sus directivas el señor Rector profesor Ignacio Mantilla (2012-2018), profesor Jaime Aguirre Ceballos Decano de la Facultad de Ciencias de la Sede Bogotá, profesor Luis Alfonso Vélez Moreno ex Decano de la Facultad de Ciencias de la Sede Medellín, y al profesor José Murillo Aldana Director del Instituto de Ciencias Naturales (ICN).

A mis directores Dr. Marcelo F. Tejedor del Centro Patagónico (CONICET), y la Dra. Adriana Magdalena Candela de la FCNyM - UNLP por su orientación y tiempo invertido en la presente investigación; a los evaluadores por su valiosos y enriquecedores comentarios al manuscrito que conllevaron a una mejor comprensión del documento: Dr. Alfredo A. Carlini profesor adjunto UNLP - investigador CONICET, Dr. Javier Marcelo Krause Museo Paleontológico Egidio Feruglio - investigador CONICET y al Dr. Martin Ubilla profesor titular Facultad de Ciencias Montevideo (Uruguay). A mi asesor, profesor Dr. Luis Norberto Parra-Sánchez Laboratorio de Génesis del Suelo - Sede Medellín UNC por su orientación, paciencia y amistad; a los doctores Thomas van der Hamnen (Q.E.P.D.) y Hermann Duque-Caro (Q.E.P.D.), por su apoyo constante, asesoría y formación académica. A los Doctores Jorge V. Crisci y Paula E. Posadas de la Facultad de Ciencias Naturales y Museo de la Universidad Nacional de La Plata, Argentina, por sus enseñanzas.

Esta investigación fue realizada gracias a la financiación otorgada por la Facultad de Ciencias - Sede Medellín - Universidad Nacional de Colombia (UNC), Facultad de Ciencias - Sede Bogotá - UNC, Servicio Geológico Colombiano (SGC), Conservación Internacional Colombia, Leakey Foundation General Grant, Laboratorio Génesis del Suelo (Facultad de Ciencias, UNC, Sede Medellín), Laboratorio GMAS, Colombia (análisis de arcillas), Asociación Colombiana de Zoología (ACZ), y la Agencia Presidencia de Cooperación Internacional.

A los curadores de colección por permitieron su ingreso: Dr. Marcelo Reguero (Colección Paleontológica de Vertebrados, Museo de La Plata (MLP), La Plata, Provincia de Buenos Aires), Geólogo José Enrique Arenas (Museo Geológico Nacional José Royo y Gómez (IGM), Servicio Geológico Colombiano, Bogotá D.C.); Dr. Pedro Patarroyo (Laboratorio de Paleontología de Vertebrados, Departamento de Geociencias, Facultad de Ciencias, Universidad Nacional de Colombia, Sede Bogotá); a los curadores de las colecciones de la Sala del Cenozoico, Museo de Historia Natural de La Sabana, Nemocón, Cundinamarca; y la Colección de Mamíferos (IAvH), Instituto de Investigación de Recursos Biológicos Alexander von Humboldt, Villa de Leyva, Boyacá. 
Por el acompañamiento en la fase de campo con su orientación y aportes en el fortalecimiento de esta tesis, en primer lugar al Dr. Luis Norberto Parra-Sánchez, líder en la investigación referida a la litografía y redefinición del Grupo La Venta; un agradecimiento especial a la Dra. María Teresa Flórez Molina profesora de la Universidad de Antioquia quien junto con el Dr. Daniel Jaramillo profesor Facultad de Ciencias, Sede Medellín - UNC, lideraron la investigación de los paleosuelos del Grupo La Venta; al Dr. Sergio Andrés Restrepo Moreno profesor Facultad de Minas, Sede Medellín - UNC, quien llevó a cabo junto con el Dr. Luis Norberto Parra-Sánchez la investigación de las dataciones de las diferentes formaciones de La Venta; al Dr. Alexis Jaramillo Justinico profesor ICN - Sede Bogotá - ICN - UNC, investigador en polen fósil, por su acompañamiento en campo y asesoría en el tema; al ingeniero forestal Jorge Mario Vélez Curador del Herbario Gabriel Gutiérrez Villegas, Sede Medellín - UNC, por su acompañamiento en campo con el objeto de caracterizar los diferentes hábitats actuales del Desierto de La Tatacoa; al Dr. Javier Guerrero profesor del Departamento de Geociencias, Sede Bogotá - UNC, asesor en estratigrafía; a la Bióloga Luz Victoria Correa por la asesoría en polen fósil; a Gilberto Mendoza asesor en la preservación del material paleontológico; a la ilustradora científica Marie Joelle Giraud López, por su paciencia y dedicación; al Dr. Thomas R. Defler por su orientación, enseñanzas y discusiones sobre la fauna actual de primates neotropicales, y por la traducción del resumen; y a don Jorge Arcila... nuestro conductor y ... "papá" en toda la fase de campo, Sede Medellín - UNC. Agradezco al Dr. Luis Norberto Parra-Sánchez, al Biólogo Francisco Castro, y al Grupo de Investigación Evolución y Ecología de Mamíferos Neotropicales (EEMN) por el permiso de uso de las fotografías de su autoría.

A mis amigos y colegas, profesores del Instituto de Ciencias Naturales - UNC, Dr. Diego Giraldo-Cañas, Dr. Fernando Fernández y Edmon Castell, por su apoyo tanto personal como académico. A los biólogos José Vicente Rodríguez-Mahecha (Conservación Internacional - Colombia), Thomas R. Defler, Enrique Castillo, y al geólogo Dr. Carlos Monsalve.

A los habitantes del municipio de Villavieja quienes durante las fases de campo nos acogieron con todo su cariño, es especial: María Eugenia Manrique Hernández, Consuelo Manrique, Faiver Martínez Perdomo "Chopo", Oswaldo Cleves Perdomo, su esposa Rocío e hijos, y a Camilo Cleves Rivera (Rincón del Cabrito).

Un especial agradecimiento a todas las personas que han sido alumnos en alguno de los cursos que he impartido en especial a todos los estudiantes que han participado en los Grupos Estudiantiles que coordino (Ecología de Mamíferos Neotropicales - EMN, y Ecología Comportamental - ECOUN), ya que gracias a la multitud de preguntas que me han realizado a través de mi vida profesional me llevaron a realizar el doctorado en paleontología para una mejor comprensión de nuestra biota. A Carlos Chamorro, Luis Stinco, Anabela Plos y Juan Pablo Galvis Llanos, quienes desinteresadamente me colaboraron con todos los trámites logísticos administrativos que conllevó la realización del doctorado; a Verónica Ribelotta por todo su apoyo desde la Secretaría del Postgrado 
de la Carrera del Doctorado en Ciencias Naturales de la Facultad de Ciencias Naturales y Museo de la Universidad Nacional de La Plata; y a Nathaly Calvo Roa por la asesoría estadística y su importante colaboración en la edición final. También agradezco a cada una de aquellas personas, cuya lista es larga, que contribuyó con su grano de arena en la realización de esta investigación.

Por último, pero para mí los más importantes, a mi familia, por la formación y el apoyo, y a mis amigos porque siempre están. 


\section{ÍNDICE}

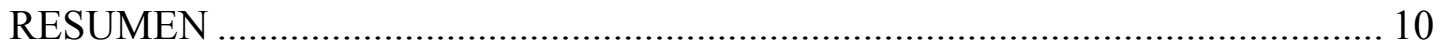

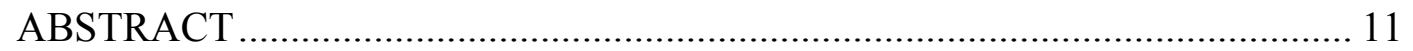

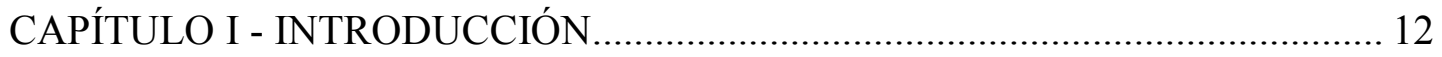

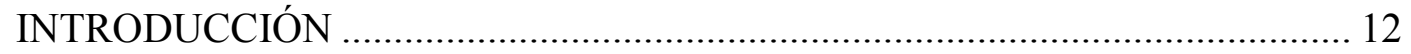

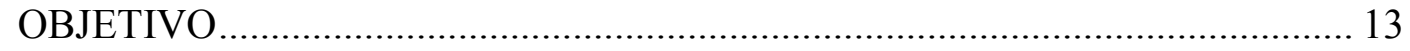

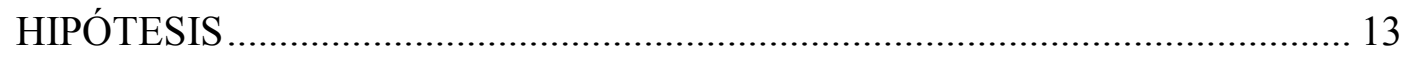

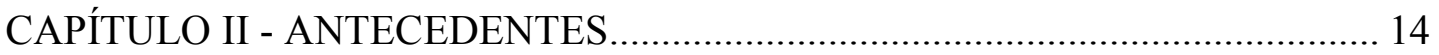

GEOLOGÍA Y GEOCRONOLOGÍA ........................................................... 14

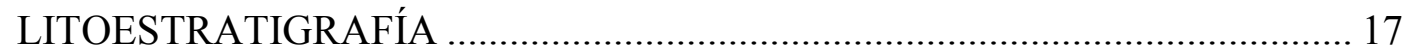

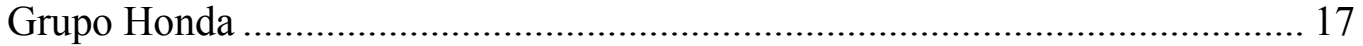

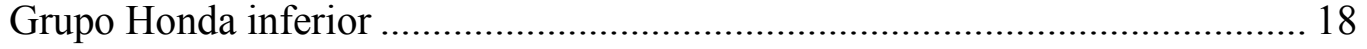

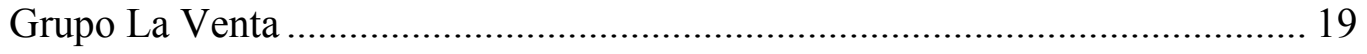

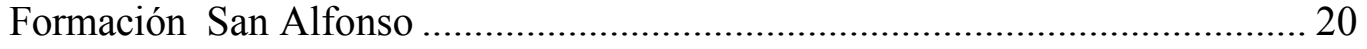

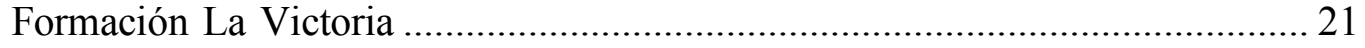

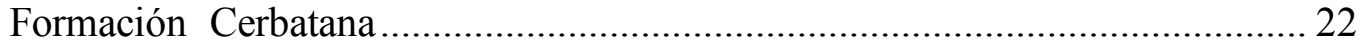

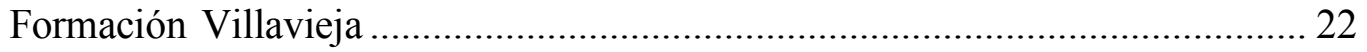

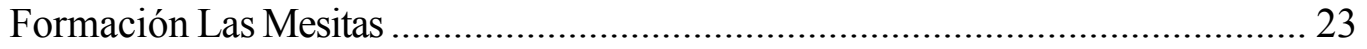

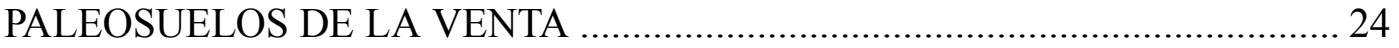

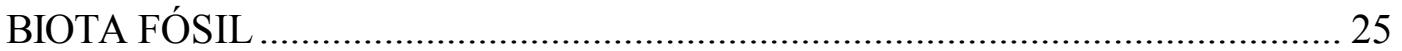

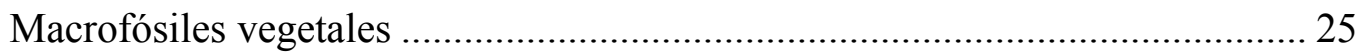

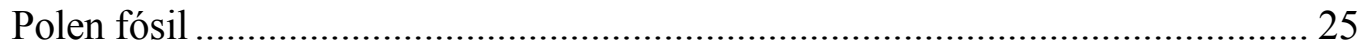

Fauna fósil: diversidad taxonómica y aspectos bioestratigráficos....................... 26

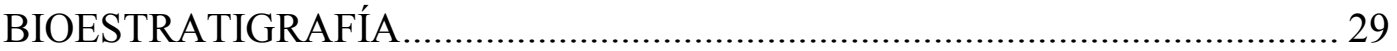

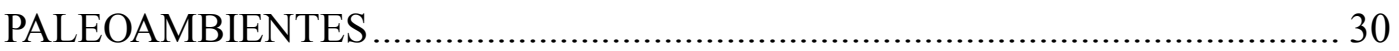

CAPÍTULO III - MATERIALES Y MÉTODOS .................................................... 33

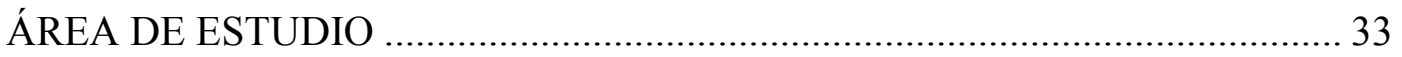

LITOESTRATIGRAFÍA Y GEOCRONOLOGÍA ............................................. 33

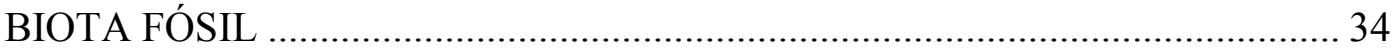

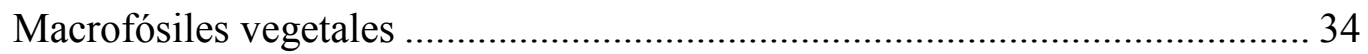

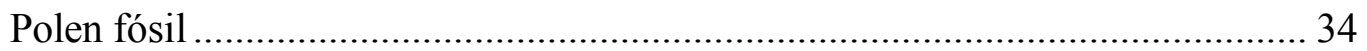

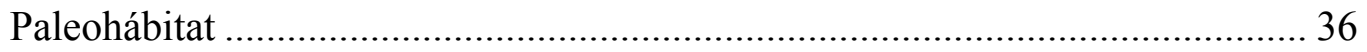

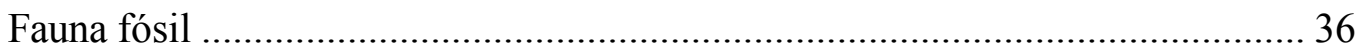

Análisis comparativo entre las diferentes formaciones .................................. 38 


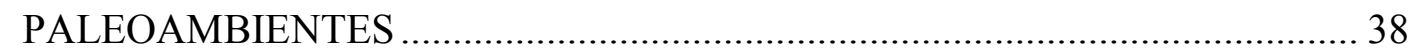

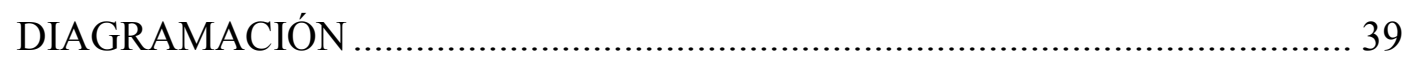

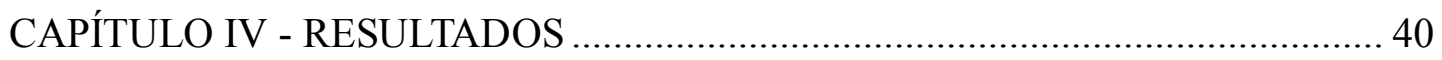

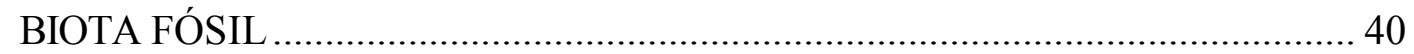

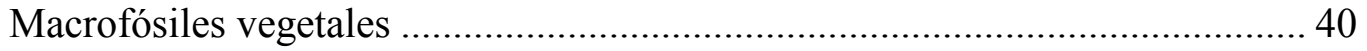

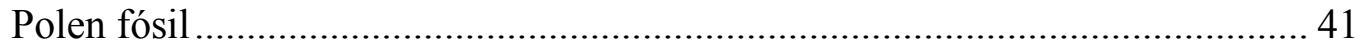

Análisis comparativo entre las diferentes formaciones a partir del polen fósil.. 42

Análisis comparativo entre las diferentes formaciones a partir de los paleohábitats

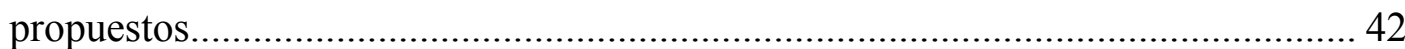

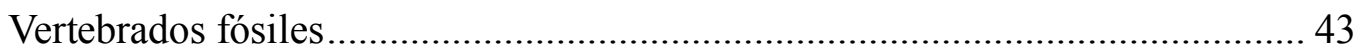

Análisis comparativo entre las diferentes formaciones a partir de los vertebrados fósiles

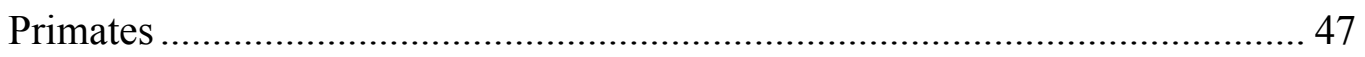

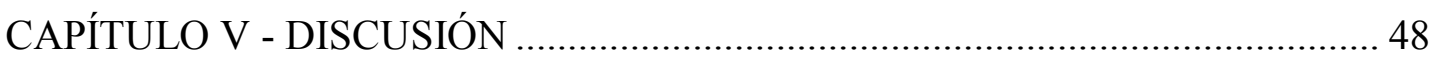

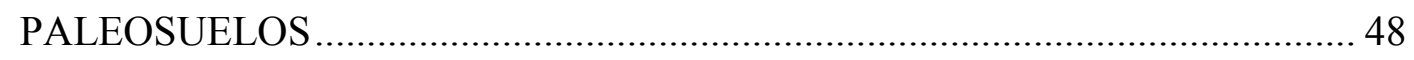

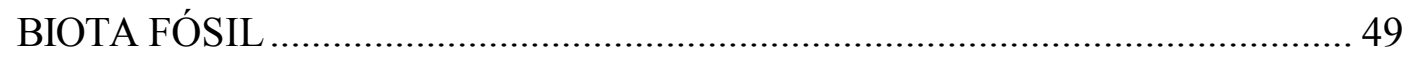

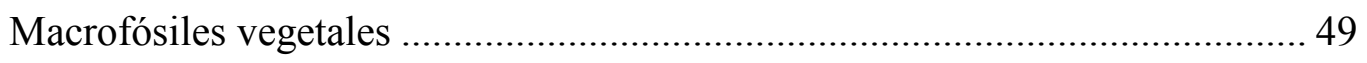

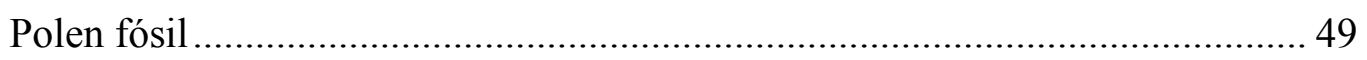

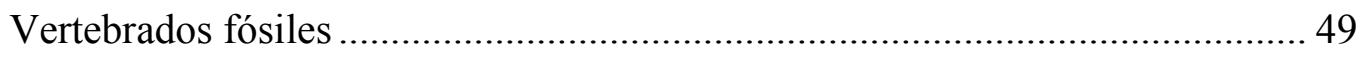

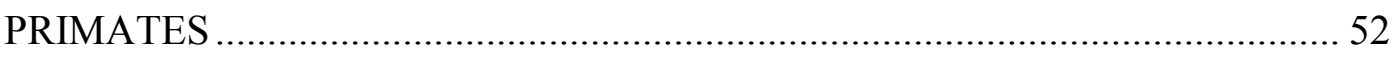

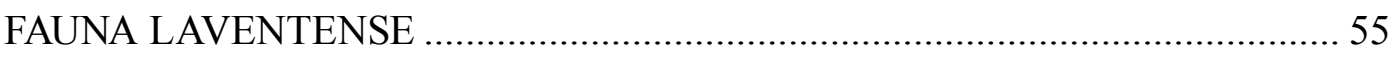

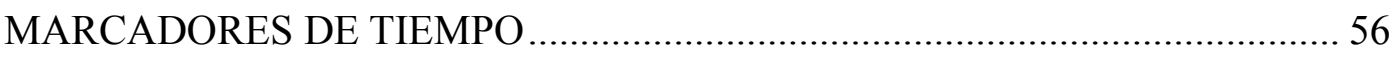

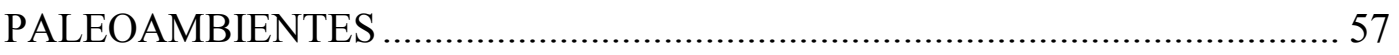

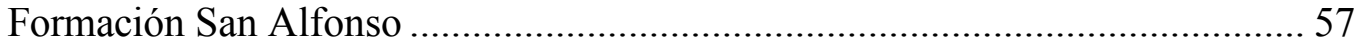

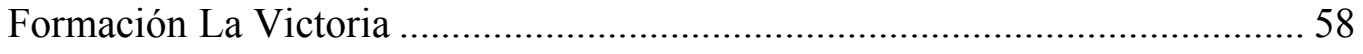

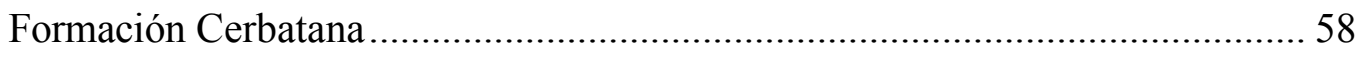

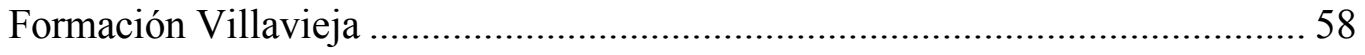

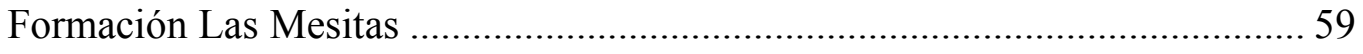

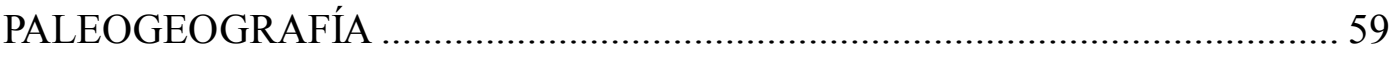

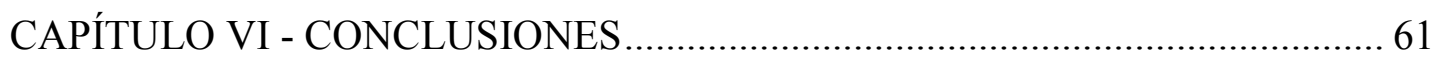

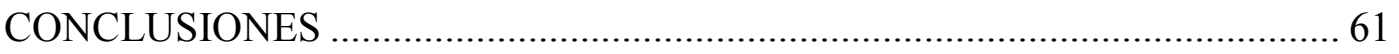

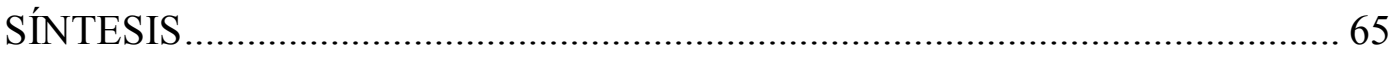

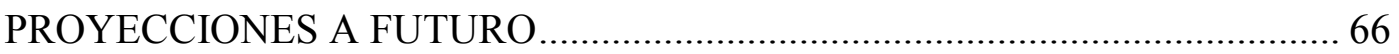

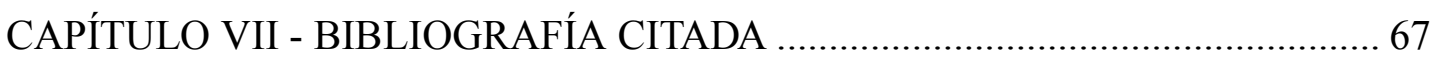

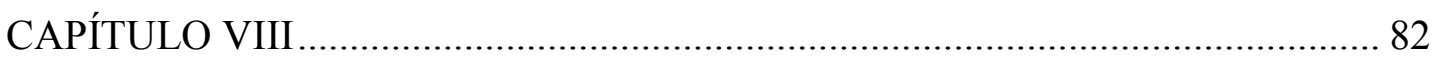

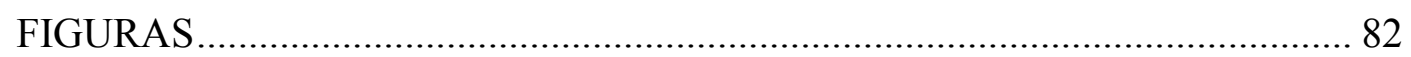


Paleoambientes y vertebrados asociados con los Primates del Mioceno medio de La Venta, Colombia Yaneth Muñoz-Saba

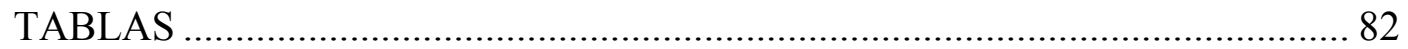

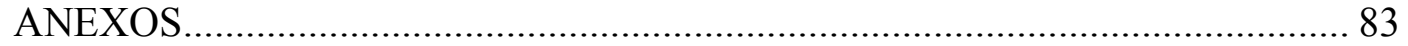




\section{RESUMEN}

Se determinaron los paleoambientes relacionados con los primates fósiles del Mioceno medio del Grupo La Venta (Colombia), a partir de estudios de paleovegetación (macrofósiles, polen fósil) y vertebrados fósiles (con énfasis en mamíferos), resultados enmarcados en la litoestratigrafía de la región, previamente realizada por Fields (1959), Guerrero (1997), y Parra-Sánchez (2016). El Grupo La Venta, sensu Parra-Sánchez (2016) alcanza un área aproximada de $534.151 .529 \mathrm{~m} 2$, en la cual se diferencian cinco formaciones, de base a techo: San Alfonso, La Victoria, Cerbatana, Villavieja y Las Mesitas, que comprenden un intervalo de tiempo entre 13 y 11 Ma (Parra-Sánchez et al. 2015). Se identifican los primeros registros de vertebrados fósiles de las formaciones San Alfonso y Las Mesitas. Se describe un nuevo tipo de fosilización característico del Mioceno medio, presente en las formaciones La Victoria, Cerbatana, Villavieja y Las Mesitas; la base de este tipo de fosilización es la arena. Se registra por primera vez polen fósil para el Grupo La Venta, representado por 622 taxones, en las formaciones San Alfonso, La Victoria y Villavieja. Se redefine la Fauna Laventense, la cual la conforman 99 taxones pertenecientes a 12 órdenes (Primates, Astrapotheria, Chiroptera, Cingulata, Didelphimorphia, Litopterna, Notoungulata, Paucituberculata, Pilosa, Rodentia, Sirenia, Sparassodonta). Teniendo en cuenta la litoestratigrafía y la información de paleosuelos, macrovegetación, polen fósil, vertebrados fósiles (específicamente mamíferos, y dentro de estos los primates), se infieren los siguientes paleohábitats para el Grupo La Venta: (1) Formación San Alfonso: matorral abierto, matorral denso, sabana seca; (2) Formación La Victoria: matorral abierto, matorral denso, humedal, sabana inundable, sabana arbolada, sabana seca, bosques de ribera; (3) Formación Cerbatana: bosque de ribera (3 m altura); (4) Formación Villavieja: sabana arbolada, sabana seca, matorral abierto, matorral denso, bosque húmedo siempre verde (15 m altura); (5) Formación Las Mesitas: bosque húmedo siempre verde (40 m altura), bosque de ribera, sabana arbolada. Los paleoambientes asociados con las especies fósiles de primates de La Venta fueron: (1) Formación La Victoria: humedales Lagonimico conclutatus, Nuciruptor; en bosques de ribera Stirtonia victoriae; en sabanas inundables, sabanas arboladas y matorrales abiertos Miocallicebus villaviejai, Nuciruptor; (2) Formación Villavieja: en bosques de ribera estratificados Laventiana annectens, Neosaimiri fieldsi, Nuciruptor rubricae; en bosques de ribera estratificados y sabanas inundables Cebupithecia sarmientoi, Mohanamico herskovitzi, Micodon kiotensis, Neosaimiri fieldsi, Stirtonia tatacoensis; en bosques estratificados de más de 15 metros de altura Aotus dindensis; siendo estos hábitats diversos, complejos y semejantes a los asociados con las especies de primates actuales. Miocochilius, el notoungulado que previamente se consideraba el fósil indicador del Mioceno medio, sólo se encuentra en las formaciones La Victoria, Cerbatana, Villavieja y Las Mesitas.

Palabras claves: Grupo La Venta, Mioceno medio, primates fósiles, Miocochilius, paleovegetación, polen fósil, vertebrados fósiles, paleohábitats, Fauna Laventense. 


\section{ABSTRACT}

Paleoenvironments relating to fossil primates of the middle Miocene of the La Venta Group (Colombia) were determined based on results from paleovegetation (macrofossils, pollen fossil) and vertebrate fossils (emphasis on mammals) studies registered in the lithostratigraphy of the region and previously published by Fields (1959), Guerrero (1997) and Parra-Sánchez (2016). The La Venta Group, sensu Parra-Sánchez (2016) has an approximate area of 534,151,529 $\mathrm{m}^{2}$, and this author distinguishes five formations in this Group: San Alfonso, La Victoria, Cerbatana, Villavieja and Las Mesitas, comprising a time interval between 13 - 11 Ma (Parra-Sánchez et al. 2015). The first fossil vertebrate records of the San Alfonso and Las Mesitas formations are highlighted. A new type of fossilization characteristic of the Middle Miocene is described and is present in the formations La Victoria, Cerbatana, Villavieja and Las Mesitas. The basis of this type of fossilization is sand. For the first-time fossil pollen was recorded for the La Venta Group. The pollen comprises 622 taxa in the San Alfonso, La Victoria and Villavieja formations. The Laventense Fauna is redefined, and this fauna makes up 99 taxa belonging to 12 orders (Primates, Astrapotheria, Chiroptera, Cingulata, Didelphimorphia, Litopterna, Notoungulata, Paucituberculata, Pilosa, Rodentia, Sirenia, and Sparassodonta). Taking into account the lithostratigraphy and information on paleosols, macrovegetation, fossil pollen, and vertebrates (specifically mammals, and especially primates in this study), the following paleohabitats are inferred for the La Venta Group: (1) San Alfonso Formation: open shrub, dense scrubs, dry savannah; (2) La Victoria Formation: open scrubs, dense scrubs, wetland, flooded savannah, wooded savannah, dry savannah, riparian forests; (3) Cerbatana Formation: riparian forest (3 m height); (4) Villavieja Formation: wooded savannah, dry savannah, open scrubs, dense scrubs, evergreen wet forest (15 m height); (5) Las Mesitas Formation: humid evergreen forest (40 $\mathrm{m}$ height), riparian forest, wooded savannah. The paleoenvironments associated with the fossil species of primates of La Venta were: (1) La Victoria Formation: wetlands habitat of Lagonimico conclutatus, Nuciruptor; riparian forests Stirtonia victoriae; flooded savannahs, wooded savannahs and open bushes Miocallicebus villaviejai, Nuciruptor; (2) Villavieja Formation: stratified riparian forests Laventiana annectens, Neosaimiri fieldsi, Nuciruptor rubricae; stratified riparian forests and floodplains Cebupithecia sarmientoi, Mohanamico herskovitzi, Micodon kiotensis, Neosaimiri fieldsi, Stirtonia tatacoensis; stratified forests over 15 meters high Aotus dindensis. These habitats were diverse, complex and similar to those associated with living primate species. Miocochilius, a notoungulate that was previously considered the fossil indicator of the Middle Miocene in La Venta, is only found in the formations La Victoria, Cerbatana, Villavieja and Las Mesitas.

Key words: La Venta Group, Middle Miocene, fossil primates, Miocochilius, paleovegetation, fossil pollen, vertebrate fossils, paleohabitats, Laventense fauna. 


\section{CAPÍTULO I - INTRODUCCIÓN}

\section{INTRODUCCIÓN}

La paleogeografía del Mioceno medio del Valle Superior de la Cuenca del Magdalena, representada en los sedimentos de La Venta, indica depósitos aluviales, tales como planicies de inundación, diques y canales cuya presencia incidió en la diversidad de la biota fósil de la región (Fields 1959).

Los primeros trabajos referidos a la geología y a la geocronología de La Venta datan de las décadas de 1940 y 1950, con los trabajos de Royo y Gómez (1942a), Fields \& Henao-Londoño (1949), Henao-Londoño et al. (1949), Henao-Londoño (1950) y Fields (1959). Wellman (1970), realiza un estudio sobre la estratigrafía y petrografía del Grupo Honda, donde incluye el área de La Venta. La litoestratigrafía de la región la redefinen Guerrero (1993, 1997), Villarroel et al. (1996) y Parra-Sánchez (2016).

En cuanto a la fauna fósil de La Venta, el trabajo sistemático comenzó en 1929 con los primeros registros de yacimientos de vertebrados en las areniscas del Grupo Honda superior, camino a San Alfonso; y desde la década de 1940 el trabajo de investigación en el área continuó bajo la dirección de J. Royo y Gómez y R.A. Stirton (Butler 1942, Royo y Gómez 1941, 1942a, b, 1945, 1946, Stirton 1947, 1953a, b). Como producto de dichas expediciones se recolectaron vertebrados fósiles con novedosos hallazgos para el grupo de los primates (Stirton 1951, Stirton \& Savage 1952, Miller 1953). Posteriormente, durante las décadas de 1980 y 1990, se realizaron nuevas expediciones paleontológicas mediante acuerdos entre el Instituto Nacional de Geología y Minería de Colombia (INGEOMINAS) (actual Servicio Geológico Colombiano - SGC), y las universidades de Duke y Kyoto, investigaciones que se reflejan en numerosas publicaciones (Wellman 1970, Auffenberg 1971, Presch 1973, Hirschfeld 1976, Hirschfeld \& Marshall 1976, Wood 1976, Busbey 1986, Luchterhand et al. 1986, Cifelli \& Guerrero 1989, Ford 1990, Gebo et al. 1990, McFadden 1990, Takai \& Setoguchi 1990, Van der Wiel 1991, Takai et al. 1992, Guerrero 1993, 1997, Villarroel et al. 1996, Kay et al. 1997, Villarroel 1998, 2000, Takai et al. 2001, Lundberg 2005, Croft 2007, Wheeler 2010).

Las investigaciones desde un punto de vista sistemático en diferentes grupos biológicos continúan hasta la fecha, y se basan en material previamente recolectado o a partir de nuevas prospecciones efectuadas. Entre estas, se puede citar el trabajo de grado de la geóloga Catalina Suárez Gómez (2010), basado en el estudio de un notoungulado; las tareas de prospección del Dr. Carlos Jaramillo (Smithsonian Tropical Research Institute) y su equipo en la región de La Venta; la tesis doctoral de la bióloga Mariela Castro (Universidad Nacional de La Plata), sobre la revisión de la tribu Dasypodini en La Venta; y la tesis doctoral de Marie Hoermer (Universidad de Chicago, USA), sobre la dieta de los mamíferos de La Venta. 
Estos estudios representan diferentes enfoques que incrementan la comprensión de la extraordinaria fauna de mamíferos de La Venta, una de las más diversas en términos ecológicos y taxonómicos, y la más importante de vertebrados fósiles del Mioceno medio a nivel mundial (Henao-Londoño 1950, Stirton 1953b, Kay et al. 1997).

La investigación realizada complementa a las que actualmente están en desarrollo, ya que permite tener un enfoque paleoambiental, en donde se hace énfasis en los posibles paleohábitats de los primates, grupo taxonómico de importancia para la región de La Venta, ya que permiten inferir la incidencia que pudieron tener en la radiación asociada con los clados de primates modernos de la Región Neotropical, así como su comparación con los primates extintos del sur de Argentina (Tejedor com. pers. 2013). De otra parte, hasta la fecha sólo se cuenta con la biozonificación elaborada por Madden et al. (1997), a pesar del incremento en el número de fósiles de vertebrados pertenecientes a distintos grupos taxonómicos; esto se debe, en parte, a que la ubicación geográfica y litoestratigráfica de esos fósiles no se conoce con un nivel de precisión para evaluar la diversidad faunística y su asociación con los principales paleoambientes, y el escenario paleobiogeográfico de La Venta durante el Mioceno.

\section{OBJETIVO}

Determinar los paleoambientes y los vertebrados asociados con las especies fósiles de primates de La Venta, Colombia (formaciones La Victoria y Villavieja), con el fin de contribuir a la reconstrucción de la evolución de la biota del Mioceno medio en el norte del Neotrópico.

\section{HIPÓTESIS}

1. Los paleoambientes asociados con las especies fósiles de primates del Mioceno medio de La Venta, Colombia, fueron más diversos y complejos de lo que se ha interpretado hasta el momento.

2. Los paleoambientes asociados con las especies fósiles de primates del Mioceno medio de La Venta, Colombia, fueron más áridos y secos con respecto a los ambientes asociados con las especies de primates actuales. 


\section{CAPÍTULO II - ANTECEDENTES}

\section{GEOLOGÍA Y GEOCRONOLOGÍA}

El Distrito Honda sensu Butler (1942) se encuentra entre los valles medio y superior de la Cuenca del Magdalena, las capas más antiguas forman parte de la Serie Colorado superior del Oligoceno, edad inferida por su registro fósil; estas capas también se han registrado para la Formación La Cira del Valle Medio de la Cuenca del Magdalena (Wellman 1970, Van der Wiel 1991, Van der Wiel \& Van der Bergh 1992). El Alto del Patá vuelve a tener influencia en la Cuenca Alta del Magdalena desde el Oligoceno hasta el Mioceno, por los procesos de exposición y erosión que experimentó durante este periodo; por lo tanto, se trata como una estructura positiva que separó las subcuencas de Girardot y Neiva. Durante el Plioceno el Alto del Patá inició un proceso de elevación activa (Van Houten \& Travis 1968, Villarroel et al. 1996). Las características de este Alto permiten establecer que era un paleorelieve ubicado en posición transversal con respecto al Valle Superior de la Cuenca del Magdalena (Villarroel et al. 1996).

Los sedimentos semejantes a los del Grupo Honda no se depositaron al mismo tiempo en el Valle de la Cuenca del Magdalena, probablemente porque este proceso fue diferente entre el drenaje principal de la cuenca con respecto a la de sus tributarios (Fields 1959). Por ejemplo, en Coyaima se registran sedimentos clásticos gruesos del Grupo Gualanday, los cuales presentan discordancia y se traslapan con areniscas de grano grueso y limo, minerales característicos del Grupo Honda.

El Valle Superior de la Cuenca del Magdalena probablemente se originó durante el Cretácico (Hauteriviano) cuando se desarrolló un gran delta intracratónico con ríos que tenían sus cabeceras en esta región. Este Valle limitaba con la parte baja del norte de Los Andes, cordillera que tiene sus inicios en el Mesozoico inferior periodo en el que se depositó la Formación Payandé (Jurásico - Cretácico) (Cáceres et al. 2003).

La Venta forma parte de la paleogeografía del Mioceno medio del Valle Superior de la Cuenca del Magdalena, y el levantamiento de la Cordillera Oriental en el Paleógeno contribuye a su formación (Harrington 1962, Van Houten \& Travis 1968). Se estima que el levantamiento de la Cordillera Oriental ocurrió entre 15,10 - 13,90 Ma (edad calculada usando trazas de fisión de apatita) (Van der Wiel 1991, Van der Wiel \& Van der Bergh 1992); pero Duque-Caro (1990c) y Guerrero $(1993,1997)$ consideran que ocurrió entre los 12,90 y 11,80 Ma, siendo el principal levantamiento a los 11,80 Ma, lo cual aisló el Valle de la Cuenca del Magdalena y originó cambios en la red hidrográfica de ésta, cuyo cauce en la actualidad tiene una dirección E a W (Guerrero 1997, De Porta 2003). La formación de esta cuenca incidió en la biota fósil de la región (De Porta 2003); Villarroel et al. (1996) plantean en el contexto tectónico-sedimentario aspectos relacionados con la presencia, expansión y extinción de la fauna de La Venta. 
La Venta se localiza en el Valle Superior de la Cuenca del Magdalena, entre un paleorelieve de altitud baja a moderadamente alta, limita al oriente con la Sierra de Gulumán y los cerros del Remolino, La Mula, La Buitrera y Cerro Gordo (Royo y Gómez 1942a, b), y al occidente con un paleorelieve de baja altitud; se encuentra inmersa en una depresión estrecha y elongada que se formó en el Cretácico inferior (Aptiano) y está bordeada por el Alto del Patá o Alto de Payandé, el cual se compone de rocas sedimentarias volcánicas de la Formación Payandé, los sedimentos del Alto del Patá contribuyeron a la formación del Valle Superior de la Cuenca del Magdalena; este valle lo circunda la Formación Guadalupe del Cretácico tardío (Maastrichtiano), al sur la Formación Guaduas (Paleoceno), al nor occidente la Formación Gualanday (Eoceno - Oligoceno) y su parte media reposa sobre rocas del Triásico - Jurásico (Cáceres et al. 2003, Villarroel et al. 1996).

En La Venta los niveles estratigráficos más bajos de la Formación La Victoria, sensu Villarroel et al. (1996) presentan afloramientos de la planicie de Natagaima y el Alto del Patá; se registran sedimentos del Eoceno - Oligoceno en Baraya (suroriente), y en otros sectores del Valle Superior de la Cuenca del Magdalena, los cuales provienen del sur y suroriente (Fields 1959). Al seguir la secuencia de depósito, Fields (1959) infiere que el área actual de este valle fue sometida a procesos de pliegues, fallas y erosión sucesiva.

Entre Cerro Gordo y La Venta no se presentan depósitos del Paleógeno, pero en áreas aledañas se evidencia que el Grupo Honda superior descansa sobre rocas de este periodo y se registran discordancias locales (Fields 1959). Por su parte, Royo y Gómez (1942a, b) reconoce sedimentos del Grupo Honda inferior en cercanías a Potosí y entre Villavieja y Baraya. Villarroel et al. (1996) plantean que la distribución de las unidades litoestratigráficas no sólo es independiente de la orientación NNE-SSW de los ejes estructurales, sino también de la transversalidad del Alto del Patá; por lo tanto, infieren que la última fase de levantamiento del Alto del Patá ocurrió en el Plioceno tardío y/o en el Pleistoceno temprano.

Las capas de los Conglomerados de Cerbatana, presentes en La Venta, fueron depositadas según Takemura \& Danhara (1985) entre 15 - 16 Ma, y según Guerrero (1993) alrededor de 12 - 13 Ma, lo cual probablemente marca un período de levantamiento de la Cordillera Central. Por su parte, el Miembro Baraya se formó en una planicie con una suave pendiente que se desarrolló como consecuencia de un incipiente levantamiento de la Cordillera Oriental (Guerrero 1993). Este escenario es apoyado principalmente por la presencia de una litología arcillo - limosa, y el desarrollo local de los depósitos lacustres y pantanosos en Fish Beds. De manera similar, la aparición de las capas rojas en el Miembro Cerro Colorado sería el resultado de la conformación del Valle Superior de la Cuenca del Magdalena como una cuenca sedimentaria aislada de la cuenca amazónica. Esta hipótesis se sustenta en el cambio abrupto de las paleocorrientes, las cuales indican un flujo principal de E a ESE en la Formación La Victoria y en el Miembro Baraya de la Formación Villavieja (Guerrero 1993), mientras que las paleocorrientes del Miembro Cerro Colorado indican un flujo hacia el oeste (Wellman 1970, Villarroel et al. 1996). 
Por otra parte, Wellman (1970) divide originalmente al Grupo Honda en: (1) Formación La Dorada, parte inferior, depositado durante el incremento tectónico y volcánico, con la litofacies nombrada como Miembro Perico, la cual incluye una capa contrastante de ortoconglomerados llamada informalmente por el autor como Río Seco Conglomerate; (2) Formación Villavieja, parte superior, formada durante la actividad tectónica media y por episodios de volcanismo; los cuales formaron litofacies contrastantes, los miembros Baraya Volcanic y Cerro Colorado Redbed. Este autor, considera que el Valle Superior de la Cuenca del Magdalena se derivó de la actividad volcánica ígneo metamórfica proveniente de la Cordillera Central y por lo tanto fue cubierto por clastos sedimentarios y metamórficos depositados por ríos siguiendo generalmente una dirección este a suroeste. Los dos principales ambientes de sedimentación fluvial fueron: (1) bajo gradiente - alta sinuosidad, (2) alto gradiente baja sinuosidad; por lo tanto, el Mioceno del Grupo Honda superior comprendía canales fluviales de areniscas y planicies de inundación de lutitas, con remanentes de fauna y flora que indican que el clima alternó entre tropical húmedo y seco, con sabanas interfluviales separadas por ríos bordeadas por bosques.

Van der Wiel (1991) en su tesis doctoral enfatiza la estratigrafía de la Formación Honda y establece, a partir de estudios de petrología, que las gravas y areniscas tienen una procedencia del oeste.

Guerrero (1997) define que la litología del Grupo Honda superior presenta dos formaciones: (1) Formación La Victoria, la cual se formó durante una fase de intensa actividad volcánica y tectónica de la Cordillera Central y se depositó con una tasa de sedimentación de aproximadamente $950 \mathrm{~mm} / 1.000$ años; las capas del Conglomerado Cerbatana, en el techo de esta formación, se conformaron como resultado de un pulso de levantamiento rápido de la Cordillera Central. (2) Formación Villavieja, se formó durante el ya activo levantamiento y volcanismo de la Cordillera Central y durante el primer levantamiento de la Cordillera Oriental; se depositó con una tasa de sedimentación de aproximadamente $423 \mathrm{~mm} / 1.000$ años. El autor corrobora algunos planteamientos de Fields \& Henao-Londoño (1949) y propone el nombre de Formación La Victoria para el techo del Grupo Honda superior.

Por último, Anderson et al. (2016) a partir de un estudio integrado con información de petrografía y paleoprecipitación, plantean que el levantamiento del Macizo de Garzón (Huila) se convirtió en una barrera orográfica que generó una gran cantidad de lluvias e influyó en la evolución de los principales sistemas fluviales del norte de Suramérica (ríos Amazonas, Magdalena, Orinoco); estos autores postulan que la elevación del Macizo de Garzón (Cordillera Oriental) comenzó cuando se establecía la Formación Villavieja, época del inicio de las lluvias (12 - 11 Ma).

Fields \& Henao-Londoño (1949) fueron los primeros en elaborar un mapa detallado de la geología de La Venta, el cual cubrió un área de 21.043.248 $\mathrm{m}^{2}$ desde Cerro Gordo hasta Quebrada La Venta (Huila). Posteriormente, Diego Henao-Londoño (1950) 
describe el primer informe técnico de la geología de La Venta, el cual se complementa con la tesis doctoral sobre la geología de esta zona, realizada por Fields en 1959, investigación que se apoyó en una versión simplificada del mapa geológico (HenaoLondoño et al. 1949). En 1970 se publica la tesis doctoral de Wellman sobre estratigrafía y petrografía del Grupo Honda, la cual incluye el área de La Venta (Valle Superior de la Cuenca del Magdalena). Guerrero (1993, 1997) amplía la cartografía original de Henao-Londoño (1950) a 421.345.005 $\mathrm{m}^{2}$ y propone la Formación La Victoria, antigua Formación Cerbatana, y retoma el nombre de Formación Villavieja sensu Wellman (1970), corroborando algunos planteamientos de Henao-Londoño (1950) y de Fields (1959), y establece los ambientes sedimentarios de esta región. Villarroel et al. (1996) se basan en la cartografía de Guerrero (1997) y discuten la nomenclatura estratigráfica de La Venta y hacen énfasis en el Grupo Honda. Finalmente, Parra-Sánchez (2016) propone que La Venta es un Grupo estratigráficamente diferente que el Grupo Honda (Figura 1).

En cuanto a la geocronología en el área de La Venta, las primeras investigaciones fueron realizadas por Stirton (1951, 1953b) y Fields (1959). Hayshida (1984) establece la edad de catorce muestras de La Venta y cinco de El Dinde a partir de análisis paleomagnéticos; con datos de huellas de fisión. Takemura \& Danhara (1985) reconocen tres edades para el área de La Venta: 15,7 1,1 Ma / 14,6 1,1 Ma / 16,1 0,9 Ma (Molina Member: 16,1 0,9 / 14,6 1,1 Ma, Los Mangos Red Member: 15,7 1,1 Ma); con esta misma metodología, Takai et al. (1992) registran las siguientes edades: 12,6 0,5 Ma / 13,6 0,7 Ma / 13,6 0,5 Ma (Los Mangos Red Member (LV 13): 15,7 1,1 Ma, Molina Member KS4: 14,6 1,1 Ma y LV8: 16,1 0,9 Ma). Takemura et al. (1992) reconocen para La Venta otras tres edades: 13,6 0,5 Ma / 13,6 0,7 Ma / 12,6 0,5 Ma para Tatacoa Red Member; Van der Wiel (1991) determina por medio de dataciones con K - Ar y huellas de fisión la edad de la Formación Honda, la cual se encuentra entre $\geq 16$ y 9 Ma (Van der Wiel \& Van der Bergh 1992). A partir de estudios magnetoestratigráficos, Flynn et al. (1997) proponen que el Grupo Honda se registra en un intervalo entre los 13,50 y los 11,60 Ma; estos autores y Guerrero (1993) plantean que la Formación La Victoria tiene una edad entre 13,8 y 12,5 Ma. Finalmente, para la Formación Villavieja, Anderson et al. (2016) proponen una edad entre los 13,2 y los 12 Ma, y Parra-Sánchez et al. (2015) un intervalo entre 13 y 11 Ma.

\section{LITOESTRATIGRAFÍA}

\section{Grupo Honda}

Localidad tipo: Cordillera de San Antonio o Río Grande, al oriente del Municipio de Honda, Departamento del Tolima, Colombia (Butler 1942). La principal fuente de sedimentos se produce desde el occidente, con un espesor aproximado de más de 4.000 m (Butler \& Schamel 1988). 
Relaciones estratigráficas: el Grupo Honda del Valle Superior de la Cuenca del Magdalena se encuentra enmarcado entre dos discordancias: en la base, a unos 13,5 Ma, con el techo del Grupo Gualanday (Oligoceno ?), y en el techo, a unos 10,1 Ma, con la base del Grupo Huila. Por lo tanto, se infieren episodios de volcanismo y levantamiento tectónico de las cordilleras Central y Oriental (Guerrero 1997) (Anexo 1).

Caracterización litológica y composicional: se distinguen dos unidades, el Grupo Honda superior y el Grupo Honda inferior (Butler 1942). El Grupo Honda superior se caracteriza por presentar abundantes andesitas y material clástico dacítico (Butler 1942, Butler \& Schamel 1988); cuyos sedimentos provienen de las cordilleras Central y Oriental (Hettner 1892, Henao-Londoño \& Fields 1949) (Anexo 1).

\section{Grupo Honda inferior}

Sección tipo: $104 \mathrm{~m}^{2}$, con un espesor máximo de 130 m (Fields 1959).

Área de distribución: Fields (1959) limita el área de La Venta Badlands, al nororiente del municipio de Villavieja en la parte norte del departamento del Huila y específicamente define esta área dentro del patrón de drenajes de las quebradas La Tatacoa, El Líbano, La Venta y la parte más baja de la Quebrada Las Lajas; precisando su posición geográfica en $03^{\circ} 19^{\prime} \mathrm{N}$ y $75^{\circ} 0,8^{\prime} \mathrm{W}$.

Relaciones estratigráficas: presencia de una discordancia entre las rocas del Honda y de la Serie Gualanday, a $7 \mathrm{~km}$ a lo largo de la carretera de Potosí a Aguacaliente, sobre el Río Cabrera. Arenosa Sandstone and Siltstones en la Quebrada La Arenosa, afluente del Río Cabrera, a $8 \mathrm{~km}$ en línea recta al oriente de Cerro Gordo, en donde se encuentra la base del Grupo Honda (Henao-Londoño 1950).

Caracterización litológica y composicional: las unidades litoestratigráficas propuestas por Fields \& Henao-Londoño (1949), Henao-Londoño et al. (1949), Henao-Londoño (1950) y Fields (1959) son (Anexo 1):

- Serie Gualanday (Henao-Londoño 1950). Área de distribución: Río Cabrera, Municipio de San Alfonso, Quebrada La Arenosa. Litología: variedad de arcillas rojizas, con areniscas de color rojizo a rosado.

- Arenosa Sandstone and Siltstones (Henao-Londoño 1950). Litología: secuencia de areniscas de grano grueso, predominan las arcilitas de color marrón a rojo, las limolitas y lutitas de color marrón a gris. Observación: reconocida por Royo y Gómez (1942 a, b) y puede ser parte del Mioceno medio.

El Líbano Sands and Clays (Henao-Londoño 1950). Litología: predominan las areniscas de color rojizo a marrón, es pobre en arcillas y limos. Observación: Fields (1959) considera que estos son los sedimentos más viejos del Grupo Honda.

- Cerbatana Gravels and Clays including San Nicolás Clays (Henao-Londoño 1950). Litología: areniscas, excesivamente rico en gravas; el color predominantemente es 
gris con pocas variaciones locales a amarillento. Se registran dos unidades características: (1) El Miembro San Nicolás, el cual es un bloque de arcilla blanca con predominante color marrón, con algunas capas delgadas de carácter arenoso, lo que da un aspecto gris a la arcilla; la base de la arcilla presenta alto contenido de carbonato de calcio (Henao-Londoño 1950). (2) El Miembro Cerbatana, con gravas que se encuentran en las areniscas, generalmente de grano grueso (Villarroel et al. 1996).

Monkey Unit (Henao-Londoño 1950). Litología: predominan las arcillas y limos en secuencia, sobre las areniscas; donde también se presentan abundantes concreciones, algunas tienen forma de pequeños cilindros verticales de $30 \mathrm{~m}$ de alto y aproximadamente 10 a $15 \mathrm{~cm}$ de diámetro.

Unit below Fish Bed (Henao-Londoño 1950). Litología: conformada principalmente por areniscas grises, intercaladas con arcillas marrón a marrón-grisáceas, con limos.

- Fish Bed (Henao-Londoño 1950). Litología: conformada por arcillas limosas de color verde, con algunas capas de areniscas; es una capa delgada y continua.

- Unit above Fish Bed (Henao-Londoño 1950). Litología: conformada principalmente de arcillas de color marrón, color semejante a Unit below Fish Bed, con niveles de areniscas intercaladas con capas delgadas de areniscas lenticulares.

- Ferruginous Sandstones (Henao-Londoño 1950). Litología: se conforma de piedra arenisca ferruginosa de color gris y arcillas marrones, con lentes de arenisca.

- La Venta Clays and Sandstones (Henao-Londoño 1950) o Unit between Ferruginous Sands and Lower Red Bed (Fields \& Henao-Londoño 1949). Litología: conformada por areniscas lenticulares de color gris que localmente tienen algunos guijos que alternan con arcillas finas de color marrón, arcillas grises y limolitas; las areniscas predominan en la secuencia.

- Lower Red Beds (LRB) (Henao-Londoño 1950). Litología: capas de arcilla, conspicuas por su color rojo intenso en su parte superior.

- Intermediate Clays and Sandstones (Henao-Londoño 1950) o Unit between Upper and Lower Red Beds (Fields \& Henao-Londoño 1949). Litología: la secuencia es predominante arenosa, de color gris.

Upper Red Beds (URB) (Henao-Londoño 1950). Litología: formada por una sucesión de arcillas rojas, alternando con otros colores de rojo a marrón y varias capas de areniscas grises con un promedio de $30 \mathrm{~m}$ de espesor.

Brown Sequence (Henao-Londoño 1950) o Las Mesitas Sands and Clays (Fields 1959). Litología: se caracteriza por presentar alternancia de cuerpos lenticulares grandes y pequeños de areniscas pardas y grisáceas, con arcillas limosas marrón y rojizas y tobas delgadas intercaladas.

\section{Grupo La Venta}

El Grupo La Venta, sensu Parra-Sánchez (2016) es una secuencia de sedimentos continentales de origen fluvial, con un área aproximada de $534.151 .529 \mathrm{~m}^{2}$, y está conformado por cinco unidades litoestratigráficas, las cuales de base a techo son: 
Formación San Alfonso, Formación La Victoria, Formación Cerbatana, Formación Villavieja y Formación Las Mesitas; el tiempo que comprende está entre los 13 y los 11 Ma, según las últimas dataciones realizadas a partir de aproximadamente 700 datos de U-Pb (Parra-Sánchez et al. 2015) (Figuras 2, 3; Anexos 1, 2).

Formación San Alfonso (sensu Royo y Gómez 1942b, en parte; Parra-Sánchez 2016; com. pers. Parra-Sánchez 2016)

Sinónimos

- "Fosfatos de San Alfonso": Formación Gualanday: Oligoceno (Royo y Gómez 1942b, en parte)

- San Alfonso: Serie Gualanday: Oligoceno (Henao-Londoño 1950, en parte)

- Secuencia A: Formación Honda (Van der Wiel 1991, en parte)

\section{Localización}

Es la base del Grupo La Venta, aflora en el Alto Natagaima; son los estratos localizados sobre el techo de la Formación Gualanday (Oligoceno, Cerro Chacarón) y la Formación Payandé (Triásico - Jurásico, Alto del Patá) (Royo y Gómez 1942b, Henao-Londoño 1950, Parra-Sánchez 2016) (Figura 3).

\section{Características}

Estratos compuestos por areniscas gravillosas de geometría lenticular y poco espesor; limolitas y estratos finos subordinados; gran parte de los cantos rodados gruesos y detritos provienen de rocas del Triásico - Jurásico, por lo tanto, los estratos son de coloración rosada; la secuencia no supera los $50 \mathrm{~m}$ de espesor (Anexo 2).

\section{Ambiente Sedimentario}

La Formación San Alfonso se formó por corrientes de régimen torrencial en abanicos aluviales que drenaban el macizo de Natagaima. Las terrazas, drenajes y características sedimentológicas, como los cantos rodados gruesos de coloración rosada, la estructura lenticular de escala pequeña y la presencia de relieve positivo con pendiente fuerte, permiten inferir que fueron abanicos aluviales cuyas corrientes probablemente fluyeron desde los depósitos del Triásico - Jurásico del Estrecho de Natagaima o Alto del Patá o Payandé, hacia el sur. Estos ríos presentaron un gran cauce torrencial que corría por un estrecho canal con mucha carga con respecto al caudal, los cuales pudieron ser permanentes o no, y desembocaban en un gran río caudaloso asociado con llanuras aluviales y pedregosas (Figura 4; Anexo 3).

\section{Características marcadoras}

- Cantos rodados, gruesos de coloración rosada provenientes del Triásico - Jurásico.

- Estratos con estructura lenticular de escala pequeña.

- Nódulos de óxido de hierro de coloración roja que evidencian la presencia de paleosuelos.

- Paleorelieve colinado. 
Formación La Victoria (sensu Guerrero 1993, en parte; Parra-Sánchez 2016; com. pers. Parra-Sánchez 2016)

\section{Sinónimos}

- Serie Honda inferior (Butler 1942, en parte)

- Gravas y Arcillas de Cerbatana con las Arcillas de San Nicolás (Henao-Londoño et al. 1949, en parte)

- Cerbatana Gravels and Clays (Henao-Londoño 1950, en parte)

- Cerbatana Gravels and Clays including San Nicolás Clays (Fields \& HenaoLondoño 1949, en parte)

- Cerbatana Gravels and Clays (Stirton 1953b, en parte)

- Cerbatana Gravels and Clays (incluye San Nicolás Clays) (Fields 1959, en parte)

- Miembro Perico: Formación La Dorada (Wellman 1970, en parte)

- Secuencia B: Formación Honda (Van der Wiel 1991, en parte)

- Secuencia C: Formación Honda (Van der Wiel 1991, en parte)

- Formación La Victoria (Villarroel et al. 1996, en parte)

\section{Localización}

Localizada entre las formaciones San Alfonso en la base y Cerbatana en el techo (Figura 3).

\section{Características}

Esta formación es muy espesa; se caracteriza por presentar bancos planares de areniscas grises de hasta $30 \mathrm{~m}$ de espesor, separados por limolitas (denominada Chunchullo). Lodolitas y en menor cantidad arcilitas separan los bancos de areniscas; se registran algunas arcilitas de origen lacustre (denominada San Nicolas Clays) (Anexo 2).

\section{Ambiente Sedimentario}

Las características sedimentológicas indican que, como resultado de procesos fluviales, se desarrolló un río meándrico, permanente y estable, con gran caudal y baja carga de sedimentos de granos finos compuestos principalmente por bancos de arena de hasta 30 metros de espesor intercalados con segmentos de limos y limolitas arcillosas de grosor similar, el cual atravesaba la formación. Esta tipología permite inferir un ambiente sedimentario; y a partir de las montañas de arena hacia la base occidental de la formación se deduce la presencia de un gran lago. Nódulos de óxido de hierro de coloración roja evidencian la presencia de paleosuelos (Figura 5; Anexo 4).

\section{Características marcadoras}

Litológicamente consta de bancos de areniscas de hasta 30 metros de espesor intercalados con segmentos de limos y limolitas arcillosas de espesor similar. Por lo tanto, se pueden definir dos capas marcadoras:

- Capa de Los Lagos.

- Areniscas de San Nicolás. 
Formación Cerbatana (sensu Henao-Londoño 1950, en parte; Takai et al. 1992; com. pers. Parra-Sánchez 2016)

Sinónimos

- Serie Honda inferior (Butler 1942, en parte)

- Cerbatana Gravels and Clays (incluye San Nicolás Clays) (sensu Stirton 1953b, Fields 1959, en parte)

- Río Seco Conglomerate: Formación La Dorada (sensu Wellman 1970)

- Secuencia C: Formación Honda (Van der Wiel 1991, en parte)

- Cervetana Formation (Takemura et al. 1992)

- Miembro Cerbatana: Formación La Victoria (Villarroel et al. 1996)

- Cerbatana Conglomerate Beds: Formación La Victoria (Guerrero 1997)

\section{Localización}

Localizada entre las formaciones La Victoria en la base y Villavieja en el techo. Enmarcada en la cuenca de la Quebrada Cerbatana (Figura 3).

\section{Características}

Capas muy ricas en cantos que afloran en la divisoria de aguas de las quebradas Cerbatana y La Venta; conformada por un segmento de estratos ricos en cantos y guijos. Presenta estratos lenticulares de areniscas y lodolitas. El estrato basal lo conforma una arenisca gruesa con gravas flotantes o pequeños nidos lenticualares de éstas; el techo es un banco espeso de $10 \mathrm{~m}$ de conglomerados (Anexo 2).

\section{Ambiente Sedimentario}

La cuenca de la Quebrada Cerbatana se caracteriza por presentar capas de sedimentos de diferentes tamaños, especialmente grano grueso (grava). Representa una sedimentación torrencial, quizás por ríos trenzados (Guerrero 1993), lo que sugiere que era un gran río torrencial (alta carga), elongado y trenzado, muy ancho, profundo cuyo caudal era más reducido con respecto al de la Formación La Victoria (Guerrero 1993). Este tipo de río permite el desarrollo de llanuras de inundación y llanuras pedregosas (Figuras 6; Anexo 5).

\section{Características marcadoras}

La característica sedimentológica marcadora son los grandes espesores de estratos de gravas.

Formación Villavieja (sensu Guerrero 1993; Parra-Sánchez 2016; com. pers. ParraSánchez 2016)

\section{Sinónimo}

- Upper Red through Monkey Unit (Fields 1959)

- Formación Villavieja (sensu Wellman 1970, en parte)

- Secuencia D: Formación Honda (Van der Wiel 1991, en parte)

- Formación Villavieja (sensu Villarroel et al. 1996, en parte)

- Miembro Baraya: Formación Villavieja (sensu Guerrero 1997) 
- Miembro Cerro Colorado: Formación Villavieja (sensu Guerrero 1997, en parte)

\section{Localización}

Localizada entre la Formación Cerbatana, en la base, y las mesetas de la Formación Mesa del Plioceno (Butler 1942, Royo y Gómez 1942, Henao-Londoño 1950, Wellman 1970) (Figura 3).

\section{Observación}

Basado en la propuesta sensu stricto realizada por Fields (1959), pero se redefine el nombre ya que se prioriza la nominación dada por Wellman (1970) a la mayor parte de esta unidad.

\section{Características}

Litológicamente presenta varias capas claramente distinguibles, definidas por HenaoLondoño (1950) y Fields (1959). Es un conjunto de capas dominadas por lodolitas, con areniscas intercaladas y en menor cantidad arcilitas, al igual que nódulos de óxido de hierro de coloración roja que evidencian la presencia de paleosuelos (Anexo 2).

\section{Ambiente Sedimentario}

A partir de las características sedimentológicas como la presencia de areniscas y arcillas (areniscas ferruginosas, areniscas, arcillas de la Quebrada La Venta), se infiere que esta área estaba bañada por un gran río ondulado de bajo caudal al cual llegaba una gran cantidad de tributarios (Capas de Peces), lo que permitió la formación de llanuras de inundación (Guerrero 1993). Se registran zonas de relieve ondulado, no inundable, con suaves pendientes (estratos rojos); al parecer este relieve está conformado por material de la Cordillera Oriental (Figura 7; Anexo 6).

\section{Características marcadoras}

Litológicamente presenta varias capas claramente distinguibles:

- Monkey Unit: limos y arcillas de color gris a rojizo.

- Fish Beds: areniscas de color verde.

- La Venta Clays and Sandstones: arenisca de color gris.

- Ferruginous Sandstones.

- Lower Red Beds: arcillas de color rojo intenso (pardo rojizo y pardo rojizo oscuro).

- Unit between Upper and Lower Red Beds.

- Upper Red Beds: arcillas rojas que alternan con arcillas de color marrón, capas de areniscas de color gris.

Formación Las Mesitas (sensu Fields 1959; com. pers. Parra-Sánchez 2016)

\section{Sinónimos}

- Brown Sequence (Henao-Londoño 1950)

- Formación Cambras (De Porta 1966)

- Formación San Antonio (De Porta 1966)

- Formación Los Limones (De Porta 1966) 
- Cerro Colorado Redbed Member (Wellman 1970, en parte)

- Miembro Cerro Colorado (Wellman 1970)

- Secuencia D: Formación Honda (Van der Wiel 1991, en parte)

- Miembro Cerro Colorado: Formación Villavieja (sensu Guerrero 1997, en parte)

\section{Localización}

Inmersa en parte en la Formación Villavieja; corresponde a las capas que están por encima de Upper Red Beds y por debajo de la Formación Neiva, separada de esta por una leve discordancia (Henao-Londoño 1950) (Figura 3).

\section{Características}

Consiste en un alternado de limolitas de coloración rosa a pardo en grandes bancos separados por estratos de areniscas grises de menor espesor; varía la geometría de las areniscas, entre los que se encuentran capas de estructura lenticular de pocas decenas de metros y suave pendiente, con areniscas gravillosas y estratos planares de areniscas; el espesor estimado es de $300 \mathrm{~m}$ (Anexo 2).

\section{Ambiente Sedimentario}

Presenta una mezcla de estratos de diferente geometría, entre los que se encuentran capas de estructura lenticular semejante a las de la Formación San Alfonso, pero de pocas decenas de metros (mucho más finas) y con una pendiente más suave (abanicos aluviales), con gravas y areniscas gravillosas. Se registran estratos planares de areniscas y limos de pocos metros de espesor, lo que permite deducir la presencia de un río ondulado con abundantes tributarios semejantes a los de la Formación Villavieja, pero mucho más pequeño en carga sedimentaria y cauce. También presenta una pequeña franja de relieve positivo a partir del cual se infiere que esta formación presenta influencia de la Cordillera Oriental (Figura 8; Anexo 7).

\section{Características marcadoras}

- Capas de estructura lenticular de pocas decenas de metros con gravas y areniscas gravillosas.

- Estratos planares de areniscas de pocos metros de espesor junto con limos de igual espesor.

- Paleorelieve colinado de baja altura.

\section{PALEOSUELOS DE LA VENTA}

Los paleosuelos de La Venta se evidencian por cambios de color, de gris verdoso (material parental) a rojo y púrpura, pequeños nódulos de calcita dispera, grietas de desecación, restos radiculares con coloraciones grises, pequeños nódulos de óxido de hierro, horizontes de suelo (Guerrero 1997). Cuando los paleosuelos son suficientemente desarrollados, extensos y continuos, pueden ser usados como marcadores estratigráficos. 
Según Guerrero (1997) no hay evidencia faunística ni ninguna otra que indique que los paleosuelos de La Venta se vieran afectados por algún cambio climático, y resalta que si hubo alguna variación climática causada por el enfriamiento en alta mar durante el Neógeno (12,9 - 11,9 Ma) (Keller \& Barron 1987), su afectación en los paleosuelos fue muy pequeña en comparación con los dramáticos cambios que se presentaron en las tasas de sedimentación (tasa de sedimentación promedia: Formación La Victoria: aproximadamente $950 \mathrm{~mm} / 1.000$ año, Formación Villavieja: aproximadamente 413 $\mathrm{mm} / 1.000$ año).

Flórez et al. (2013) reconocen siete fragmentos de paleosuelos al interior de Red Bed (sensu Fields 1959), formados en el Mioceno bajo climas que habrían variado desde húmedos hasta áridos y en paleorelieves colinados de baja altura; según estos autores, los paleosuelos analizados fueron portadores de biomas secos, los cuales debieron coexistir con planicies aluviales asociadas a biomas húmedos boscosos, y plantean que es probable que dependieran de la humedad residual del sedimento y fueran tolerantes a la inmersión temporal durante las inundaciones de grandes ríos.

\section{BIOTA FÓSIL}

\section{Macrofósiles vegetales}

En los estratos cerca a Fortalecillas se registran xilópalos o árboles silicificados, algunos de aproximadamente un metro de diámetro ( $\mathrm{km} 158$ - 500 del ferrocarril de Neiva, km 18 - 200, km 29 - 800 de la carretera Neiva - Villavieja) (Fields 1959); en las terrazas de San Alfonso, Royo y Gómez (1942a, b) indica la presencia de vegetales (sensu lato); en Río Seco Conglomerate hay fósiles de plantas silicificadas (Wellman 1970); en Ferruginous Sands se registra la presencia de gran cantidad de pequeños fragmentos de madera fosilizada; y en Brown Sequence hay abundantes hojas y troncos fósiles (Fields 1959).

\section{Polen fósil}

Para las rocas aflorantes en el área de La Venta, no se ha publicado ningún registro sobre polen fósil (ver Kay \& Madden 1997, P: 537). Los únicos trabajos para el Mioceno en Colombia son los de Jaramillo et al. (2006) quienes analizan el polen y las esporas fósiles de diferentes secciones estratigráficas que comprenden entre el Cretácico superior (Campaniano) y el Mioceno medio del centro de Colombia (flanco oriental de la Cordillera Oriental) y el occidente de Venezuela. Parra et al. (2009) establecen la biozonificación palinológica del Paleoceno superior al Mioceno inferior de la Formación Carbonera en la Cuenca Medina ubicada en el flanco oriental de la Cordillera Oriental de Colombia. 


\section{Fauna fósil: diversidad taxonómica y aspectos bioestratigráficos}

La fauna de La Venta se empieza a conocer a partir de las primeras publicaciones realizadas por Royo y Gómez $(1942 \mathrm{a}, \mathrm{b})$ en las cuales registra yacimientos de vertebrados para las areniscas del Grupo Honda superior, camino a San Alfonso: al sur de la Loma de La Barqueta: reptiles (Crocodilia); en las terrazas de San Alfonso: anfibios (Anura), cocodrilos, peces teleósteos, pequeños coprolitos; al occidente de Cerro Gordo: tortugas; entre la Quebrada Pechoyo y Cerro Gordo: abundantes fragmentos de tortugas, cocodrilos, dientes de roedores (Scleromys schümanni) y ungulados; y cerca a la hacienda San Nicolás: tortugas y grandes mamíferos.

Henao-Londoño (1950) establece que la Serie Honda superior expuesta en La Venta pertenece al Mioceno superior, inferencia realizada a partir de la fauna de mamíferos fósiles. Este autor registra que la capa Arenosa Sandstone and Siltstones no es tan fosilífera; en la parte superior se encuentra una localidad muy rica en fósiles de Astrapotheria, Toxodonte y abundantes restos de peces; a $150 \mathrm{~m}$ por debajo de la localidad "Astrapothere", registraron un cráneo de un pequeño mamífero aff. Interatheridae; el autor considera que Unit above Fish Bed, Fish Bed, Unit below Fish Bed y Monkey Unit son las capas más fosilíferas de La Venta; en Monkey Unit la riqueza fosilífera predomina sobre las capas de areniscas, y en Fish Bed registra un alto contenido de dientes de roedores, coprolitos, entre otros.

Henao-Londoño (1950) y Stirton (1953b) mencionan que no se han encontrado diferencias evolutivas entre los fósiles de vertebrados de las capas donde se registra la fauna de La Venta; desde la base, en Cerro Gordo, hasta el techo, las capas debajo de Villavieja.

En 1951, Savage hace un compendio de la lista de vertebrados fósiles del Valle Superior de la Cuenca del Magdalena. Stirton \& Savage (1951) describen un nuevo primate para La Venta (Cebupithecia sarmientoi). Stirton (1953b, P: 607, 909: Fig. 2, P: 612) hace un análisis sobre la fauna de La Venta interpretada para el Mioceno superior, específicamente de la fauna de mamíferos, a partir del cual se establece que es uno de los mayores ensambles de vertebrados fósiles de Suramérica, evidencia que se relaciona con el carácter litológico de sus capas (Fields 1959). Por su parte, Miller (1953) describe para La Venta, un nuevo género y especie de ave, Hoazinoides magdalenae (Opisthocomidae). Fields (1959), para el Líbano Sands and Clays, reconoce vertebrados fósiles sobre limolitas, y que algunas de las arcillas son muy fosilíferas, especialmente las que están en la parte más inferior, y las areniscas contienen tortugas en concreciones. En Cerbatana Gravels and Clays la riqueza fosilífera se presenta en El Dinde (San Nicolás). En Monkey Unit se registran primates, entre otros vertebrados fósiles; en Unit below Fish Bed fósiles de vertebrados; en Fish Bed abundantes espinas de peces, coprolitos y dientes de roedores. Ferruginous Sands es una capa con pocos vertebrados fósiles, con excepción de algunos restos de reptiles. Los fósiles son muy abundantes, especialmente en Unit between Ferruginous Sands, Lower 
Red Bed, Unit between Upper (URB) y Lower Red Bed.

Estes (1961) describe dos lagartijas de La Venta pertenecientes a las familias Teiidae e Iguanidae; este mismo autor en 1963 realiza un estudio osteológico del material de anfibios (familia Bufonidae) presentes en la región. De Porta (1969) hace una lista de la fauna de vertebrados fósiles de Colombia registrados desde el Cretácico hasta el Cuaternario, con énfasis en el aislamiento del continente suramericano. Auffenberg (1971) describe un nuevo fósil de tortuga para La Venta y Hirschfeld (1976) registra una nueva especie fósil de oso hormiguero (Neotamandua borealis). Hirschfeld \& Marshall (1976) realizan una nueva lista de la fauna de La Venta de Colombia; Marshall (1976) describe un nuevo marsupial (Marmosa laventica); Wood (1976) describe dos nuevas especies de Chelus (Testudines); Marshall (1977) describe otro nuevo marsupial (Lycopsis torresi); Villarroel (1983) describe una nueva especie de Glyptodontidae (Asterostemma acostae); Setoguchi \& Cadena (1984) relacionan la morfología y la función de la dentición de Stirtonia con la de Alouatta; Setoguchi \& Rosenberger (1985a, b) reconocen otro nuevo Cebidae para La Venta (Micodon kiotensis); Setoguchi et al. (1985) describe un nuevo primate de la familia Cebidae, "Kondous laventicus", luego referido a Stirtonia tatacoensis (Kay et al. 1987); Busbey (1986) refiere nuevo material de Sebecus cf. huilensis para el área; Luchterhand et al. (1986) describen un nuevo primate, Mohanamico hershkovitzi (Cebidae); Kay et al. (1987) describen una nueva especie de primate (Stirtonia victoriae); Setoguchi \& Rosenberger (1987) registran un nuevo Pitheciidae para La Venta (Aotus dindensis) y Gebo et al. (1990) analizan nuevo material de este primate; Cifelli \& Guerrero (1989) publican nuevos registros de Prothoatherium colombianus (Litopterna: Mammalia), grupo de los ungulados de "tobillo simple" (Guerrero 1985).

Meldrum et al. (1990) analizan el húmero de Cebupithecia sarmientoi y Neosaimiri fieldsi; Takai \& Setoguchi (1990) registran las localidades de los fósiles de primates de La Venta Badlands; Meldrum \& Lemelin (1991) analizan el esqueleto axial de Cebupithecia sarmientoi (Pitheciidae); Rosenberger et al. (1991b) registran un nuevo género de Primate (Laventiana annectens); Takai et al. (1991) describen un murciélago de la familia Molossidae; Lundberg \& Chernoff (1992) registran un nuevo Arapaimidae (Arapaima gigas); Kay (1994) describe a Lagonimico conclucatus (? Pitheciidae); Takai (1994) registra nuevo material de Neosaimiri fieldsi; Meldrum \& Kay (1997) registran un nuevo Pitheciidae (Nuciruptor rubricae); Nakatsukasa et al. (1997) analizan material de poscráneo de Neosaimiri fieldsi con el fin de caracterizar su morfología funcional y comportamiento locomotor y lo comparan con ejemplares del género Saimiri; y Villarroel (1997) realiza una descripción detallada de los dientes del Leontiniidae (Huilatherium pluripicatum).

Kay et al. (1997) hacen un compendio de la información de La Venta, en donde se registran cerca de 128 taxones de vertebrados, de los cuales 93 son mamíferos $(72,66 \%)$ y 11 son primates $(11,83 \%)$, siendo La Venta el área más importante en riqueza de primates del Mioceno medio en América del Sur. Villarroel (2000) registra un nuevo Mylodontidae (Brievabradys laventensis); Takai et al. (2001) un nuevo Platyrrhini para el 
Mioceno medio (Miocallicebus villaviejai: Pitheciidae); Czaplewski et al. (2003) establecen nuevas especies y géneros de murciélagos para esta región (Emballonuridae, Molossidae, Noctilionidae, Phyllostomidae, Thyropteridae, Vespertilionidae); Lundberg (2005) describe un nuevo Pimelodidae (Brachyplatystoma promagdalena); Takai et al. (2009) realizan un análisis sobre el significado del dimorfismo sexual en Aotus dindensis.

Madden et al. (1997) describieron 71 especies de mamíferos terrestres, pertenecientes a 53 géneros y 29 familias, los cuales se han ubicado en 52 niveles fosilíferos estratigráficos; estos autores mencionan que los fósiles de mamíferos, generalmente identificables, han sido recuperados en 48 de estos niveles (Nivel 1: Duke Locality 49, 110, 146 - Nivel 48: Duke Locality: 126), y definen el nivel fósil como una serie de localidades prospectadas que no pueden ser subdivididas estratigráficamente.

Madden et al. (1997) reconocen e identifican la Zona de Asociación de Miocochilius (ZAM) la cual lleva el nombre del fósil más común del Grupo Honda, Miocochilius (Interatheriidae: Notoungulata), es un mamífero pequeño herbívoro. La base del ZAM es definida por la coincidencia estratigráfica de la ocurrencia del primer registro de Miocochilius sp. nov.1, junto con la presencia de Scleromys colombianus (Dinomyiidae: Rodentia), Granastrapotherium snorky (Uruguaytheriinae: Astrapotheriidae: Astrapotheria) y Scirrotherium hondaensis (Pampatheriidae: Cingulata: Xenarthra). El límite superior del ZAM está definido por la última ocurrencia de: Miocochilius anomopodus, "Scleromys" schurmanni, Prodolichotis pridiana (Dolichotinae: Caviidae: Rodentia), "Olenopsis" (Dinomyidae: Rodentia) (tamaño grande), Xenastrapotherium kraglievichi (Uruguaytheriinae: Astrapotheriidae: Astrapotheria), Pericotoxodon platignathus (Dinotoxodontinae: Toxodontidae: Notoungulata). Otros taxones característicos del ZAM son: Pedrolypeutes praecursor (Tolypeutinae: Dasypodini, Dasypodinae: Dasypodidae: Cingulata: Xenarthra), "Neoreomys" huilensis (Dasyproctidae: Rodentia), Stirtonia spp. (Alouattinae: Atelidae: Primates), Huilatherium pluriplicatum (Leontiniidae: Notoungulata), Glossotheriopsis pascuali (Mylodontinae: Mylodontidae: Xenarthra).

En síntesis, teniendo en cuenta las unidades litoestratigráficas de Henao-Londoño (1950), Fields (1959) hay registro fósil en:

Arenosa Sandstone and Siltstone: aunque no es tan fosilífera como los demás estratos de la parte superior, se registran fósiles en la parte media.

- Líbano Clays and Sandstones: algunas de las arcillas son muy fosilíferas, especialmente las que están en la parte más inferior; mientras que en las areniscas ocasionalmente se registran remanentes de tortugas en bloques de concreciones.

- Cerbatana Gravels and Clays: miembro San Nicolás: es la parte más gruesa y fosilífera.

Monkey Unit: nombre dado por los primeros fósiles de primates registrados en La Venta.

- Fish Beds: abundancia de restos fósiles de peces (coprolitos, dientes, espinas, vértebras) y alto contenido de dientes de roedores. 
- Ferruginous Sandstones: muy rica en pequeños fragmentos de madera fosilizada y concreciones redondas de carácter ferruginoso. Casi no hay vertebrados fósiles, con excepción de algunos restos de reptiles.

- La Venta Clays and Sandstones: los fósiles son muy abundantes especialmente hacia el suroriente.

- Intermediate Clays and Sandstones: no hay registros de fósiles.

- Brown Sequence: se registran pocos fósiles de vertebrados, abundantes hojas y troncos fósiles.

\section{BIOESTRATIGRAFÍA}

Madden et al. (1997) plantean la siguiente bioestratigrafía referida a las especies de mamíferos no voladores del área de La Venta (Grupo Honda):

- Tres especies de Miocochilius con rango estratigráfico superpuesto:

- Miocochilius anomalus Stirton: Nivel 3 - 48

- Miocochilius sp. nov.1 (tamaño mediano): Nivel 1 - 21

- Miocochilius sp. nov.2 (tamaño pequeño): distribución restringida, no se registra en los límites del (ZAM)

- Las especies más basales de cada linaje se encuentran en los niveles más bajos:

- "Scleromys" schurmanni: Nivel 1 - 29

- "Scleromys" colombianus: Nivel 4 - 25

- Las especies de tamaño más grande afines a las especies de "Scleromys" se registran en la Formación Villavieja:

- "Scleromys" schurmanni: Nivel 35 - 45

- "Scleromys" colombianus: Nivel 35 - 48

- Astrapotheria:

- Granastrapotherium snorky: Nivel 1 - 45

- Xenastrapotherium kraglievichi: Nivel 33-48

- Otros taxones:

- Scirrotherium hondaensis: Nivel $1-43$

- Prodolichotis pridiana: Nivel $10-48$

- “Olenopsis” spp. (tamaño grande): Nivel 3 - 48

- Pericotoxodon platignathus: Nivel $3-48$

- Huilatherium pluriplicatum: Nivel 3 - 45

- "Neoreomys" huilensis: Nivel 7 - 35

- Glossotheriopsis pascuali: Nivel 7 - 35

\section{Primates}

Stirtonia: es el fósil de primate más común del Grupo Honda:

- Stirtonia tatacoensis: Nivel 24 - 37

- Stirtonia victoriae: Nivel 4 - 22 


\section{PALEOAMBIENTES}

A partir de la evidencia litológica y de la información fósil se define que el Grupo Honda se estableció en abanicos aluviales y sedimentos volcánicos, en grandes planicies de inundación del Grupo Gualanday (Oligoceno) (Butler 1942, Stirton 1953b) [? Eoceno superior a Oligoceno] sensu Van der Wiel 1991, Van der Wiel \& Van der Bergh 1992, Van der Wiel et al. 1992), y parcialmente en sedimentos más viejos como penillanuras (Henao-Londoño 1950, Fields 1959) durante el levantamiento activo o de volcanismo en los periodos de quietud tectónica y volcánica (Van der Wiel 1991, Van der Wiel \& Van der Bergh 1992, Van der Wiel et al. 1992).

Los estratos incluidos en el Grupo Honda superior evidencia períodos de lluvias y orogénesis local con depósitos de areniscas y gravas que fueron precedidos por una amplia acumulación de areniscas, limos y lodos (Stirton 1953b). Henao-Londoño \& Fields (1949) sugieren que los sedimentos se acumularon y se hundieron lentamente, alcanzando una gran extensión y que formaron una cuenca lagunar donde se depositaron las areniscas y el fango a lo largo de sistemas de ríos trenzados y meándricos que corrían hacia el oriente, sobre una parte del área que hoy ocupa la Cordillera Oriental (Butler 1942); para esta zona también se registran conglomerados que indican periodos de inundación (Henao-Londoño \& Fields 1949).

En Cerro Gordo, dentro de las areniscas, se encuentran numerosos bloques angulares de andesitas, evidentemente lavadas por las llanuras de inundación y enterradas por El Líbano Sands and Clays; esta capa se depositó en un periodo de fuertes lluvias estacionales cuyas inundaciones transportaron granos finos de limos y arcillas; simultáneamente las corrientes meándricas atravesaban las tierras bajas y depositaron areniscas de diferente grosor; por otra parte, zonas oxidadas indican periodos de humedad y sequía, probablemente como resultado del cese de las inundaciones durante la estación seca cuando las corrientes parcialmente se retiraron de las llanuras de inundación (Fields 1959).

Las características de Cerbatana Gravels and Clays indican que el clima y el relieve en su inicio, eran semejantes a las que se presentaron cuando se depositó la capa de El Líbano, posteriormente se intensificó la lluvia y la orogenia. Afloramientos de chert del Cretácico al igual que áreas que contienen rocas metamórficas ígneas contribuyeron con el material clástico grueso. La parte basal de esta unidad en contacto con El Líbano Sands and Clays está marcada por un cambio de predominancia de limos y arcillas a areniscas gruesas, lo que indica que hubo un aumento en las precipitaciones, acompañado de un incremento en el gradiente de la corriente; las inundaciones fueron extensas y probablemente continuas. En las planicies de inundación, las areniscas se depositaron rápidamente; las corrientes proporcionaron areniscas, limos y fango sobre las áreas húmedas del Cerbatana (Fields 1959). 
La Formación La Victoria se formó por depósitos de ríos meándricos de hasta 8 a 10 $\mathrm{m}$ de profundidad, que corrían en dirección oriente - suroriente, siendo ríos aparentemente continuos hacia el este. El Conglomerado Cerbatana estaba conformado por ríos trenzados y la Formación Villavieja por ríos meándricos hasta de 2 a $3 \mathrm{~m}$ de profundidad, cuyo cauce inicial corría hacia el oriente; posteriormente la dirección de estas corrientes se invirtió hacia el occidente, con un patrón de ríos anastomosado (Guerrero 1997).

Fish Bed acumuló mucho material de areniscas y arcilla que se depositó en la corriente y nuevamente formó un lago semejante a una playa, y los sedimentos de la capa Lower Red Beds (LRB) se depositaron allí; el color rojo de esta capa presumiblemente se deba a la oxidación subaérea de minerales de hierro. Extensas inundaciones depositaron arcillas en LRB que se distribuyen en las tierras bajas y junto con las areniscas se situaron a lo largo de los canales de los ríos. Al mismo tiempo había una renovación del volcanismo en la Cordillera Central que se observa en las capas superiores de LRB (Fields 1959).

Las Mesitas, con sus capas gruesas de areniscas, se establecieron a lo largo de los canales y los limos que contienen bentonita se propagaron sobre las planicies de inundación (Fields 1959).

Takemura (1985) establece la dirección de las paleocorrientes deducidas a partir de la dirección de los torpedo shape, lo cual permitió definir las características meándricas de los ríos y propone que los sedimentos de areniscas fueron depositados alrededor de estos.

El Miembro Baraya y la parte baja de Cerro Colorado fueron depositados por ríos meándricos, más pequeños que los que dieron origen a la parte inferior de la Formación La Victoria. La parte superior del Miembro Cerro Colorado pudo haber sido depositada por ríos meándricos y anastomosados. Las paleocorrientes presentes en estos dos miembros indican que los ríos fluyeron en la misma dirección que los de la Formación La Victoria, es decir hacia el E y ESE; sin embargo, en la parte superior del Miembro Cerro Colorado las paleocorrientes indican una tendencia hacia el oeste (Villarroel et al. 1996, Guerrero 1997).

Los sedimentos de La Venta, sensu Fields (1959) se establecieron en depósitos aluviales y planicies de inundación del Grupo Gualanday; teniendo en cuenta los minerales aquí registrados, es probable que los principales sedimentos provengan tanto del sur como del occidente de la región, como es el caso de las hornblendas derivadas de la desintegración de rocas plutónicas graníticas y dioríticas de la Cordillera Central. Este último autor enfatiza que no se cuenta con una buena información sistemática y estratigráfica acerca de los fósiles del Grupo Honda y, por lo tanto, la información paleontológica de esta unidad no se puede integrar con su litología. 
Flynn et al. (1997) plantean que las diferencias litológicas entre las formaciones La Victoria y Villavieja son el resultado de cambios en las tasas de sedimentación o de cambios paleoambientales; además, respecto a la composición faunística, proponen la hipótesis de que los cambios de la fauna de vertebrados evidenciados a través de dichas formaciones serían el resultado de tectónica regional, cambio climático y ambiental (fragmentación, inmigración), entre otros factores.

Kay \& Madden (1997) realizan un análisis paleoecológico en el cual establecen una relación entre los mamíferos registrados en La Venta y la intensidad de las lluvias y postulan que la fauna de La Venta corresponde a un medio ecuatorial de baja altitud, caracterizado por la presencia de llanuras de inundación, selvas inundadas y diversos bosques, incluyendo bosques de ribera. De acuerdo a estos autores, las llanuras de inundación se habrían desarrollado dentro de un cinturón de meandros sometidos a períodos de inundación. En síntesis, ellos proponen la presencia de bosques húmedos extensos sin el predominio de áreas abiertas, un ambiente conformado por mosaicos de vegetación caracterizados por diferentes etapas sucesionales iniciadas por los cambios en los cursos de los ríos y posiblemente modificadas por la presencia de grandes herbívoros.

Las interpretaciones paleoambientales, deducidas del registro estratigráfico y de los fósiles han sido variadas, especialmente en lo concerniente a la existencia o no de periodos secos prolongados. Kay \& Madden (1997) sugieren que, durante el Mioceno medio, La Venta se ubicó sobre una península aislada del resto del continente por un brazo del mar que se extendía desde la cuenca del Maracaibo hasta la Amazonia occidental. El Grupo Honda superior no incluye características asociadas a déficits estacionales prolongados de lluvias, los vertebrados fósiles (Kay et al. 1997 y referencias allí citadas) demuestran evidencias de la presencia de bosques que refieren a un ambiente muy diferente al de llanos y sabanas planteado por Stirton (1953b) y Wellman (1970). 


\section{CAPÍTULO III - MATERIALES Y MÉTODOS}

\section{ÁREA DE ESTUDIO}

E1 Grupo La Venta se encuentra en la ribera derecha del Valle Superior de la Cuenca del Magdalena enmarcado entre tres discordancias: la base, limita con el techo del Grupo Gualanday; el techo, limita con la base de la Formación Valla del Mioceno superior; y el flanco occidental, limita con el techo de la Formación Xilópalo del Mioceno inferior (Parra-Sánchez 2016) (Figura 2).

La Venta se localiza en el extremo norte de la subcuenca de Neiva, entre 35 a 40 $\mathrm{km}$ del NNE de la ciudad con este mismo nombre, a lo largo de la ribera derecha del Valle Superior de la Cuenca del Magdalena, entre las cordilleras Central y Oriental, en el área conocida desde la década de 1940 como Desierto de La Tatacoa (Villarroel et al. 1996).

El área tenida en cuenta en la presente investigación es de $534.151 .529 \mathrm{~m}^{2}$, la cual limita al nororiente con la población de San Alfonso, en la ribera izquierda de las quebradas Las Gutiérrez y Zanja Honda; al noroccidente con la población de Potosí, bordeada por el Alto del Patá cerca al Paso de Golondrinas; al sur con el norte de la población de Polonia, Cerro Colorado y la ribera derecha del Río Villavieja; al oriente con la ribera izquierda de la cuenca media del Río Cabrera, flanco izquierdo de Cerro Gordo y la ribera izquierda de las quebradas La Arenosa, Peralta, El Totumo y Saltarén; al occidente con la ribera derecha de la cuenca alta del Río Magdalena y la ribera derecha de las quebradas El Líbano, Yeguerita y La Yeguera. Esta área actualmente es drenada por las quebradas Potosí, Los Indios, El Cardón, La Victoria, Arenoso, Tres Pasos, Chunchullo, Atoyosa, La Tatacoa, Guayabo, Balsillas, Pontesula, Cerbatana, La Arenosa, Salto, Cabuyal, Los Hoyos, Barzalosa, Pachingo, La Venta, El Venado, San Francisco y Las Lajas. El Grupo La Venta se encuentra entre las coordenadas: Norte: 03,415 latitud Norte -75,102 longitud Oeste, Sur: 03,149 latitud Norte -75,105 longitud Oeste, Oriente: 03,183 latitud Norte -75,071 longitud Oeste, Occidente: 03,288 latitud Norte - 75,235 longitud Oeste.

\section{LITOESTRATIGRAFÍA Y GEOCRONOLOGÍA}

El objetivo de la presente investigación es la reconstrucción de los paleoambientes del Mioceno medio, por lo tanto, se partió de la información disponible de los ambientes sedimentarios propuestos por Fields (1959), Guerrero (1997), y Parra-Sánchez (2016) (Anexo 1); la geocronológica que se siguió fue la de Parra-Sánchez \& RestrepoMoreno (2014) y Parra-Sánchez et al. (2015); y la información de paleosuelos de Flórez et al. (2013); a estas investigaciones se le incorporó la información biótica en la cual se incluyen macrofósiles vegetales, polen fósil e información de 
vertebrados registrada en la literatura y obtenida en nuevas pesquisas, lo cual permitió inferir el ambiente biótico. A partir de la integración de estos dos ambientes, el sedimentario y el biótico, se proponen posibles paleohábitats para el Grupo La Venta.

\section{BIOTA FÓSIL}

\section{Macrofósiles vegetales}

Las concreciones registradas se detallaron de acuerdo a si presentaban o no en su parte interna arena y se les comprobó la presencia de carbonato de calcio con una solución de ácido clorhídrico $(\mathrm{HCl})$. El ácido produce efervescencia debido a la liberación de $\mathrm{CO}_{2}$, lo cual revela la presencia de carbonatos libres. El procedimiento que se realizó fue agregar unas gotas de HCL a la concreción y observar si había o no efervescencia, si reacciona es positivo a material calcáreo (McKean 1993).

\section{Polen fósil}

Los estudios previos sobre polen fósil de esta región se han basado en otras formaciones, siendo ésta la primera vez que se extrae polen fósil de La Venta. Las muestras para procesamiento de polen fósil fueron recolectadas en los sitios identificados, previamente por los doctores M.T. Flórez Molina y L.N. Parra-Sánchez, como paleosuelos y en aquellos donde se registraron limos arcillosos finos de colores entre gris a gris oscuro (Figura 9). Se realizó el muestreo principalmente en las capas, sensu Fields (1959): Cerbatana Gravels and Clays: San Nicolás Clays, Fish Bed y Upper Red Bed (Anexo 2). Se recolectaron 100 centímetros cúbicos como mínimo por muestra.

\section{Procesamiento químico de polen fósil}

El procedimiento químico de las muestras se realizó en el Laboratorio de Génesis de Suelos de la Facultad de Ciencias de la Universidad Nacional de Colombia (Medellín, Antioquia), con el fin de establecer la presencia o no de polen fósil. El análisis de estas muestras indicó que eran muy pobres en materia orgánica y muy ricas en detritos siliciclásticos, por lo cual resultaron estériles cuando se emplearon los ácidos clorhídrico (HCl) y fluorhídrico (HF) del procedimiento estándar para arcillas (Gray 1965, Traverse 1988). A fin de precisar los análisis se realizaron las siguientes modificaciones:

- De cada muestra se trituró (en mortero de cerámica) entre 100 y 150 gramos de sedimento y se dejó a un tamaño de grano igual al de la arenisca de grano fino.

- El sedimento triturado se colocó en beaker de plástico (polipropileno), se agregó $\mathrm{HCl}$ al $37 \%$ en frío durante una hora, se lavó, se dejó en HF comercial durante una hora, se lavó con agua destilada y acidulada al $10 \%$, se centrifugó a $3.000 \mathrm{rpm}$, se descartó el sobrenadante.

- Se verificó la parecencia de palinomorfos en el residuo, se repitió el procedimiento hasta completar cuatro ciclos de HCl-HF-HCl-HF. 
- Se repitió cuatro veces el procedimiento de lavar con agua destilada y acidulada al $10 \%$, se centrifugó a 3.000 rpms y se descartó el sobrenadante.

- Se filtró el residuo con tamiz de 120 micras con el fin de descartar materiales de mayor tamaño.

- Se dejó el residuo en solución $\mathrm{HCl} / \mathrm{HF}$ en proporción 1:1 durante cuatro a seis horas, se calentó en baño maría con el fin de evitar la formación de coloides de fluorosilicatos, que debido a la digestión rápida de HF son comunes por el exceso de silicatos, los cuales, cuando se secan se expresan en la placa palinológica en forma de cristales.

- Se lavó el residuo cuatro veces con agua destilada y acidulada al $10 \%$.

No se realizó el procedimiento de flotación, cuyo objetivo es concentrar el polen, debido a la presencia de granos de polen muy pequeños que se pierden en el proceso.

- Se montaron las muestras en bálsamo de Canadá siguiendo el procedimiento estándar. Se prepararon varias placas palinológicas por muestra, entre 8 y 15. En general las placas presentaron un bajo número de granos de polen.

- Las placas de polen fósil pertenecientes al proyecto "Paleoambientes y vertebrados asociados con los Primates del Mioceno medio de La Venta, Colombia", se etiquetaron bajo el acrónimo: YMS-Po-001A, el cual significa: YMS: Yaneth Muñoz-Saba; Po: Polen; 001A: cada muestra tiene varias placas, la muestra se diferencia por el número $(001,002, \ldots)$ y las placas de la misma muestra por la letra $(\mathrm{A}, \mathrm{B}, \ldots)$.

- Las placas de polen fósil se depositaron en el Laboratorio de Génesis de Suelos de la Facultad de Ciencias de la Universidad Nacional de Colombia (Medellín, Antioquia).

\section{Análisis de polen}

Cada placa palinológica fue analizada empleando un microscopio marca Olympus CX41, oculares WBB10X/20, aumentado a 400, objetivos 40X; los palinomorfos registrados se fotografiaron en este microscopio con cámara fotográfica incluida, marca Microscope Eyepiece Camera, 10MP Apetina Color CMOS, MU 1.000. Para la interpretación paleobotánica del registro fósil se empleó el concepto de afinidad con los taxones vegetales actuales (Graham 1999), asociados principalmente a los hábitats de bosque seco tropical, sabanas y bosque húmedo tropical, a partir de: (1) listas de plantas registradas en estos hábitats (Berrío et al. 2002, Figueroa \& Galeano 2007, Leal et al. 2011, 2013, Instituto Humboldt 2014); (2) teniendo en cuenta lo anterior, se realizó una búsqueda de atlas palinológicos (Germeraad et al. 1968, Salgado Labouriau 1976, Dueñas 1980, Lorente 1986, Hoorn 1994a, b, Graham 2009, Magalhâes \& Ribeiro 2009, Nogué et al. 2009, Urrego et al. 2009, 2010, Leal et al. 2011); (3) se consultaron las bases digitales de palinomorfos disponibles en la página web de Carlos Jaramillo en el Smithsonian Tropical Research Institute en Panamá (Jaramillo \& Dilcher 2001a, b, Raine et al. 2011 para New Zealand http://www.gns. cri.nz/what/earthhist/fossils/spore_pollen/catalog/index.htm); (4) se examinó la Palinoteca del Laboratorio de Paleoecología de la Universidad Nacional de Colombia (Medellín, Antioquia); (5) con la información recopilada se realizó un atlas 
palinológico con énfasis en la vegetación de bosque seco tropical, sabanas y bosque húmedo tropical; (6) el polen fósil se identificó a nivel de especie, género o familia, y se establecieron posibles marcadores (Tabla 1, Anexo 8).

\section{Paleohábitat}

Con el fin de plantear cuáles serían las posibles coberturas vegetales del Grupo La Venta, se partió de los ambientes sedimentarios propuestos por Parra-Sánchez (2016) para cada una de las formaciones del Grupo, y se llevó a cabo un análisis de presencia - ausencia de taxones (especies, géneros, familias) de polen fósil. El polen fue nominado a nivel de familia teniendo en cuenta su afinidad moderna, este tipo de designación del polen fósil facilita su comparación con coberturas vegetales actuales (Graham 1999); a partir de lo anterior, se identificaron asociaciones bióticas y se infirieron paleocomunidades vegetales del Mioceno del Valle Medio del Magdalena (Tabla 1, Anexo 8).

\section{Fauna fósil}

Para la compilación de la información de la fauna fósil del Grupo La Venta y con el fin de conocer las especies fósiles de esta zona se realizó una revisión de las siguientes colecciones:

\section{$\underline{\text { Argentina }}$}

Colección de Primates, Laboratorio de Investigaciones en Evolución y Biodiversidad (LIEB), Facultad de Ciencias Naturales, Universidad Nacional de La Patagonia San Juan Bosco, Esquel, Provincia de Chubut; Colección Paleontológica de Vertebrados, Museo de La Plata (MLP), La Plata, Provincia de Buenos Aires.

\section{$\underline{\text { Colombia }}$}

Colección Paleontológica, Museo Geológico Nacional José Royo y Gómez (IGM), Servicio Geológico Colombiano, Bogotá D.C.; Laboratorio de Paleontología de Vertebrados, Departamento de Geociencias, Facultad de Ciencias, Universidad Nacional de Colombia, Bogotá D.C.; Sala del Cenozoico, Museo de Historia Natural de La Sabana, Nemocón, Cundinamarca; Colección de Mamíferos (IAvH), Instituto de Investigación de Recursos Biológicos Alexander von Humboldt, Villa de Leyva, Boyacá; Colección de Mamíferos, Instituto de Ciencias Naturales, Universidad Nacional de Colombia, Bogotá D.C.

Se llevó a cabo trabajo de campo en el área delimitada como Grupo La Venta, con el fin de recolectar, si era posible, material adicional de fósiles de primates del Mioceno medio e incrementar el registro fósil de otros vertebrados; los números de campo asignados van desde el YMS-P-001 hasta el YMS-P-1.458 (YMS: Yaneth Muñoz-Saba; P: Paleontología), este material se depositará en las colecciones de la Universidad Nacional de Colombia. Los periodos de muestreo fueron: (1) 11 - 15 octubre 2010, (2) 16 - 20 noviembre2010, (3) 13 - 24 febrero 2012, (4) 25 - 30 junio 2012, (5) 7 - 16 mayo 2013, (6) 30 septiembre - 9 octubre 2013, (7) 11 - 20 agosto 
2014.

En general el material recolectado se encontraba en buen estado de preservación, sólo algunos ejemplares de Balanerodus (Alligatoridae: Crocodylia) registrados hacia el techo de la Formación La Victoria, se observaron erosionados, algunos sin bordes y con una coloración característica a los registros fósiles del Mioceno inferior; por lo tanto, estos fueron considerados como material retrabajado.

Se georeferenció el material fósil de vertebrados de La Venta, recolectado en la presente investigación (GPSmap 60CSx, marca Garmin). Este punto se priorizó ya que los materiales pertenecientes a muchas de las antiguas colecciones carecen de datos estratigráficos precisos (e.g. Formación La Victoria, Formación Villavieja: Fish Beds, Monkey Beds) y los nuevos estudios realizados y el trabajo de campo que se llevó a cabo en la presente investigación, indicaron que se requiere ser estricto con la ubicación del sitio de recolección, ya que en algunos sectores de La Venta se registran hiatos (antes no determinados) que revelan que a tan sólo a un metro de distancia lineal, estratigráfamente podemos tener registros del Mioceno medio o del Mioceno inferior (com. pers. L.N. Parra-Sánchez 2010). Por lo tanto, es necesario este control estratigráfico para el establecimiento de la fauna asociada con los diferentes paleoambientes y así definir con un mejor nivel de confianza los cambios de la diversidad (Tabla 2).

Se georeferenciaron 378 puntos registrados en Auffenberg (1971), Cifelli \& Guerrero (1989), Estes (1961), Fields \& Henao-Londoño (1949), Guerrero (1985, 1997), Henao-Londoño (1949), Madden et al. (1997), Marshall (1976), Royo y Gómez (1945), Stirton (1951), Takai (1994), Takai \& Setoguchi (1990), Takai et al. (1992, 2001) y Takemura et al. (1992) (Tabla 3).

Se realizó la determinación taxonómica alfa del nuevo material fósil de mamíferos hallado durante las prospecciones de la presente investigación. Se incorporaron a esta lista los fósiles y sus identificaciones, siguiendo a diferentes autores: Antoine et al. 2011, 2013, Bourque 2012, Cabrera 1929, Carlini et al. 2008, 2013, Chimento 2012, Cifelli 1983, Cifelli \& Soria 1983, Cifelli \& Guerrero 1989, Croft 2007, Czaplewski et al. 2003, De Iuliis et al. 2000, 2009, De Muizon et al. 2003, 2004a, b, De Porta 1959, 1961, 1962, González-Ruiz \& Scillato-Yané 2008, González-Ruiz 2010, González-Ruiz et al. 2009, 2010, 2011, Hershkovitz 1984, Hsiou 2007, Hsiou et al. 2009, 2013, Kay et al. 1987, 1997, Kramarz 2009, Meldrum et al. 1990, Meldrum \& Lemelin 1991, Meldrum \& Kay 1997, Miño-Boilini et al. 2011, Monsch 1998, Murelaga et al. 2002, Oliva et al. 2010, Nakatsukasa et al. 1997, Patterson 1934, Pujos \& Salas 2004, Rinderknecht et al. 2011, Rivera-Sylva et al. 2011, Rosenberger et al. 1991b, Salas et al. 2005, Setoguchi \& Cadena 1984, Setoguchi \& Rosenberger 1985a, b, 1987, Setoguchi et al. 1985, Stehln 1939, Stirton 1947a, b, Stirton \& Savage 1951, Takai 1994, Takai et al. 1991, 2000, 2001, 2009, Tejedor et al. 2005, Villaroel 1983, 1997, Zurita et al. 2009, 2012. 
El objetivo central de la tesis es la reconstrucción de los paleoambientes del Mioceno medio, por lo tanto, se determinó el material fósil sin llevar a cabo revisiones sistemáticas exhaustivas de algún grupo en particular, pero asignando cada fragmento de acuerdo con sus rasgos diagnósticos provistos en las últimas revisiones taxonómicas. En las determinaciones cuando se llegó a nivel de especie o sólo hasta género, así se especifica. Sin embargo, en algunos casos, en un mismo género fueron evidentes "morfos", que podrían a futuro corresponder a especies diferentes, por lo tanto, se indican tentativamente con el nombre del género seguido por la partícula sp1, sp2, etc. (Tabla 4; Anexo 12).

Para el género de primates Nuciruptor (Pitheciinae), se emplea el $c f$. en aquellos ejemplares en los cuales su taxonomía no ha sido aún definida, lo cual se debe a que el ejemplar es un fragmento o no hay material dentario asociado a los restos registrados; por lo tanto, Meldrum \& Kay (1997) describen a estos morfos en similitudes por confirmar (cf.) basados en comparaciones morfológicas (forma, tamaño) y la procedencia de los ejemplares, lo cual les permite relacionarlos a un género o familia específico (e.g. IGM KU-8602: maxilar derecho con C1, P2; IGM 184667: pelvis parcial, extremidades pélvicas; IGM 184074: astrágalo izquierdo).

\section{Análisis comparativo entre las diferentes formaciones}

Se empleó el índice de similitud de Simpson (Programa PAST, versión 2.17c, 4.1 MB; http://palaeo-electronica.org/2001_1/past/issue1_01.htm), con el objeto de calcular la similitud entre localidades (Simpson 1943, 1960), es decir, cuantificar si la composición de los taxones entre las formaciones del Grupo La Venta es similar o no. Este índice se emplea generalmente en análisis de muestras de registros fósiles, ya que algunas son más ricas taxonómicamente que otras; el análisis se realiza teniendo en cuenta la presencia o ausencia de los taxones, en la matriz estos son las filas y las formaciones las columnas (Vavrek 2011). Para los análisis de similitud entre el polen fósil presente en las diferentes formaciones del Grupo La Venta y el polen de las coberturas vegetales actuales, el estudio se realizó exclusivamente a nivel de familia (Tablas 5, 6). Para el análisis de vertebrados se tuvo en cuenta la presencia/ausencia de las especies, géneros y/o familias reconocidas (Tablas 7,8 ); no se incluyó en el análisis el material indeterminado.

\section{PALEOAMBIENTES}

Teniendo en cuenta lo planteado por Kay et al. (1997), los paleoambientes asociados a la depositación del Grupo Honda son generalizados y se basan en información de los tipos de vegetación de la Formación Neiva (Grupo Huila) (Guerrero 1997), pero esta formación es principalmente volcánica y más joven que las formaciones La Victoria y Villavieja (Zapata 2006). 
La reconstrucción de los paleoambientes de La Venta se basó en la información de los vertebrados fósiles recopilada en esta investigación y referenciada en la literatura, haciendo énfasis en el grupo de los mamíferos, la litología (sensu: Fields 1959, Guerrero 1997, Parra-Sánchez 2015), los paleosuelos (sensu: Flórez et al. 2013), el polen fósil y los macrorestos vegetales; estos dos últimos proporcionan evidencia directa sobre la vegetación presente en los yacimientos fosilíferos.

\section{DIAGRAMACIÓN}

El diseño de las ilustraciones fue realizado por Yaneth Muñoz-Saba; sugerencias al diseño y a la diagramación fueron elaboradas por la ilustradora científica Marie Joelle Giraud López. 


\section{CAPÍTULO IV - RESULTADOS}

\section{BIOTA FÓSIL}

\section{Macrofósiles vegetales}

En cuanto a los macrofósiles vegetales se plantea la siguiente hipótesis, inicialmente los moldes de troncos vegetales se enterraron en bancos de arena húmeda (Figura 10), lo cual acelera su ablandamiento, causado por su lenta descomposición y por el incremento de la porosidad de los troncos parcialmente descompuestos, lo cual probablemente permite la percolación hacia su interior de la arena y de los fluidos carbonatados liberados por meteorización de los feldespatos presentes en el banco de arena (Figura 11). Esta aseveración se respalda porque la parte externa de los moldes están conformados por arenisca, restos de materia vegetal dispersos y matriz cementante de carbonatos. El proceso de fosilización avanza de afuera hacia adentro, de tal forma que la arena remplaza gradualmente al material vegetal original mientras que los carbonatos aportan firmeza.

En el proceso queda un residuo vegetal polvoriento que ocupa la posición medular que es reemplazado por arena al final de la fosilización (Figura 12a); en esta fase se conserva la estructura lineal de troncos elongados, pero poco o nada de las estructuras internas de la madera, a diferencia de lo que ocurre con los xilópalos (Figura 13). Estas estructuras internas de la madera solo se observan cuando la arena es muy fina (Figura 12a), su ausencia es lo que dificulta el reconocimiento de los torpedo-shape como fósiles vegetales. Teniendo en cuenta lo anterior, en este tipo de fosilización el reemplazo de la materia orgánica es por arena muy fina, proceso al que podría denominarse arenización y su resultado son los moldes de troncos vegetales, muy diferente a los xilópalos (fosilización por sílice) (Figura 13).

Se registraron moldes de troncos vegetales en las siguientes formaciones del Grupo La Venta (Figura 14; Anexo 2):

Formación La Victoria: Ubicación: en el techo de la formación.

- Formación Cerbatana: Ubicación: Cerbatana Gravels and Clays, parte superior cerca del suroccidente de la línea del ferrocarril. Dimensión: 1 a $3 \mathrm{~m}$ de longitud. Dirección: sureste (N40W). Nota: también registrados por Fields (1959).

Formación Villavieja: Ubicación: Monkey Unit, parte suroccidental de las gravas; Unit below Fish Bed; Ferruginous Sands. Dimensión: $15 \mathrm{~m}$ de longitud, $1 \mathrm{~m}$ de diámetro. Dirección: N10E donde las cabezas se dirigen hacia el sur, orientadas paralelas una de otra. Nota: abundantes en las capas de areniscas; también registrados por Fields (1959).

Formación Las Mesitas: Ubicación: base de la formación. Dimensión: 30 - $40 \mathrm{~m}$ de longitud, 0,60 - $1 \mathrm{~m}$ de diámetro, forman especies de empalizadas. Dirección: E, ESE. Nota: abundantes en las capas de areniscas; el proceso de formación descrito 
se hace con los moldes presente en esta área.

\section{Polen fósil}

Se registran 622 taxones de polen fósil para el Grupo La Venta, 381 están indeterminados, los cuales siguen en proceso de verificación de la identificación y/o en consecuencia descripción de nuevos registros para la ciencia; cuatro son monoletes y 67 triletes. Las formaciones comparten los siguientes taxones (Tabla 1, Anexo 8):

- Formación San Alfonso - La Victoria - Villavieja (1): Ficus sp1.

- Formación San Alfonso - Villavieja (1): Arecaceae sp2.

- Formación La Victoria - Villavieja (1): Piperaceae sp4.

A nivel de familia los taxones que se comparten son (Anexo 8):

- Formación San Alfonso - La Victoria - Villavieja (10): Apocynaceae, Asteraceae, Cyperaceae, Euphorbiaceae, Fabaceae, Malpighiaceae, Moraceae, Piperaceae, Poaceae, Polypodiaceae.

- Formación San Alfonso - Villavieja (7): Arecaceae, Bombacaceae, Burseraceae, Cecropiaceae, Dioscoreaceae, Onagraceae, Sapindaceae.

- Formación San Alfonso - La Victoria (2): Commelinaceae, Malvaceae.

- Formación La Victoria - Villavieja (4): Araceae, Araucariaceae, Podocarpaceae, Sapotaceae.

\section{Formación San Alfonso}

En el paleosuelo se halló el polen fósil. Se registran 144 taxones, 97 son indeterminados, 142 son exclusivos de esta formación (Anexos 8,9).

\section{Formación La Victoria}

En el paleosuelo se halló el polen fósil, particularmente en las arcillas y limos de la Capa Libano Sands and Clays. Se registran 121 taxones, 85 son indeterminados, 119 son exclusivos de esta formación (Anexos 8, 10).

\section{Formación Cerbatana}

No se registra polen fósil, no se observaron arcillas.

\section{Formación Villavieja}

En el paleosuelo se halló el polen fósil, particularmente en la Capa Lower Red Bed. Se registran 357 taxones, 199 son indeterminados, 354 son exclusivos de esta formación (Anexos 8, 11).

\section{Formación Las Mesitas}

No se registra polen fósil, no se observaron arcillas. 


\section{Análisis comparativo entre las diferentes formaciones a partir del polen fósil}

Se comparó la presencia o ausencia de 66 taxones (géneros, familias) de polen fósil registrados en las formaciones San Alfonso, La Victoria y Villavieja. El análisis de similitud muestra una mayor relación entre las formaciones La Victoria y Villavieja (Coeficiente de correlación de Simpson: 0,8322) (Figura 15; Tablas 5, 6; Anexo 8).

\section{Análisis comparativo entre las diferentes formaciones a partir de los paleohábitats propuestos}

Se comparó la presencia o ausencia de 51 taxones (familias) de polen fósil registrados en las formaciones San Alfonso, La Victoria y Villavieja con el polen actual de las coberturas vegetales modernas. El análisis de similitud muestra las siguientes afinidades (Figura 16; Tablas 5, 6; Anexo 8):

- El bosque de ribera tiene una mayor afinidad con la Formación Villavieja. Coeficiente de correlación de Simpson: 0, 8636 (Figura 16a; Tabla 6b).

El matorral denso tiene una mayor afinidad con las formaciones Villavieja y San Alfonso. Coeficiente de correlación de Simpson: 0,9231 y 0,6154, respectivamente (Figura 16b; Tabla 6c).

- El matorral abierto tiene una mayor afinidad con las formaciones Villavieja y San Alfonso. Coeficiente de correlación de Simpson: 0,8462 y 0,6923, respectivamente (Figura 16c; Tabla 6d).

- La sabana seca tiene una mayor afinidad con las formaciones San Alfonso y Villavieja. Coeficiente de correlación de Simpson, de las dos formaciones: 0,7857 (Figura 16d; Tabla 6e).

- Las formaciones La Victoria y Villavieja son más similiares entre sí, las cuales comparten elementos del matorral denso y de la sabana seca. Coeficiente de correlación de Simpson: 0,8095) (Figuras 16b,d).

A partir de lo anterior se plantean los siguientes paleohábitats para cada una de las formaciones del Grupo La Venta (Figura 16; Tablas 5, 6; Anexo 8):

\section{Bosque de ribera}

Familias (19): Annonaceae, Apocynaceae, Araceae, Asclepiadaceae, Asteraceae, Bignoniaceae, Boraginaceae, Bromeliaceae, Burseraceae, Cecropiaceae, Euphorbiaceae, Fabaceae, Malpighiaceae, Meliaceae, Mimosaceae, Moraceae, Piperaceae, Rubiaceae, Sapindaceae.

Formación: Villavieja.

\section{Matorral denso}

Familias (13): Apocynaceae, Asclepiadaceae, Asteraceae, Bromeliaceae, Burseraceae, Euphorbiaceae, Fabaceae, Malvaceae, Mimosaceae, Moraceae, Poaceae, Rubiaceae, Scrophulariaceae. 
Formación: San Alfonso, La Victoria, Villavieja.

\section{Matorral abierto}

Familias (13): Apocynaceae, Asteraceae, Boraginaceae, Bromeliaceae, Burseraceae, Euphorbiaceae, Fabaceae, Loranthaceae, Malpighiaceae, Malvaceae, Mimosaceae, Rubiaceae, Sapindaceae.

Formación: San Alfonso, Villavieja.

\section{$\underline{\text { Sabanas Secas }}$}

Familias (14): Asclepiadaceae, Asteraceae, Burseraceae, Cyperaceae, Euphorbiaceae, Fabaceae, Loranthaceae, Malvaceae, Mimosaceae, Moraceae, Piperaceae, Poaceae, Rhamnaceae, Rubiaceae.

Formación: San Alfonso, La Victoria, Villavieja.

\section{Vertebrados fósiles}

A partir de la información de vertebrados fósiles del Neógeno recolectada y la información de colecciones históricas georeferenciada, se caracterizó la fauna para cada una de las formaciones del Grupo La Venta. Se recolectaron 1.970 registros fósiles (1.218 presente investigación, 578 literatura), a 1.553 se les precisó su ubicación estratigráfica, los cuales corresponden a 174 taxones; 902 son registros de mamíferos, 122 taxones; y 56 coprolitos, probablemente de Crocodylia, ya que siempre se registraron asociados con restos de estos (Tablas 2-4; Anexos 2, 12-14, 27).

\section{Formación San Alfonso}

Son los primeros registros (99) de vertebrados fósiles para esta formación, representados por 18 taxones: Actinopterygii (4 taxones), Chondrichthyes y Sarcopterygii (Lepidosiren); el gran grupo de los Crocodylia lo conforman las familias Alligatoridae (Balanerodus) y Gavialidae. Los mamíferos (6 taxones) Astrapotheria, Cingulata (Nanoastegotherium), Notoungulata (4): Leontiniidae, Toxodontidae (Pericotoxodon) se registran hacia el techo de la formación; en la base de esta se encuentran los peces.

\section{Formación La Victoria}

En la Formación La Victoria se registraron 95 taxones, 198 son mamíferos que corresponden a 72 taxones. La fauna de vertebrados fósiles se compone de: Actinopterygii (4 taxones), Chondrichthyes (Myliobatis) y Sarcopterygii (Lepidosiren); Crocodylia, representados por dientes sueltos de Balanerodus sp. (probablemente algunos retrabajados), Balanerodus logimus, Gavialis, Gryposuchus colombianus (exclusivo de la formación), Purussaurus; Teiidae (Paradracaena colombiana); Testudines (Podocnemis pritchardi). Los mamíferos: Primates (5 taxones): Patasola magdalenae (Cebidae), estatrigrafía no definida; Astrapotheria (2 taxones); Chiroptera; Cingulata (16 taxones): Neoglyptatelus; Didelphimorphia (2 taxones); Litopterna (9 taxones); Notoungulata (12 taxones); Paucituberculata; Pilosa: (7 taxones); Rodentia (12 taxones); Sirenia; y Sparassodonta (2 taxones, cada uno). 
Las especies exclusivas de esta formación son 5: Litopterna (1): Villarroelia totoyoi; Paucituberculata (1): Pithiculites chenche; Pilosa (1): Brievabradys laventensis; Rodentia (1): Scleromys sp3; Sparassodonta (1): Anachlysisctis gracilis.

\section{Formación Cerbatana}

Se registran 53 taxones: Actinopterygii, Sarcopterygii (Lepidosiren); Crocodylia: Balanerodus y Purussaurus. Los mamíferos (44 taxones) están representados por Astrapotheria (2 taxones); Cingulata (12 taxones); Didelphimorphia (2 taxones); Litopterna (4 taxones); Notoungulata (11 taxones); Pilosa (4 taxones); Rodentia (7 taxones): Sirenia; y Sparassodonta.

\section{Formación Villavieja}

Se registraron 770 restos de 142 taxones, siendo la formación más rica en vertebrados, representados por: Actinopterygii (7 taxones; Brachyplatystoma promagdalena, exclusivo de esta formación; Phractocephalus), Chondrichthyes (Myliobatis) y Sarcopterygii (Lepidosiren); Amphibia (Rhinella marina, Wellesaurus peabodyi); dentro de los Crocodylia: Balanerodus, Caiman lutescens, Charactosuchus fieldsi, Mourasuchus atopus, Purussaurus neivensis, Tupinambis teguixin; Testudines: Chelus clombianus, Geochelone hesterna; y Aves (Hoazinoides magdalenae). En cuanto a los mamíferos se registran 104 taxones, dentro de los que se destacan: Primates (13 taxones); Astrapotheria (6 taxones), distribuidos en la base y la parte media de la formación; Chiroptera (13 taxones); Cingulata (14 taxones); Didelphimorphia (9 taxones); Litpterna (8 taxones); Notoungulata (13 taxones); Paucituberculata; Pilosa (9 taxones); Rodentia (15 taxones); Sirenia (2 taxones); Sparassodonta.

Las especies de mamíferos, no primates, exclusivas de esta formación son 16: Chiroptera (8): Kiotomops lopezi, Noctilio albiventris, Notonycteris madalenensis, Notonycteris sucharadeus, Palynephyllum antimaster, Thyroptera lavalis, Thyroptera robusta, Thyroptera tricolor; Didelphimorphia (4): Marmosa laventica, Pachybiotherium minor, Thylamys colombianus, Thylamys minutus; Paucituberculata (1): Hondathentes cazador; Pilosa (1): Neotamandua borealis; Rodentia (2): Rhodanodolichotis antepridiana, Microsteiromys jacobsi.

\section{Formación Las Mesitas}

Los fósiles en esta formación son relativamente escasos; se registraron 20 taxones, representados por: Actinopterygii (3 taxones), Crocodylia con los géneros Balanerodus, Gavialis y Purussaurus. Los mamíferos, están representados por doce taxones: Astrapotheria; Litopterna (Prolicaphrium); Notoungulata (4 taxones): Pericotoxodon platignathus, Miocochilius anomopodus; Rodentia (5 taxones): Prodolichotis pridiana, Olenopsis sp2, Scleromys colombianus, Ricardomys longiden. La especie exclusiva de esta formación es Dukecynus magnus (Sparassodonta). 


\section{Análisis comparativo entre las diferentes formaciones a partir de los vertebrados fósiles}

Se comparó la presencia o ausencia de 137 taxones de vertebrados fósiles, entre los cuales 103 eran de mamíferos. El análisis comprendió 87 especies, 71 son mamíferos; 35 géneros, 25 son mamíferos; y 15 a nivel taxonómico de familia u orden, principalmente, 7 son taxones de mamíferos (Tabla 7; Anexo 12). A partir del análisis de similitud entre los taxones de vertebrados de las diferentes formaciones se establecen dos grupos (Coeficiente de correlación de Simpson - vertebrados fósiles: 0,8312; coeficiente de correlación de Simpson - mamíferos fósiles: 0,7201); el primero conformado por las formaciones La Victoria y Cerbatana (41 taxones de vertebrados compartidos, coeficiente de correlación de Simpson: 0,9762; 37 taxones de mamíferos compartidos, coeficiente de correlación de Simpson: 0,9737), y el segundo lo conforman las formaciones Villavieja y Las Mesitas (15 taxones de vertebrados compartidos, coeficiente de correlación de Simpson: 0,9375; 10 taxones de mamíferos compartidos, coeficiente de correlación de Simpson: 0,9091) (Figura 17; Tablas 7, 8).

Las formaciones Villavieja y Cerbatana comparten 39 taxones de vertebrados (Coeficiente de correlación de Simpson: 0,9286) y 36 de mamíferos (Coeficiente de correlación de Simpson: 0,9474); y las formaciones Villavieja y la Victoria comparten 53 taxones de vertebrados (Coeficiente de correlación de Simpson: 0,7260) y 45 de mamíferos (Coeficiente de correlación de Simpson: 0,7627) (Figura 17; Tabla 8).

Las especies de mamíferos compartidas entre las diferentes formaciones del Grupo La Venta son (Tabla 8b):

Formaciones San Alfonso - La Victoria - Cerbatana - Villavieja - Las Mesitas (1): Notoungulata (1): Pericotoxodon sp1.

Formaciones La Victoria - Cerbatana (36): Sparassodonta (1): Lycopsis longirostrus; Didelphimorphia (2): Hondadelphys fieldsi, Micoureus laventicus; Cingulata (9): Anadasyus hondanus, Boreostema acostae, Boreostemma gigantea, Nanoastegotherium sp., Nanoastegotherium prostatum, Neoglypatelus originalis, Pedrolypeutes praecursor, Scirrotherium sp., Scirrotherium hondaensis; Pilosa (3): Glossotheriopsis pascuali, Neonematherium flabellatum, Pseudoprepotherium confusum; Litopterna (4): Megadolodus molariformes, Prolicaphrium sanalfonsensis, Prothoatherium colombianus, Theosodon sp.; Notoungulata (8): Huilatherium sp1, Huilatherium pluripicatum, Miocochilius sp., Miocochilius anomopodus, Pericotoxodon sp., Pericotoxodon sp1, Pericotoxodon sp2, Pericotoxodon platignatus; Astrapotheriidae (2): Granastrapotherium snorki, Xenastrapotherium kraglievichi; Sirenia (1): Potamosiren magdalenensis; Rodentia (6): Neoreomys huilensis, Olenopsis sp2, Olenopsis sp3, Prodolichotis pridiana, Scleromys sp1, Scleromys sp2.

Formaciones La Victoria - Cerbatana - Villavieja (34): Sparassodonta (1): Lycopsis longirostrus; Didelphimorphia (2): Hondadelphys fieldsi, Micoureus laventicus; Cingulata (8): Anadasyus hondanus, Boreostema acostae, Boreostemma gigantea, 
Nanoastegotherium prostatum, Neoglypatelus originalis, Pedrolypeutes praecursor, Scirrotherium sp., Scirrotherium hondaensis; Pilosa (3): Glossotheriopsis pascuali, Neonematherium flabellatum, Pseudoprepotherium confusum; Litopterna (4): Megadolodus molariformes, Prolicaphrium sanalfonsensis, Prothoatherium colombianus, Theosodon sp.; Notoungulata (8): Huilatherium sp1, Huilatherium pluripicatum, Miocochilius sp., Miocochilius anomopodus, Pericotoxodon sp., Pericotoxodon sp1, Pericotoxodon sp2, Pericotoxodon platignatus; Astrapotheriidae (2): Granastrapotherium snorki, Xenastrapotherium kraglievichi; Sirenia (1): Potamosiren magdalenensis; Rodentia (5): Neoreomys huilensis, Olenopsis sp2, Olenopsis sp3, Prodolichotis pridiana, Scleromys sp2.

Formaciones La Victoria - Cerbatana - Villavieja - Las Mesitas (6): Notoungulata (3): Miocochilius anomopodus, Pericotoxodon sp1, Pericotoxodon platignatus; Astrapotheriidae (1): Xenastrapotherium kraglievichi; Rodentia (2): Olenopsis sp2, Prodolichotis pridiana.

Formaciones Cerbatana - Villavieja (35): Sparassodonta (1): Lycopsis longirostrus; Didelphimorphia (2): Hondadelphys fieldsi, Micoureus laventicus; Cingulata (8): Anadasyus hondanus, Boreostema acostae, Boreostemma gigantea, Nanoastegotherium prostatum, Neoglypatelus originalis, Pedrolypeutes praecursor, Scirrotherium sp., Scirrotherium hondaensis; Pilosa (3): Glossotheriopsis pascuali, Neonematherium flabellatum, Pseudoprepotherium confusum; Litopterna (4): Megadolodus molariformes, Prolicaphrium sanalfonsensis, Prothoatherium colombianus, Theosodon sp.; Notoungulata (9): Huilatherium sp1, Huilatherium sp2, Huilatherium pluripicatum, Miocochilius sp., Miocochilius anomopodus, Pericotoxodon sp., Pericotoxodon sp1, Pericotoxodon sp2, Pericotoxodon platignatus; Astrapotheriidae (2): Granastrapotherium snorki, Xenastrapotherium kraglievichi; Sirenia (1): Potamosiren magdalenensis; Rodentia (5): Neoreomys huilensis, Olenopsis sp2, Olenopsis sp3, Prodolichotis pridiana, Scleromys sp2.

- Formaciones La Victoria - Villavieja (8): Cingulata (1): Pedrolypeutes sp.; Pilosa (1): Neonematherium sp.; Litopterna (1): Prolicaphrium sp.; Notoungulata (1): Huilatherium sp.; Sirenia (1): Potamosiren sp.; Rodentia (3): Olenopsis sp1, Scleromys colombianus, Scleromys schürmanni.

- Formaciones La Victoria - Villavieja - Las Mesitas (2): Litopterna(1): Prolicaphrium sp; Rodentia (1): Scleromys colombianus.

- Formaciones Villavieja - Las Mesitas (10): Litopterna (1): Prolicaphrium sp.; Notoungulata (3): Miocochilius anomopodus, Pericotoxodon sp1, Pericotoxodon platignatus; Astrapotheriidae (1): Xenastrapotherium kraglievichi; Rodentia (5): Microscleromys paradosalis, Olenopsis sp2, Prodolichotis pridiana, Ricardomys longiden, Scleromys colombianus.

Los taxones con geoposición espacial y capa litológica no definida son:

Astrapotheria: Astrapotherium (Astrapotheriidae).

- Chiroptera: Eumops, Nyctinomops colombiensis (Molossidae), Vespertilionidae.

Notoungulata: Hegetotheriidae, Henricosborniidae. 
- Pilosa: Hapalops (Megatheriidae), Huilabradys magdaleniendis (Nothrotheriidae).

- Rodentia: Eosteiromys (Erethizontidae).

- Sparassodonta: Cladosictis (Hathliacynidae).

\section{Primates}

En la presente investigación no se recolectó ningún fósil de primate, pero teniendo en cuenta la literatura se georeferenciaron las localidades; por lo tanto, se registran fósiles de primates en las formaciones La Victoria y Villavieja (Anexos 2, 12, 15).

\section{Formación La Victoria (6 taxones)}

Atelidae: Stirtonia victoriae; Pitheciidae: Lagonimico conclucatus, Miocallicebus villaviejai, cf. Nuciruptor IGM-KU 8602, cf. Nuciruptor IGM 184667.

\section{Formación Villavieja (13 taxones)}

Atelidae: Stirtonia tatacoensis; Cebidae: Cebidae KU 9-86A, Callitrichinae (IGM-KU 8402, IGM-KU 8403), Laventiana annectens, Micodon kiotensis, Mohanamico herskovitzi, Neosaimiri fieldsi; Pitheciidae: Aotus dindensis IJM-KU 8601, Aotus cf. dindensis IGM KU 8802, Cebupithecia sarmientoi, Nuciruptor rubricae IGM 251074, cf. Nuciruptor IGM 184074.

La especie con geoposición espacial y capa litológica no definida es:

- Cebidae: Patasola magdalenae. 


\section{CAPÍTULO V - DISCUSIÓN}

\section{PALEOSUELOS}

En la presente investigación se registraron para el Grupo La Venta paleosuelos en las formaciones San Alfonso y La Victoria (Figuras 18a, c), específicamente en las arcillas y limos de la capa Líbano Sands and Clays; los paleosuelos de Villavieja, de la capa Lower Red Beds, ya habían sido citados por diversos autores como Guerrero (1997) y Madden et al. (1997), quienes sólo mencionan la presencia de éstos sin llevar a cabo investigaciones específicas en el tema. A partir estos registros Flórez et al. (2013), Salazar Jaramillo et al. (2017) y Sánchez et al. (2017) realizaron estudios detallado de los paleosuelos de la Formación Villavieja (Figura 18b) y otras zonas del Grupo La Venta; información que fue tenida en cuenta en la presente investigación en el análisis de los paleohábitats del Grupo La Venta.

Teniendo en cuenta lo registrado por Flórez et al. (2013), los paleosuelos de la Formación Villavieja se formaron bajo climas contrastados desde húmedos hasta áridos, y en paleorelieves colinados de baja altitud; es decir, paisajes terrestres y suelos portadores de biomas secos que debieron coexistir con planicies aluviales asociadas con biomas boscosos que dependían de la humead del sedimento y los aportes de agua de desborde de los grandes ríos.

Por su parte, Salazar et al. (2017) concluyen que: (1) el Grupo Honda muestra diferentes velocidades de sedimentación entre la parte superior y la inferior de la unidad, siendo el tiempo de residencia de los sedimentos, en la llanura de inundación, un control importante en la formación de los suelos. (2) Los paleosuelos con mayor grado de desarrollo son más abundantes en la Formación Villavieja que en la Formación La Victoria. (3) Las propiedades morfológicas y geoquímicas de los paleosuelos del Miembro Cerro Colorado sugieren altas tasas de meteorización y por consiguiente disminución del $\mathrm{CO}_{2}$ atmosférico en un periodo de miles de años. (4) Se presenta coherencia entre el ciclo de retroalimentación negativa de la meteorización química, y los estudios de paleosuelos en zonas templadas, que indican una disminución de $\mathrm{CO}_{2}$ atmosférico hacia finales del Mioceno medio.

En la investigación realizada por Sánchez et al. (2017) concluyeron que: (1) la Formación Villavieja se encontraría entre selva húmeda y bosque húmedo templado cálido de acuerdo a las zonas de vida de Holdridge. (2) Identificaron dos fuentes de proveniencia del material parental: material volcano-clástica, el cual origina a las esmectitas (in situ ?); y material detrítico de origen fluvial, que da origen a la caolinita, dickita, e ilita. (3) El carácter detrítico corresponde a un ambiente fluvial, particularmente con depósitos de desborde; la textura de los paleosuelos es principalmente arcillosa. (4) La continuidad lateral de las secuencias de paleosuelos la identificaron a partir de propiedades morfológicas, mineralógicas y geoquímicas, las cuales permiten subdividir los paleosuelos en cuatro 
pedofacies (P1 - P4) de acuerdo a sus condiciones de drenaje y procesos de alteración (e.g oxidación) ocurridas posenterramiento; y (5) la información preliminar del paleosuelo de la pedofacie P3 indican que la precipitación media anual era de 1.300 aprox. $181 \mathrm{~mm} / \mathrm{año}$, y la temperatura media anual se encontraba entre $\operatorname{los} 20^{\circ} \mathrm{C}$, con una desviación de más o menos $0,6^{\circ} \mathrm{C}$.

\section{BIOTA FÓSIL}

\section{Macrofósiles vegetales}

A lo largo del Grupo La Venta se presentan concreciones esferoidales clásicas de tipo arenoso cementadas por carbonatos, los denominados Cannon ball, registradas en la Sierra de Gulumán cerca de Potosí, por el camino a San Alfonso sobre areniscas grises (Royo y Gómez 1942a, b), y en el Líbano Sands and Clays concreciones redondas hasta de $40 \mathrm{~mm}$ de diámetro formando cornisas (Fields 1959) (Figura 19a); sin embargo, las más llamativas son las denominadas por Fields (1959) como torpedo-shaped (Figura 19b), quien propone un mecanismo de formación diagenético e inorgánico muy complejo para explicar el paralelismo que mantienen dentro del estrato. En la presente investigación, se realizaron observaciones detalladas de estas concreciones presentes en las formaciones La Victoria, Cerbatana, Villavieja y Las Mesitas.

Teniendo en cuenta lo observado y consultado en la literatura sobre procesos de fosilización, es indudable que la fosilización de los torpedo-shaped, aún no ha sido descrita y merece estudios más detallados. A partir de los registros de campo de la presente investigación, se considera que este tipo de fosilización de la madera ocurre en el Grupo La Venta, por lo tanto, se sugiere como un marcador de tiempo. Los moldes de troncos vegetales se pueden hallar aislados dentro de los estratos arenosos, pero es común encontrarlos agrupados con su eje largo subparalelo (Formación Las Mesitas); teniendo en cuenta la hipótesis aquí planteada, se trataría de empalizadas transportadas hasta su lugar de depositación por corrientes de agua (Figura 14).

\section{Polen fósil}

Kay \& Madden (1997, P: 537) mencionan fragmentos de troncos fósiles de Goupoioxylon stutzeri (Celastraceae) identificados por Schönfeld (1947) y asignados erróneamente al área de La Venta, ya que éstos corresponden a fósiles extraídos de la Formación Amagá (Oligoceno) en Antioquia.

\section{Vertebrados fósiles}

Kay et al. (1997) registraron para La Venta 128 taxones de vertebrados, 93 son mamíferos; en la presente investigación se registran para el Grupo La Venta 174 taxones de vertebrados, de los cuales 122 son mamíferos (Tablas 2-4; Anexos 2, 12). 
A partir de la información que proveen los vertebrados fósiles se establece una mayor afinidad entre las formaciones La Victoria y Cerbatana, las cuales se caracterizan por presentar llanuras de inundación y entre los paleohábitats propuestos se encuentran los bosques de ribera (Figura 19; Tabla 8; Anexos 2, 4, 5, 22, 23); y entre las formaciones Villavieja y Las Mesitas, las cuales se caracterizan por presentar llanuras de inundación, y entre los paleohábitats propuestos se encuentran los bosques de ribera y los bosques húmedos siempre verdes estratificados (Figura 17; Tabla 8; Anexos 2, 6, 7, 24, 25).

La mayor riqueza de taxones de mamíferos se asocia con las formaciones Villavieja (104), La Victoria (72) y Cerbatana (44), lo cual está relacionado con la diversidad de paleohábitats que en la presente investigación se registra, como son, en la Formación La Victoria bosques de ribera que rodean un gran río meándrico y grandes sabanas inundables y arboladas; en la Formación Cerbatana bosques de ribera de hasta 3 metros de altura que rodean un gran río trenzado, y en la Formación Villavieja bosques húmedos de cerca de 15 metros de altura y bosques de ribera que rodean un gran río ondulado (Anexos 12, 21-25).

La diversificación de estos ambientes se asocia no sólo con la riqueza de taxones y abundancia de los mismos, especialmente en las formaciones Villavieja y La Victoria, sino con la riqueza de hábitats y hábitos de la mastofauna (Vizcaíno et al. 2016), así:

\section{$\underline{\text { San Alfonso - La Victoria, Cerbatana - Villavieja }}$}

- Cingulata: Dieta: los dasipódidos extintos presentan en general una dieta omnívora, algunos se especializan en el consumo insectos, otros principalmente consumen vegetales (Straehl et al. 2012); específicamente los armadillos eran omnívoros o consumían insectos, los pampaterios eran herbívoros y los gliptodontes herbívoros (Vizcaino et al. 2004). Hábitat: bosques estratificados, bosques de ribera bajos, sabanas secas, sabanas arboladas. Formación: San Alfonso (1), La Victoria (16), Cerbatana (12), Villavieja (14).

\section{$\underline{\text { San Alfonso - Las Mesitas }}$}

Comparten megamamíferos de hábito herbívoro:

- Astrapotheria: Dieta: hierbas. Hábitat: grandes sabanas inundables, bosques de ribera abiertos y matorrales abiertos. Formación: San Alfonso (1), La Victoria (2), Cerbatana (2), Villavieja (6), Las Mesitas (1).

- Notoungulata: Dieta: hojas. Hábitat: sabanas secas, sabanas arboladas, bosques de ribera bajos. Formación: San Alfonso (4), La Victoria (12), Cerbatana (11), Villavieja (13), Las Mesitas (4).

\section{Villavieja - La Victoria}

Comparten grupos de tamaño pequeño a mediano, con diversidad de dietas y hábitats, como son: 
- Primates: Dieta: insectos, frutos, hojas, omnívora, semillas (dispersor ?, predador). Hábitat: bosques estratificados, bosques de ribera, humedales, sabanas arboladas, sabanas secas arboladas. Formación: La Victoria (6), Villavieja (13).

- Chiroptera: Dieta: insectos. Hábitat: bosques estratificados, bosques de ribera, sabanas abiertas. Formación: La Victoria (1), Villavieja (13).

- Paucituberculata: Dieta: insectos. Hábitat: bosques con suelos húmedos y ricos en nutrientes, que se puedan arar para hacer madrigueras, bosques de ribera. Formación: La Victoria (Pithiculites chenche), Villavieja (Hondathentes cazador).

\section{Villavieja - La Victoria - Cerbatana}

Comparten megamamíferos de hábito herbívoro, e insectívoro de tamaño mediano.

- Didelphimorphia: Dieta: insectos. Hábitat: bosques estratificados, bosques de ribera. Formación: La Victoria (2), Cerbatana (2), Villavieja (9).

- Litopterna: Dieta: hojas. Hábitat: bosques de ribera bajos, sabanas secas, sabanas arboladas, matorrales abiertos. Formación: La Victoria (9), Cerbatana (4), Villavieja (7).

- Pilosa: Dieta: material vegetal (hojas, tallos), provenientes de ramas de arbustos y árboles; frutos, insectos, hojas, tubérculos. Hábitat: sabanas secas, sabanas arboladas, bosques estratificados, bosques de ribera. Formación: La Victoria (7), Cerbatana (4), Villavieja (9).

- Sirenia: Dieta: hojas. Hábitat: lagos, grandes ríos meándricos, grandes ríos ondulados. Formación: La Victoria (2), Cerbatana (1), Villavieja (2).

\section{Villavieja - La Victoria - Cerbatana - Las Mesitas}

Comparten mamíferos de hábito herbívoro y depredador.

- Rodentia: Dieta: frutos, semillas, hojas, insectos. Hábitat: bosque con suelos húmedos y ricos en nutrientes, bosques estratificados, bosques de ribera, sabanas inundables. Formación: La Victoria (12), Cerbatana (7), Villavieja (15), Las Mesitas (5).

- Sparassodonta: Dieta: carnívoro (Rose 2006). Hábitat: bosques de ribera bajos, sabanas arboladas, sabanas secas. Formación: La Victoria (2), Cerbatana (1), Villavieja (1), Las Mesitas (1). 


\section{PRIMATES}

Teniendo la geoposición espacial, la capa litotógica y los paleoambientes definidos para el Grupo La Venta, se plantea que la distribución de los taxones de primates del Mioceno medio en Colombia de base a techo es (Anexos 2, 12, 15, 22, 24, 26):

Formación La Victoria (I: Capa de los Lagos; III: Areniscas de San Nicolás)

I.

Ambiente sedimentario: lagos.

Paleohábitat: humedal.

- Lagonimico conclucatus

- $\quad$ cf. Nuciruptor IGM 184667

II.

Ambiente sedimentario: río meándrico.

- Paleohábitat: bosque de ribera.

- Stirtonia victoriae

III.

Ambiente sedimentario: río meándrico.

- Paleohábitat: sabana inundable, sabana arbolada, matorral abierto.

- Miocallicabus villaviejai

- $\quad$ cf. Nuciruptor IGM KU 8602

IV.

Incertum locum

- Patasola magdalenae

Formación Villavieja (I: Monkey Unit; II: Lower Red Bed; III - IV: Upper Red Bed)

I.

Ambiente sedimentario: río ondulado.

Paleohábitat: bosque de ribera estratificado.

- Laventiana annectens

- Neosaimiri fieldsi

- Nuciruptor rubricae IGM 251074

- $\quad$ cf. Nuciruptor IGM 184074

II.

Ambiente sedimentario: río ondulado.

- Paleohábitat: bosque de ribera estratificado, sabana inundable.

- Callitrichinae: IGM-KU 8402, IGM-KU 8403

- Cebupithecia sarmientoi

- Micodon kiotensis

- Neosaimiri fieldsi

- Stirtonia tatacoensis 
III.

Ambiente sedimentario: río ondulado.

Paleohábitat: bosque de ribera estratificado, sabana inundable.

- Cebidae KU 9-86A

- Mohanamico herskovitzi

- Stirtonia tatacoensis

IV.

Ambiente sedimentario: río ondulado.

Paleohábitat: bosque siempre verde estratificado (15 m altura).

- Aotus dindensis IGM-KU 8601

- Aotus cf. dindensis IGM-KU 8802

La ubicación de Patasola magdalenae es tentativa (incertum locum), a partir de la estratigrafía de Parra-Sánchez (2016; Figura 1, P: 16), la localidad de esta especie dada por Kay \& Meldrum (1997), Duke Locality 40, y situada en el mapa en Takai et al. (2001; Figura 1, P: 290) se registra para la capa Líbano Sands and Clays, por lo tanto, se infiere para el Mioceno inferior. Horizonte y Localidad (sensu Kay \& Meldrum 1997; P: 438): "The type is from Duke Locality 40 in the stratigraphic interval between the Cerro Gordo Sandstone Beds and the Chunchullo Sandstone Beds, La Victoria Formation (middle Miocene), Colombia (...). This stratigraphy Interval is approximately $560 \mathrm{~m}$ below the Monkey Beds, from wich Neosaimiri fieldsi is recovered, and the further $720 \mathrm{~m}$ below the stratigraphic level of Neosaimir annectens in the El Cardón Red Beds.".

La mayor riqueza de taxones de primates se registra para la Formación Villavieja (13), seguida por la Formación La Victoria (5; Patasola magdalenae (Cebidae), estatrigrafía no definida); esto se asocia con la riqueza de hábitats que ofrece la Formación Villavieja, los cuales van desde bosques estratificados a bosques de ribera, principalmente. Teniendo en cuenta la geoposición espacial y la capa litológica (Anexo 2), así como las variaciones morfológicas, se postula que los registros fósiles de primates identificados dentro del género Nuciruptor podrían ser diferentes entre sí [IGM 184667, IGM 184074 (Takai et al. 2001), IGM KU 8602 (Takai et al. 1992)] y también diferentes a Nuciruptor rubricae (IGM 251074, Takai 1994), aunque puede que pertenezcan a este género, por lo que se sugiere realizar un estudio detallado a nivel morfológico y filogenético. Esto se infiere porque los ejemplares IGM 184667 e IGM KU 8602, nominados como cf. Nuciruptor, si bien se localizan en la Formación La Victoria, el primero se registra para la Capa de Lagos, en la base occidental de la formación, mientras que el segundo se localiza hacia la parte oriental del techo de la formación (Areniscas de San Nicolás), estando estas dos zonas separadas por el gran río meándrico que atraviesa esta unidad; probablemente por ser meándrico, el río no fue una clara barrera biogeográfica para el paso de esta fauna, pero sí pudo haber propiciado procesos de especiación por hábitat (humedales, sabanas arboladas). Por su parte, N. rubricae (IGM 251074) y cf. Nuciruptor (IGM 184074), de la Formación Villavieja, se encuentran separados biogeográficamente de los anteriores por el gran río trenzado y caudaloso que recorre la Formación Cerbatana. Meldrum \& Kay (1997) postulan que N. rubricae se 
relaciona con los pitecinos actuales y con Cebupithecia sarmientoi de la Formación Villavieja (Anexo 2).

Lagonimico conclucatus y cf. Nuciruptor (IGM 184667) se asocian con los humedales (Capa de Lagos), y Miocallicebus villaviejai y cf. Nuciruptor (IGM 8602) se registran en el techo de la Formación La Victoria, asociadas con grandes sabanas arboladas (Anexo 2).

Stirtonia es un género que está estrechamente relacionado con Alouatta (Stirton 1951, Hershkovitz 1970, Kay et al.1987, Perez et al. 2013, Cooke et al. 2017), género actual que se adapta a diversas latitudes y hábitats, entre los que se encuentran bosques de ribera, bosques caducifolios y bosques húmedos (Defler 2010). Stirtonia victoriae se asocia con los bosques de ribera ubicados en la base de la Formación La Victoria; esta especie presentaba una dieta principalmente folívora, similar al primate actual Alouatta palliata, especie con la cual planteo la hipótesis que presenta mayor cercanía filogenética. Defler (2010) registra que $A$. palliata consume hojas y frutos, y se encuentra asociada en Colombia con bosques húmedos y semideciduos, y en Centroamérica con bosques secos, deciduos y de ribera (Anexo 2).

Laventiana annectens, Neosaimiri fieldsi, Nuciruptor rubricae (IGM 251074) y cf. Nuciruptor (IGM 184074) especies registradas para la Formación Villavieja, capa Monkey Unit, se asocian principalmente con bosques de ribera estratificados. L. annectens y $N$. fieldsi son especies con hábito arbóreo y dieta frugívora - omnívora, relacionadas con el género actual Saimiri, el cual presenta una dieta variada, principalmente frutos e insectos, y con una amplia gama de hábitats entre los que se encuentran los bosques de ribera; $N$. rubricae probablemente era un predador de semillas, tal como se observa en las adaptaciones de su grupo, los actuales Pitheciinae (Rosenberger 1992, Defler 2010, Tejedor \& Muñoz-Saba 2013).

Los Callitrichinae indeterminados de la Formación Villavieja (IGM-KU 8402, IGMKU 8403) y Cebupithecia sarmientoi, Micodon kiotensis, N. fieldsi, Stirtonia tatacoensis, se registran en la base oriental de la Formación Villavieja, capas Lower Red Bed, se asocian con bosque de ribera estratificado, sabana inundable; $C$. sarmientoi se relaciona con el género actual Pithecia, que habita bosques de ribera (Defler 2010).

El espécimen asignando a Cebidae (KU 9-86A), Mohanamico herskovitzi y Stirtonia tatacoensis, ubicados en las llanuras de inundación de Upper Red Bed, se asocian con bosque de ribera estratificado, sabana inundable.

Se sugiere revisar la sistemática de las especies Aotus dindensis (IGM-KU 8601; Localidad: KU 9-86A = El Dinde Locality 9-86-A = La Venta Locality 9-86A; coordenadas: 3,268961 N, -75,210178 W) y Mohanamico herskovitzi (IGM 181500, Localidad: Duke Locality 22 = DU 22 = UCMP Locality V-4536 = Baraya Member: coordenadas: 3,264218 N, -75,215345 W), debido a que Kay (1990) menciona que 
probablemente sean sinónimos, y Takai et al. (2009) clarifican el estatus taxonómico de Aotus dindensis y determinan que existe dimorfismo sexual; la propuesta que se plantea es realizar una comparación morfológica entre los ejemplares de A. dindensis y $M$. herskovitzi, extensiva a los grupos actuales de Aotinae y Callitrichinae con el fin de comprobar la hipótesis que se propone de simpatría, así como la posible diferencia genérica que se plantea.

Aotus dindensis (IGM-KU 8601), Aotus cf. dindensis (IGM-KU 8802), de las llanuras aluviales de las capas Upper Red Bed, se asocian con bosques estratificados hasta de 15 $\mathrm{m}$ de altura. A. dindensis se relaciona con los Aotus actuales, los cuales habitan sabanas con arbustos, entre otros hábitats (Defler 2010).

\section{FAUNA LAVENTENSE}

A partir de las colecciones de Savage (1951), el trabajo original de Stirton (1953) (incluye Carmen de Apicalá), De Porta (1969), Hirschfeld \& Marshall (1976), Marshall (1976, 1977), Marshall et al. (1983), Takai et al. (1991), Kay et al. (1997), Madden et al. (1997), Czaplewski et al. (2003), en los cuales se reconoce a la Fauna Laventense, y la información de la presente investigación, se plantea una nueva lista de esta fauna, especificando su ubicación en cada una de las formaciones del Grupo La Venta (Anexo 27).

Se hace énfasis en que, si bien del material recolectado en la presente investigación se conoce claramente su geoposición espacial y capa litológica, esta información en las colecciones históricas es ambigua ya que son imprecisas las localidades, y por ende su litología y geoposición; uno de los factores que contribuyeron a ello es que no se conocía la cartografía original del Grupo La Venta realizada por Henao-Londoño et al. (1949), la cual se define en detalle en el mapa publicado por Fields \& HenaoLondoño (1949). Por ejemplo, en la zona delimitada por estos autores como "Líbano Sands and Clays" con respecto a los mapas propuestos por Parra-Sánchez (2016), es evidente que ellos incluyen en esta unidad tanto rocas del Mioceno medio (Formación La Victoria) como del Mioceno inferior. Por ejemplo, en Duke-ING Locality 040 sensu Takai et al. (2001), se georeferenció y se ubicó en el Mioceno inferior; Duke Locality 092 sensu Cifelli \& Guerrero (1989) se georeferenció y se ubicó en la Formación La Victoria; UCMP Locality V-4933 se cita que pertenece a la Formación La Victoria.

En otras, la localidad es imprecisa debido a que en esas épocas no se empleaban equipos de geoposición, o estos no tenían el nivel de certeza de los actuales, o simplemente para proteger la localidad de recolecciones inescrupulosas, no se ubicaron en los mapas publicados en las localidades exactas. Al realizar el proceso de georeferenciación de las colecciones históricas se evidenció que la misma localidad, dependiendo de la publicación varía su ubicación en el mapa. Por ejemplo, en localidades como Chepe Site (Takemura et al. 1992, Takai et al. 2001), FT Site (Takemura et al. 1992), FT Site 1, 2, 4 (Takai 1994), Kyoto Site 
(Takai 1994, Takai et al. 2001) y Masato Site (Takemura et al. 1992; Takai 1994, Takai et al. 2001).

Por lo tanto, al incluir la información litoestratigráfica detallada en la que se han delimitado nuevamente no sólo el Grupo La Venta sino también las formaciones que lo componen (Parra-Sánchez 2016), así como la información de la presente investigación a nivel de biota y posibles barreras biogeográficas, se plantea la verificación de las localidades de las colecciones históricas.

La Fauna Laventense la conforman 94 taxones de mamíferos, pertenecientes a 12 órdenes: Primates 18, Astrapotheria 3, Chiroptera 12, Cingulata 8, Didelphimorphia 6, Litopterna 7, Notoungulata 9, Paucituberculata 2, Pilosa 8, Rodentia 16, Sirenia 2, Spararassodonta 3. La mayor riqueza se presenta en las formaciones Villavieja, 88 taxones de mamíferos, La Victoria 59, Cerbatana 38, Las Mesitas 11, y San Alfonso 3 (Anexo 27).

Madden et al. (1997) al referirse a la bioestratigrafía de la fauna de mamíferos de La Venta y del Grupo Honda, establecen que la diversidad disminuye hacia la base de la sección, lo cual relacionan con la reducción del área de exposición de los niveles más bajos de la Formación La Victoria, cerca de Cerro Chacarón y de los niveles más altos de la Formación Villavieja, en el Cardón y Red Beds. También indican que la baja diversidad en el techo de la sección podría estar relacionada con una disminución en la tasa de sedimentación, aumentando la madurez de los paleosuelos (laterización) y la consecuente destrucción y pobre preservación de huesos. De todos modos, hay que tener en cuenta que en ese momento se había inspeccionado al sur solo hasta Polonia Red Beds (Duke Locality 126, Nivel 48) y al Norte hasta Cerro Chacarón (Duke Locality 128, Nivel 37).

Con la información aquí obtenida se infiere que la riqueza de especies disminuye tanto en la base como en el techo del Grupo La Venta (formaciones San Alfonso y Las Mesitas, respectivamente); esto se puede deber a la poca diversidad de ecosistemas (Formación San Alfonso: sabanas secas, matorrales abiertos), a la variación gradual de biomas secos a biomas húmedos de bosques multiestratificados, a que estas formaciones no han sido tan prospectadas como las otras del Grupo, y a la falta de una buena geoposición espacial y de la clarificación de la capa litológica de las colecciones históricas.

\section{MARCADORES DE TIEMPO}

\section{Macrofósiles vegetales}

Empalizadas fosilizadas - Moldes de troncos vegetales: características del Grupo La Venta; se registran en: 
- Formación La Victoria

- Formación Cerbatana

- Formación Villavieja

- Formación Las Mesitas

\section{Polen fósil}

Los palinomorfos guías son los exclusivos de cada una de las formaciones (Anexos 811):

- Formación San Alfonso: 145 taxones

- Formación La Victoria: 124 taxones

- Formación Villavieja: 253 taxones

\section{Vertebrados fósiles}

Madden et al. (1997) reconocen la Zona de Asociación de Miocochilius (ZAM), taxón fósil más común del Grupo Honda según los autores; en la presente investigación reconocemos que este género no sólo no es estricto del Grupo La Venta, ya que se registró en capas litológicas del Mioceno inferior, sino que es evidente su ausencia hacia la base del grupo, en la Formación San Alfonso (Anexo 27).

\section{PALEOAMBIENTES}

Stirton (1953b) planteó que los paleoecosistemas de La Venta eran semejantes a los llanos y sabanas (región Orinoquence) y Kay \& Madden (1997) los relacionó con los bosques tropicales de la actual Amazonia, es decir con selvas inundadas, llanuras de inundación, bosques, bosques de ribera, y no predominaban las áreas abiertas. A partir de la presente investigación, teniendo en cuenta la litoestratigrafía y el registro fósil tanto de paleosuelos, macrofósiles vegetales, polen fósil y vertebrados, se infiere que los paleohábitats del Grupo La Venta son como se describen a continuación:

\section{Formación San Alfonso}

Los paleoambientes de la Formación San Alfonso eran abanicos aluviales con ríos entrelazados como lo atestigua la sección Zanja Honda. Los ríos que alimentaban estos abanicos provenían de los relieves altos del Triásico - Jurásico los cuales se encuentran subyacentes a esta formación y fueron los que aportaron los cantos a la misma. ParraSánchez (com. pers. 2016) registra la presencia de paleosuelos de tipo aridisol de forma muy localizada. En esta formación predominan los paleohábitats de sabana seca, representado por Asteraceae, Cyperaceae, Euphorbiaceae, Fabaceae, Malvaceae, Piperacea, Poaceae; y de matorrales abiertos con Apocynaceae, Asteraceae, Euphorbiacea, Malpighiacea, Malvaceae (Figuras 16, 20; Anexos 2, 3, 8, 16). 


\section{Formación La Victoria}

A partir de los ambientes sedimentarios, se infiere que esta formación estaba constituida por bosques de ribera que rodeaban un gran río meándrico, de alto caudal y baja carga de erosión, y bosques que rodean a la Capa de Lagos (humedales), al occidente de la formación. Teniendo en cuenta el polen fósil, se infiere que hacia el oriente (Areniscas de San Nicolás) había grandes sabanas inundables y arboladas y, ocasionalmente, matorrales abiertos, elementos de polen fósil vs. vegetación actual que se comparten: Apocynaceae, Asteraceae, Euphorbiaceae, Fabaceae, Malpighiaceae, Malvaceae. El paisaje era semejante al de los bosques de ribera actuales; los elementos de polen fósil que se comparten con la vegetación actual de estos ambientes son: Apocynaceae, Araceae, Asteraceae, Euphorbiaceae, Fabaceae, Malpighiaceae, Malvaceae, Moraceae, Piperaceae), como los del Río Orinoco, al oriente de Colombia (llanos, región Orinoquence colombiana), corroborando en parte los llanos y sabanas propuestos por Stirton (1953b) (Figuras 16, 21, 22; Anexos 2, 4, 8, 17).

\section{Formación Cerbatana}

La presencia de empalizadas denominadas por Fields (1959) como torpedo shaped permiten inferir bosques de ribera estratificados, los cuales pueden alcanzar alturas hasta de 3 metros; estos bosques se ubican alrededor de un gran río trenzado, el cual atraviesa la formación y es ancho y profundo, de caudal medio y de gran carga de erosión. Este paleohábitat era similar al que presenta en la actualidad el Río Ariari (llanos, Orinoquia colombiana), similar en parte a lo propuesto por Stirton (1953b) (Figuras 23, 24; Anexos 2, $5,18)$.

\section{Formación Villavieja}

Flórez et al. (2013) estudiaron paleosuelos en las capas rojas, Lower Red Beds (LRB) y Upper Red Beds (URB) e infirieron ambientes áridos, con procesos de mineralización rápidos y acúmulo de materia orgánica. Los autores deducen grandes sabanas secas arboladas que coexistieron con bosques húmedos siempre verdes de cerca de $15 \mathrm{~m}$ de altura; esto se deduce por la presencia de empalizadas (torpedo shaped), localizadas principalmente en Monkey Unit, Unit Below Fish Bed y Ferrugineous Sandstones. La Formación Villavieja la atravesaba un río central, ondulado, de aguas tranquilas, de caudal bajo con carga de erosión media y abundantes tributarios, alrededor del cual se encontraba un bosque de ribera, lo cual se corrobora con el registro de polen fósil. Los elementos de polen fósil que se comparten con la vegetación actual de estos ambientes son: Acanthaceae, Annonaceae, Apocynaceae, Araceae, Asteraceae, Burseraceae, Cecropiaceae, Euphorbiaceae, Fabaceae, Malpighiaceae, Moraceae, Piperaceae, Sapindaceae. El paisaje era similar al que presenta en la actualidad el Valle Medio del Magdalena (Colombia) (Figuras 16, 25, 26; Anexos 2, 6, 8, 19). 


\section{Formación Las Mesitas}

Las características sedimentológicas permiten inferir un bosque de ribera alrededor de los cauces de los ríos cordilleranos, de caudal y carga de erosión baja; las llanuras aluviales estaban relacionadas con ecosistemas de sabanas arboladas, semejantes a las que presenta la Formación San Alfonso; la empalizada sugiere un bosque multiestratificado de cerca de 30 a $40 \mathrm{~m}$ de altura, ubicado en el relieve colinado de baja altura. El paisaje era similar al que presenta en la actualidad el piedemonte llanero colombiano (Figuras 27, 28; Anexos 2, 7, 20).

\section{PALEOGEOGRAFÍA}

El Grupo La Venta se encuentra dentro de una gran ensenada estrecha, enmarcada en el Valle Superior del Magdalena. Este Valle tiene una forma de reloj de arena formado por dos subcuencas, al norte la de Girardot y al sur la de Neiva, separados en su parte media por el Estrecho de Natagaima o Alto del Patá o Payandé (Fields 1959, Fuquen \& Osorno 2002, Cáceres et al. 2003), y al sureste lo limita el Macizo de Garzón (Anderson et al. 2016) (Figuras 29, 30). De otra parte, esta ensenada se encontraba irrigada por las cuencas de Neiva y La Venta, cuyo caudal principal tenía una dirección E a ESE (Guerrero 1993) y probablemente desembocaban en las cuencas del Caquetá Amazonas.

Teniendo en cuenta lo anterior, se acepta la hipótesis de que el Grupo La Venta en el Mioceno medio se encontraba dentro de una gran ensenada estrecha, la Cuenca Superior del Magdalena, como lo había planteado Butler (1942, P: 794) a partir de la interpretación del Valle del Magdalena como un gran graben limitado por fallas en el occidente y en el oriente, el cual se originó antes del final del Cretácico (Anderson 1926, Stille 1907). Esta cuenca estaría enmarcada al norte por el Estrecho de Girardot, el cual ya se conformaba como relieve elevado y barrera faunística; al occidente por la Cordillera Central; y al oriente por la Sierra de Gulumán (NE Potosí), donde el Río Magdalena se encajona en el Paso de Golondrinas e ingresa a la planicie de Natagaima, después de su confluencia con el Río Cabrera (Royo y Gómez 1942a, b). La Cordillera Oriental no sería parte del límite ya que no era una barrera sino hasta finales del Mioceno medio a superior (Butler 1942, Nutall 1990), como lo indican Lundberg et al. (1986) y Lundberg \& Chernoff (1992) con la conexión de la fauna de peces teleósteos fósiles (Arapaima, Colossoma) entre la Amazonia y el Valle del Magdalena (Fish Beds: Formación Villavieja: Grupo Honda). Anderson et al. (2016), a partir de información paleoclimática, sugieren que el inicio de la elevación del Macizo de Garzón (Cordillera Oriental) coincide con el inicio de la Formación Villavieja (12 - $11 \mathrm{Ma}$ ), lo que ocasiona un cambio de clima (incremento de las lluvias) y a la vez este macizo se convierte, hace cerca de $10 \mathrm{Ma}$, en una barrera orográfica para la flora y fauna del Valle del Magdalena y de la región Amazónica (Hoorn et al. 2010, Ochoa et al. 2012, Aguilera et al. 2013). 
Durante el Mioceno medio, el Valle Alto del Magdalena, ya se encontraba aislado en su parte norte (Estrecho de Girardot). Butler (1942) y Nutall (1990) postulan que la Cordillera Oriental era una barrera de dispersión, ya que la base del Grupo La Venta, Formación San Alfonso, estaba conformada por paleohábitats compuestos por sabanas secas y matorrales abiertos, los cuales no permitían la migración de la fauna arborícola como los primates. Si bien el paleoambiente de la Formación La Victoria (13,8 - 12,5 Ma) (Guerrero 1993, Anderson et al. 2016) estaba conformada por bosques de ribera, al parecer estos corredores de vegetación partían de esta formación, continuando en parte en la Formación Cerbatana, y como lo mencionan Anderson et al. (2016), en la parte sur ya había emergido el Macizo de Garzón (12 - $11 \mathrm{Ma})$, lo cual ocasionó el incremento en la precipitación, que permitió una diversificación de hábitats; esto se corrobora en la presente investigación en la Formación Villavieja, allí se registran diversos paleohábitats como sabanas secas en las tierras no inundables, bosques húmedos siempre verdes estratificados ( $15 \mathrm{~m}$ de altura) y bosques de ribera. Por lo tanto, en el Mioceno medio ya existían barreras biogeográficas que impidieron la radiación de los primates desde el Valle Alto del Magdalena hacia una posible conexión Caribe. Para corroborar la anterior hipótesis, se debe hacer una comparación de los taxones de vertebrados registrados para el Grupo La Venta, así como un estudio del polen fósil en localidades de la Cuenca de Girardot, como Carmen de Apicalá, Saldaña, Purificación, Coyaima, Prado y Natagaimaya. 


\section{CAPÍTULO VI - CONCLUSIONES}

\section{CONCLUSIONES}

Los torpedo shaped denominados por Fields (1959) como estructuras sedimentarias secundarias se redefinen como macrofósiles vegetales, a partir de los registros de las empalizadas de la Formación Las Mesitas.

- La fosilización de estos macrofósiles vegetales es distinta al proceso de fosilización que se presenta con el sílice y denominados xilópalos, característico del Mioceno inferior; la base fundamental de la fosilización del torpedo shaped es la arena, por lo que aquí se denominan moldes de troncos vegetales y son característicos del Mioceno medio.

- Se registran moldes de troncos vegetales en las formaciones La Victoria, Cerbatana, Villavieja, Las Mesitas.

- Se registra por primera vez polen fósil para el Grupo La Venta (622 taxones) de los cuales 142 son exclusivos para la Formación San Alfonso, 119 para la Formación La Victoria, y 254 para la Formacón Villavieja.

Se obtienen los primeros registros de vertebrados fósiles de la Formación San Alfonso (99 registros; 18 taxones, 6 son mamíferos), y la Formación Las Mesitas (21 registros; 20 taxones, 12 son mamíferos).

- Los taxones de mamíferos registrados para la Formación San Alfonso, estratigráficamente la base del Grupo La Venta, son: Astrapotheria, Dasypodidae (Nanoastegotherium), Leontiniidae, Toxodontidae (Pericotoxodon).

- Los taxones de mamíferos registrados para la Formación Las Mesitas, estratigráficamente el techo del Grupo La Venta, son: Astrapotheria; Litopterna (Prolicaphrium); Notoungulata: Pericotoxodon platignathus, Miocochilius anomopodus; Rodentia: Prodolichotis pridiana, Olenopsis sp2, Scleromys colombianus, Ricardomys longiden.

Las especies de mamíferos, no primates, exclusivas de algunas de las formaciones del Grupo La Venta son:

- Formación La Victoria (5): Villarroelia totoyoi (Litopterna), Pithiculites chenche (Paucituberculata), Brievabradys laventensis (Pilosa), Scleromys sp3 (Rodentia), Anachlysisctis gracilis (Sparassodonta).

- Formación Villavieja (16): Chiroptera: Kiotomops lopezi, Noctilio albiventris, Notonycteris madalenensis, Notonycteris sucharadeus, Palynephyllum antimaster, Thyroptera lavalis, Thyroptera robusta, Thyroptera tricolor; Didelphimorphia: 
Marmosa laventica, Pachybiotherium minor, Thylamys colombianus, Thylamys minutus; Paucituberculata: Hondathentes cazador; Pilosa: Neotamandua borealis; Rodentia: Rhodanodolichotis antepridiana, Microsteiromys jacobsi.

- Formación Las Mesitas: Dukecynus magnus (Sparassodonta).

Las especies de mamíferos compartidas entre las diferentes formaciones del Grupo La Venta son:

- Formaciones San Alfonso - La Victoria - Cerbatana - Villavieja - Las Mesitas (1): Notoungulata (1): Pericotoxodon sp1.

- Formaciones La Victoria - Cerbatana (36): Sparassodonta (1): Lycopsis longirostrus; Didelphimorphia (2): Hondadelphys fieldsi, Micoureus laventicus; Cingulata (9): Anadasyus hondanus, Boreostema acostae, Boreostemma gigantea, Nanoastegotherium sp., Nanoastegotherium prostatum, Neoglypatelus originalis, Pedrolypeutes praecursor, Scirrotherium sp., Scirrotherium hondaensis; Pilosa (3): Glossotheriopsis pascuali, Neonematherium flabellatum, Pseudoprepotherium confusum; Litopterna (4): Megadolodus molariformes, Prolicaphrium sanalfonsensis, Prothoatherium colombianus, Theosodon sp.; Notoungulata (8): Huilatherium sp1, Huilatherium pluripicatum, Miocochilius sp., Miocochilius anomopodus, Pericotoxodon sp., Pericotoxodon sp1, Pericotoxodon sp2, Pericotoxodon platignatus; Astrapotheriidae (2): Granastrapotherium snorki, Xenastrapotherium kraglievichi; Sirenia (1): Potamosiren magdalenensis; Rodentia (6): Neoreomys huilensis, Olenopsis sp2, Olenopsis sp3, Prodolichotis pridiana, Scleromys sp1, Scleromys sp2.

- Formaciones La Victoria - Cerbatana - Villavieja (34): Sparassodonta (1): Lycopsis longirostrus; Didelphimorphia (2): Hondadelphys fieldsi, Micoureus laventicus; Cingulata (8): Anadasyus hondanus, Boreostema acostae, Boreostemma gigantea, Nanoastegotherium prostatum, Neoglypatelus originalis, Pedrolypeutes praecursor, Scirrotherium sp., Scirrotherium hondaensis; Pilosa (3): Glossotheriopsis pascuali, Neonematherium flabellatum, Pseudoprepotherium confusum; Litopterna (4): Megadolodus molariformes, Prolicaphrium sanalfonsensis, Prothoatherium colombianus, Theosodon sp.; Notoungulata (8): Huilatherium sp1, Huilatherium pluripicatum, Miocochilius sp., Miocochilius anomopodus, Pericotoxodon sp., Pericotoxodon sp1, Pericotoxodon sp2, Pericotoxodon platignatus; Astrapotheriidae (2): Granastrapotherium snorki, Xenastrapotherium kraglievichi; Sirenia (1): Potamosiren magdalenensis; Rodentia (5): Neoreomys huilensis, Olenopsis sp2, Olenopsis sp3, Prodolichotis pridiana, Scleromys sp2.

- Formaciones La Victoria - Cerbatana - Villavieja - Las Mesitas (6): Notoungulata (3): Miocochilius anomopodus, Pericotoxodon sp1, Pericotoxodon platignatus; Astrapotheriidae (1): Xenastrapotherium kraglievichi; Rodentia (2): Olenopsis sp2, Prodolichotis pridiana.

- Formaciones Cerbatana - Villavieja (35): Sparassodonta (1): Lycopsis longirostrus; Didelphimorphia (2): Hondadelphys fieldsi, Micoureus laventicus; Cingulata (8): Anadasyus hondanus, Boreostema acostae, Boreostemma gigantea, 
Nanoastegotherium prostatum, Neoglypatelus originalis, Pedrolypeutes praecursor, Scirrotherium sp., Scirrotherium hondaensis; Pilosa (3): Glossotheriopsis pascuali, Neonematherium flabellatum, Pseudoprepotherium confusum; Litopterna (4): Megadolodus molariformes, Prolicaphrium sanalfonsensis, Prothoatherium colombianus, Theosodon sp.; Notoungulata (9): Huilatherium sp1, Huilatherium sp2, Huilatherium pluripicatum, Miocochilius sp., Miocochilius anomopodus, Pericotoxodon sp., Pericotoxodon sp1, Pericotoxodon sp2, Pericotoxodon platignatus; Astrapotheriidae (2): Granastrapotherium snorki, Xenastrapotherium kraglievichi; Sirenia (1): Potamosiren magdalenensis; Rodentia (5): Neoreomys huilensis, Olenopsis sp2, Olenopsis sp3, Prodolichotis pridiana, Scleromys sp2.

- Formaciones La Victoria - Villavieja (8): Cingulata (1): Pedrolypeutes sp.; Pilosa (1): Neonematherium sp.; Litopterna (1): Prolicaphrium sp.; Notoungulata (1): Huilatherium sp.; Sirenia (1): Potamosiren sp.; Rodentia (3): Olenopsis sp1, Scleromys colombianus, Scleromys schürmanni.

- Formaciones La Victoria - Villavieja - Las Mesitas (2): Litopterna (1): Prolicaphrium sp; Rodentia (1): Scleromys colombianus.

- Formaciones Villavieja - Las Mesitas (10): Litopterna (1): Prolicaphrium sp.; Notoungulata (3): Miocochilius anomopodus, Pericotoxodon sp1, Pericotoxodon platignatus; Astrapotheriidae (1): Xenastrapotherium kraglievichi; Rodentia (5): Microscleromys paradosalis, Olenopsis sp2, Prodolichotis pridiana, Ricardomys longiden, Scleromys colombianus.

Teniendo en cuenta la información sedimentológica, de paleosuelos, macrovegetación, polen, vertebrados, específicamente mamíferos, y dentro de éstos los primates, se proponen los siguientes paleoambientes para el Grupo La Venta:

- Formación San Alfonso: sabanas secas, matorrales abiertos, ambientes semiacuáticos que rodean pequeños ríos.

- Formación La Victoria: matorrales abiertos, humedales, sabanas inundables, sabanas arboladas, bosques de ribera.

- Formación Cerbatana: bosques de ribera ( $3 \mathrm{~m}$ altura).

- Formación Villavieja: sabanas secas arboladas, bosques húmedos siempre verdes (15 m altura), bosque de ribera.

- Formación Las Mesitas: bosque húmedo siempre verde estratificado (30 - 40 $\mathrm{m}$ altura), bosque de ribera, sabanas arboladas.

Teniendo en cuenta los paleambientes propuestos, se establece que de base a techo se presenta una variación gradual de biomas secos a biomas húmedos de bosques multiestratificados.

A partir de los taxones de vertebrados, en especial los mamíferos fósiles, se establece una mayor afinidad entre: (1) las formaciones La Victoria y Cerbatana; Paleohábitat: bosques de ribera; (2) las formaciones Villavieja y Las Mesitas; 
Paleohábitats: bosques húmedos siempre verdes, bosques de ribera.

- Se reconocen los siguientes paleohábitat asociados a los primates dentro del Grupo La Venta:

Formación La Victoria (I: Capa de los Lagos; III: Areniscas de San Nicolás)

I.

Ambiente sedimentario: lagos.

Paleohábitat: humedal.

- Lagonimico conclucatus

- $\quad$ cf. Nuciruptor IGM 184667

II.

Ambiente sedimentario: río meándrico.

- Paleohábitat: bosque de ribera.

- Stirtonia victoriae

III.

Ambiente sedimentario: río meándrico.

Paleohábitat: sabana inundable, sabana arbolada, matorral abierto.

- Miocallicabus villaviejai

- $\quad$ cf. Nuciruptor IGM KU 8602

IV.

- Incertum locum

- Patasola magdalenae

Formación Villavieja (I: Monkey Unit; II: Lower Red Bed; III - IV: Upper Red Bed)

I.

Ambiente sedimentario: río ondulado.

Paleohábitat: bosque de ribera estratificado.

- Laventiana annectens

- Neosaimiri fieldsi

- Nuciruptor rubricae IGM 251074

- $\quad$ cf. Nuciruptor IGM 184074

II.

Ambiente sedimentario: río ondulado.

- Paleohábitat: bosque de ribera estratificado, sabana inundable.

- Callitrichinae: IGM-KU 8402, IGM-KU 8403

- Cebupithecia sarmientoi

- Micodon kiotensis

- Neosaimiri fieldsi

- Stirtonia tatacoensis

III.

Ambiente sedimentario: río ondulado.

Paleohábitat: bosque de ribera estratificado, sabana inundable. 
- Cebidae KU 9-86A

- Mohanamico herskovitzi

- Stirtonia tatacoensis

IV.

Ambiente sedimentario: río ondulado.

Paleohábitat: bosque siempre verde estratificado (15 m altura).

- Aotus dindensis IGM-KU 8601

- Aotus cf. dindensis IGM-KU 8802

- Se redefine la Fauna Laventense para el Grupo La Venta y para cada una de sus formaciones, la cual está conformada por 94 taxones de mamíferos, pertenecientes a 12 órdenes. Primates 18, Astrapotheria 3, Chiroptera 12, Cingulata 8, Didelphimorphia 6, Litopterna 7, Notoungulata 9, Paucituberculata 2, Pilosa 8, Rodentia 16, Sirenia 2, Spararassodonta 3.

- Se proponen los siguientes marcadores de tiempo para el Grupo La Venta:

- Macrofósiles vegetales: moldes de troncos vegetales. Formaciones: La Victoria, Cerbatana, Villavieja, Las Mesitas.

- Polen fósil:

$\checkmark$ Formación San Alfonso - La Victoria - Villavieja: Ficus sp1.

$\checkmark$ Formación San Alfonso - Villavieja: Arecaceae sp2.

$\checkmark$ Formación La Victoria - Villavieja: Piperaceae sp4.

- Vertebrados fósiles: el género Miocochilius fue registrado en el Mioceno inferior y no se registró en la Formación San Alfonso del Grupo La Venta.

\section{SÍNTESIS}

En marco del objetivo principal de la presente investigación: "Establecer los paleoambientes y los vertebrados asociados con las especies fósiles de primates de La Venta, Colombia (formaciones La Victoria y Villavieja), con el fin de contribuir a la reconstrucción de la evolución de la biota del Mioceno medio en el norte del Neotrópico", se procedió a probar las siguientes hipótesis:

1. Los paleoambientes asociados con las especies fósiles de primates del Mioceno medio de La Venta, Colombia, fueron más diversos y complejos de lo que se ha interpretado hasta el momento.

- El análisis realizado permitió corroborar esta hipótesis.

2. Los paleoambientes asociados con las especies fósiles de primates del Mioceno medio de La Venta, Colombia, fueron más áridos y secos con respecto a los ambientes asociados con las especies de primates actuales.

- Esta hipótesis fue rechazada. 
Los resultados de esta investigación permitieron establecer los ambientes asociados con las especies de primates, cumpliendo con el objetivo principal: "Establecer los paleoambientes y los vertebrados asociados con las especies fósiles de primates de La Venta, Colombia (formaciones La Victoria y Villavieja), con el fin de contribuir a la reconstrucción de la evolución de la biota del Mioceno medio en el norte del Neotrópico".

\section{PROYECCIONES A FUTURO}

- Se sugiere realizar una biozonación con énfasis en los mamíferos, la cual se debe realizar teniendo en cuenta la especie, la geoposición espacial, la capa litológica, y el tipo de hábitat. Por ejemplo, mamíferos fósiles registrados sólo en matorrales secos, llanuras de inundación, bosques multiestratificados, en donde se especifique la primera aparición de la especie.

- La recolección de material fósil de vertebrados se debe realizar bajo un control estratigráfico preciso en nuevas áreas de prospección del Grupo La Venta, tal como se propone en esta investigación, lo cual permitirá plantear hipótesis referidas a la evolución de los vertebrados fósiles, con énfasis en mamíferos.

- Esta investigación proporciona una amplia base de datos de los fósiles de mamíferos del Mioceno medio del norte del Neotrópico. Por lo tanto, se plantea realizar un análisis comparativo con enfoque paleobiogeográfico de la fauna registrada en las formaciones San Alfonso, La Victoria, Cerbatana, Villavieja y Las Mesitas que respalde las inferencias en torno a la reconstrucción integral de los paleoambientes del Mioceno medio.

- Se sugiere realizar una revisión sistemática de algunos grupos de vertebrados con énfasis en los grandes ríos y ecosistemas, como posibles barreras biogeográficas del Mioceno medio Neotropical. 


\section{CAPÍTULO VII - BIBLIOGRAFÍA CITADA}

Aguilera, O., J. Lundberg, J. Bririndelli, M. Sabaj Pérez, C. Jaramillo, M.R. Sánchez-Villagra. 2013. Palaeontological evidence for the last temporal occurrencie of the ancient western Amazonian river outflow into the Caribbean. PLoS One 8 (9): e76202. https://doi.org/10.1371/journal.pone.0076202.

Alberdi, M.T., J.L. Prado, E. Ortiz-Jareguizar. 1995. Patterns of body size changes in fossil and living Equini (Perissodactyla). Biological Journal of the Linnean Society 54: 349-370.

Alván, A., J. Apolín, C. Chacaltana. Los dientes de seláceos (Condrichthyies) y su aplicación estratigráfica en las Lomas de Ullujaya (Ica, Perú). XIII Congreso Peruano de Geología, Resúmenes Extendidos Sociedad Geológica del Perú, Pp: 595-598.

Anderson, F.M. 1926. Original source of oil in Colombia. Bulletin of the American Association of Petroleum Geologists 10: 382-404.

Anderson, T.A. 1972. Paleogene nonmarine Gualanday Group, Neiva Basin, Colombia, and regional development of the Colombian Andes. Geological Society of America Bulletin 83: 2423-2438.

Anderson, V.J., B.K. Horton, J.E. Saylor, A. Mora, E. Tesón, D.O. Breecker, R.A. Ketcham. 2016. Andean topographic growth and basement uplift in southern Colombia: implications for the evolution of the Magdalena, Orinoco, and Amazon river systems. Geosphere 12 (4): 1235-1256.

Andrews, P., J.M. Lord, E.M. Nesbit Evans. 1979. Patterns of ecological diversity in fossil and modern mammalian faunas. Biological Journal of the Linnean Society 11: 177-205.

Antoine, P.O., R. Salas-Gismondi, P. Baby, M. Benammi, S. Brusset, D. De Franceschi, N. Espurt, C. Goillot, F. Pujos, J. Tejada, M. Urbina. 2007. The Middle Miocene (Laventan) Fitzcarrald fauna Amazonian Peru. Pp: 19-24 en: E. Díaz-Martínez, I. Rábano (eds.), $4^{\text {th }}$ European Meeting on the Palaeontology and Stratigraphy of Latin America. Cuadernos del Museo Geominero, No. 8, Instituto Geológico y Minero de España, Madrid, España.

Antoine, P.O., L. Marivaux, D.A. Croft, G. Billet, M. Ganerod, C. Jaramillo, T. Martin, M.J. Orliac, J. Tejada, A.J. Altamirano, F. Duranthon, G. Fanjat, S. Rousse, R. Salas Gismondi. 2011. Middle Eocene rodents from Peruvian Amazonia reveal the pattern and timing of caviomorph origins and biogeography. Proceedings of the Royal Society B DOI: 10.1098/rspb.2011.1732.

Antoine, P.O., M. Roddaz, S. Brichau, J. Tejada-Lara, R. Salas, A. Altamirano, M. Louterbach, L. Lambs, T. Otto, S. Brusset. 2013. Middle Miocene vertebrates from the Amazonian Madre de Dios Subandean Zone, Perú. Journal of South American Earth Sciences 42: 91-102.

Auffenberg, W. 1971. A new fossil totoise, with remarks on the origins of South American Testudinines. American Society of Ichthyologists and Herpetologists (ASIH) (1): 106-117.

Berrío, J.C., H. Hooghiemstra, R. Marchant, J.O. Rangel-Ch. 2002. Late-glacial and Holocene history of the dry forest area in the south Colombian Cauca Valley. Jouranl of Quaternaty Science 17 (7): 667-682.

Bourque, J.R. 2012. A fossil mud turtle (Testudines, Kinosternidae) from the Early Middle Miocene (Early Barstovian) of New Mexico. Journal of Vertebrate Paleontology 32 (4): 836-853.

Busbey III, B. 1986. New material of Sebecus cf. huilensis (Crocodilia: Sebecosuchidae) from the Miocene La Venta Formation of Colombia. Journal of Vertebrate Paleontology 6 (1): 20-27.

Butler Jr., J.W. 1942. Geology of Honda District, Colombia. Bulletin of the American Association of Petroleum Geologists 26 (5): 793-837.

Butler, K., S. Schamel. 1988. Structure along the eastern margin of the Central Cordillera, Upper Magdalena Valley, Colombia. Journal of South American Earth Sciences 1 (1): 109-120.

Cabrera, A. 1929. Un astrapotérido de Colombia. Revista de la Sociedad Argentina de Ciencias Naturales (IX): 436-439.

Carlini, A.A., A.E. Zurita, G.J. Scillato-Yané, R. Sánchez, O.A. Aguilera. 2008. New Glyptodont from the Codore Formation (Pliocene), Falcón State, Venezuela, its relationship with the Asterostemma problem, and the paleobiogeography of the Glyptodontinae. Papäontologishe Zeitschrift 82 (2): 139-152.

Carlini, A.A., M.C.Castro, R.H. Madden, G.J. Scillato-Yané. 2013. A new species of Dasypodidae (Xenarthra: Cingulata) from the late Miocene of northwestern South America: implications in the Dasypodini 
phylogeny and diversity. Historical Biology: An International Journal of Paleobiology, DOI: 10.1080/08912963.2013.840832, Pp: 1-9.

Chimento, N.R. 2012. Revisión de algunos Xenarthra (Mammalia) del "Puelchense" de la Provincia de Buenos Aires, Argentina. Historia Natual, Fundación de Historia Natural Féliz de Azara (FHN), Universidad Maimónides, Tercera Serie, 2 (1): 5-40.

Cifelli, R.L. 1983. Eutherian tarsal from the Late Paleocene of Brazil. American Museum Novitates (2761): $1-31$.

Cifelli, R.L. 1985. Biostratigraphy of the Casamayoran, Early Eocene, of Patagonia. American Museum Novitates (2820): 1-26.

Cifelli, R.L., M.F. Soria. 1983. Systematics of the Adianthidae (Litopterna, Mammalia). American Museum Novitates (2771): 1-25.

Cifelli, R.L., J. Guerrero. 1989. New remains of Prothoatherium colombianus (Litopterna, Mammalia) from the Miocene of Colombia. Journal of Vertebrate Paleontology 9 (2): 222-231.

CEN. 2010. Código Estratigráfico Norteamericano. Comisión Norteamericana de Nomenclatura Estratigráfica, Boletín 117, Director G. Tolson Jones, Servicio Geológico Mexicano, Sociedad Geológica Mexicana, México D.F., México, 64p.

Cooke, S.B., A.F. Vanegas, A. Link, B.M. Shearer, L.K. Stroit, M. Tallman. 2017. New specimens of Stirtonia from the La Victoria Formation, La Venta, Colombia and the evolution of Alouattine dental form. Conference: American Association of Physical Anthropology, New Orleans, LA, USA, abril 2017.

Creighton, G.K. 1980: Static allometry of mammalian teeth and the correlation of tooth size and body size in contemporary mammals. J. Zool., Lond. 191: 435-443.

Croft, D.A. 2007. The Middle Miocene (Laventan) Quebrada Honda fauna, Southern Bolivia and a description of its notoungulates. Palaeontology 50 (1): 277-303.

Czaplewski, N.J., M. Takai, T.M. Naeher, N. Shigehara, T. Setoguchi. 2003. Additonal bats from the Middle Miocene La Venta Fauna of Colombia. Revista de la Academia de Ciencias Exactas, Físicas y Naturales XX-VII (103): 263-282.

De Iuliis, G., M.S. Bargo, S.F. Vizcaíno. 2000. Variation in skull morphology and mastication in the fossil giant aramadillos Pampatherium spp. and allied genera (Mammalia: Xenarthra: Pampatheriidae), with comments in their systematics and distribution. Journal of Vertebrate Paleontology 20 (4): 743-754.

De Iuliis, G., F. Pujos, C. Cartelle. 2009. A new ground sloth (Mammalia: Xenarthra) from the Quaternary of Brazil. Comptes Rendus Palevol 8: 705-715.

De Muizon, C., H.G. McDonald, R. Salas, M. Urbina. 2003. A new early species of the aquatic sloth Thalassocnus (Mammalia, Xenarthra) from the Late Miocene of Peru. Journal of Vertebrate Paleontology 23 (4): 886-894.

De Muizon, C., H.G. McDonald, R. Salas, M. Urbina. 2004a. The youngest species of the aquatic sloth Thalassocnus and a reassessment of the relationships of the nothrothere sloths (Mammalia: Xenarthra). Journal of Vertebrate Paleontology 24 (2): 387-397.

De Muizon, C., H.G. McDonald, R. Salas, M. Urbina. 2004b. The evolution of feeding adaptations of the aquatic sloth Thalassocnus. Journal of Vertebrate Paleontology 24 (2): 398-410.

De Porta, J. 1959. Nueva subespecie de toxodontidae del Cuaternario de Colombia. Boletín de Geología (3): 55-61.

De Porta, J. 1961. Edentata Xenarthra del Pleistoceno de Colombia: nota preliminar. Boletín de Geología (6): 5-32.

De Porta, J. 1962. Edentata Xenarthra del Pleistoceno de Colombia: I Dasypodoidea y Glyptodontoidea. Boletín de Geología (10): 5-23.

De Porta, J. 1969. Les vertébrés fossiles de Colombie et les problèmes posés par L'isolement du continent Sud-Américan. Palaeovertebrata 2: 77-94.

De Porta, J. 2003. La formación del Istmo de Panamá. Su incidencia en Colombia. Revista de la Academia Colombiana de Ciencias Exactas, Físicas y Naturales 27 (103): 191-216.

De Porta, J., F. Etayo. 1996. José Royo y Gómez y las investigaciones sobre los vertebrados fósiles de Colombia. Geogaceta 19: 181-182.

Defler, T.R. 2010. Historia Natural de los Primates Colombianos. $2^{\mathrm{a}}$ ed., Departamento de Biología, 
Facultad de Ciencias, Universidad Nacional de Colombia, Conservación Internacional Colombia, Bogotá D.C., 609p.

Dino, R., E.A. Amaral S., L. Antonioli, C. Riccomini, A.C. Rodríguez N. 2012. Palynostratigraphy and sedimentary facies of middle Miocene fluvial deposits of the Amazonas Basin, Brazil. Journal of South American Earth Sciences 34: 61-80.

Domning, D.P. 1982. Evolution of manatees: a speculative history. Journal of Paleontology 56: 599-619.

Domning, D.P. 1997. Sirenia. Pp: 383-391 en: R.F. Kay, R.H. Madden, R.L. Cifelli, J.J. Flynn (eds.), Vertebrate Paleontology in the Neotropics: the vertebrate fauna of La Venta, Colombia. Smithsonian Institution Press, Washington D.C., USA.

Domingo, L., J. Cuevas-González, S.T. Grimes, M. Hernández Fernández, N. López-Martínez. 2009. Multiproxy reconstruction of the palaeoclimate and palaeoenvironment of the Middle Miocene Somosaguas site (Madrid, Spain) using herbivore dental enamel. Palaeogeography, Palaeoclimatology, Palaeoecology 272: 53-68.

Dueñas J., H. 1980. Palynology of Oligocene-Miocene strata of Borehole Q-E-22, Planeta Rica, Northern Colombia. Review of Palaeobotany and Palynology 30 (3/4): 313-3

Duque-Caro, H. 1990a. Estratigrafía, paleoceanografía y paleobiogeografía de la Cuenca del Atrato y la evolución del Istmo de Panamá. Boletín Geológico de INGEOMINAS (Instituto Nacional de Investigaciones Geológicas y Mineras) 31 (1): 3-46.

Duque-Caro, H. 1990b. El bloque del Chocó en el noroccidente Suramericano: implicacines estructurales, tectonoestratigráficas y paleogeográficas. Boletín Geológico de INGEOMINAS (Instituto Nacional de Investigaciones Geológicas y Mineras) 31 (1): 47-71.

Duque-Caro, H. 1990c. The Choco block in the northwestern corner of South America: structural, tectonostratigraphic, and paleogeographic implications. Journal of South America Earth Sciencie 3 (1): 71-84.

Duque-Caro, H. 1990d. Neogene stratigraphy, paleoceanography and paleobiogeography in northwest South América and the evolution on the Panamá seaway. Palaeogeography, Palaeoclimatology, Palaeoecology 77: 203-234.

Estes, R. 1961. Miocene Lizards from Colombia. South America. Breviora: Museum of Comparative Zoology, Cambridge, Mass. (143): 1-11.

Estes, R, R. Wassersug. 1963. A Miocene toad from Colombia. South America. Breviora: Museum of Comparative Zoology, Cambridge, Massachusetts, USA (193): 1-13.

Feagle, J.F. 1978. Size distributions of living and fossil Primate faunas. Paleobiology 4 (1): 67-76.

Fields, R.W. 1957. Hystricmorph rodents from the Late Miocene of Colombia, South America. University of California Press, Berkeley, USA, Publications in Geological Sciences 35: 273-404.

Fields, R.W. 1959. Geology of the La Venta badlands, Colombia, South America. University of California Press, Berkeley, USA, Publications in Geological Sciences 32 (6): 405-444, + 1 mapa.

Fields, R.W., D. Henao-Londoño. 1949. Detailed Geologic Map of the area from Cerro Gordo to La Venta, Huila, Colombia, South America. Prepared in cooperation with the Servicio Geológico Nacional de Colombia, Bogotá, Colombia. Mapa.

Figueroa-C., Y., G. Galeano. 2007. Lista comentada de las plantas vasculares del enclave seco interandino de La Tatacoa (Huila, Colomiba). Caldasia 29 (2): 263-281.

Fleming, T.H. 1973. Numbers of mammalian species in North and Central America forest communities. Ecology 54 (3): 555-563.

Flórez M., M.T., L.N. Parra-Sánchez, D.F. Jaramillo J., J.M. Jaramillo M. 2013. Paleosuelos del Mioceno en el Desierto de La Tatacoa. Revista de la Academia de Ciencias Exactas, Físicas y Naturales XXXVII (143): 229-244.

Flynn, J.F., J. Guerrero, C.C. Swisher III. 1997. Geochronology of the Honda Group. Pp: 44-59 en: R.F. Kay, R.H. Madden, R.L. Cifelli, J.J. Flynn (eds.), Vertebrate Paleontology in the Neotropics: the vertebrate fauna of La Venta, Colombia. Smithsonian Institution Press, Washington D.C., USA.

Ford, S.M. 1990. Locomotor adaptations of fossil platyrrhines. Journal of Human Evolution 19: 141-173. Fuquen M., J.A., J.F. Osorno M. 2002. Geología de la Plancha 303 Colombia, departamentos de Huila, Tolima y Meta: Escala 1:100.000. Memoria Explicativa, República de Colombia, Ministerio de Minas y Energía, Instituto de Investigación e Información Geocientífica, Minero-Ambiental y Nuclear 
(INGEOMINAS), Bogotá D.E., Colombia, septiembre de 2002, 88p.

Gebo, D.L. 1989. New platyrrhine tali from La Venta American Journal of Physical Anthropology 78: 226.

Gebo, D.L., M. Dagosto, A.L. Rosenberger, T. Setoguchi. 1990. New platyrrhine tali from La Venta, Colombia. Journal of Human Evolution 19: 737-746.

Germeraad, J.H., C.A. Hopping, J. Muller. 1968. Palynology of Tertiary sediments from tropical areas. Review of Palaeobotany and Palynology 6: 189-348.

Gillette, D.D. 1984. A marine ichthyofauna from the Miocene of Panama, and the Tertiatry Caribbean Faunal Province. Journal of Vertebrate Paleontology 4 (2): 172-186.

Gingerich, P.D. 1974. Size variability of the teeth in living mammals and the diagnosis of closely related sympatric fossil species. Journal of Paleontology 48 (5): 895-903.

Gingerich, P.D., E.L. Simons. 1977. Systematics, phylogeny, and evolution of early Eocene Adapidae (Mammalia: Primates) in North America. Museum of Paleontology, The University of Michigan 24 (22): 245-279.

Gingerich, P.D., A.S. Ryan. 1979. Dental and cranial variation in living Indriidae. Primates 20 (1): 141-159.

Gingerich, P.D., B. Holly Smith, K. Rosenberg. 1982. Allometric scaling in the dentition of Primates and prediction of body weight from tooth size in fossils. American Journal of Physical Anthropology 58: 81-100.

Gómez Cano, A.R., B.A. García Yelo, M. Hernández Fernández. 2006. Cenogramas análisis bioclimático y muestreo en faunas de mamíferos: implicaciones para la aplicación de métodos de análisis palaeocológicos. Estudios Geológicos 62 (1): 135-144.

González-Ruiz, L.R. 2010. Los cingulata (Mammalia, Xenarthra) del Mioceno temprano y medio de Patagonia (edades Santacrucense y "Friasense") revision sistemática y consideraciones bioestratigráficas. Tesis Doctoral, Facultad de Ciencias Naturales y Museo, Universidad Nacional de La Plata, La Plata, Provinicia de Buenos Aires, Argentina, 471p.

González-Ruiz, L.R., G.J. Scillato-Yané. 2008. Una nueva especie de Stegotherium Ameghino (Xenarthra, Dasypodidae, Stegotheriini) del Mioceno de la provincial de Santa Cruz (Argentina), MAEGHINIANA (Revista de la Asociación Paleontológica Argentina - APA) 45 (4): 641-648.

González-Ruiz, L.R., E. Scillato-Yané, G.J. Scillato-Yané. 2009. A new Stegotheriini (Mammalia, Xenarthra, Dasypodidae) from the "Notohippidian" (early Miocene) of Patagonia, Argentina. N. Jb. Geol. Palâont. Abh. 252 (1): 81-90.

González-Ruiz, L.R., A.E. Zurita, J. Feagle, G.J. Scillato-Yané, M.T. Dozo, M. Zamorano. 2010. The southernmost record of a Neuryurini Hoffstetter, 1958 (Mammalia, Xenarthra, Glyptodontidae). Paläontol Z, Springer, DOI 10.1007/s12542-010-0083-8.

González-Ruiz, L.R., A.E. Zurita, G.J. Scillato-Yané, M. Zamorano, M.F. Tejedor. 2011. Un Nuevo Glyptodontidae (Mammalia, Xenarthra, Cingulata) del Mioceno de Patagonia (Argentina) y comentarios acerca de la sistemática delos gliptodontes “friasenses". Revista Mexicana de Ciencias Geológicas 28 (3): 566-579.

González-Ruiz, L. R., F. Góis, M. R. Ciancio, G.J. Scillato-Yané. 2013. Los Peltephilidae (Mammalia, Xenarthra) de la Formación Collón Curá (Colloncurense, Mioceno medio), Argenina. Revista Brasileira de Paleontologia 16 (2): 319-330.

Gould, S.J. 1975. On the scaling of tooth size in mammals. American Zoologist 15 (2): 351-362.

Graham, A. 1999. Studies in Neotropical paoleobotany. XIII. An Oligo-Miocene palynoflora from Simojovel (Chiapas, Mexico). American Journal of Botany 86 (1): 17-31.

Graham, A. 2009. Fossil record of the Rubiaceae. Annals of the Missouri Botanical Garden 96 (1): 90108.

Gray, J. 1965. Extraction techniques. Pp: 530-587 en: B. Kummel, D. Raup (Eds.), Handbook of Paleontological Techniques. Freeman, San Francisco, CA.

Guerrero, J. 1985. Geología de un sector del nororiente del municipio de Villavieja y descripción de un mamífero del orden Liptopterna. Trabajo de grado, Departamento de Geociencias, Facultad de Ciencias, Universidad Nacional de Colombia, Bogotá D.E., Colombia, 81p.

Guerrero, J. 1993. Magnetostratigraphy of the upper part of the Honda Group and Neiva Formation. Miocene uplift of the Colombian Andes. Thesis Ph.D., Duke University, Durham, North Carolina, 
USA, 87p.

Guerrero, J. 1997. Stratigraphy, sedimentary environments, and the Miocene Uplift of the Colombian Andes. Pp: 15-43 en: R.F. Kay, R.H. Madden, R.L. Cifelli, J.J. Flynn (eds.), Vertebrate Paleontology in the Neotropics: the vertebrate fauna of La Venta, Colombia. Smithsonian Institution Press, Washington D.C., USA.

Harrington, H.J. 1962. Paleogeographic development of South America. Bulletin of the American Association of Petroleum Geologists 46 (10): 1773-1814.

Hartwig, W.C., D.J. Meldrum. 2002. Miocene Platyrrhines of the Northern Neotropics. Pp. 175-188 en: W.C. Hartwig (ed.), The Primate Fossil Record. Cambridge, Cambridge University Press.

Hayashida, A. 1984. Paleomagnetic study of the Miocene continental deposits in La Venta Badlands, Colombia. Kyoto University Overseas Research, Reports of New World Monkeys, Kyoto University Primate Research Institute 4: 77-83.

Henao-Londoño, D. 1950. Geology of La Venta District: the fossiliferous area of the Upper Magdalena Valley. Informe No. 718, Ministerio de Minas y Petroleos, Sección 5a, Servicio Geológico Nacional, Bogotá, Colombia, 49p, + 6 mapas, + 2 columna estratigráfica. Informe técnico, 13 septiembre 1950.

Henao-Londoño, D., R.W. Fields. 1949. Honda Formation of the Upper Magdalena River Basin, Colombia, S.A. Bulletin of the Geological Society of America 60: 1894.

Henao-Londoño, D., R.W. Fields, I. Osorio M. 1949. Estudio Geológico en el municipio de Villavieja, departamento del Huila. Hoja No. 1: La Venta; Hoja No. 2: El Dinde; Hoja No. 3: Cerro Gordo. Servicio Geológico Nacional de Colombia, Bogotá, Colombia. Mapas: 3.

Hernández Fernández, M., M.T. Alberdi, B. Azanza, P. Montoya, J. Morales, M. Nieto, P. PeláezCampomanes. 2006. Identification problems of arid environments in the Neogene-Quaternary mammals record of Spain. Journal of Arid Environments 66: 585-608.

Hershkovitz, P. 1970. Notes on Tertiary platyrrhine monkeys and description of a new genus from the late Miocene of Colombia. Folia Primatologica 12: 1-37.

Hershkovitz, P. 1984. More on the Homunculus Dpm4 and M1 and comparison with Alouatta and Stirtonia (Primates, Platyrrhini, Cebidae). American Journal of Primatology 7: 261-283.

Hettner, A. 1892. Die Kordillere von Bogotá. Pettermanns Mitteil, 22, Ergänzungsheft 104, 131p.

Hilgen, F.J., H.A. Abels, S. Iaccarino, W. Krijgsman, I. Raffi, R. Sprovieri, E. Turco, W.J. Zachariasse. 2009. The Global Stratotype Section and Point (GSSP) of the Serravallian Stage (Middle Miocene. Episodes 32 (3): 152-166.

Hirschfeld, S.E. 1976. A new fossil anteater (Edentata, Mammalia) from Colombia, S.A. and evolution of the Vermilingua. Journal of Paleontology 50 (3): 419-432.

Hirschfeld, S.E. 1985. Ground sloths from the Friasian La Venta Fauna, with additions to the Pre-Friasina Coyaima Fauna of Colombia, South America. University of California Publications in Geological Science 128: 1-92.

Hirschfeld, S.E., L.G. Marshall. 1976. Revised faunal list of the La Venta Fauna (Friasian-Miocene) of Colombia, South America. Journal of Paleontology 50 (3): 433-436.

Hodgson, J . A, K. N. Sterner, L.J. Matthews, A.S. Burrell, R.A. Jani, R.L. Raaum, C.B. Stewart, T.R. Disotell. 2009. Successive radiations, not stasis, in the South American primate fauna. Proceedings of the national Academy of Sciences of the United States of America (PNAS): 1-6.

Holling, C.S. 1992. Cross-scale morphology, geometry, and dynamics of ecosystems. Ecological Monographs 62 (4): 447-502.

Hoorn, C. 1993. Marine incursions and the influence of Andean tectonics on the Miocene depositional history of northwestern Amazonia: results of a palynostratigraphic study. Palaeogeography, Palaeoclimatology, Palaeoecology 105: 267-309.

Hoorn, C. 1994a. Fluvial palaeoenvironments in the intracratonic Amazonas Basin (Early Miocene-early Middle Miocene, Colombia. Palaeogeography, Palaeoclimatology, Palaeoecology 109: 1-54.

Hoorn, C. 1994b. An environmental reconstruction of the palaeo-Amazon River system (Middle-Late Miocene, NW Amazonia). Palaeogeography, Palaeoclimatology, Palaeoecology 112: 187-238.

Hoorn, C., F.P. Wesselingh (eds.). 2010. Amazonai: landscape and species evolution a look into the past. Wiley-Blackwell a John Wiley \& Sons, Ltd., Publication, 447p.

Hoorn, C., J. Guerrero, G.A. Sarmiento, M.A. Llorente. 1995. Andean tectonics as a cause for changing drainage patterns in Miocene northern South America. Geology 23: 237-240. 
Hoorn, C., F.P. Wesselingh, H. Ter Steege, M.A. Bermudez, A. Mora, J. Sevink, I. Sanmartín, A. SanchezMeseguer, C.L. Anderson, J.P. Figueiredo, C. Jaramillo, D. Riff, F.R. Negri, H. Hooghiemstra, J. Lundberg, T. Stadler, T. Särkinen, A. Antonelli. 2010. Amazonian through time: Andean uplift, climate change, landscape evolution, and biodiversity. Science 330: 927-931.

Hooghiemstra, H., T. Van der Hammen. 1998. Neogene and Quaternary development of the neotropical rain forest: the forest refugia hypothesis, and a literature overview. Earth-Science Reviews 44: 147183.

Howe, M.W. 1974. Nonmarine Neiva Formation (Pliocene ?), Upper Magdalena Valley, Colombia: regional tectonism. Geological Society of America Bulletin 85: 1031-1042.

Hsiou, A.S. 2007. A new Teiidae species (Squamata, Scincomorpha) from the Late Pleistocene of Rio Grande Do Sul State, Brazil. Revista Brasileira de Paleontologia 10 (3): 181-194.

Hsiou, A.S., A.M. Albino, J. Ferigolo. 2009. First Lizard remains (Teiidae) from the Miocene of Brazil (Solimôes Formation). Revista Brasileira de Paleontologia 12 (3): 225-230.

Hsiou, A.S., G.R. Winck, B.W. Schubert, L. Ávilla. 2013. On the presence of Eunectes murinus (Squamata, Serpentes) from the Late Pleistocene of Northern Brazil. Revista Brasileira de Paleontologia 16 (1): 77-82.

Hubach, E. 1930. Exploracion en la region de Apulo-An Antonio-Viotä. Boletín de Minas y Petróleos 4: 41-60.

Huxley, J.S. 1932. Problems of Relative Growth. Methuen, London, 276p.

Instituto de Investigaciones de Recursos Biológicos Alexander von Humboldt. 2014. Lista de plantas de $\begin{array}{llllll}\text { Bosque } & \text { Seco } & \text { Tropical } & \text { de }\end{array}$ ipt.sibcolombia.net/iavh/resource.do?r=bosquessecos_colombia_2013].

Jaramillo, C. 2002. Response of tropical vegetation to Paleogene warming. Paleobiology 28 (2): 222243.

Jaramillo, C., D.L. Dilcher. 2001a. Middle Paleogene palynology of central Colombia, South America: a study of pollen and spores from tropical latitudes. Palaeontographica 258: 87-213.

Jaramillo, C., D.L. Dilcher. 2001b. Microfloral diversity patterns of the late Paleocene-Eocene interval in Colombia, northern South America. Geology 28 (9): 815-818.

Jaramillo, C., M.J. Rueda, G. Mora. 2006. Cenozoic plant diversity in the Neotropics. Science 311 (5769): 1893-1896.

Jaramillo, C., G. Bedoya, A. Pardo-Trujillo, M. Rueda, V. Torres, G.J. Harrington, G. Mora. 2007. The palynology of the Cerrejón Formation (Upper Paleocene) of Northern Colombia. Palynology 31 (1): 153189.

Jaramillo, C., D. Ochoa, L. Contreras, M. Pagani, H. Carvajal-Ortiz, L.M. Pratt, S. Krishnan, A. Cardona, M. Romero, L. Quiroz, G. Rodriguez, M.J. Rueda, F. de la Parra, S. Morón, W. Green, G. Bayona, C. Montes, O. Quintero, R. Ramírez, G. Mora, S. Schouten, H. Bermudez, R. Navarrete, F. Parra, M. Alvarán, J. Osorno, J.L. Crowley, V. Valencia, J. Vervoort. 2010. Effects of rapid global warming at the PaleoceneEocene boundary on Neotropical vegetation. Science 330: 957-961.

Jaramillo, C., C. Hoorn, S.A.F. Da Silva, F. Leite, F. Herrera, L. Quiroz, R. Dinoo, L. Antonioli. 2010. The origin of the modern Amazon rainforest: implications of the palynological and palaeobotanical record. Pp: 351-368 en: C. Hoorn, F.P. Wasseling (eds.), Amazonia: landscape and species evolution. A look into the past, Wiley-Blackwell: a John Wiley \& Sons, Ltd., Publication, USA.

Jaramillo Justinico, A., L.N. Parra-Sánchez, J.O. Rangel-Ch. 2011. El registro de los cambios de clima en la estratigrafía de la Amazonia colombiana I. Neógeno - inicios del Cuaternario. Caldasia 33 (2): 539 572.

Kay, R.F. 1990a. A possible "giant" tamarin from the Miocene of Colombia. American Journal of Physical Antrhopology 81: 248.

Kay, R.F. 1990b. The phyletic relationships of extant and fossil Pitheciinae (Platyrrhini, Anthropoidea). Journal of Human Evolution 19: 175-208.

Kay, R.F. 1994. "Giant” tamarin from the Miocene of Colombia. American Journal of Physical Antrhopology 95: 333-353.

Kay, R.F., C.D. Frailey. 1993. Large fossil platyrrhines from the Río Acre local fauna, late Miocene, western Amazonia. Journal of Human Evolution 25: 319-327. 
Kay, R.F., R.H. Madden. 1997. Mammals and rainfall: paleoecology of the middle Miocene at La Venta (Colombia, South America). Journal of Human Evolution 32: 161-199.

Kay, R.F., J. Meldrum. 1997. A new small Platyrrhine and the phyletic position of Callitrichinae. Pp: 435-458 en: R.F. Kay, R.H. Madden, R.L. Cifelli, J.J. Flynn (eds.), Vertebrate Paleontology in the Neotropics: the Miocene Fauna of La Venta, Colombia. Smithsonian Institution Press, Washington D.C., USA.

Kay, R.F., R.H. Madden. 1997. Paleogeography and paleoecology. Pp: 520-550 en: R.F. Kay, R.H. Madden, R.L. Cifelli, J.J. Flynn (eds.), Vertebrate Paleontology in the Neotropics: the Miocene Fauna of La Venta, Colombia. Smithsonian Institution Press, Washington D.C., USA.

Kay, R.F., M.A. Cozzuol. 2006. New platyrrhine monkeys from the Solimôes Formation (late Miocene, Acre State, Brazil). Journal of Human Evolution 50: 673-686.

Kay, R.F., H.G. Fleagle. 2010. Stem taxa, homoplasy, long lineages, and the phylogenetic position of Dolichocebus. Journal of Human Evolution 59: 218-222.

Kay, R.F., R.H. Madden, J.M. Plavcan, R.L. Cifelli, J. Guerrero. 1987. Stirtonia victoriae, a new species of Miocene Colombian primate. Journal of Human Evolution 16: 73-196.

Kay, R.F., R.H. Madden, R.L. Cifelli, J.J. Flynn (eds.). 1997. Vertebrate Paleontology in the Neotropics: the Miocene Fauna of La Venta, Colombia. Smithsonian Institution Press, Washington D.C., USA, 592p.

Kay, R.F., B.A. Williams, F. Anaya. 2002. The adaptations of Branisella boliviana, the Earliest South American monkey. Pp: 339-370 en: J.M. Plavcan, R.F. Kay, W.L. Jungers, C.P. Van Schaik (eds.), Reconstructing Behavior in the Primate Fossil Record. Kluwer Academic/Plenum Publishers, New york, USA.

Kay, R.F., J.G. Fleagle, T.R.T. Mitchell, M. Colbert, T.M. Bown, D.W. Powers. 2008. The anatomy of Dolichocebus gaimanensis, a stem platyrrhine monkey from Argentina. Journal of Human Evolution 54: 323-382.

Kay, R.F., K.D. Hunt, C.D. Beeker, G.W. Conrad, C.C. Johnson, J. Keller. 2011. Preliminary notes on a newly discovered skull of the extinct monkey Antillothrix from Hispaniola and the origin of the Greater Antillean monkeys. Journal of Human Evolution 60: 124-128.

Keller, G., J.A. Barron. 1987. Paleodepth distribution of Neogene deep-sea hiatuses. Paleoceanography 2: 697-713.

Kramarz, A.G. 2009. Adiciones al conocimieno de Astrapothericulus (Mammalia, Astrapotheria): anatomía cráneo-dentaria, diversidad y distribución. Revista Brasileira de Paleontologia 12 (1): 55-66.

Latrubesse, E.M., S.A.F. Da Silva-Caminha, M. Cozzuol, M.L. Absy. 2007. Late Miocene continental sedimentation in southwestern Amazonia and its regional significance: biotic and geological evidence. Journal of South American Earth Science 23: 61-80.

Latrubesse, E.M., M. Cozzuol, S.A.F. Da Silva-Caminha, C.A. Rigsby, M.L. Absy, C. Jaramillo. 2010. The late Miocene paleogeography of the Amazon Basin and the evolution of the Amazon River system. Earth Science Reviews 99: 99-124.

Leal, A., J.C. Berrío, E. Raimúndez, B. Bilbao. 2011. A pollen atlas of Premontane Woody and Herbaceous communities from the Upland Savannahs of Guayana, Venezuela. Palynology 35 (2): 226-266.

Leal, A., B. Bilbao, J.C. Berrío. 2013. A contribution to pollen rain characterization in forest-savannah mosaics of the Venezuelan Guayana and its use in vegetation reconstructions from sedimentary records. American Journal of Plant Science 4: 33-52.

Legendre, S. 1986. Analysis of mammalian communities from the Late Eocene and Oligocene of Southern France. Paleovertebrata 16: 191-212.

Lorente, M. 1986. Palynology and palynofacies of the Upper Tertiary in Venezuela. J. Cramer, Berlin, $222 \mathrm{p}$.

Luchterhand, K., R.F. Kay, R.H. Madden. 1986. Mohanamico hershkovitzi, gen. et sp. nov., un primate du Miocène moyen d'Amérique du Sud. Comptes Rendus de l'Académie des Sciences de Paris sér. II, 303:1753-1758.

Lundberg, J.G. 1992. A Miocene fossil of the Amazonian Fish Arapaima (Teleostei, Arapaimidae) from the Magdalena River Region of Colombia: biogeographic and evolutionary implications. Biotropica 24 (1): 2-14. 
Lundberg, J.G. 1997. Freshwater fisches and their paleobiotic implications. Pp: 67-92 en: R.F. Kay, R.H. Madden, R.L. Cifelli, J.J. Flynn (eds.), Vertebrate Paleontology in the Neotropics: the vertebrate fauna of La Venta, Colombia. Smithsonian Institution Press, Washington D.C., USA.

Lundberg, J.G. 2005. Brachyplatystoma promagdalena, new species, a fossil goliath catfish (Siluriformes: Pimelodidae) from the Miocene of Colombia, South America. Neotropical Ichthyology 3 (4): 597-605.

Lundberg, J.G., B. Chernoff. 1992. A Miocene fossil of the Amazonian fish Arapaima (Teleostei, Arapaimidae) from the Magdalena River region of Colombia: biogeographic and evolutionary implications. Biotropica 24 (1): 2-14.

Lundberg, J.G., A. Machado-Allison, R.F. Kay. 1986. Miocene Characid fishes from Colombia: evolutionary stasis and extirpation. Science 234 (4773): 208-209.

Lundberg, J.G., O.J. Linares, M.E. Antonio, P. Nass. 1988. Phractocephalus hemiliopterus (Pimelodidae, Siluriformes) from the Upper Miocene Urumaco Formation, Venezuela: a further case of evolutionary stasis and local extinction among South American fishes. Journal of Vertebrate Paleontology 8 (2): 131-138.

Lyman, R.L. 2013. Taxonomic composition and body-mass distribution in the terminal Pleistocene mammalian fauna from the Marmes site, southeastern Washington State, USA. Paleobiology 39 (3): 345-359.

Lynch A., J.W., J.P. Boubli, L.E. Olson, A.D. Fiore, B. Wilson, G.A. Gutiérrez-Espeleta, K.L. Chiou, M. Schulte, S. Neitszel, V. Ross, D. Schwochow, M.T.T. Nguyen, I. Farias, C.H. Janson, M.E. Alfaro. 2011. Explosive Pleistocene range expansion leads to widespread Amazonian sympatry between robust and gracile capuchin monkeys. Journal of Biogeography 1-17.

MacFadden, B.J. 1990. Chronology of Cenozoic primate localities in South America. Journal of Human Evolution 19: 7-21.

Madden, R.H., J. Guerrero, R.F. Kay, J.J. Flynn, C.C. Swisher III, A.H. Walton. 1997. The Laventan Stage and Laventan Age: new chronostratigraphic and geochronologic units for the Miocene of South America. Pp: 499-519 en: R.F. Kay, R.H. Madden, R.L. Cifelli, J.J. Flynn (eds.), Vertebrate Paleontology in the Neotropics: the vertebrate fauna of La Venta, Colombia. Smithsonian Institution Press, Washington D.C., USA.

Magalhâes e Silva, F.H., F.A. Ribeiro dos Santos. 2009. Pollen morphology of the shrub and arboreal flora of mangroves of Northeastern Brazil. Wetlands Ecology and Management 17: 423-443.

Marshall, C.R. 1990. Confi ce intervals on stratigraphic ranges. Paleobiology 16 (1): 1-10.

Marshall, L.G. 1976. New Didelphine marsupials from the La Venta Fauna (Miocene) of Colombia, South America. Journal of Paleontology 50 (3): 402-418.

Marshall, L.G. 1977. A new species of Lycopsis (Borahyaenidae: Marsupialia) from the La Venta Fauna (Late Miocene) of Colombia, South America. Journal of Paleontology 51 (3): 633-642.

Marshall, L.G., R. Hoff tetter, R. Pascual. 1983. Mammals and stratigraph: geochronology of the continental Mammal-bearing Tertiary of South America. Paleovertebrata 1-93.

Marshall, L.G., R. Pascual, G.H. Curtis, R.E. Drake. 1977. South American geochronology: radiometric time scale for Middle to Late Tertiary Mammal-bearing horizons in Patagonia. Science 195 (4284): $1325-1328$.

Marshall, L.G., S.D. Webb, J.J. Sepkoski, D.M. Raup. 1982. Mammalian evolution and the Great American Interchange. American Association for the Advancement of Science 215 (4538): 1351-1357.

Marshall, L.G., R.F. Butler, R.E. Drake, G.H. Curtis, R.H. Tedford. 1979. Calibration of the Great American Interchange. Science 204 (4390): 272-279.

Martínez, J.N., R. Cadenillas. 2006. Paleoambientes de la region de Talara - La Brea (Piura, Perú) hacia el fin del Pleistoceno: datos sugeridos por la paleocomunidad de mamíferos. XII Congreso Peruano de Geología, Resúmenes extendidos, Sociedad Geológica del Perú, Lima, Perú, Pp: 481-484.

McKean, S.J. 1993. Manual de Análisis de Suelos y Tejido Vegetal: una guía y practica de metodologías. Informe técnico, No. 129, Centro Internacional de Agricultura Tropical (CIAT), Laboratorio de Servicios Analíticos, Valle del Cauca, Colombia, 103p.

Meldrum, D.J., J.G. Fleagle. 1988. Morphological affinities of the postcranial skeleton of Cebupithecia sarmientoi. American Journal of Physical Anthopology 75: 249.

Meldrum D.J., R.F. Kay. 1990. A new partial skeleton of Cebupithecia sarmientoi from the Miocene of 
Colombia. American Journal of Physical Anthropology 81: 267.

Meldrum, D.J., P. Lemelin. 1991. Axial skeleton of Cebupithecia sarmientoi (Pitheciinae, Platyrrhini) from the Middle Miocene of La Venta, Colombia. American Journal of Primatology 25: 69-89.

Meldrum, D.J., R.F. Kay. 1997. Nuciruptor rubricae, a new pitheciin seed predator from the Miocene of Colombia. American Journal of Physical Anthropology 102: 407-427.

Meldrum, D.J., J.G. Fleagle, R.F. Kay. 1990. Partial humeri of two Miocene Colombian Primates. American Journal of Physical Anthropology 81: 413-422.

Miller, A.H. 1953. A fossil hoatzin from the Miocene of Colombia. Auk 70: 484-489.

Miño-Boilini, A.R., R.L. Tomassini, C. Oliva, T.M. De Bianco. 2011. Adiciones al conocimiento de Proscelidodon Bordas, 1935 (Mammalia, Xenarthra, Scelidotheriinae). Revista Brasileria de Paleontologia 14 (3): 269-278.

Monsch, K.A. 1998. Miocene fish faunas from the northwestern Amazonia basin (Colombia, Peru, Brazil) with evidence of marine incursions. Palaeogeography, Palaeoclimatology, Palaeocology 143: 31-50.

Mook, C.C. 1941. A new fossil crocodilian from Colombia. Proceedings of the United States National Museum, Smithsonian Institution U.S. National Museum 91 (3122): 55-58, Plate 9.

Mora, A., M. Parra, M.R. Strecker, E.R. Sobel, H. Hooghiemstra, V. Torres, J. Vallejo Jaramillo. 2008. Climatic forcing of asymmetric orogenic evolution in the Eastern Cordillera of Colombia. Geological Society of America Bulletin 120: 930-949.

Morrone, J.J. 2006. Biogeographic areas and transition zones of Latin America and the Caribbean Islands bases on panbiogeographic and cladistics analyses of the entomofauna. Annual Review of Entomology 51: 467-494.

Murelaga, X., X. Pereda Suberbiola, F. de Lapparent de Broin, J.C. Rage, S. Duffaud, H. Astibia, A. Badiola. 2002. Amphibian and reptiles from the Early Miocene of the Bardenas Reales of Navarre (Ebro Basin, Iberian Peninsula). Geobios 35: 347-365.

Nakatsukasa, M., M. Takai, T. Setoguchi. 1997. Functional morphology of the postcranium and locomotor behavior of Neosaimiri fieldsi, a Saimiri-like Middle Miocene Platyrrhine. American Journal of Physical Anthropology 102: 515-544.

Nogué, S., V. Rull, E. Montoya, O. Hubber, T. Vegas-Vilarrúbia. 2009. Paleoecology of the Guayana Highlands (northern South America): Holocene pollen record from the Eruoda-tepui, in the Chimantá massif. Palaeogeography, Palaeoclimatology, Palaeoecology 281: 165-173.

Nutall, C.P. 1990. A review of the Tertaty non-marine molluscan faunas of the Pebasian and other inland basins of northwestern South America. Bulletin of the British Museum of Natural History, Geology 45: $165-371$.

Ochoa, D., C. Hoorn, C. Jaramillo, G. Bayona, M. Parra, F. De la Parra. 2012. The final phase of tropical lowland conditions in the axial zone of the Eastern Cordillera of Colombia: evidence from three palynological records. Journal of South American Earth Sciences 39: 157-169.

Oliva, C., A.E. Zurita, A. Dondas, G.J. Scillato-yané. 2010. Los Glyptodontidae (Xenarthra, Glyptodontidae) del Piso/Edad Chapadmalalense (Plioceno tardío): revision y aportes al conocimiento. Revista Mexicana de Ciencias Geológicas 27 (1): 112-120.

Opazo J.C., D.E. Wildman, T. Prychitko, R.M. Johnson, M. Goodman. 2006. Phylogenetic relationships and divergence times among New World monkey (Platyrrhini, Primates). Molecular Phylogenetics and Evolution 40: 274-280.

Pardo-Trujillo, A., C. Jaramillo, F. Obohikuenobe. 2003. Paleogene palynostratigraphy of the eastern Middle Magdalena Valley, Colombia. Palinology 27: 155-178.

Parra, M., A. Mora, C. Jaramillo, M.R. Strecker, E.R. Sobel, L. Quiroz, M. Rueda, V. Torres. 2009. Orogenic wedge advance in the northern Andes: Evidence from the Oligocene-Miocene sedimentary record of the Medina Basin, Eastern Cordillera, Colombia. Geological Society of America Bulletin 121: 780800.

Parra-Sánchez, L.N. 2016. Litoestratigrafia del Neógeno de La Tatacoa, Huila, Colombia. Informe Año Sabático, Universidad Nacional de Colombia, Medellín, Colombia, 41p. Informe técnico, 1 agosto 2016.

Parra-Sánchez, L.N., S.A. Restrepo-Moreno. 2014. El Mioceno del Desierto de La Tatacoa. Primer Simposio Colombiano de Zoopaleontología en: IV Congreso Colombiano de Zoología, 1 al 5 diciembre 2014, Cartagena D.T. y C., Colombia. 
Parra-Sánchez, L.N., S.A. Restrepo-Moreno, D.A. Foster, G.D. Kamenov, A.A. Barbosa-Espitia. 2015. Revisiting stratigraphy, geochronology and paleogeography at La Venta Formation, Tatacoa Desert, Colombia. 2015 GSA Annual Meeting in Baltimore, 1 al 4 noviembre 2015, Maryland, USA. Geological Society of America Abstract with Programs 47 (7): 803.

Patterson, B. 1934. Upper premolar-molar structure in the Notoungulata with notes on taxonomy. Field Museum of Natural History VI (332): 91-111.

Perales, R., H. Serrrano, B.A. García Yelo, M. Hernández Fernández. 2009. Inferencias paleoambientales del Mioceno medio de Somosaguas (Pazuelo de Alarcón, Madrid) basadas en la estructura de tamaños corporals de su fauna de mamíferos. Paleolusitana (1): 317-325.

Perez, S.I., M.F. Tejedor, N.M. Novo, L. Aristide. 2013. Divergence times and the evolutionary radiation of New World monkeys (Platyrrhini, Primates): an analysis of fossil and molecular data. PLOS ONE 8 (6): 1-16.

Peters, R.H. 1983. The Ecological Implications of Body Size. Cambridge University Press, Cambridge, $329 \mathrm{p}$.

Presch, W. 1973. A review of the tegus, Lizard genus Tupinambis (Sauria: Teiidae) from South America. American Society of Ichthyologists and Herpetologists (ASIH) (4): 740-746.

Pujos, F., R. Salas. 2004. A new species of Megatherium (Mammalia: Xenarthra: Megatheridae) from the Pleistocene of Sacaco and Tres Ventanas, Peru. Palaeontology 47 (3): 579-604.

Raine, J.I., D.C. Mildenhall, E.M. Kennedy. 2011. New Zealand fossil spores and pollen: an illustrated catalogue. $4^{\text {th }}$ edition, GNS Science miscellaneous, Series No. 4.

Reguant, S., R. Ortiz. 2001. Guía Estratigráfica Internacional: version abreviada. Revista de la Sociedad Geológica de España 14 (3-4): 271-293.

Rinderknecht, A., E. Bostelmann T., M. Ubilla. 2011. New genus of giant Dinomyidae (Rodentia: Hystricognathi: Caviomorpha) from the late Miocene of Uruguay. Journal of Mammalogy 92 (1): 169178.

Rivera-Sylva, H.E., E. Frey, J.R. Guzmán-Gutiérrez, F. Palomino-Sánchez, W. Stinnesbeck. 2011. A Deinosuchus riograndensis (Eusuchia: Alligatoridae) from Coahuila, North Mexico. Revista Mexicana de Ciencias Geológicas 28 (2): 267-274.

Rodríguez, G. 1997. Trichodactylid crabs. Pp: 63-66 en: R.F. Kay, R.H. Madden, R.L. Cifelli, J.J. Flynn (eds.), Vertebrate Paleontology in the Neotropics: the vertebrate fauna of La Venta, Colombia. Smithsonian Institution Press, Washington D.C., USA.

Rodríguez, J. 1999. Use of cenograms in mammalian palaeoecology: a critical review. Lethaia 32: 331347.

Rose, K.D. 2006. The Beginning of the Age of Mammals. The Johns Hopkins University Press, Baltimore, Maryland, USA, 428p.

Rosenberger, A.L. 1984. Fossil New World monkeys dispute the molecular clock. Journal of Human Evolution 13: 737-742.

Rosenberger, A.L. 1992. Evolution of feedings niches in New World monkeys. American Journal of Physical Anthropology 88: 525-562.

Rosenberger, A.L. 2002. Platyrrhine paleontology and systematics: The paradigm shifts. Pp.151-159 en: W.C. Hartwig (ed.), The Primate Fossil Record. Cambridge: Cambridge University Press. USA.

Rosenberger, A.L., W.C. Kinzey. 1976. Functional patterns of molar occlusion in Platyrrhine Primates. American Journal of Physical Anthropology 45: 281-298.

Rosenberger, A.L., L.J. Matthews. 2008. Oreonax not a genus. Neotropical Primates 15 (1): 8-12.

Rosenberger, A.L., Setoguchi, T., Shigehara, N. 1990. The fossil record of callitrichine primates. Journal of Human Evolution 19: 209-236.

Rosenberger, A.L., W.C. Hartwig, M. Takai, T. Setoguchi, N. Shigehara. 1991a. Dental variability in Saimiri and the taxonomic status of Neosaimiri fieldsi, an early squirrel monkey from Colombia, South America. International Journal of Primatology 12: 291-301.

Rosenberger, A.L., T. Setoguchi, W.C. Hartwig. 1991b. Laventiana annectens, new genus and species: fossil evidence for the origin of callitrichine monkeys. Proceedings of the National Academy of Sciences 88: 2137 2140 . 
Rosenberger, A. L., M.F. Tejedor, S. Cooke, S. And Pekar. 2009. Platyrrhine ecophylogenetics in Space and Time. Pp. 69-113 en: P. Garber, A. Estrada, J. Bicca-Marquez, K. Strier (eds.), South American Primates: testing new theories in the study of primate behavior, ecology, and conservation. Developments in Primatology, Progress and Prospects, Series Editor Russell H. Tuttle, Springer Press.

Rosenberger, A.L., S.B. Cooke, R. Rímoli, X. Ni, K. Cardoso. 2010. First skull of Antillothrix bernensis, an extinct relict monkey from the Dominican Republic. Published online.

Royo y Gómez, J. 1941. Datos para la geología económica del departamento del Huila. Boletín de Minas y Petróleo, Bogotá 15: 121-205.

Royo y Gómez, J. 1942a. Contribución al conocimiento de la geología del Valle Superior del Magdalena (departamento del Huila). Ministerio de Minas y Petróleos Servicio Técnico, Bogotá, Colombia, 115p, + 4 mapas, + 7 perfiles. Informe técnico, 26 marzo 1942.

Royo y Gómez, J. 1942b. Contribución al conocimiento de la geología del Valle Superior del Magdalena (departamento del Huila). Compilación de Estudios Geológicos Oficiales en Colombia 5: 261-326.

Royo y Gómez, J. 1945. Los vertebrados del Terciario continental colombiano. Compilación de Estudios Geológicos Oficiales en Colombia. Bogotá, Colombia, 31p + 10 mapas. Informe Técnico, 15 noviembre 1975.

Royo y Gómez, J. 1946. Los vertebrados del Terciario continental colombiano. Revista de la Academia Colombiana de Ciencias Exactas, Físicas y Naturales 6: 496-512.

Salas, R., T. De Vries, M. Urbina, A. García, F. Pujos, M. Aguirre. 2004. Los vertebrados de los humedales pleistocénicos de Aguada de Lomas y Sacaco (Arequipa, Perú): interpretaciones paleoecológicas. XII Congreso Peruano de Geología, Resúmenes Extendidos, Sociedad Geológica del Perú, Pp: 529-532.

Salas, R., F. Pujos, C. de Muizon. 2005. Ossified meniscus and cyamo-fabella in some fossil sloths: a morpho-functional interpretation. Geobios 38: 389-394.

Salazar Jaramillo, S., A. Ochoa, A. Cadena, J. Guerrero. 2017. Geoquímica y climofunciones aplicadas a paleosuelos del Mioceno medio en el Desierto de La Tatacoa. Memorias XVI Congreso Colombiano de Geología: III Simposio de Exploradores, Santa Marta, Colombia, 28 septiembre de 2017, P : 1455-1456.

Salgado Labouriau, M.L. 1976. Contribuiçâo à Palinológia dos Cerrados. Editor Academia Brasilleira de Ciências, 255p.

Sánchez, C., J. Salazar, G. Bonilla. 2017. Estudio de las unidades pedogenéticas del Mioceno medio en el Desierto de La Tatacoa. Memorias XVI Congreso Colombiano de Geología: III Simposio de Exploradores, Santa Marta, Colombia, 28 septiembre de 2017, P : 1464-1470.

Savage, D.E. 1951. Report on fossil vertebrates from the Upper Magdalena Valley, Colombia. Science 114 (2955): 186-187.

Savage, D.E. 1951. A Miocene phyllostomatid bat from Colombia, South America. University of California Publications in Geological Science 28: 357-366.

Schönfeld, G. 1947. Holzer gus dem Tertiar Kolumbien. Abhandlungen Senckenbergische Naturforschung Gesellschaft 475: 1-53.

Schrago, C.G. 2007. On the time scale of New World Primate diversification. American Journal of Physical Anthropology 132: 344-354.

Setoguchi, T. 1980. Discovery of a fossil primate from the Miocene of Colombia. Monkey 24: 64-69.

Setoguchi, T. 1985. Kondous laventicus, a new ceboid primate from the Miocene of the La Venta, Colombia, South America. Folia Primatologica 44: 96-101.

Setoguchi, T., A. Cadena. 1984. Relación entre la morfología y la function de la dentadura en el linaje Stirtonia - Alouatta (Ceboidea). Kyoto University Overseas Research, Reports of New World Monkeys, Kyoto University Primate Research Institute 4: 11-20.

Setoguchi, T., A.L. Rosenberger. 1985a. Miocene Marmosets: first fossil evidence. International Journal of Primatology 6 (6): 615-625.

Setoguchi, T., A.L. Rosenberger. 1985b. Some new ceboid primates from the La Venta, Colombia, South America. Memorias VI Congreso Latinoamericanao de Geología 1: 187-198.

Setoguchi, T., A.L. Rosenberger. 1987. A fossil owl monkey from La Venta, Colombia. Nature 326: 692694. 
Setoguchi T., T. Watanabe, T. Mouri. 1981. The upper dentition of Stirtonia (Ceboidea, Primates) from the Miocene of Colombia, South America, and the origin of the postero-internal cusps of upper molars of howler monkeys (Alouatta). Kyoto University Overseas Research, Reports of New World Monkeys, Kyoto University Primate Research Institute 3: 51-60.

Setoguchi, T., N. Shigehara, A. Cadena. 1985. Kondous un Nuevo primate ceboide de el Mioceno de La Venta, Colombia. Kyoto University Overseas Research, Reports of New World Monkeys, Kyoto University Primate Research Institute 5: 1-6.

Setoguchi, T., M. Takai, A.C. Villarroel, N. Shigehara, A.L. Rosenberger. 1988. New specimen of Cebupithecia from La Venta, Miocene of Colombia, South America. Kyoto University Special Publications 7-9.

Setoguchi, T., M. Takai, N. Shigehara. 1990. A new ceboid primate, closely related to Neosaimiri, found in the Upper Red Bed in the La Venta Badlands, middle Miocene of Colombia, South America. Kyoto University Overseas Research, Reports of New World Monkeys, Kyoto University Primate Research Institute 7: 9-14.

Simpson, G.G. 1943. Mammals and the nature of continents. American Journal of Science 241: 1-31.

Simpson, G.G. 1960. Notes on the measurement of faunal resemblance. American Journal of Science 258: 300-311.

Stehln, H.G. 1939. Ein Nager aus dem Miocaen von Columbien. Eclogae Geologicae Helvetiae 32: 179183.

Stille, H. 1907. Geologische studien im gebiete des Rio Magdalena. Festschrift Adolf v. Koenen, Sttutgart, Pp: 277-358.

Stirton, R.A. 1947a. The first lower Oligocene vertebrate fauna from Northern South America. Compilación de Estudios Geológicos Oficiales en Colombia 7: 325-341.

Stirton, R.A. 1947b. A rodent and a peccary from the Cenozoic of Colombia. Compilación de Estudios Geológicos Oficiales en Colombia 7: 317-324.

Stirton R.A. 1951. Ceboid monkeys from the Miocene of Colombia. Bulletin University of California Publications in Geological Science 28: 315-335.

Stirton, R.A. 1953a. A new genus of interatheres from the Miocene of Colombia. Bulletin University of California Publications in Geological Science 29: 265-348.

Stirton, R.A. 1953b. Vertebrate paleontology and continental stratigraphy in Colombia. Bulletin of the Geological Society of America 64: 603-622.

Stirton, R.A., D.E. Savage. 1951. A new monkey from the La Venta Miocene of Colombia. Compilación de Estudios Geológicos Oficiales en Colombia 8: 347-356.

Straehl, F., M. Chassagne, A.A. Carlini. 2012. La diversidad e historia evolutiva de las perezas, cachicamos y sus parientes. Pp: 283-300 en: M.R. Sánchez-Villagra (ed.), Venezuela Paleontológica: evolución de la biodiversidad en el pasado geológico. Printwork Art GmbH, St. Gallen, Universität Zürich UZH, Suiza.

Takai, M. 1994. New specimens of Neosaimiri fieldsi from La Venta, Colombia: a middle Miocene ancestor of the living squirrel monkeys. Journal of Human Evolution 27: 329-360.

Takai, M., T. Setoguchi. 1990. Geology and localities on monkey fossils in the La Venta Badlands, Colombia, South America. Kyoto University Overseas Research, Reports of New World Monkeys, Kyoto University Primate Research Institute 7: 1-7.

Takai, M., T. Setoguchi, C. Villarroel, A. Cadena, N. Shigehara. 1991. A new Miocene Molossid bat from La Venta, Colombia, South America. Memoirs of the Faculty of Science, Kyoto University, Series of Geology \& Mineralogy LVI (1-2): 1-9.

Takai, M., K. Takemura, A. Takemura, C. Villarroel, A. Hayashida, T. Danhara, T. Ohno, R. Franco N., T. Setoguchi, y. Nogami. 1992. Geology of La Venta, Colombia, South America. Kyoto University Overseas Research, Reports of New World Monkeys, Kyoto University Primate Research Institute 8: $1-17$.

Takai, M., F. Anaya, N. Shigehara, T. Setoguchi. 2000. New fossil materials of the earliest New World monkey, Branisella boliviana, and the problem of Platyrrhine origins. American Journal of Physical Anthropology 111: 263-281.

Takai, M., F. Anaya, H. Suzuki, N. Shigehara, T. Setoguchi. 2001. A new platyrrhine from the Middle 
Miocene of La Venta, Colombia, and the phyletic position of Callicebinae. Anthropological Sciences 109 (4): 289-307.

Takai, M., FT. Nishimura, N. Shigehara, T. Setoguchi. 2009. Meaning of the canine sexual dimorphism if fossil owl monkey, Aotus dindensis from the Middle Miocene of La Venta, Colombia. Comparative Dental Morphology 13: 55-59.

Takemura, K. 1983. Geology of the east side hills of the rio Magdalena from Neiva to Villavieja, Colombia. Kyoto University Overseas Research, Reports of New World Monkeys, Kyoto University Primate Research Institute 19-28.

Takemura, K. 1985. Sedimentary environments of the Upper Part of Honda Group in La Venta Area, Huila, Colombia. Kyoto University Overseas Research, Reports of New World Monkeys, Kyoto University Primate Research Institute 5: 25-30.

Takemura, K., T. Danhara. 1983. Fission-Track age of pumice included in the Gigante Formation, North of Neiva, Colombia. Kyoto University Overseas Research, Reports of New World Monkeys, Kyoto University Primate Research Institute 3: 13-15.

Takemura, K., T. Danhara. 1985. Fission-Track dating of the Upper part of Miocene Honda Group in La Venta Badlands, Colombia. Kyoto University Overseas Research, Reports of New World Monkeys, Kyoto University Primate Research Institute 5: 31-38.

Takemura, K., M., Takai, T. Danhara, T. Setoguchi. 1992. Fission-Track ages of the Villavieja Formation of the Miocene Honda Group in La Venta, Department of Huila, Colombia. Kyoto University Overseas, Research Reports of New World Monkeys, Kyoto University Primate Research Institute 8: 19-27.

Tejedor, M.F. 1998. Origen y evolución de los platyrrhini (Primates, Anthropoidea), con especial referencia a los registros de Argentina. Estudios Geológicos 54: 249-271.

Tejedor, M.F. 2001. Aotus y los Atelinae: nuevas evidencias en la sistemática de los primates platirrinos. Mastozoología Neotropical 8 (1): 41-57.

Tejedor, M.F. 2005. New fossil platyrrhine from Argentina. Folia P r i m a t o 1 o g i c a 76 (3): 146-150.

Tejedor, M.F. 2008. The origin and evolution of Neotropical Primates. Arquivos do Museu Nacional 66 (1): 251-269.

Tejedor, M.F. 2013. Sistemática, evolución y paleobiografía de los primates Platyrrhini. Revista del Museo de La Plata, Universidad Nacional de La Plata, Facultad de Ciencias Naturales y Museo, Sección Zoología, 20 (176): 20-39.

Tejedor, M.F., N.J. Czaplewski, F.J. Goin, E. Aragón. 2005. The oldest record of South American bats. Journal of Vertebrate Paleontology 25 (4): 990-993.

Tejedor, M.F., A.L. Rosenberger. 2008. A neotype for Homunculus patagonicus Ameghino, 1891, and a new interpretation of the taxon. PaleoAnthropology 68-82.

Tejedor, M.F., Y. Muñoz-Saba. 2013. La sistemática de los platirrinos y el registro fósil. Pp: 68-87 en: T.R. Defler, P.R. Stevenson, M.L. Bueno, D.C. Guzmán (eds.), Primates Colombianos en Peligro de Extinción. Asociación Primatológica Colombiana (APA), Pacific Rubiales Energy, Conservation International, Margot Marsh Biodiversity Foundation, Bogotá D.C., Colombia, 348p.

Tejedor, M.F., A.A. Tauber, A.L. Rosenberger, C.C. Swisher III, M.E. Palacios. 2006. New primate genus from the Miocene of Argentina. Proceedings of the national Academy of Sciences of the United States of America (PNAS) 103: 5437-5441.

Tejedor, M.F., A.L. Rosenberger, C. Cartelle. 2008. Nueva especie de Alouatta (Primates, Atelinae) del Pleistoceno Tardío de Bahía, Brasil. Ameghiniana 45 (1): 247-251.

Tejedor, M.F., F.J. Goin, J.N. Gelfo, G. López, M. Bond, A.A. carlini, G.J. Scillato-Yané, M.O. Woodburne, L. Chornogubsky, E. Aragón, M.A. Reguero, N.J. Czaplewsky, S. Vincon, G.M. Martin, M.R. Ciancio. 2009. New early Eocene mammalian fauna from Western Patagonia, Argentina. American Museum Novitates (3638): 43p.

Traverse, A. 1988. Paleopalynology. Boston, London, Sydncy, Wellington: Unwin Hyman, 600p.

Travouillon, K.J., S. Legendre. 2009. Using cenograms to investigate gaps in mammalian body mass distributions in Australia mammals. Palaeogeography, Palaeoclimatology, Palaeocology 272: 69-84.

Urrego, L.E., G. Bernal, J. Polanía. 2009. Comparison of pollen distribution patterns in surface sediments of a Colombian Caribbean mangrove with geomorphology and vegetation. Review of Palaeobotany and Palynology 156: 358-375. 
Urrego, L.E., C. González, G. Urán, J. Polanía. 2010. Modern pollen rain in mangroves from San Andres Island, Colombian Caribbean. Review of Palaeobotany and Palynology 162: 168-182.

Vallejo-Pareja, M.C., J.D. Carrillo, J.W. Morano-Bernal, M. Pardo-Jaramillo, D.F. Rodríguez-González, J. Muñoz-Durán. 2015. Hilarcotherium castanedaii, gen. et sp. nov., a new Miocene astrapothere (Mammalia, Astrapotheriidae) from the Upper Magdalena Valley, Colombia. Journal of Vertebrate Paleontology, P: 1-8, DOI: 10.1080/02724634.2014.903960.

Van der Wiel, M. 1991. Uplift and volcanism of the Colombian Andes in relation to Neogene sedimentation in the Upper Magdalena Valley. Thesis Ph.D., 208p.

Van der Wiel, M., G.D. Van der Bergh. 1992. Uplift, subsidence, and volcanism in the southern Neiva Basin, Colombia, Part 1: Influence on fluvial deposition in the Miocene Honda Formation. Journal of South American Earth Sciences 5 (2): 153-173.

Van der Wiel, M., G.D. Van der Bergh, E.H. Hebeda. 1992. Uplift, subsidence, and volcanism in the southern Neiva Basin, Colombia, Part 2: Influence on fluvial deposition in the Miocene Gigante Formation. Journal of South American Earth Sciences 5 (2): 175-196.

Van Houten, F.B., R.B. Travis. 1968. Cenozoic Deposits Upper Magdalena Valley, Colombia. American Association of Petroleum Geologists 52: 675-702.

Vavrek, M.J. 2011. Fossil: palaeocological and palaeogeographical analysis tools. Palaeontologia Electronica 14 (1): 1-16.

Villarroel A., C. 1983. Descripción de Asterostemma? acostae, nueva especie de propalaehoplophorino (Glyptodontidae, Mammalia) del Mioceno de La Venta, Colombia. Geología Norandina (7): 29-34.

Villarroel A., C. 1997. La estructura de la dentición caduca de Huilatherium pluripicatum, Leontiniidae (Notoungulata) del Mioceno de Colombia. Geología Colombiana (22): 139-149.

Villarroel A., C. 1998. Los Nothrotheriinae (Megatheriidae, Gravigrada) del Mioceno de La Venta (Colombia). Descripción de Huilabradys magdaleniensis, nuevo género y especie. Revista de la Academia de Ciencias Exactas, Físicas y Naturales XXII (85): 497-506.

Villarroel A., C. 2000. Un nuevo Mylodontinae (Xenarthra, Tardigrada) en la Fauna de La Venta, Mioceno de Colombia: el estado actual de la familia Orophodontidae. Revista de la Academia de Ciencias Exactas, Físicas y Naturales XXIV (90): 117-127.

Villarroel A., C., T. Steoguchi, J. Brieva, C. Macía. 1996. Geology of the La Tatacoa "Desert" (Huila, Colombia): precisions on the stratigrafphy of the Honda Group, the evolution of the "Pata High" and the presence of the La Venta fauna. Faculty of Science, Kyoto University, Series of Geology \& Mineralogy LVIII (1-2): 41-66.

Vizcaíno, S.F., R.A. Fariña, M.S. Bargo, G. de Iuliis. 2004. Functional and phylogenetic assessment of the masticatory adaptations in Cingulata (Mammalia, Xenarthra). Ameghiniana 41 (4): 651-664.

Vizcaíno, S.F., M.S. Bargo, G.H, Cassini, N. Toledo (eds.). 2016. Forma y función en Paleobiología de Vertebrados. Editorial de la Universidad Nacional de La Plata (EDULP), La Plata, Provincia de Buenos Aires, 267p.

Wellman, S.S. 1970. Stratigraphy and petrology of the nonmarine Honda Group (Miocene), Upper Magdalena Valley, Colombia. Bulletin of the Geological Society of America: 81: 2353-2374.

Wesselingh, F.P., J.A. Salo. 2006. A Miocene perspective on the evolution of the Amazonian biota. Scripta Geol. 133: 439-458.

Wesselingh, F.P., M.E. Räsänen, G. Irion, H.B. Vonhof, R. Kaandorp, W. Renema, L. Romero Pittman, M. Gingras. 2002. Lake Pebas: a palaeoecological reconstruction of a Miocene, long-lived lake complex in western Amazonia. Cainozoic Research 1: 35-81.

Wheeler, B.C. 2010. Community ecology of the Middle Miocene primates of La Venta, Colombia: the relationship between ecological diversity, divergence time, and phylogenetic richness. Primates 51: 131138.

Wood, R.C. 1976. Two new species of Chelus (Testudines: Pleurodira) from the Late Tertiary of Northern South America. Breviora: Museum of Comparative Zoology (435): 1-26.

Woodburne, M.O. 1977. Defi tion and characterization in Mammalian chronostratigraphy. Journal of Paleontology 51 (2): 220-234.

Woodburne, M.O. 2010. The Great American biotic interchange: dispersals, tectonics, climate, sea level and holding pens. Journal of Mammalian Evolution 17: 245-264. 
Woodburne, M.O., F.J. Goin, M. Bond, A.A. Carlini, J.N. Gelfo, G.M. López, A. Iglesias, A.N. Zimiez. 2014. Paleogene Land Mammal Faunas of South America; a response to Global Climatic Changes and indigenous floral diversity. Journal of Mammalian Evolution 21: 1-73.

Zapata, L. 2006. Estratigrafia del Grupo Huila en el área de Neiva. Trabajo de Grado, Departamento de Geociencias, Facultad de Ciencias, Universidad Nacional de Colombia, Bogotá D.C., Colombia, 18p.

Zurita, A.E., A.R. Miño-Boilini, A.A. Carlini, M. Iriondo, M.A. Alcaraz. 2009. Paleontología del Chaco Oriental. Una nueva localidad de mamíferos fósiles pleistocenos en el río Bermejo (Formosa, Argentina). Revista Mexicana de Ciencias Geológicas 26 (2): 277-288.

Zurita, A.E., A.R. Miño-Boilini, A. Francia, J.E. Arenas-Mosquera. 2012. The Pleistocene Glyptodontidae Gray, 1869 (Xenarthra: Cingulata) of Colombia and some considerations about the South American Glyptodontinae. Revista Brasileira de Paleontologia 15 (3): 273-280. 


\section{CAPÍTULO VIII}

\section{FIGURAS}

Figura 1. Etapas de la cartografía del Grupo La Venta desde 1950 hasta el 2016.

Figura 2. Litoestratigrafía del Neógeno del Desierto de La Tatacoa, Huila, Colombia, 2016.

Figura 3. Grupo La Venta, se especifican las formaciones.

Figura 4. Afloramiento de la Formación San Alfonso, Grupo La Venta.

Figura 5. Afloramiento de la Formación La Victoria, Grupo La Venta.

Figura 6. Afloramiento de la Formación Cerbatana, Grupo La Venta.

Figura 7. Afloramiento de la Formación Villavieja, Grupo La Venta.

Figura 8. Afloramiento de la Formación Las Mesitas, Grupo La Venta.

- Figura 9. Limos arcillosos donde se realizaron muestreos de polen fósil. Formación La Victoria, Grupo La Venta.

- Figura 10. Moldes de troncos vegetales enterrados en bancos de arenas, Formación Las Mesitas, Grupo La Venta.

- Figura 11. Proceso de formación de los moldes de troncos vegetales, Formación Las Mesitas, Grupo La Venta.

- Figura 12. Moldes de troncos vegetales, Formación Las Mesitas, Grupo La Venta.

- Figura 13. Xilópalo, Mioceno inferior, Grupo Honda.

- Figura 14. Empalizada de moldes de troncos vegetales, Formación Las Mesitas, Grupo La Venta.

- Figura 15. Dendrograma de similitud del polen fósil entre las formaciones del Grupo La Venta.

- Figura 16. Dendrograma de similitud entre cada uno de los paleohábitats propuestos y las formaciones del Grupo La Venta.

- Figura 17. Dendrograma de similitud de los taxones de vertebrados fósiles registrados para el Grupo La Venta.

- Figura 18. Paleosuelos, Grupo La Venta.

- Figura 19. Estructuras sedimentarias secundarias.

- Figura 20. Sabana seca con matorral abierto, vegetación actual del paleohábitat de la Formación San Alfonso.

- Figura 21. Vegetación actual de la Formación La Victoria.

- Figura 22. Vegetación actual, bosque de ribera, Río Tomo, departamento del Vichada, Colombia; similar al paleohábitat de la Formación La Victoria.

- Figura 23. Vegetación actual, representativa del paleohábitat de la Formación Cerbatana.

- Figura 24. Vegetación actual, bosque de ribera, Río Ariari, departamento del Meta, Colombia; similar al paleohábitat de la Formación Cerbatana.

- Figura 25. Matorrales abiertos, vegetación actual de la Formación Villavieja.

- Figura 26. Vegetación actual, Río Bita, departamento del Vichada, Colombia; similar al paleohábitat de la Formación Villavieja.

- Figura 27. Bosque seco, vegetación actual de la Formación Las Mesitas.

- Figura 28. Vegetación actual, pie de monte llanero, Colombia; similar al paleohábitat de la Formación Las Mesitas.

- Figura 29. Paleogeografía del Grupo La Venta.

- Figura 30. Reconstrucción esquemática del Mioceno medio de la Cuenca de Neiva y el Macizo de Garzón.

\section{TABLAS}

Tabla 1. Información base (datos crudos) del análisis de polen fósil.

- Tabla 2. Información base (datos crudos) del análisis de vertebrados. Información recolectada en la presente investigación. 
- Tabla 3. Información base (datos crudos) del análisis de vertebrados. Información recopilada a partir de la literatura.

- Tabla 4. Lista de vertebrados fósiles de La Venta registrados en la presente investigación y en literatura.

- Tabla 5. Taxones de polen fósil identificados en las formaciones del Grupo La Venta y coberturas de vegetación actual del Desierto de La Tatacoa, departamento del Huila, Colombia. Datos sobre los cuales se realizó el índice de similitud de Simpson.

- Tabla 6. Índice de similitud de Simpson, teniendo en cuenta el polen fósil, los paleohábitats propuestos y las formaciones del Grupo La Venta.

- Tabla 7. Taxones de paleofauna de vertebrados identificados en las formaciones del Grupo La Venta. Datos sobre los cuales se realizó el índice de similitud de Simpson.

- Tabla 8. Índice de similitud de Simpson, teniendo en cuenta los vertebrados fósiles de las diferentes formaciones del Grupo La Venta.

\section{ANEXOS}

Anexo 1. Estratigrafía del Grupo Honda.

Anexo 2. Sección estratigráfica del Grupo La Venta.

Anexo 3. Ambiente sedimentario. Formación San Alfonso, Grupo La Venta.

Anexo 4. Ambiente sedimentario. Formación La Victoria, Grupo La Venta.

Anexo 5. Ambiente sedimentario. Formación Cerbatana, Grupo La Venta.

Anexo 6. Ambiente sedimentario. Formación Villavieja, Grupo La Venta.

Anexo 7. Ambiente sedimentario. Formación Las Mesitas, Grupo La Venta.

Anexo 8. Polen fósil del Grupo La Venta nominado según su afinidad actual.

Anexo 9. Atlas del polen fósil de la Formación San Alfonso, Grupo La Venta.

Anexo 10. Atlas del polen fósil de la Formación La Victoria, Grupo La Venta.

Anexo 11. Atlas del polen fósil de la Formación Villavieja, Grupo La Venta.

- Anexo 12. Lista de mamíferos fósiles del Grupo La Venta registrados en la presente investigación y en literatura.

- Anexo 13. Atlas de vertebrados fósiles del Grupo La Venta.

- Anexo 14. Atlas de mamíferos fósiles del Grupo La Venta.

- Anexo 15. Primates fósiles del Grupo La Venta.

- $\quad$ Anexo 16. Paleohábitat, Formación San Alfonso, Grupo La Venta.

- Anexo 17. Paleohábitat, Formación La Victoria, Grupo La Venta.

- Anexo 18. Paleohábitat, Formación Cerbatana, Grupo La Venta.

- Anexo 19. Paleohábitat, Formación Villavieja, Grupo La Venta.

- Anexo 20. Paleohábitat, Formación Las Mesitas, Grupo La Venta.

- Anexo 21. Paleoambiente, Formación San Alfonso, Grupo La Venta.

- Anexo 22. Paleoambiente, Formación La Victoria, Grupo La Venta.

- Anexo 23. Paleoambiente, Formación Cerbatana, Grupo La Venta.

- Anexo 24. Paleoambiente, Formación Villavieja, Grupo La Venta.

- Anexo 25. Paleoambiente, Formación Las Mesitas, Grupo La Venta.

- Anexo 26. Asociaciones propuestas de los Primates fósiles, Grupo La Venta.

- $\quad$ Anexo 27. Propuesta de la Fauna Laventense. 


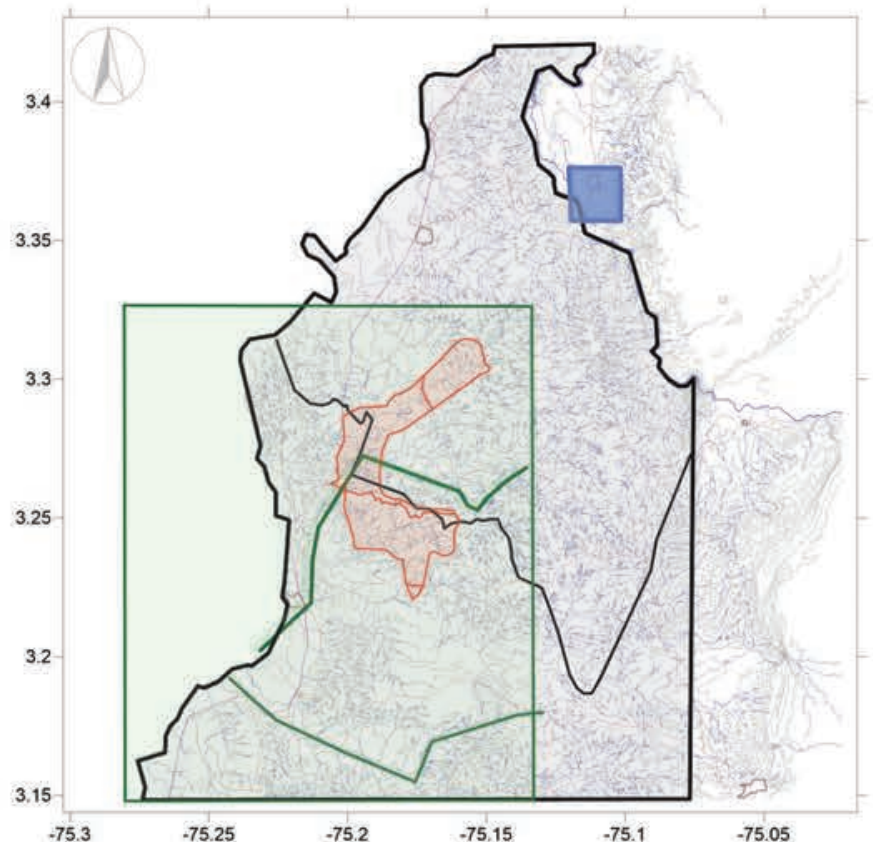

Cartografía de Royo y Gómez (1942 b)

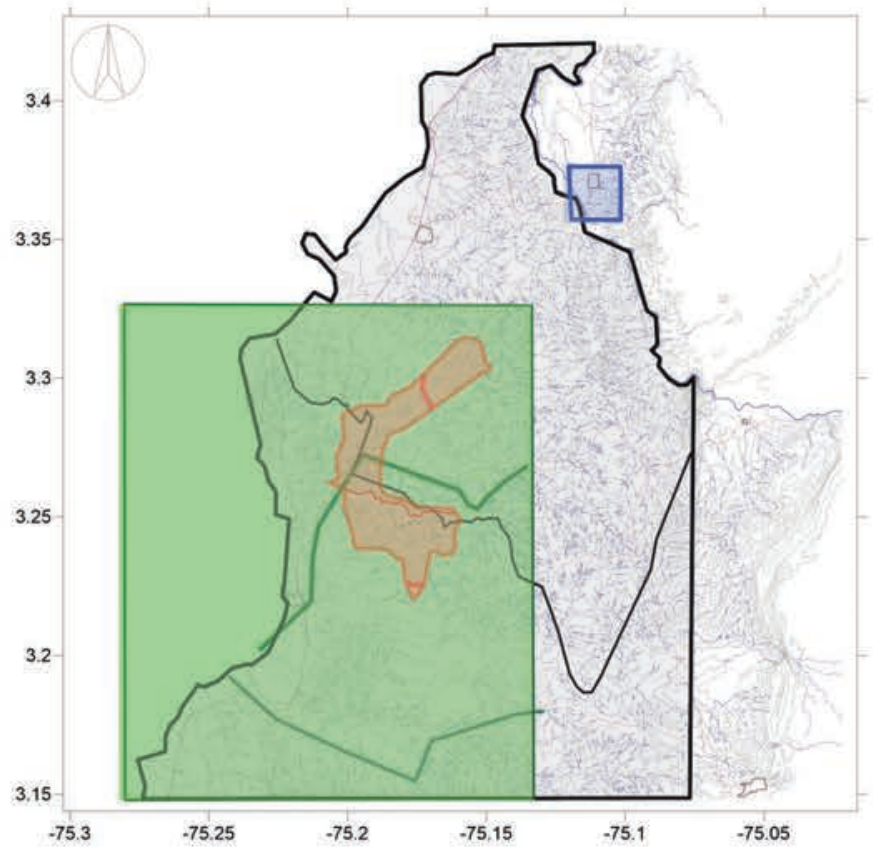

Cartografia de Guerrero $(1993,1997)$
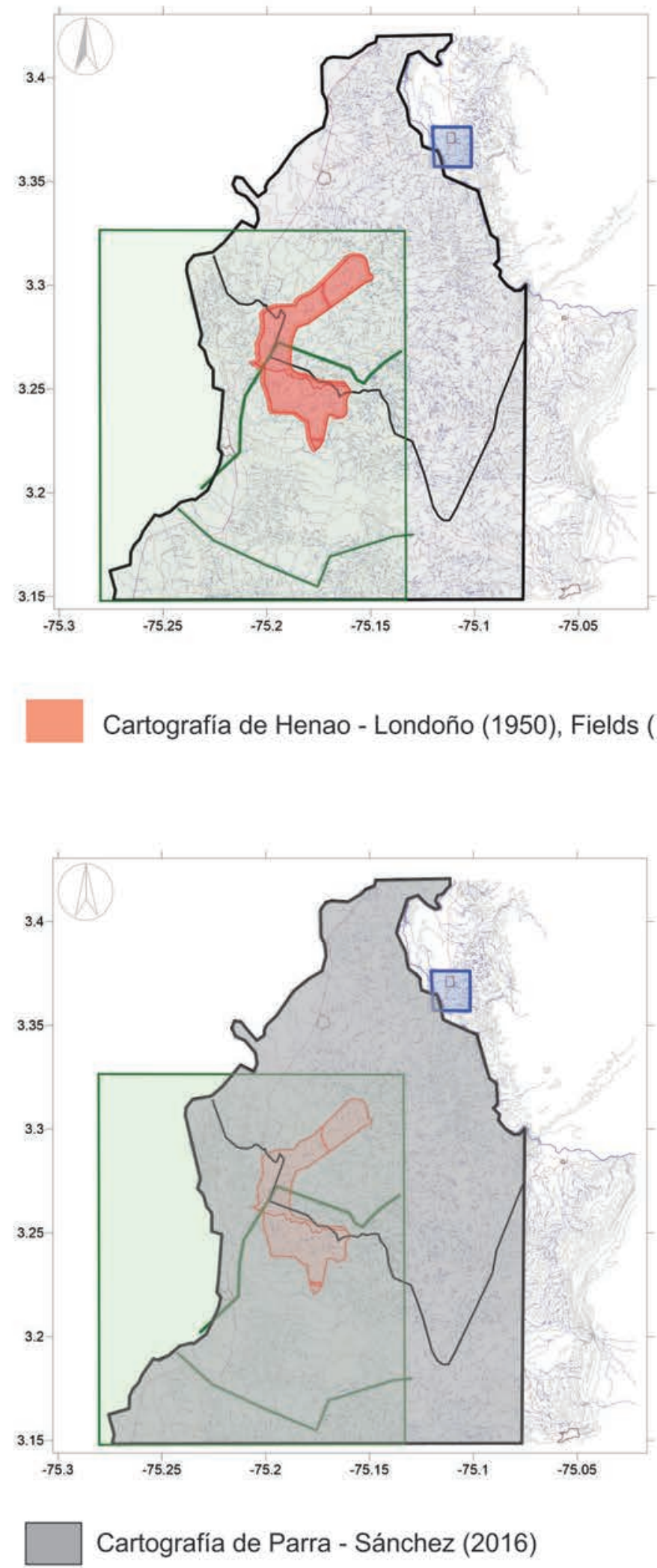

Figura 1. Etapas de la cartografia del Grupo La Venta desde 1950 hasta el 2016. 


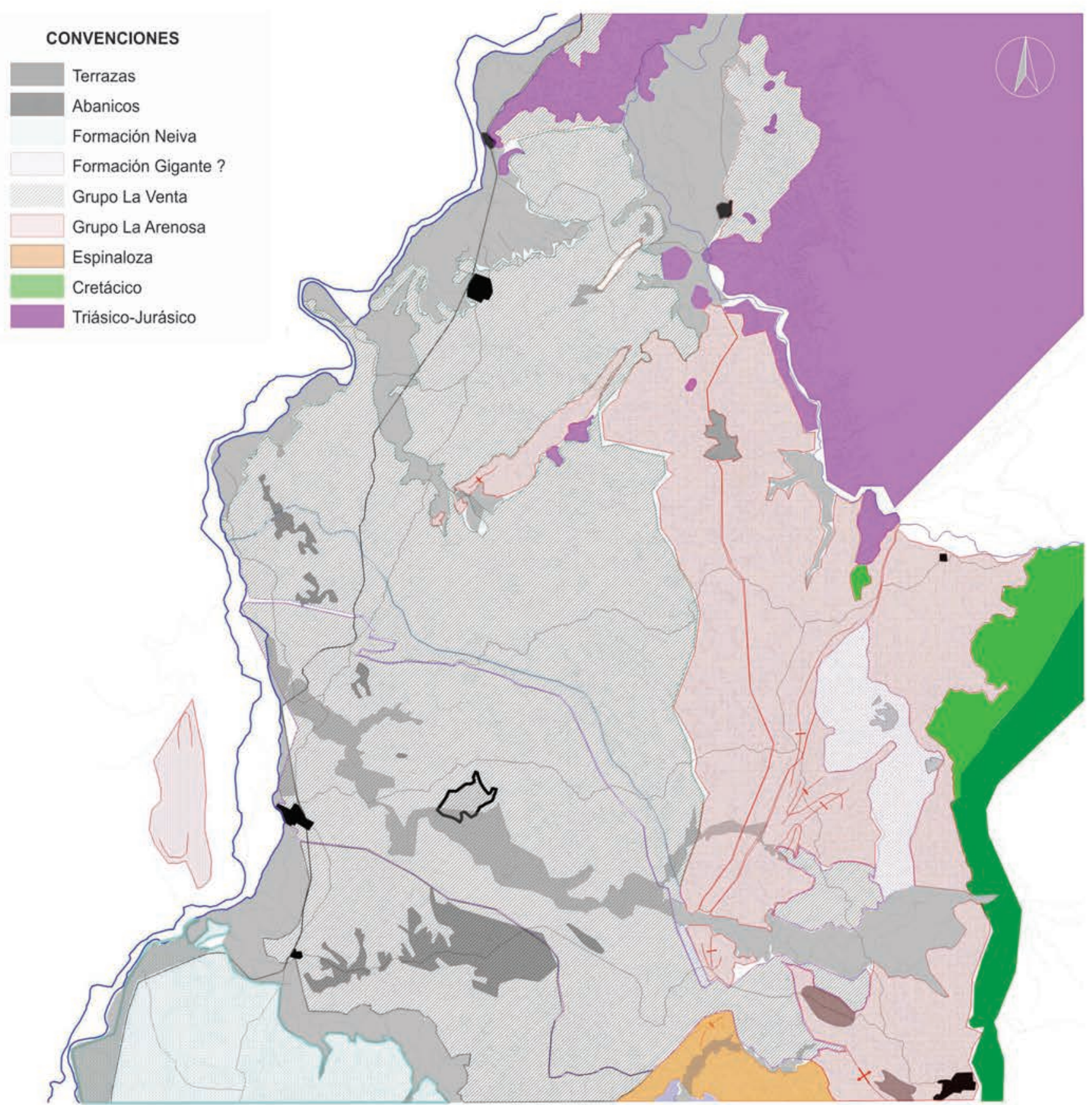

Mapa elaborado por Luis Norberto Parra-Sánchez, Universidad Nacional de Colombia, Facultad de Ciencias, Medellín, 2016

Figura 2. Litoestratigrafía del Neógeno del Desierto de la Tatacoa, Huila, Colombia, 2016. 


\section{CONVENCIONES}

Formación San Alfonso

Formación La Victoria

Formación Cerbatana

Formación Villavieja

Formación Las Mesitas

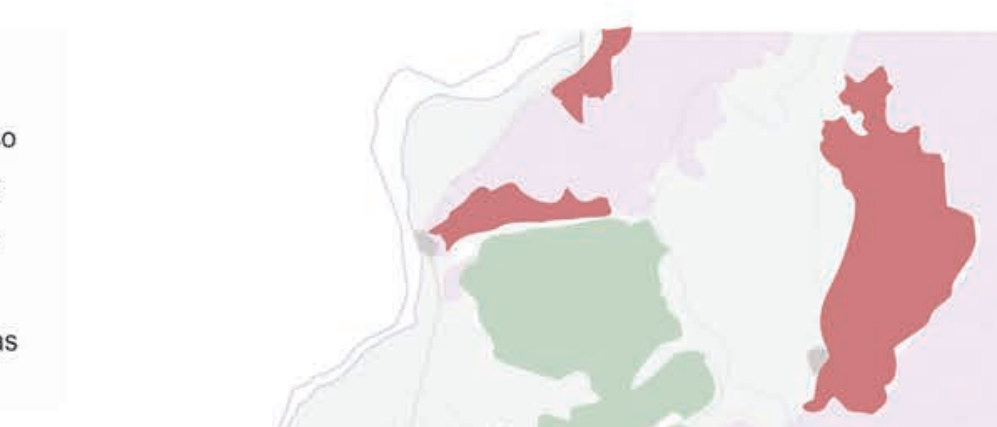




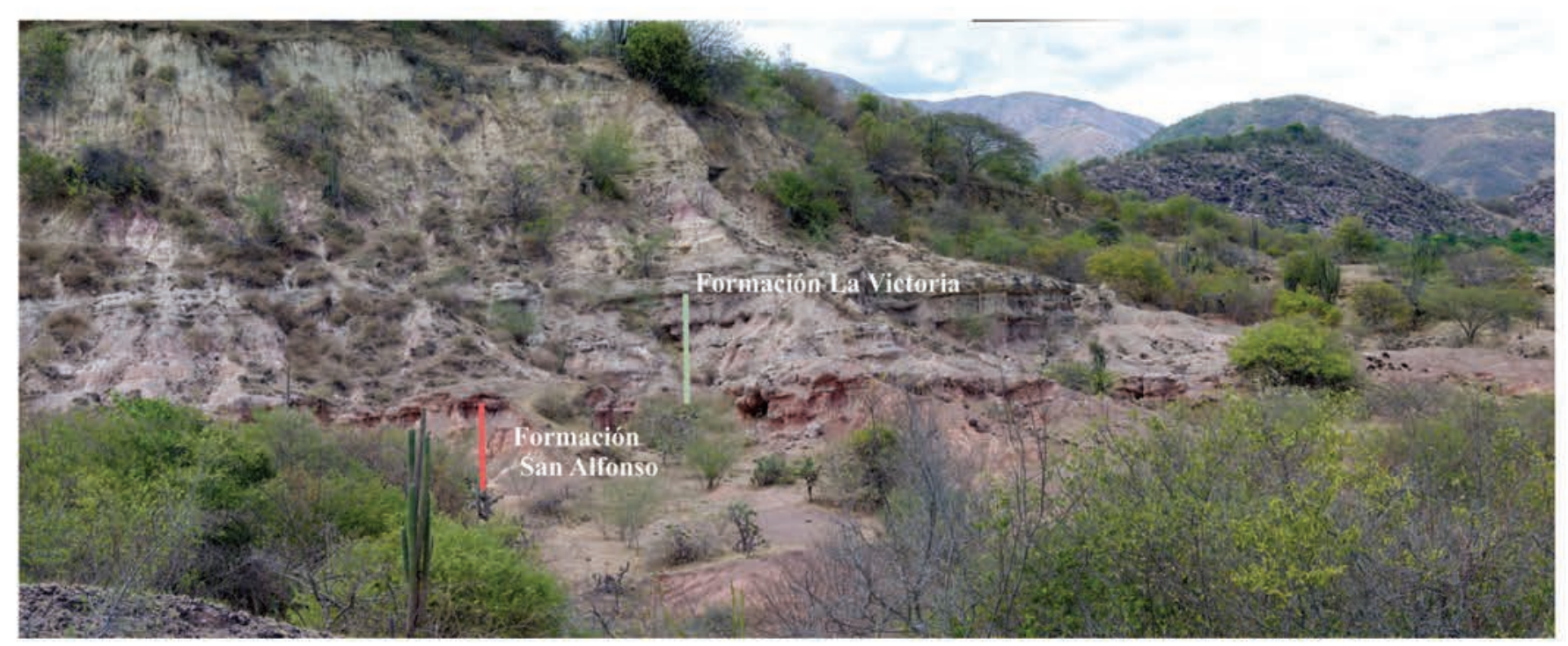

(a)

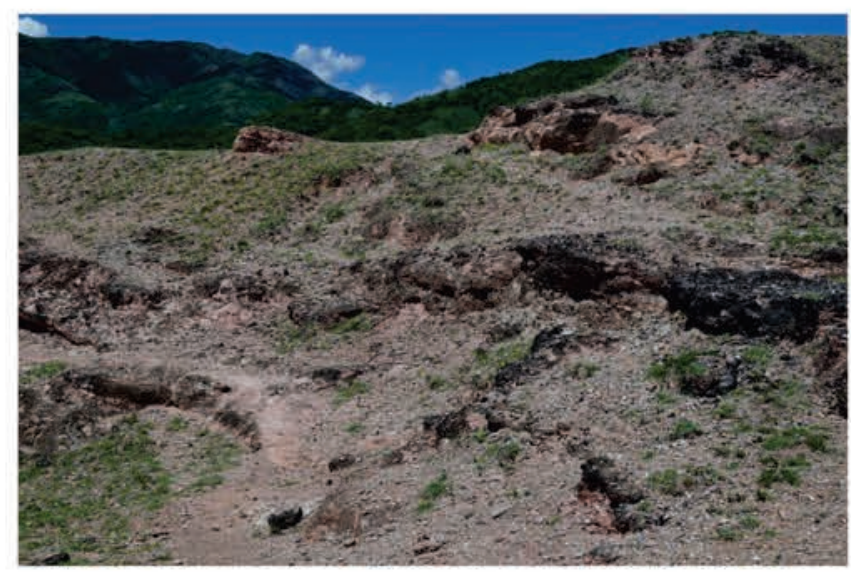

(b)

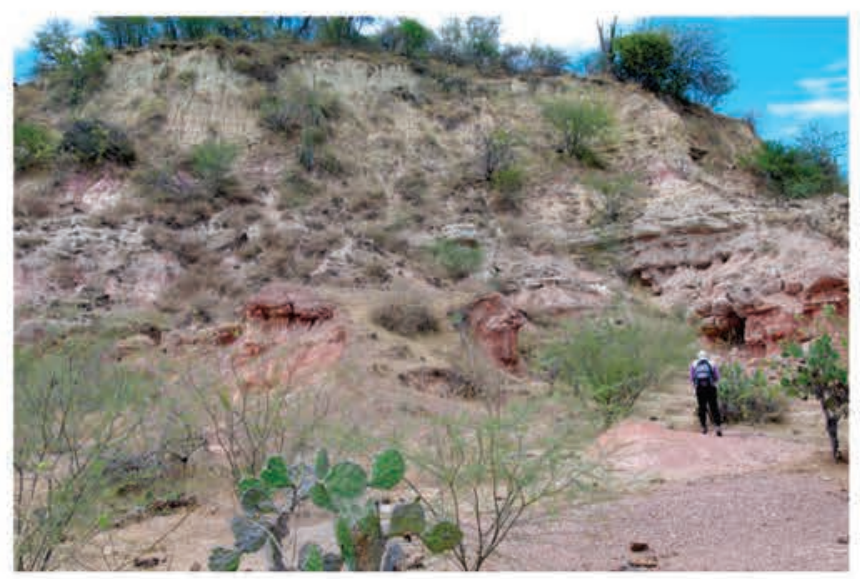

(c)

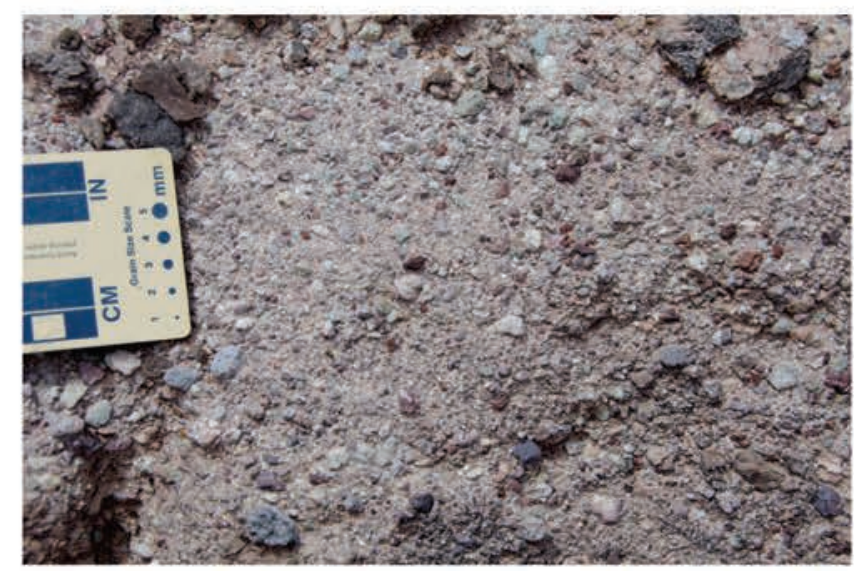

(d)

Figura 4. (a) Afloramiento de la Formación San Alfonso, Grupo La Venta. Espesor: línea verde: $10 \mathrm{~m}$, aproximadamente; línea roja: $6 \mathrm{~m}$, aproximadamente (Luis Norberto Parra-Sánchez com. pers. abril 2018). (b) (c) (d) Cantos rodados, gruesos de coloración rosada; se evidencian canales de abanico aluvial.

Fotografías: a. Yaneth Muñoz-Saba. b, c, d. Luis Norberto Parra-Sánchez. 


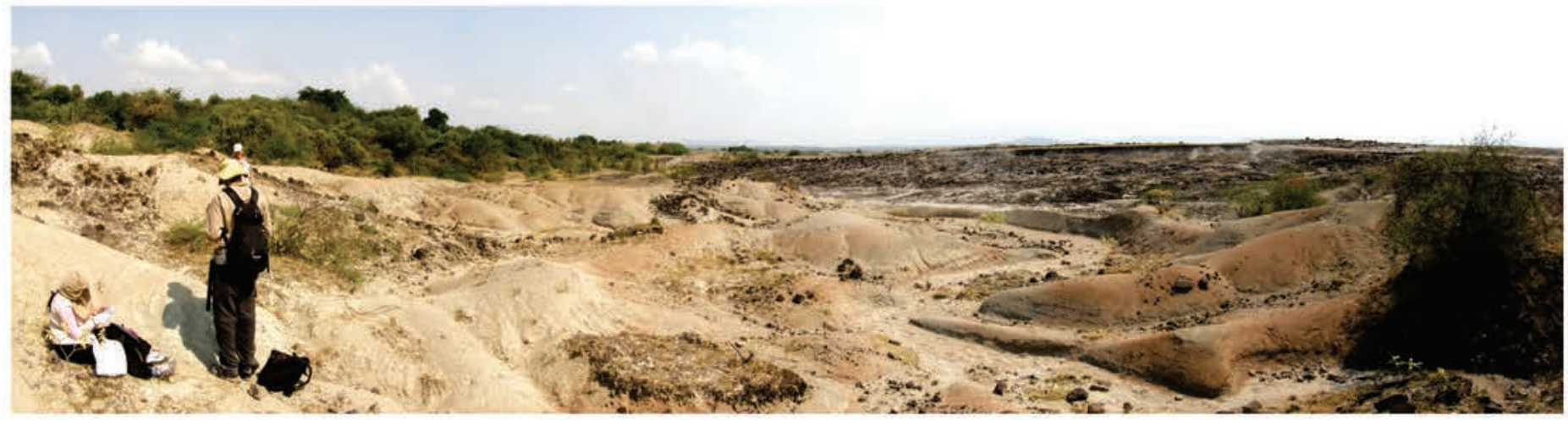

(a)

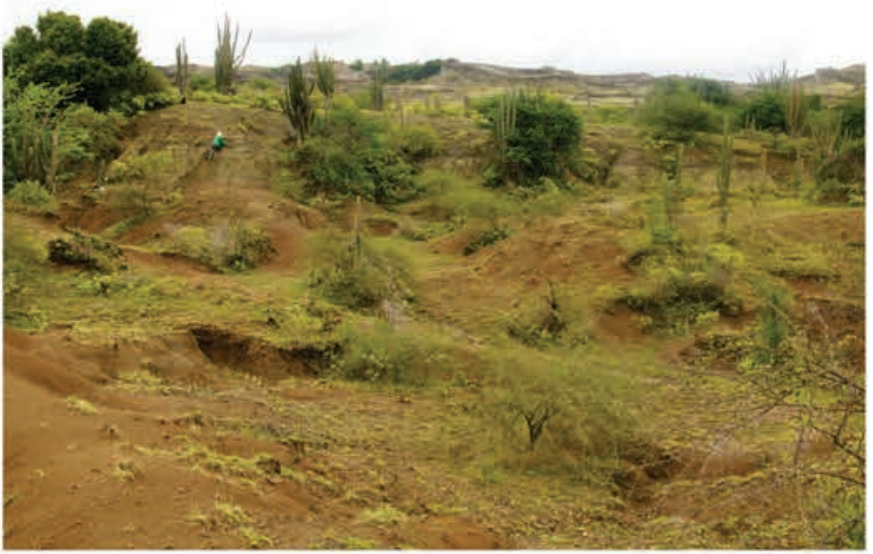

(b)

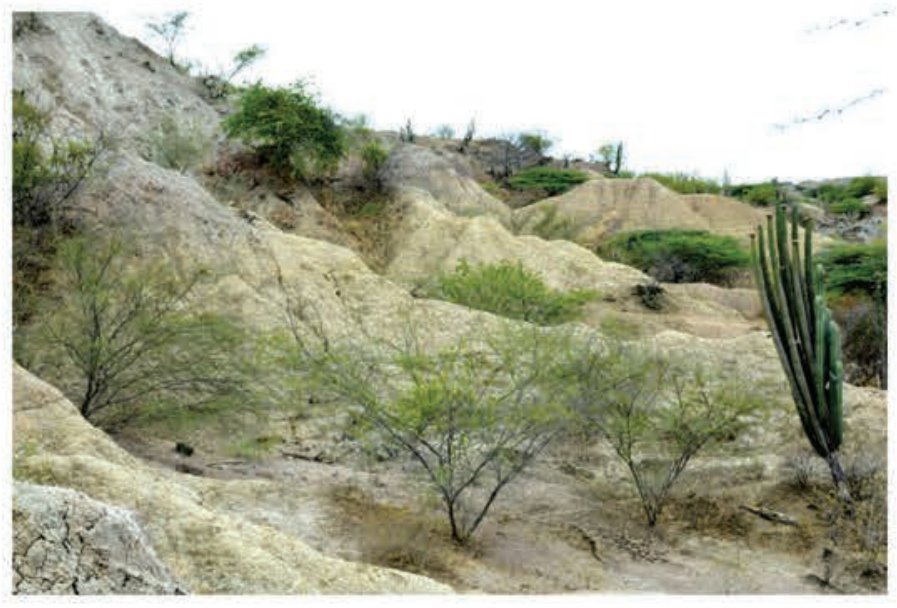

(c)

Figura 5. Afloramientos de la Formación La Victoria, Grupo La Venta. (a) (b) Areniscas de San Nicolás; (c) Capa de Los Lagos. Fotografías: Grupo de Investigación Evolución y Ecología de Mamíferos Neotropicales (EEMN). 


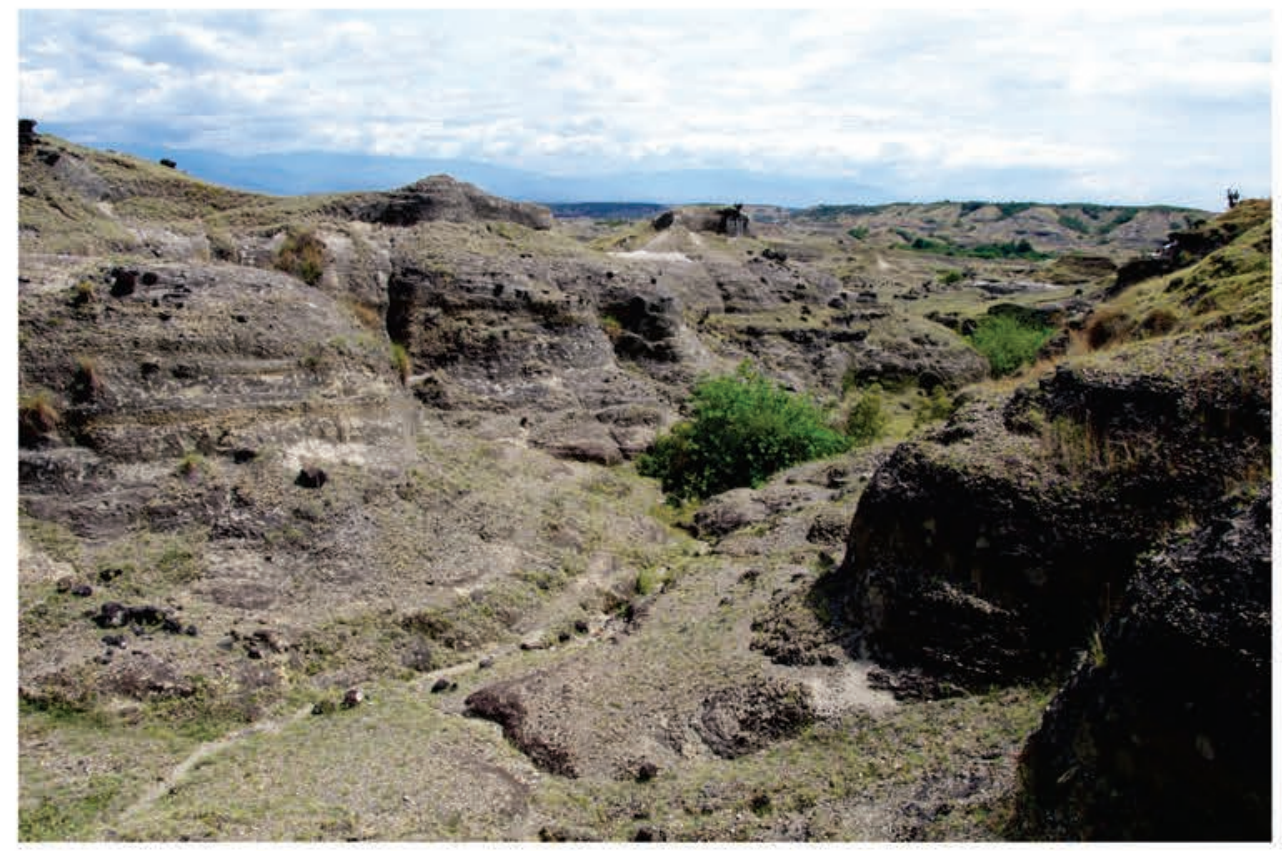

(a)

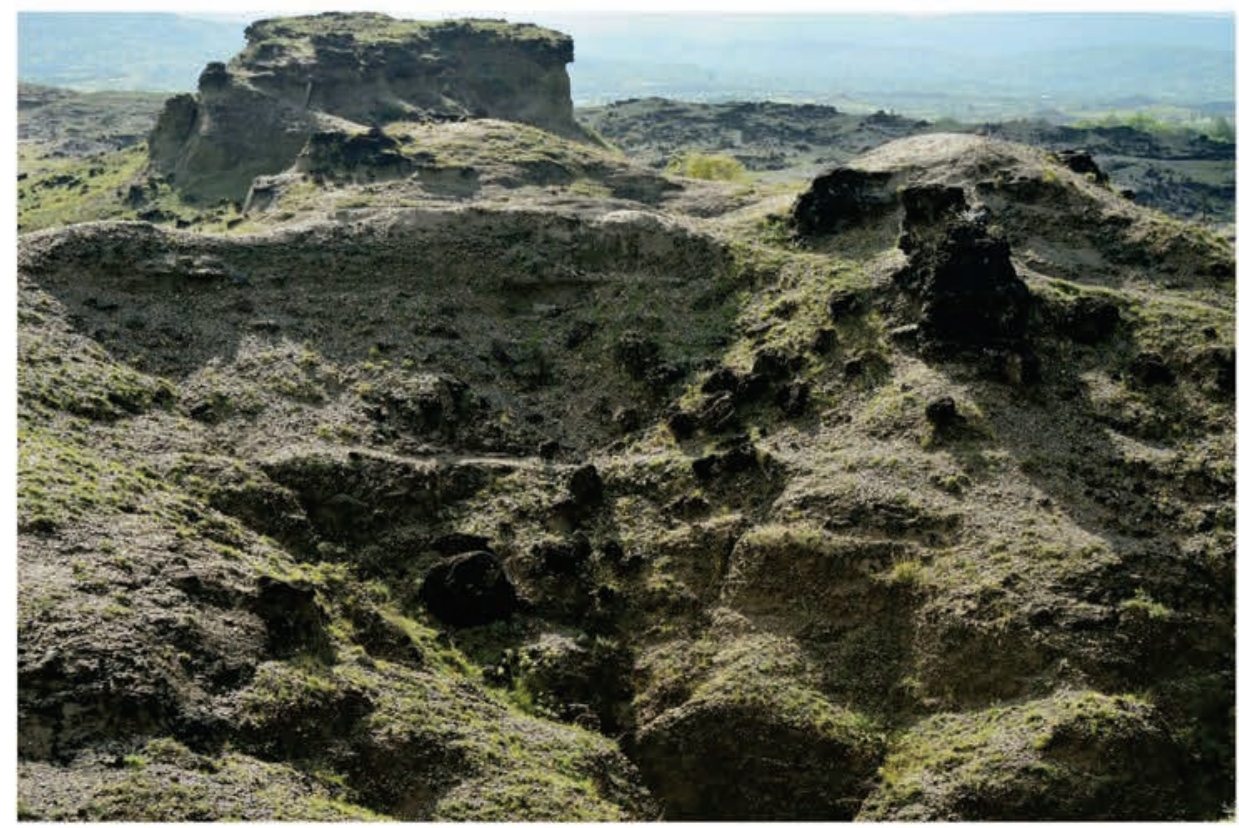

(b)

Figura 6. Afloramiento de la Formación Cerbatana, Grupo La Venta. (a) (b) Cauces fluviales de un sistema entrelazado (Luis Norberto Parra-Sánchez com. pers. abril 2018).

Fotógrafo: Luis Norberto Parra-Sánchez. 


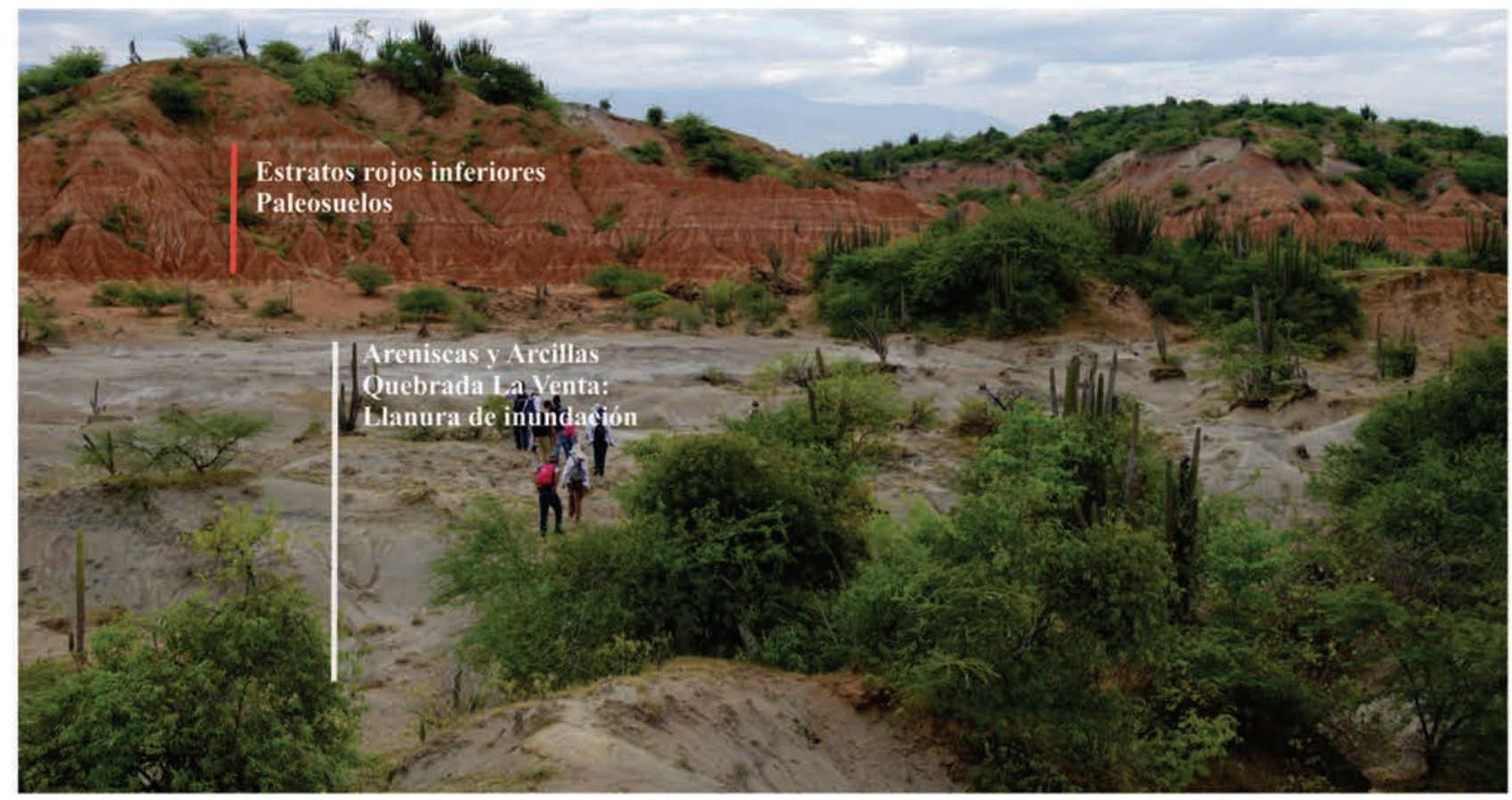

(a)

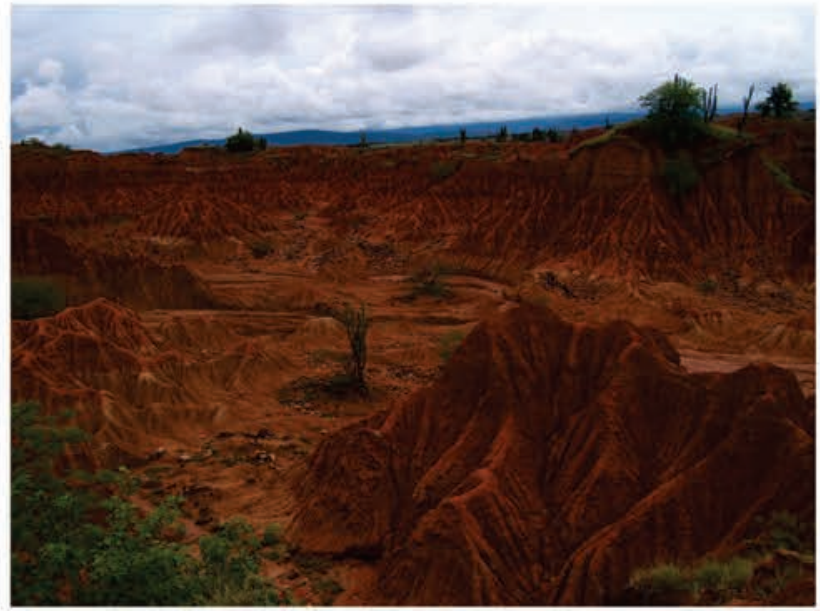

(b)

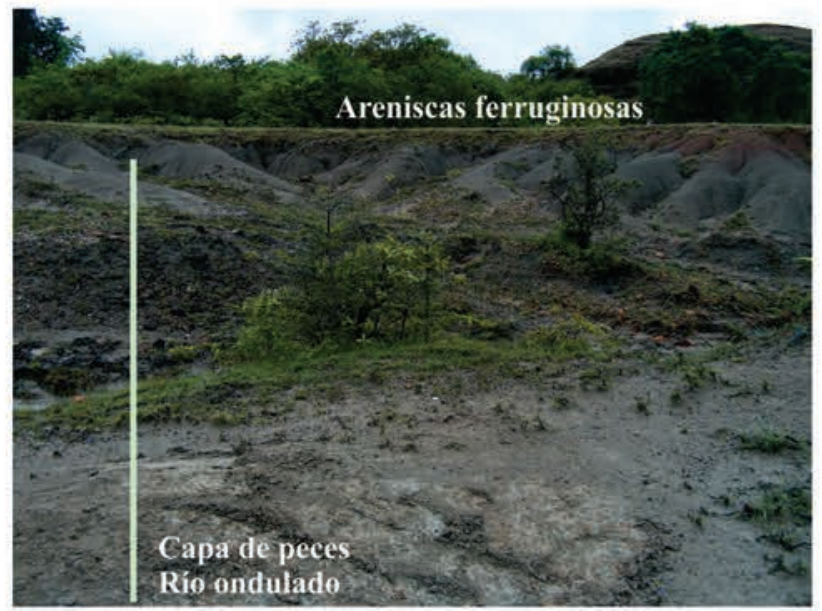

(c)

Figura 7. Afloramientos de la Formación Villavieja, Grupo La Venta. (a) (b) Monkey Unit: limos y arcillas de color gris a rojizo. (c) La Venta Clays and Sandstones: arenisca de color gris, Fish Beds: arenas de color verde.

Fotografías: Grupo de Investigación Evolución y Ecología de Mamíferos Neotropicales (EEMN). 


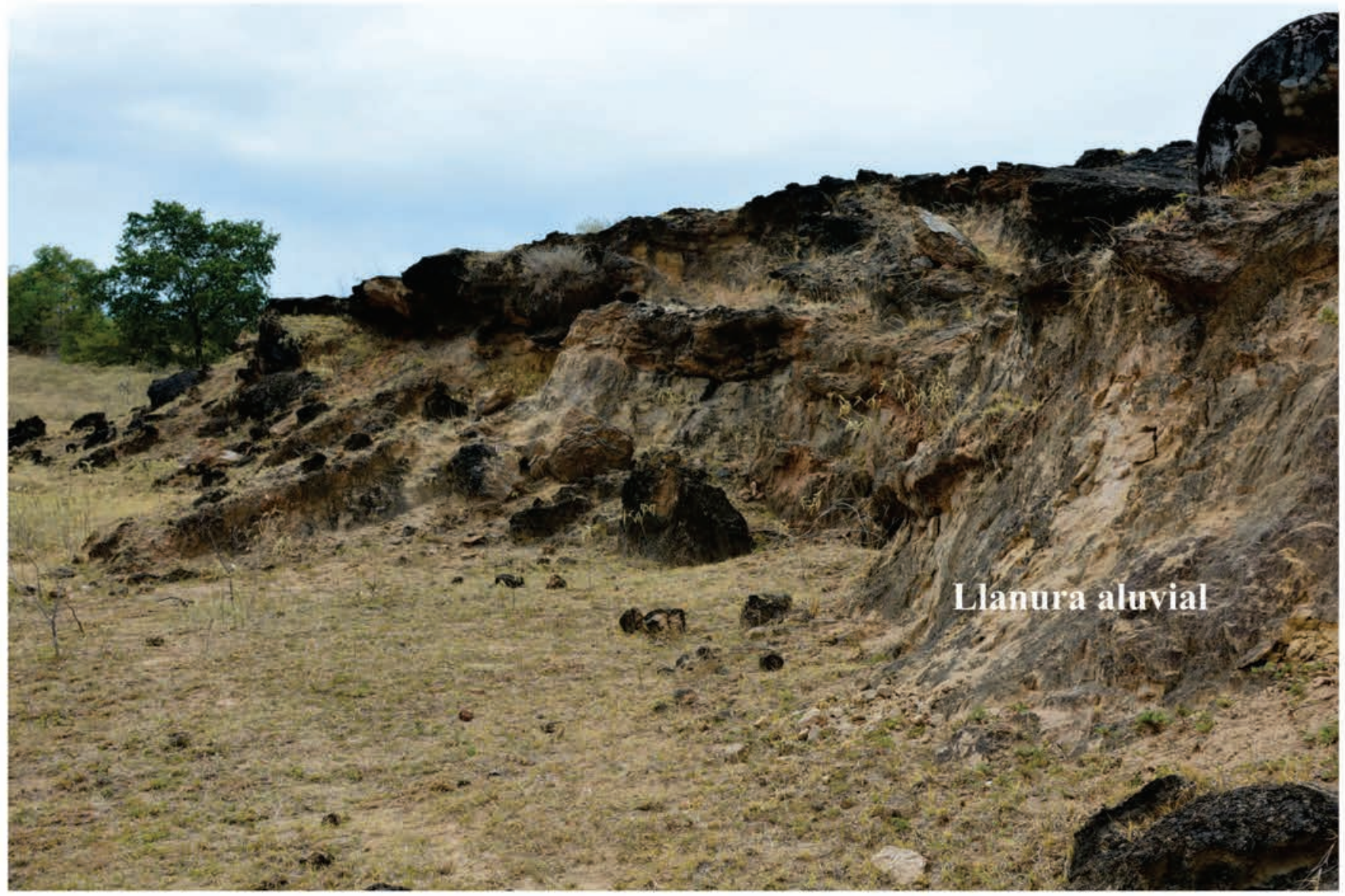

Figura 8. Afloramiento de la Formación Las Mesitas, Grupo La Venta. Litologia: capas de estructura lenticular; el afloramiento evidencia un subambiente de canal pequeño (Luis Norberto Parra-Sánchez com. pers. abril 2018).

Fotógrafo: Luis Norberto Parra-Sánchez. 


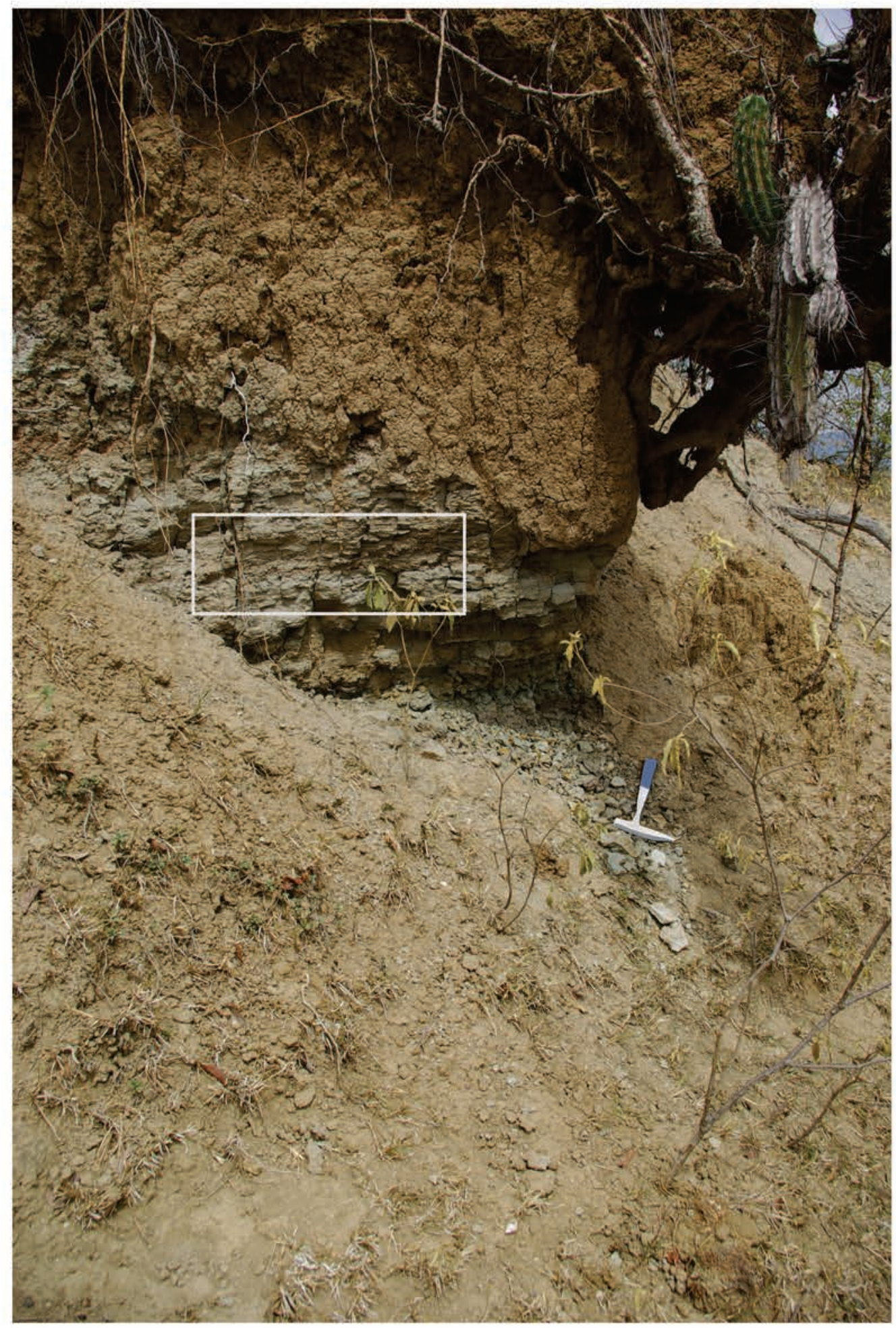

Figura 9. Limos arcillosos donde se realizaron muestreos de polen fósil. Formación La Victoria, Grupo La Venta. Escala del martillo: $30 \mathrm{~cm}$.

Fotógrafo: Luis Norberto Parra-Sánchez. 


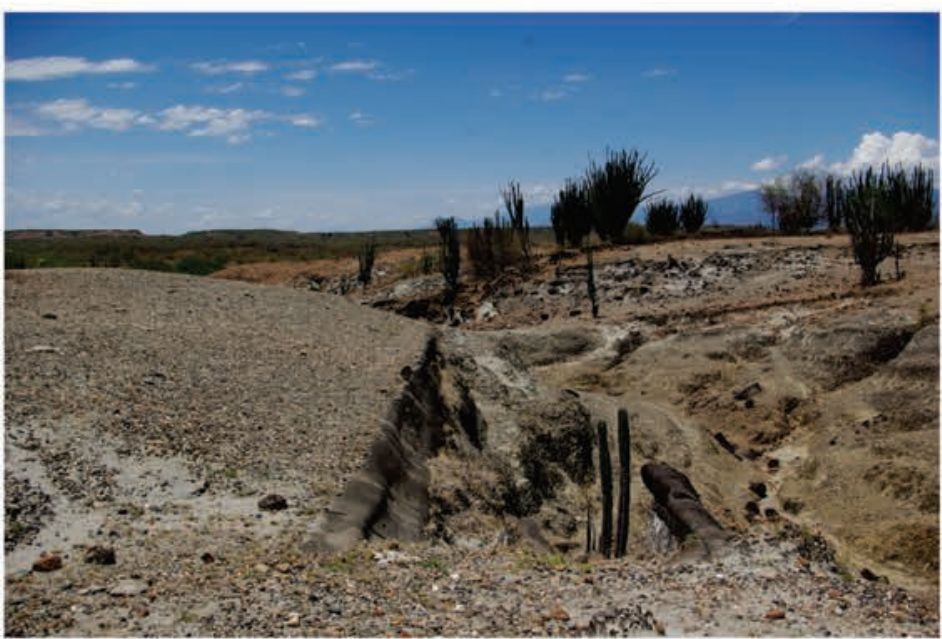

(a)

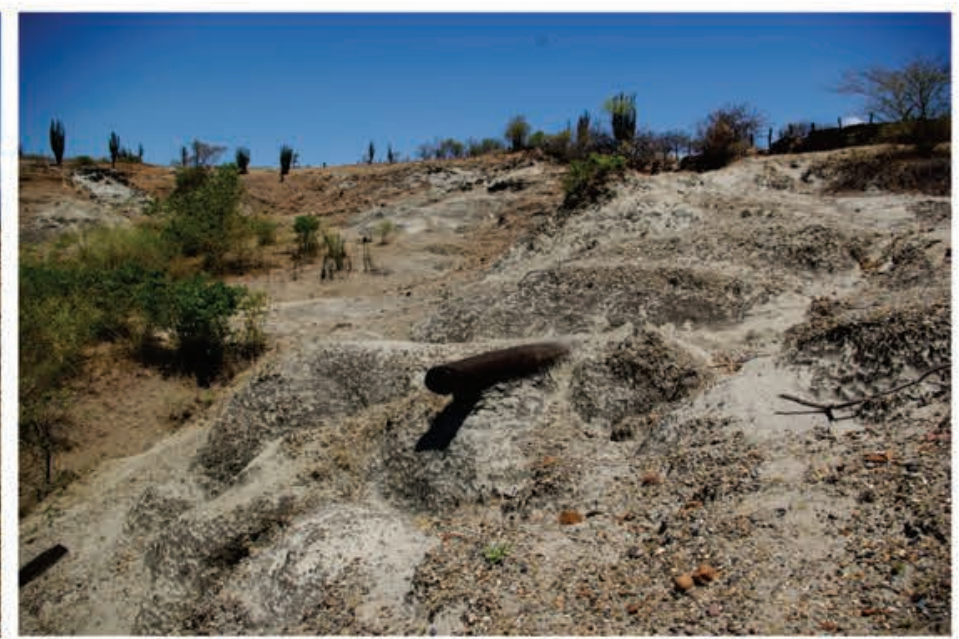

(b)

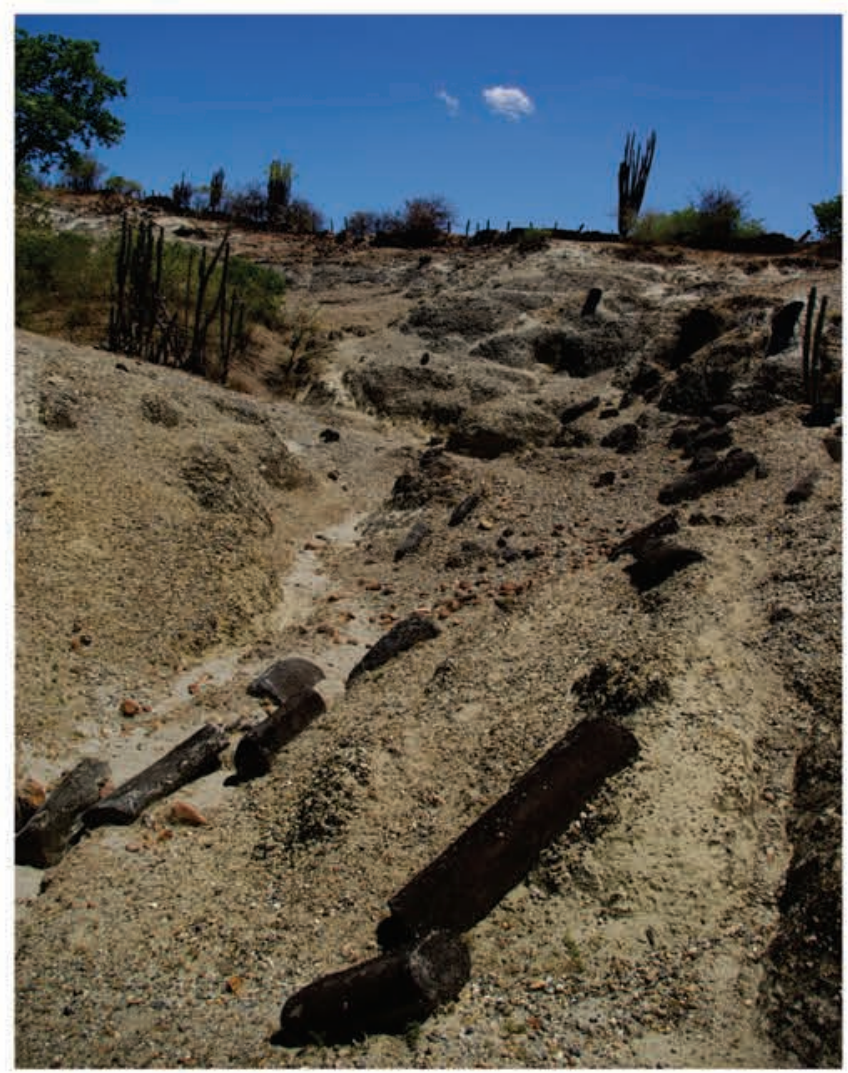

(c)

Figura 10. Molde de troncos vegetales dentro de bancos de arenas. Orientación: W-NW. Longitud: 4 m aproximadamente, el más largo. Formación Las Mesitas, Grupo La Venta.

Fotógrafo: Yaneth Muñoz Saba. 
(a)

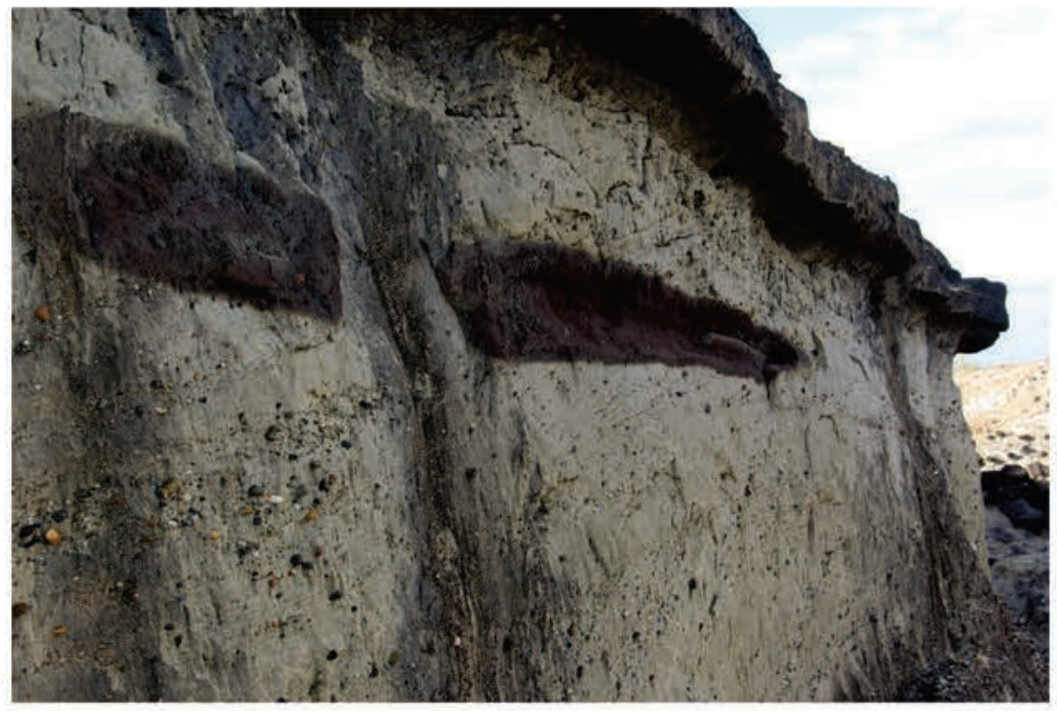

(b)

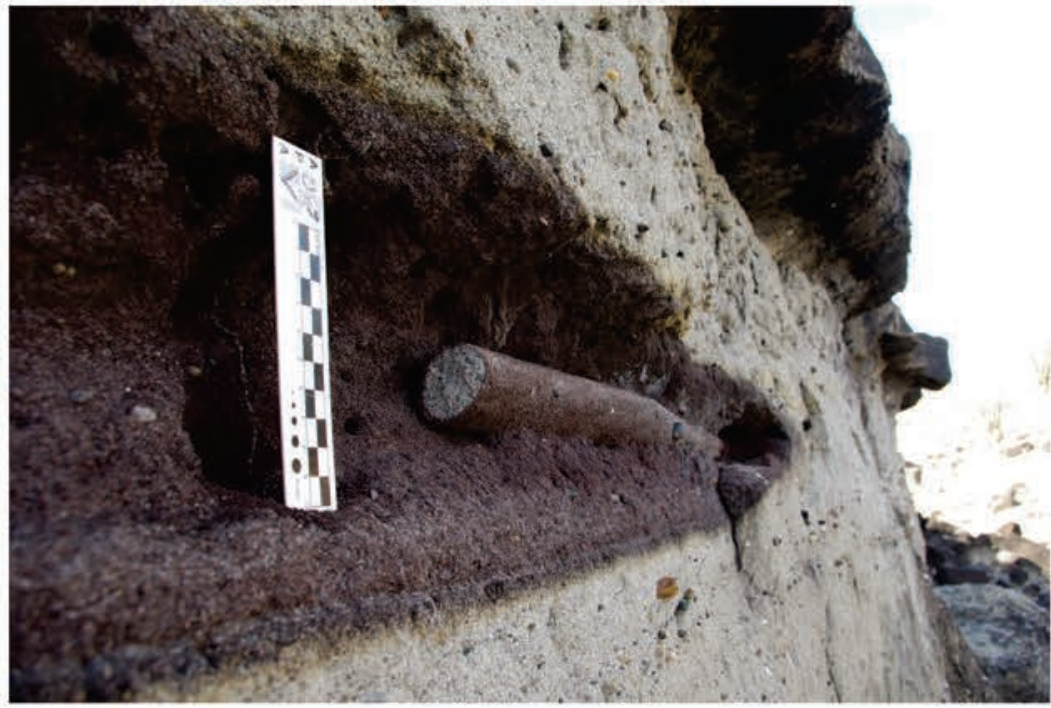

(c)

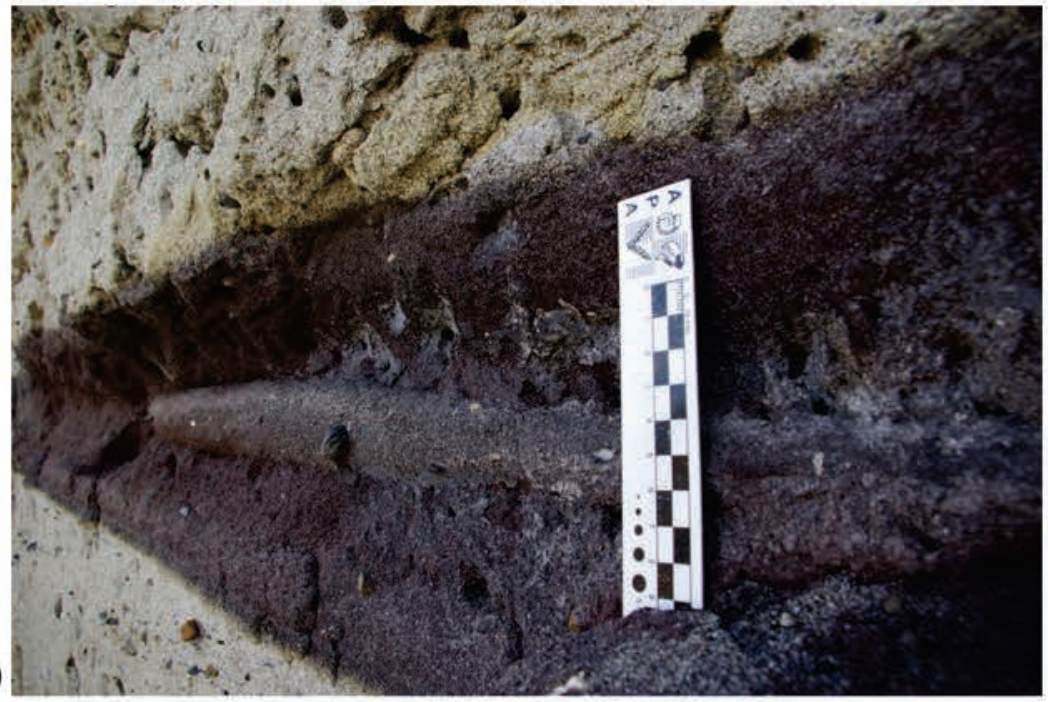

Figura 11. Proceso de formación de los moldes de troncos vegetales. Orientación: W-NW. Formación Las Mesitas, Grupo La Venta.

Fotógrafo: Yaneth Muñoz-Saba. 


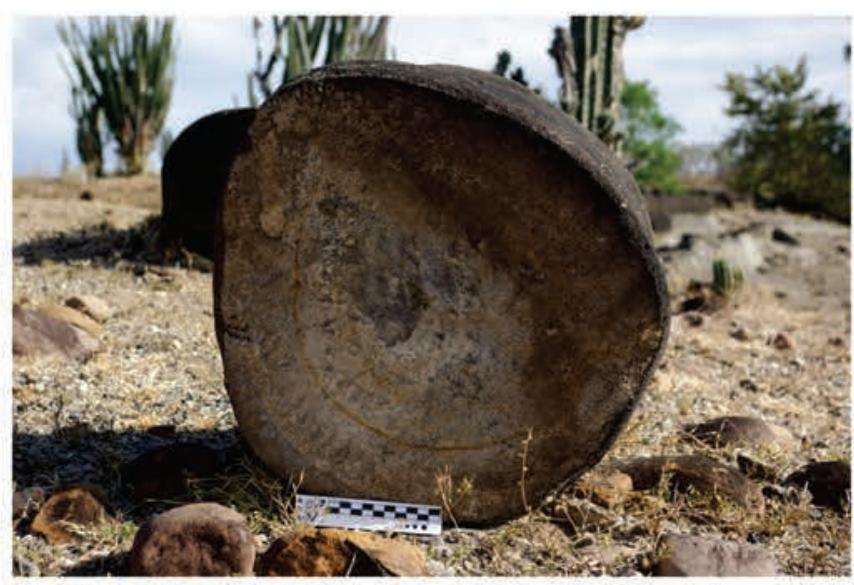

(a)

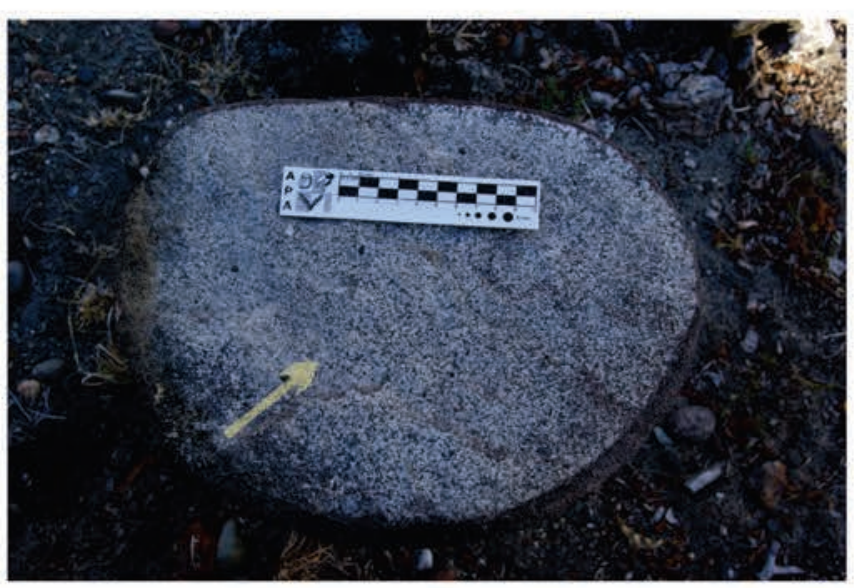

(b)

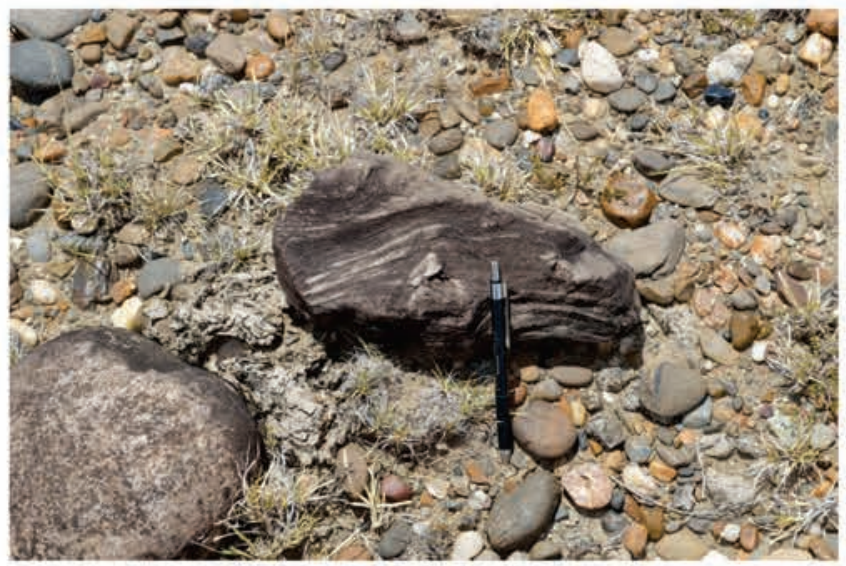

(c)

Figura 12. Moldes de troncos vegetales, Formación Las Mesitas, Grupo La Venta. (a) Se diferencia la parte medular (color amarillo ocre); (b) No se diferencia la parte medular; (c) Estructura de madera.

Fotografias: a, b. Yaneth Muñoz-Saba. c. Luis Norberto Parra-Sánchez. 


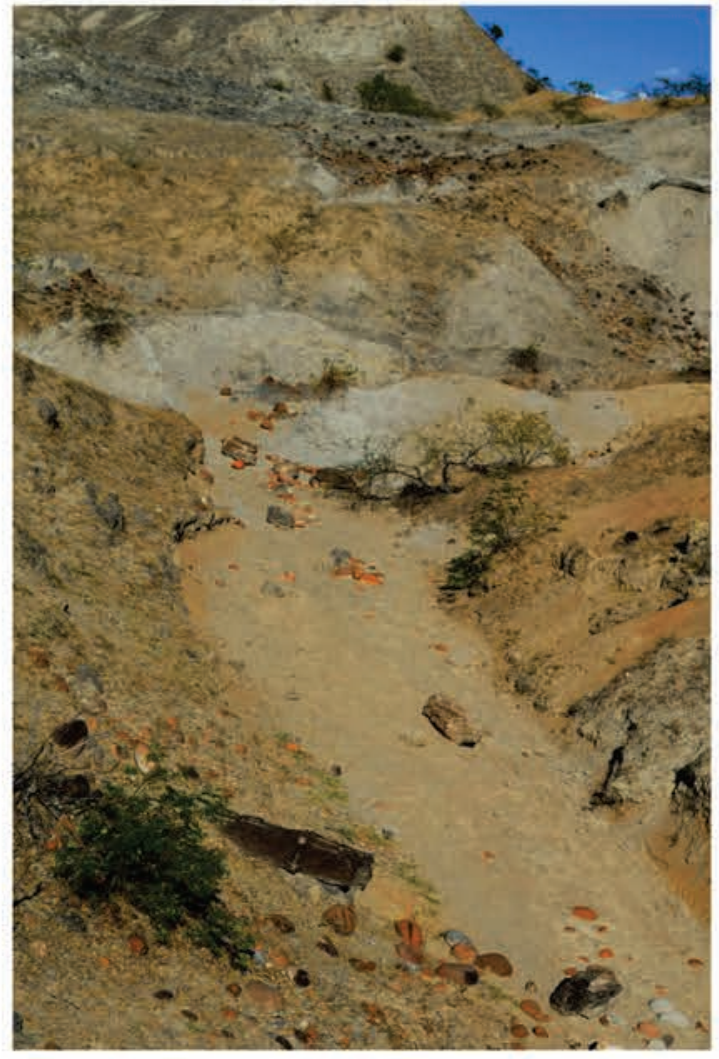

(a)

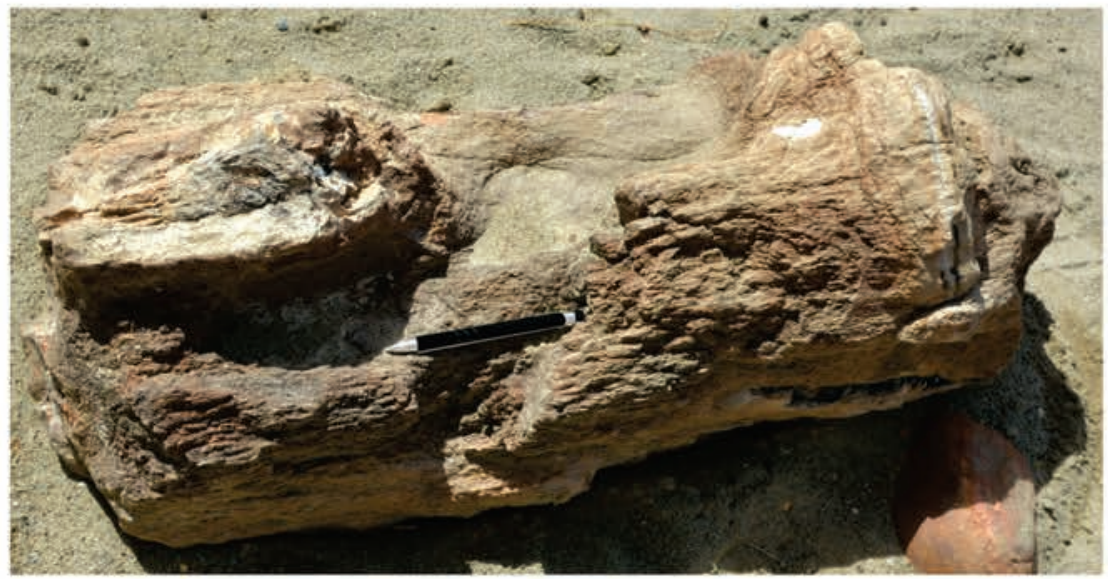

(b)

Figura 13. Xilópalo, Mioceno inferior, Grupo Honda. Escala foto (b), boligrafo de $15 \mathrm{~cm}$.

Fotógrafo: Luis Norberto Parra-Sánchez. 


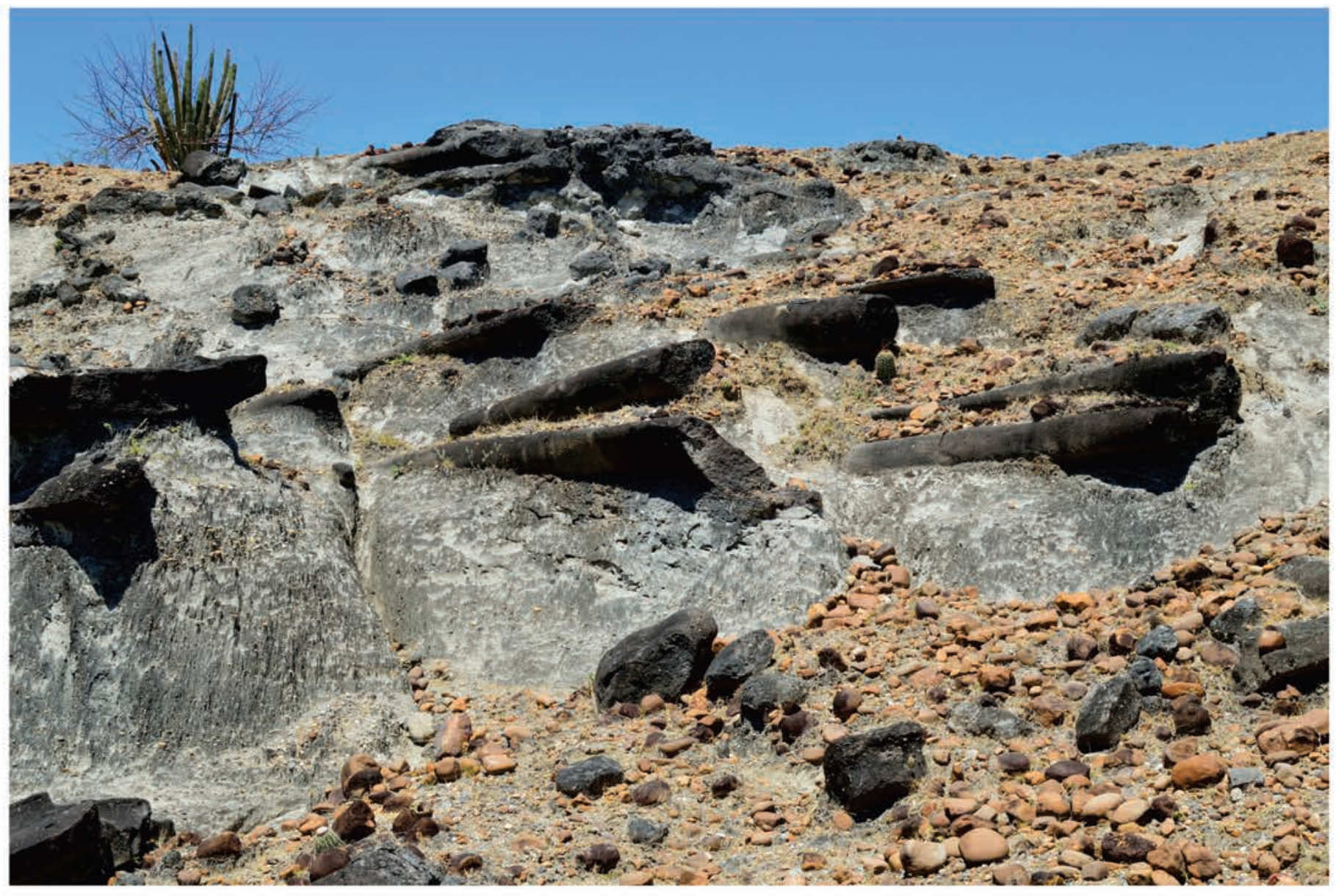

Figura 14. Empalizada de moldes de troncos vegetales. Espesor: $4 \mathrm{~m}$. Orientación: W-NW. Formación Las Mesitas, Grupo La Venta.

Fotógrafo: Yaneth Muñoz-Saba. 


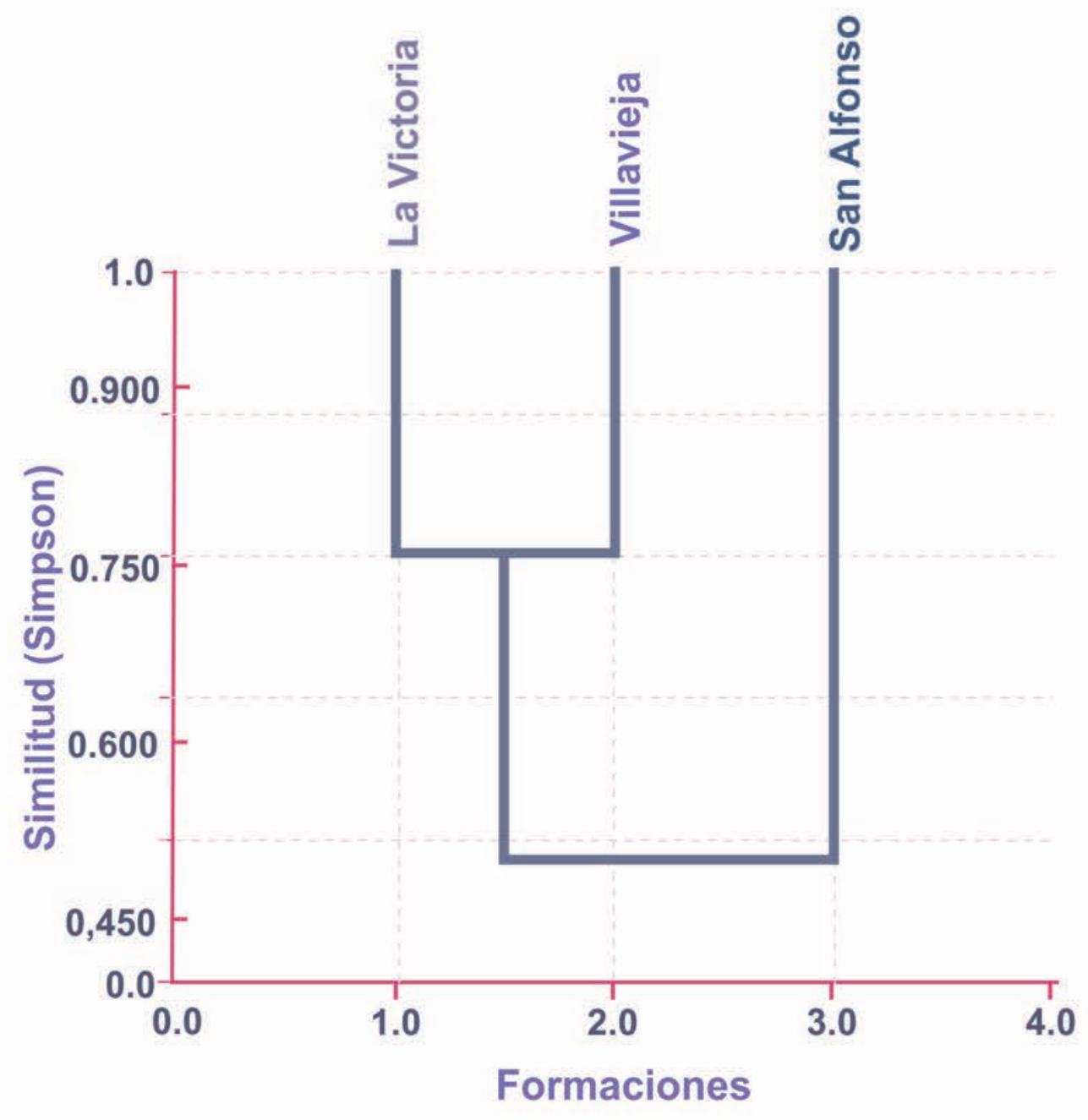

Figura 15. Dendrograma de similitud de polen fósil entre las formaciones del Grupo La Venta. Coeficiente de correlación de Simpson: 0,8322. 


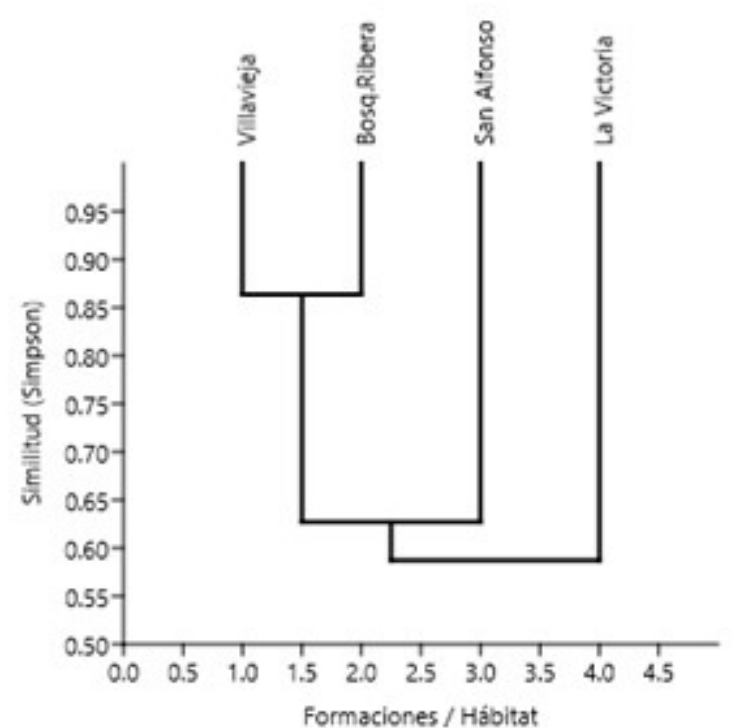

(a)

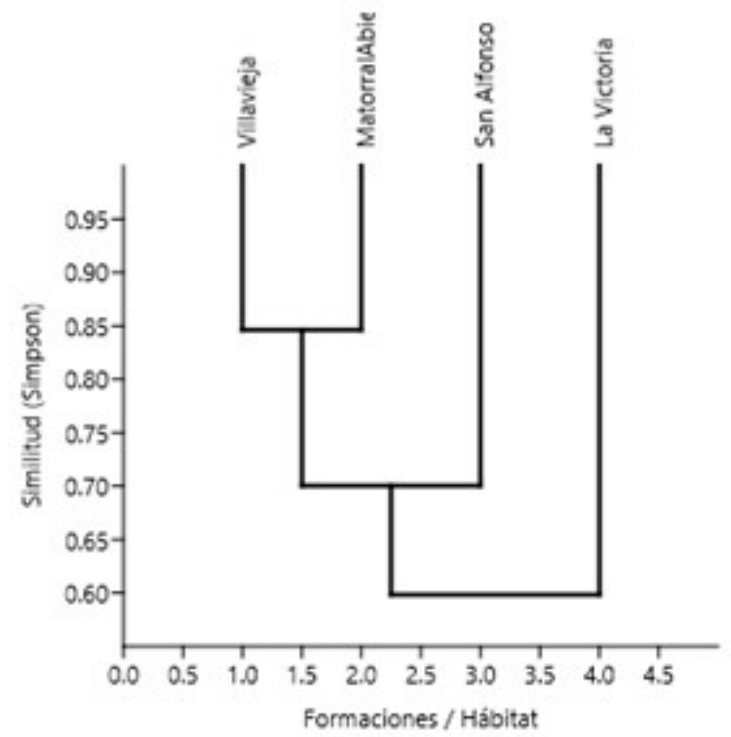

(c)

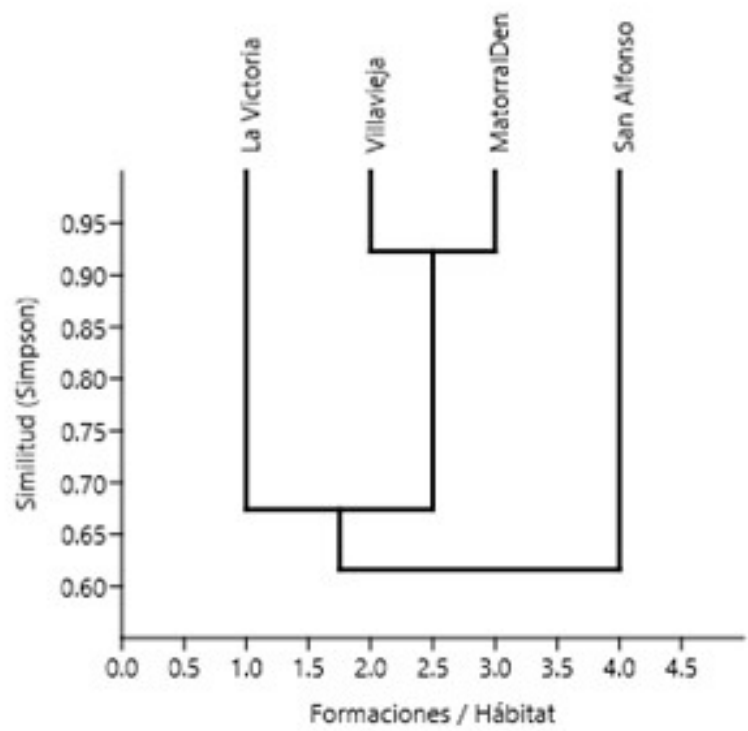

(b)

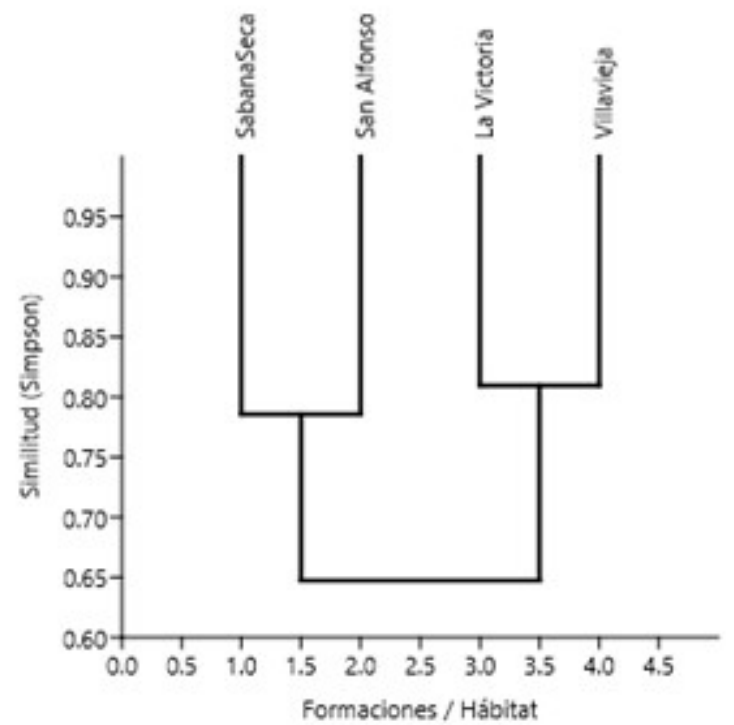

(d)

Figura 16. Dendrograma de similitud entre cada uno de los paleohábitats propuestos y las formaciones del Grupo La Venta. (a) Bosque de ribera, Coeficiente de correlación de Simpson: 0,6235; (b) Matorral denso, Coeficiente de correlación de Simpson: 0,755; (c) Matorral abierto, Coeficiente de correlación de Simpson: 0,6414; (d) Sabana seca, Coeficiente de correlación de Simpson: 0,6397 . 


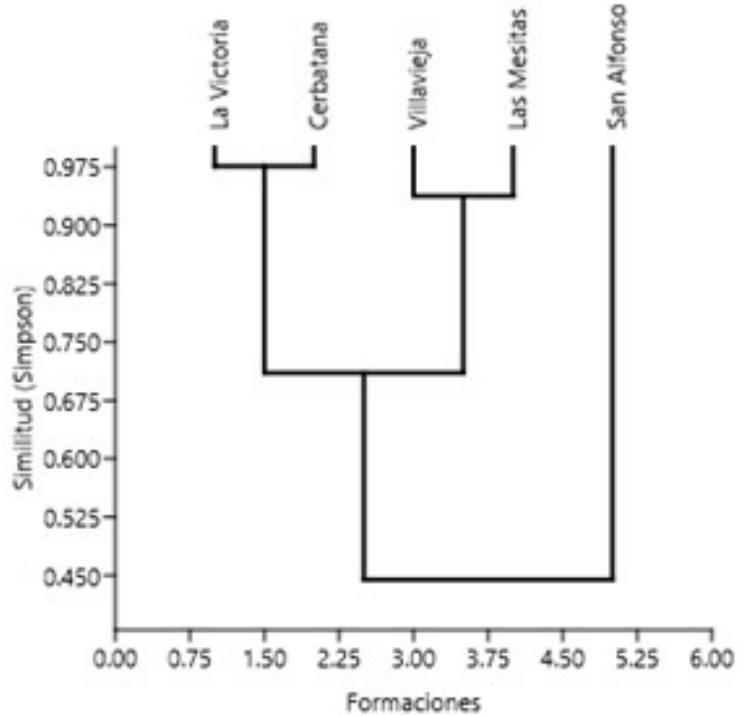

(a)

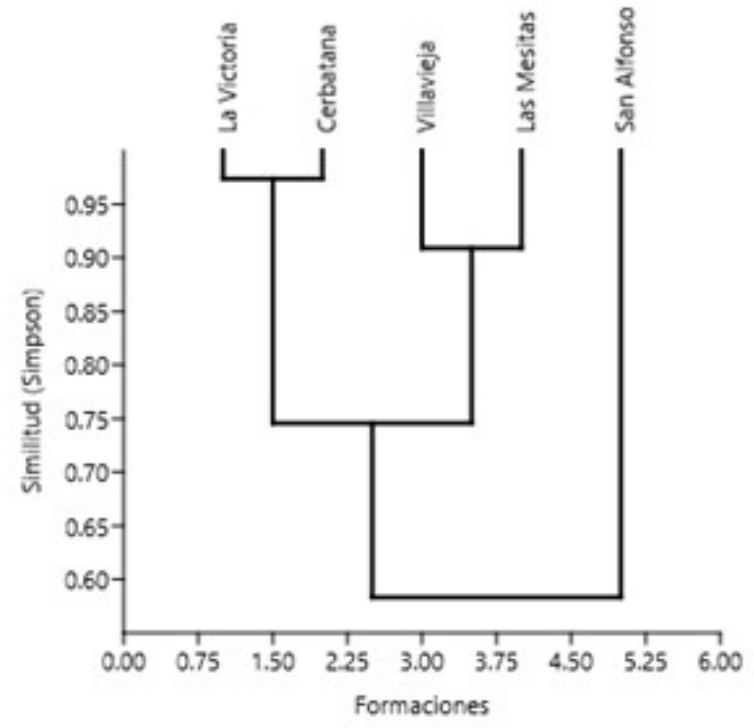

(b)

Figura 17. Dendrograma de similitud de los taxones de vertebrados fósiles registrados para el Grupo La Venta. (a) Vertebrados fósiles. Coeficiente de correlación de Simpson: 0,8312; (b) Mamíferos fósiles. Coeficiente de correlación de Simpson: 0,7201. 


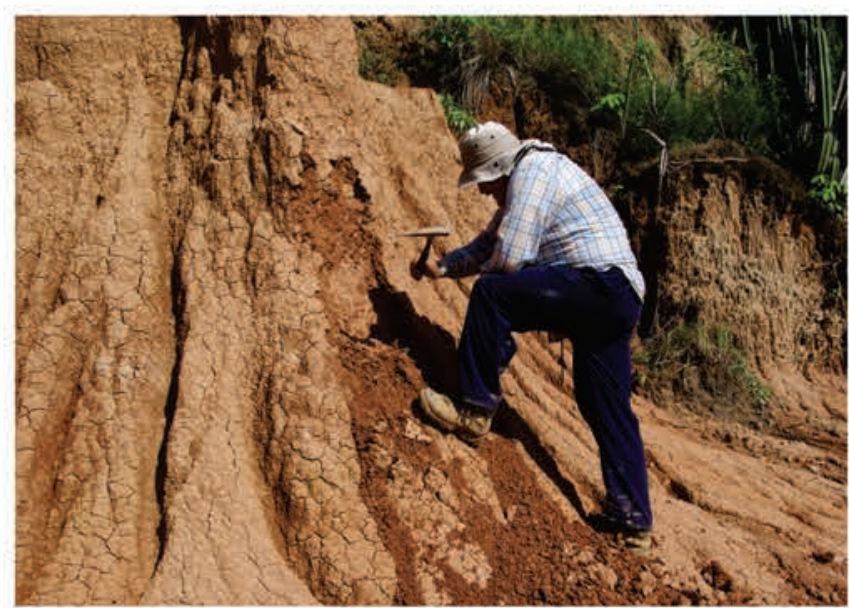

(a)

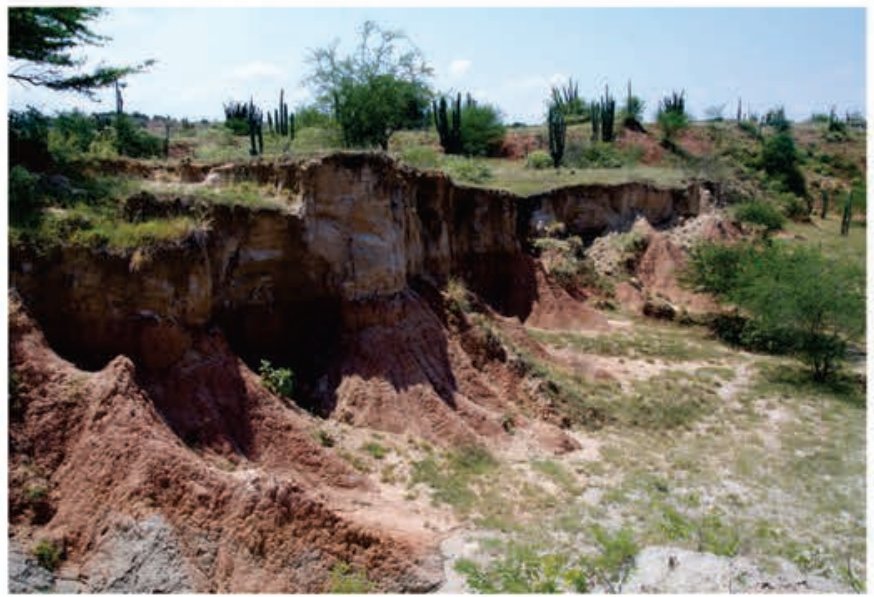

(b)

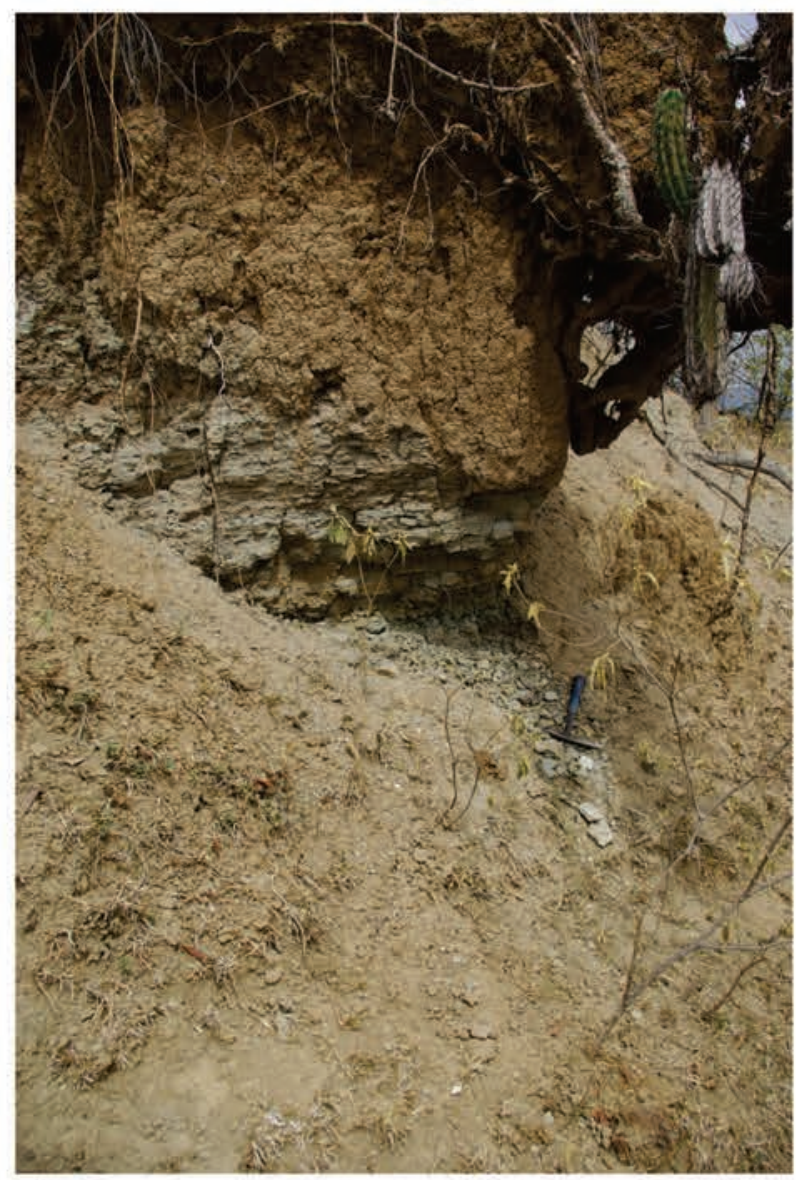

(c)

Figura 18. Paleosuelos, Grupo La Venta. Litología: Limolitas. Tipos de suelos: no nomenclados (María Teresa Flórez Molina y Daniel Jaramillo com. pers. abril 2018). (a) Formación San Alfonso; (b) Formación Villavieja; (c) Formación La Victoria.

Fotografías: a. Yaneth Muñoz-Saba. b-c. Luis Norberto Parra-Sánchez. 


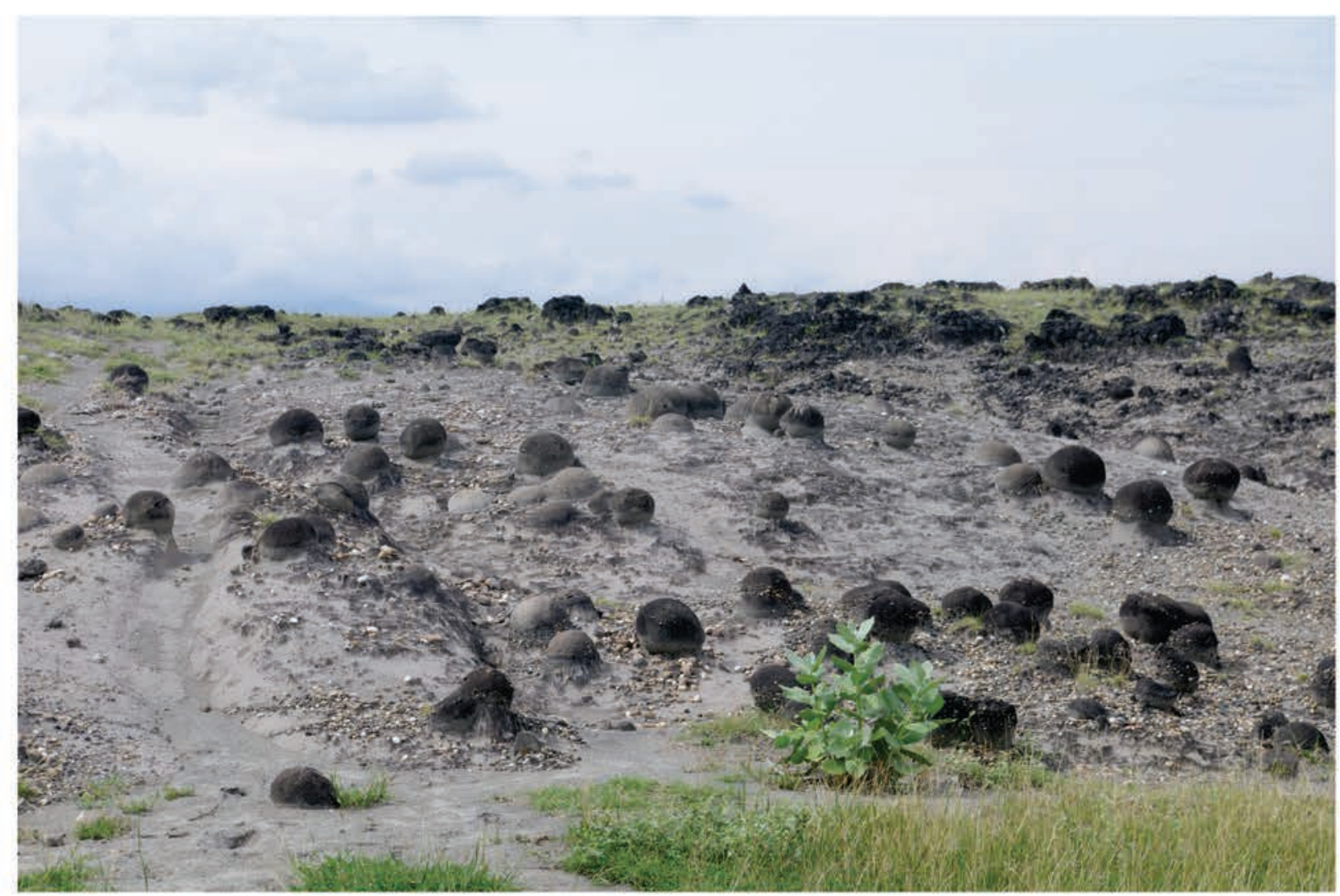

(a)

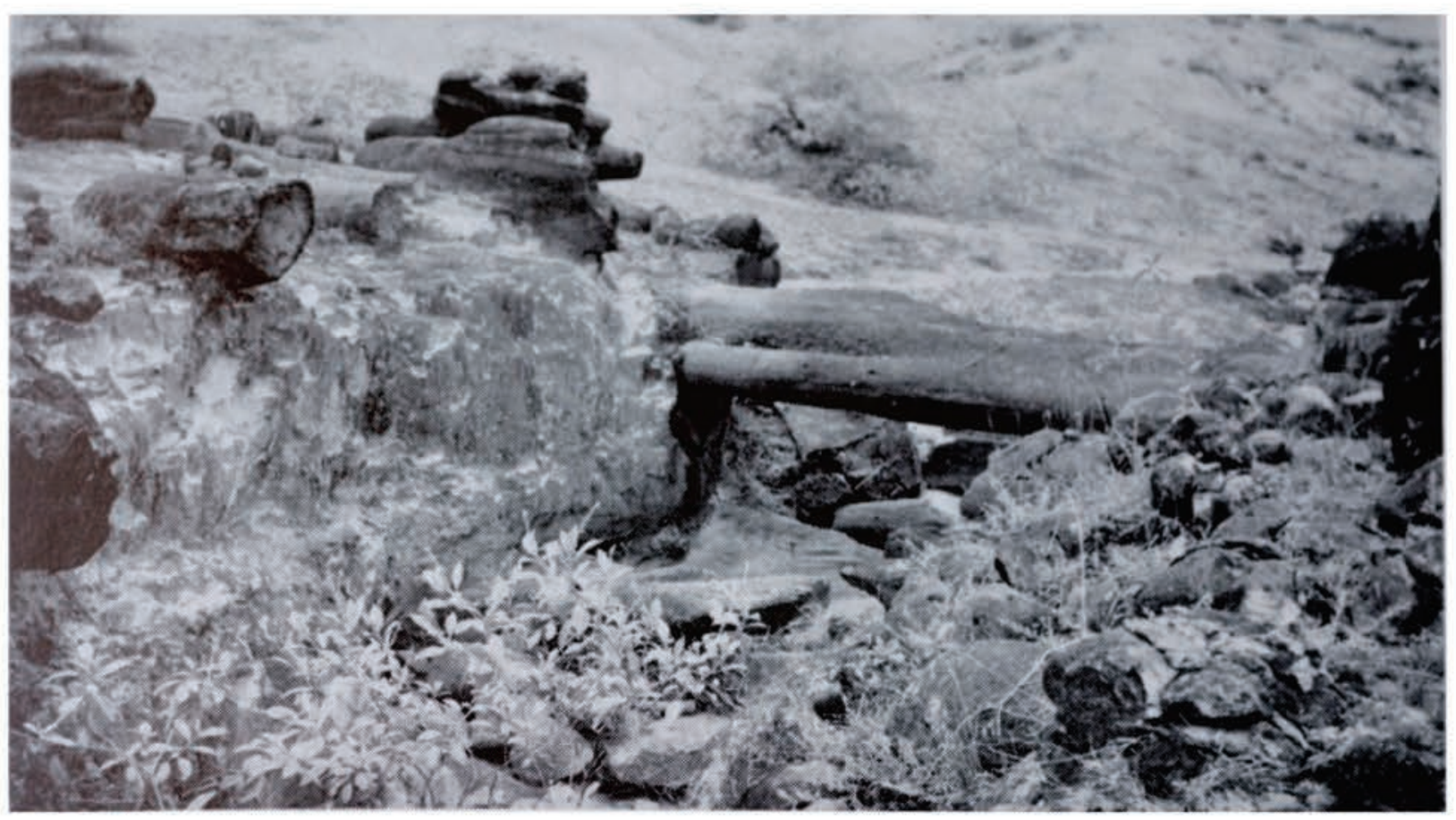

(b)

Figura 19. Estructuras sedimentarias secundarias. (a) Concreciones Cannon ball; (b) Concreciones Torpedo - shaped.

Fotografías: a. Yaneth Muñoz-Saba. b. Tomada de Fields (1959). 


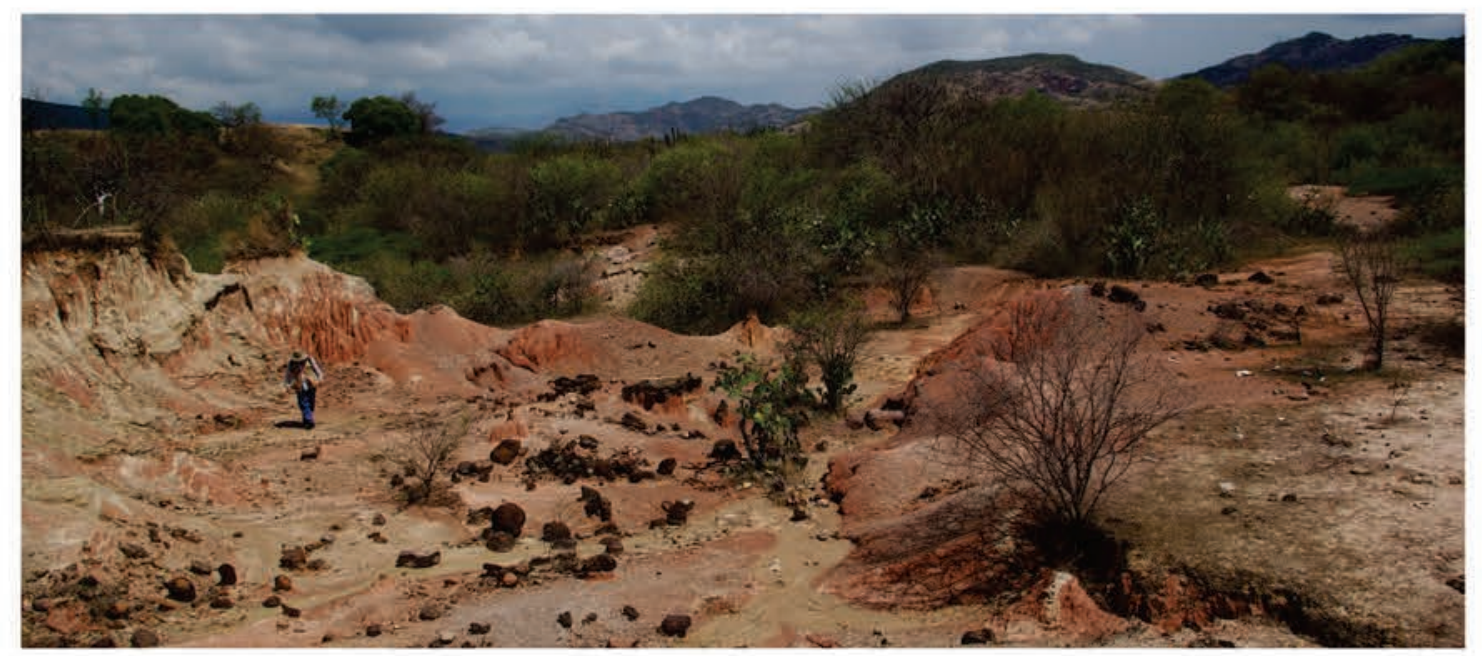

(a)

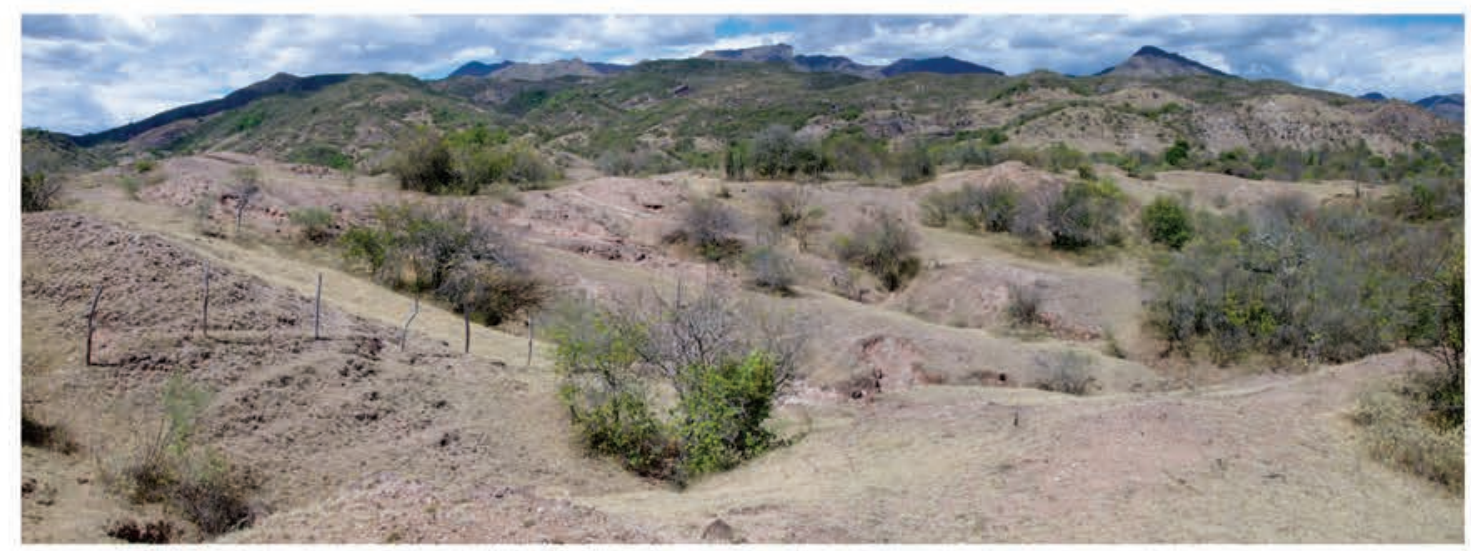

(b)

(c)

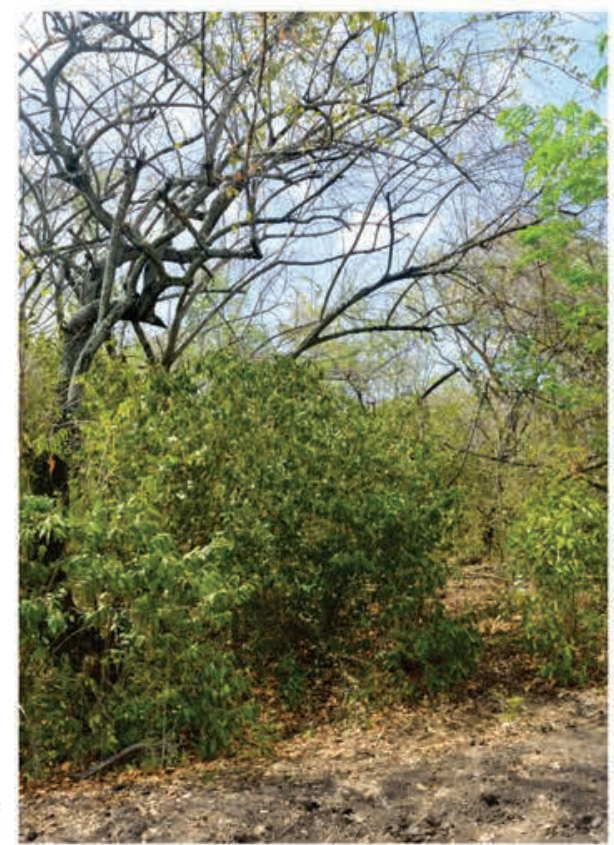

Figura 20. Sabana seca con matorral abierto, vegetación actual representativa del paleohábitat de la Formación San Alfonso. Fotografías: a, b. Grupo de Investigación Evolución y Ecología de Mamíferos Neotropicales (EEMN). c. Luis Norberto Parra-Sánchez. 


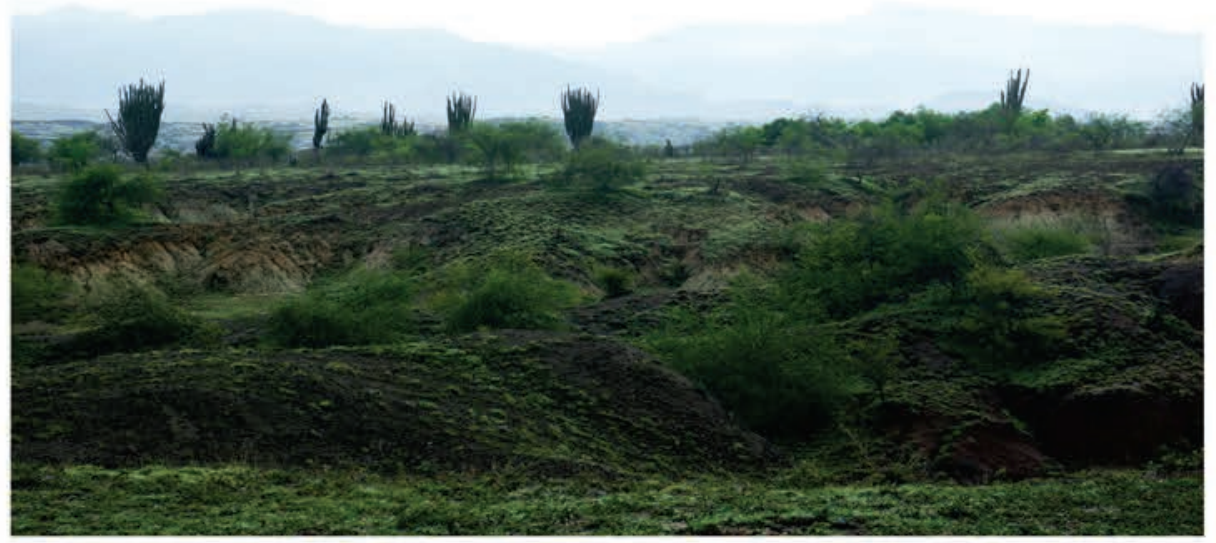

(a)

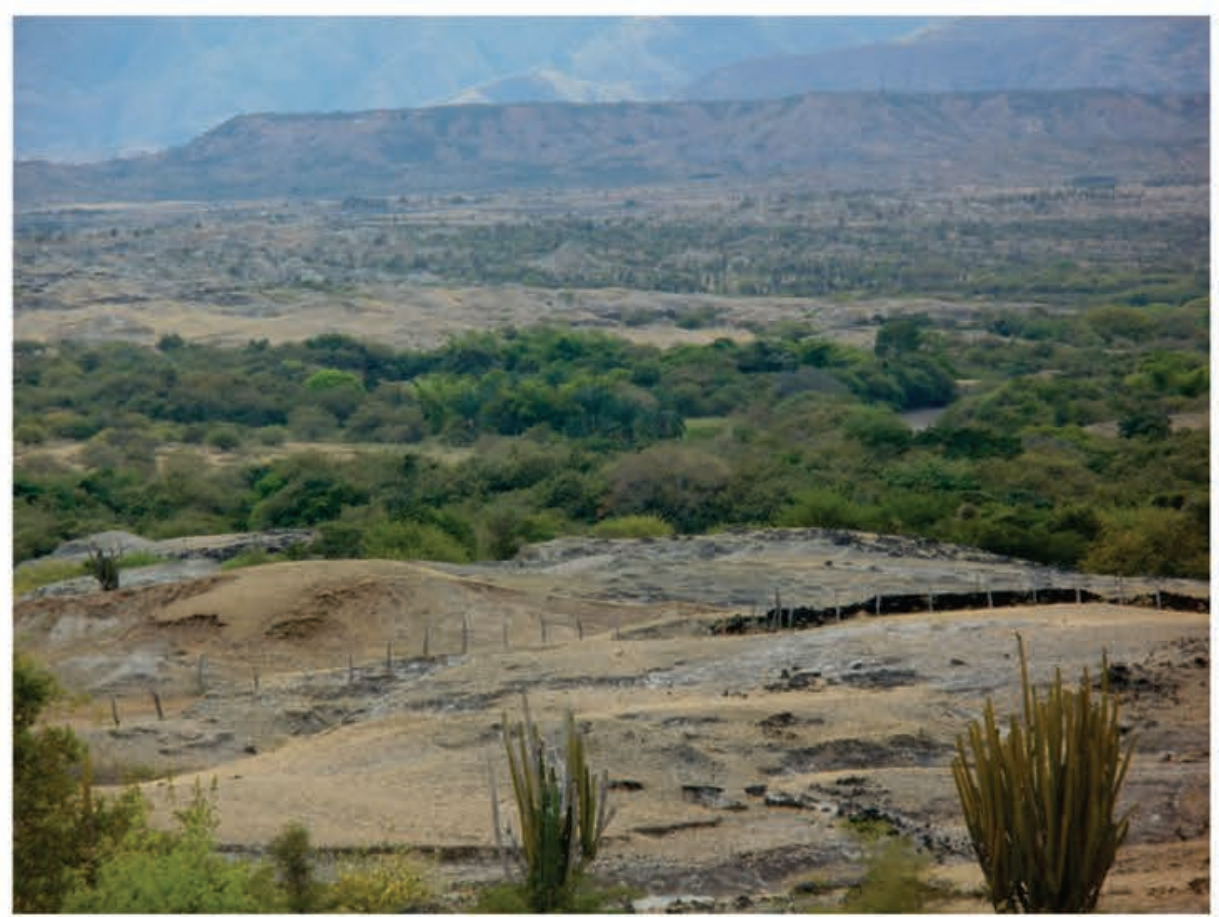

(b)

Figura 21. Vegetación actual de la Formación La Victoria. (a) Matorral abierto; (b) Sabana seca.

Fotografías. Grupo de Investigación Evolución y Ecología de Mamíferos Neotropicales (EEMN). 


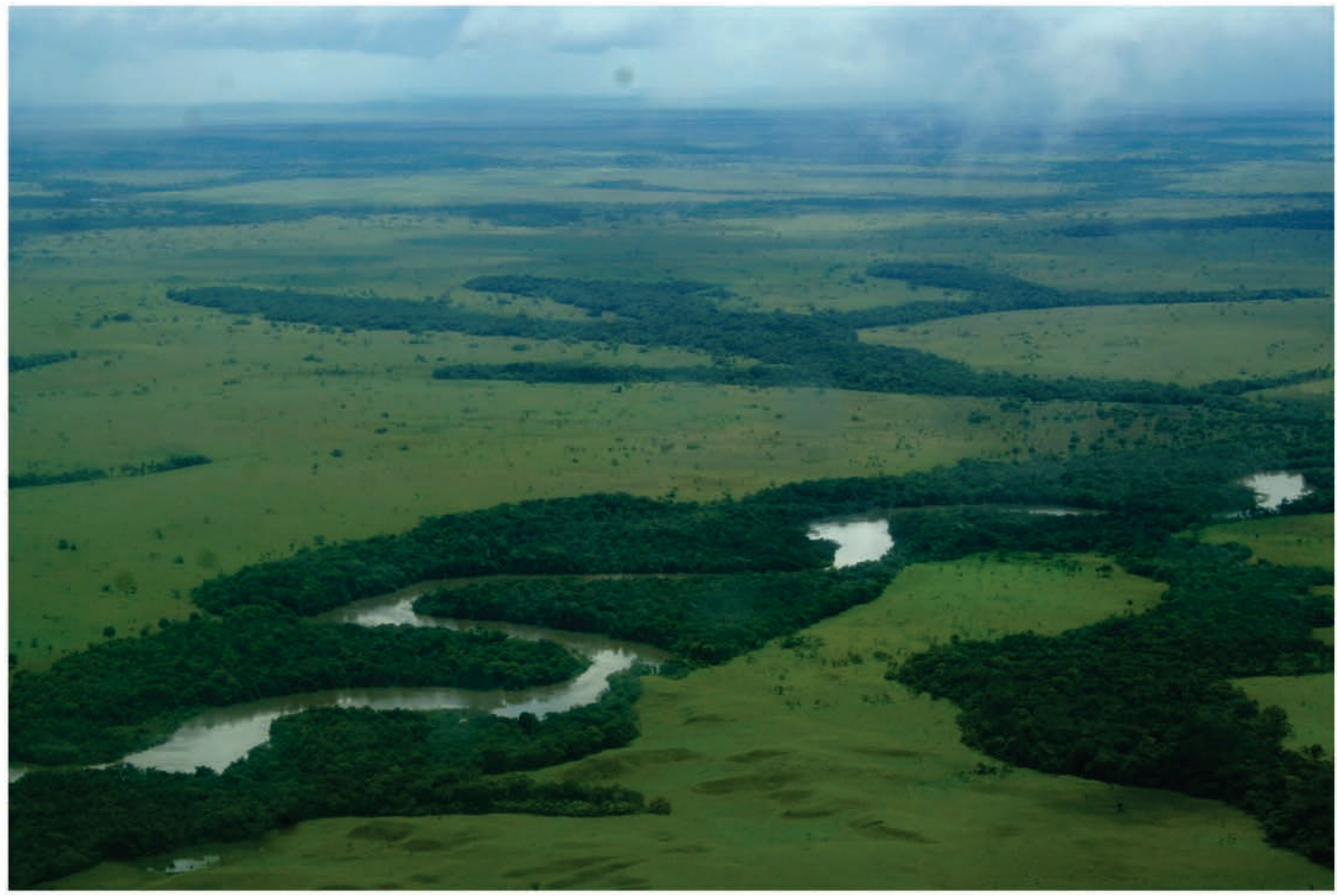

Figura 22. Vegetación actual, bosque de ribera, Río Tomo, departamento del Vichada, Colombia; similar al paleohábitat de la Formación La Victoria.

Fotógrafo: Francisco Castro. 


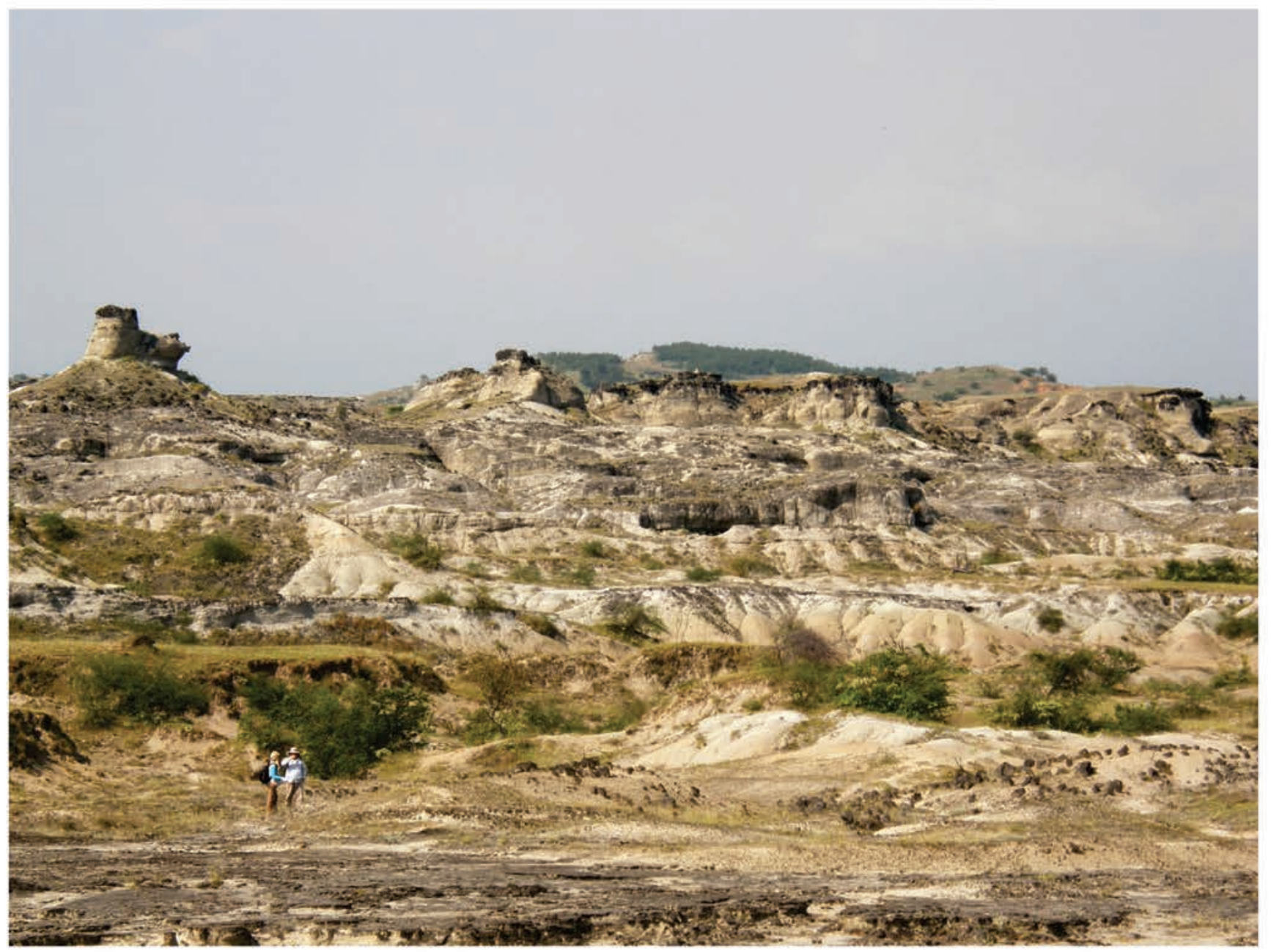

Figura 23. Vegetación actual, representativa del paleohábitat de la Formación Cerbatana: pastizales ralos con algunos arbustos de clima seco y grandes áreas carentes de vegetación.

Fotógrafo: Grupo de Investigación Evolución y Ecologia de Mamíferos Neotropicales (EEMN). 


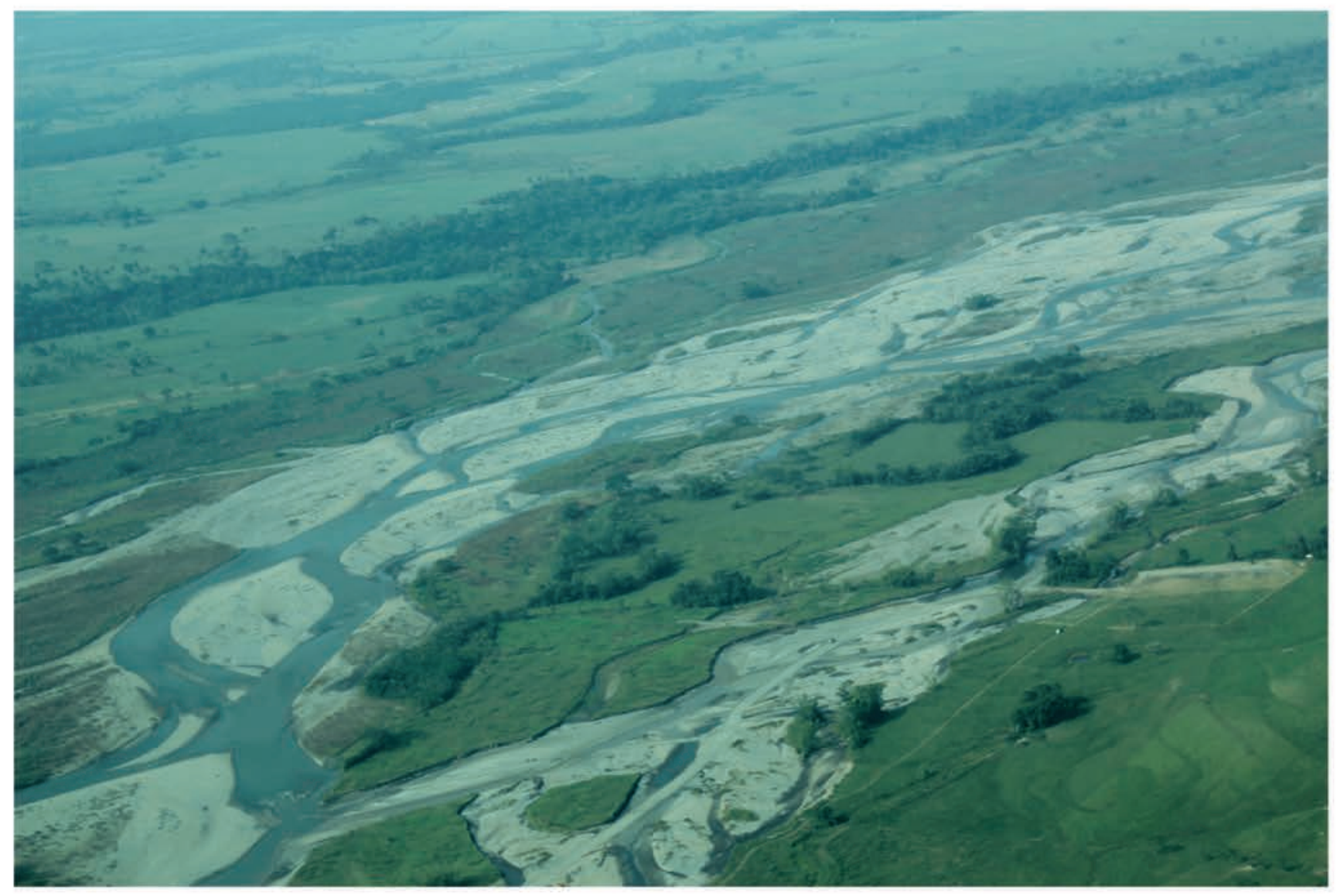

Figura 24. Vegetación actual, bosque de ribera, Río Ariari, departamento del Meta, Colombia; similar al paleohábitat de la Formación Cerbatana.

Fotógrafo: Francisco Castro. 


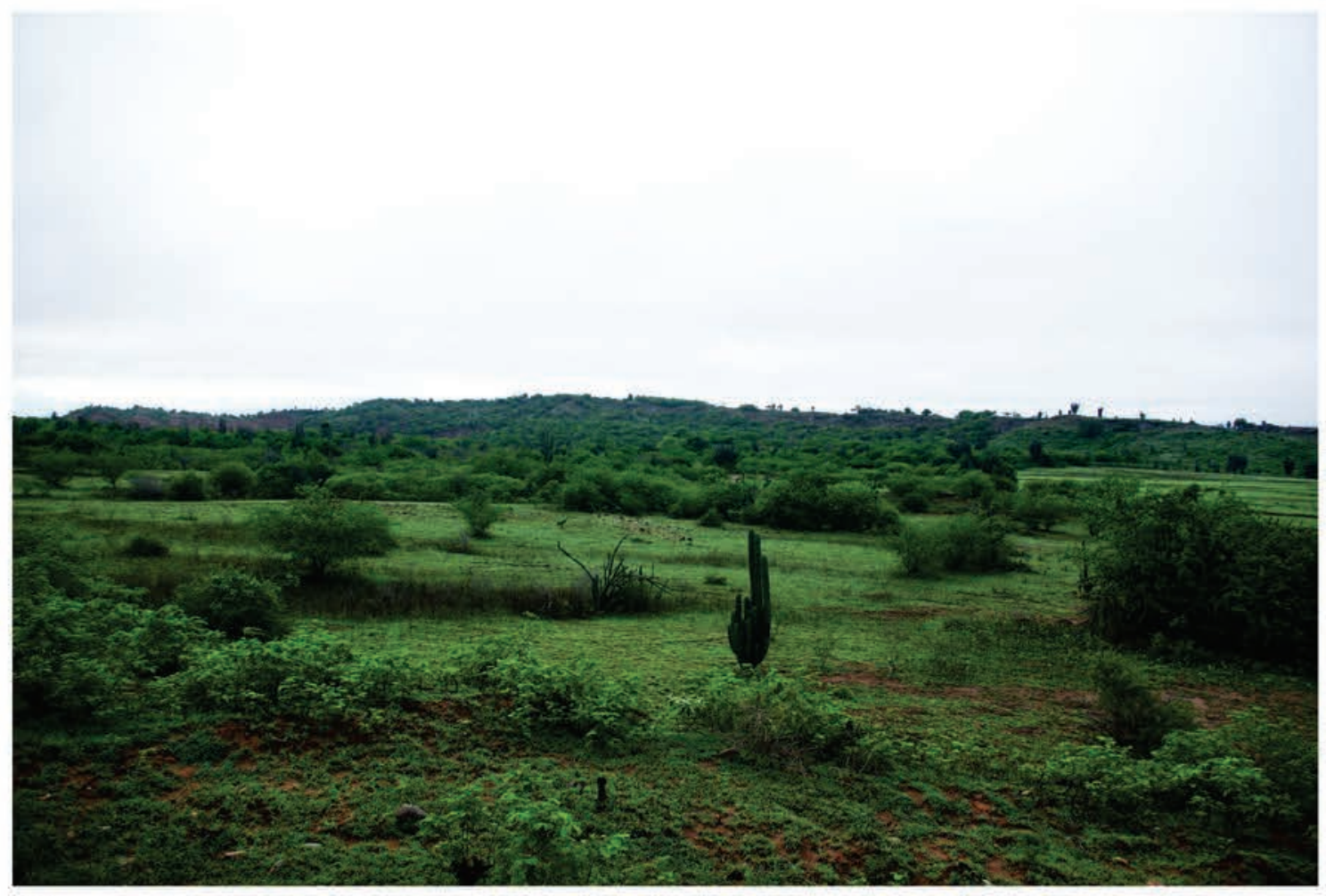

(a)

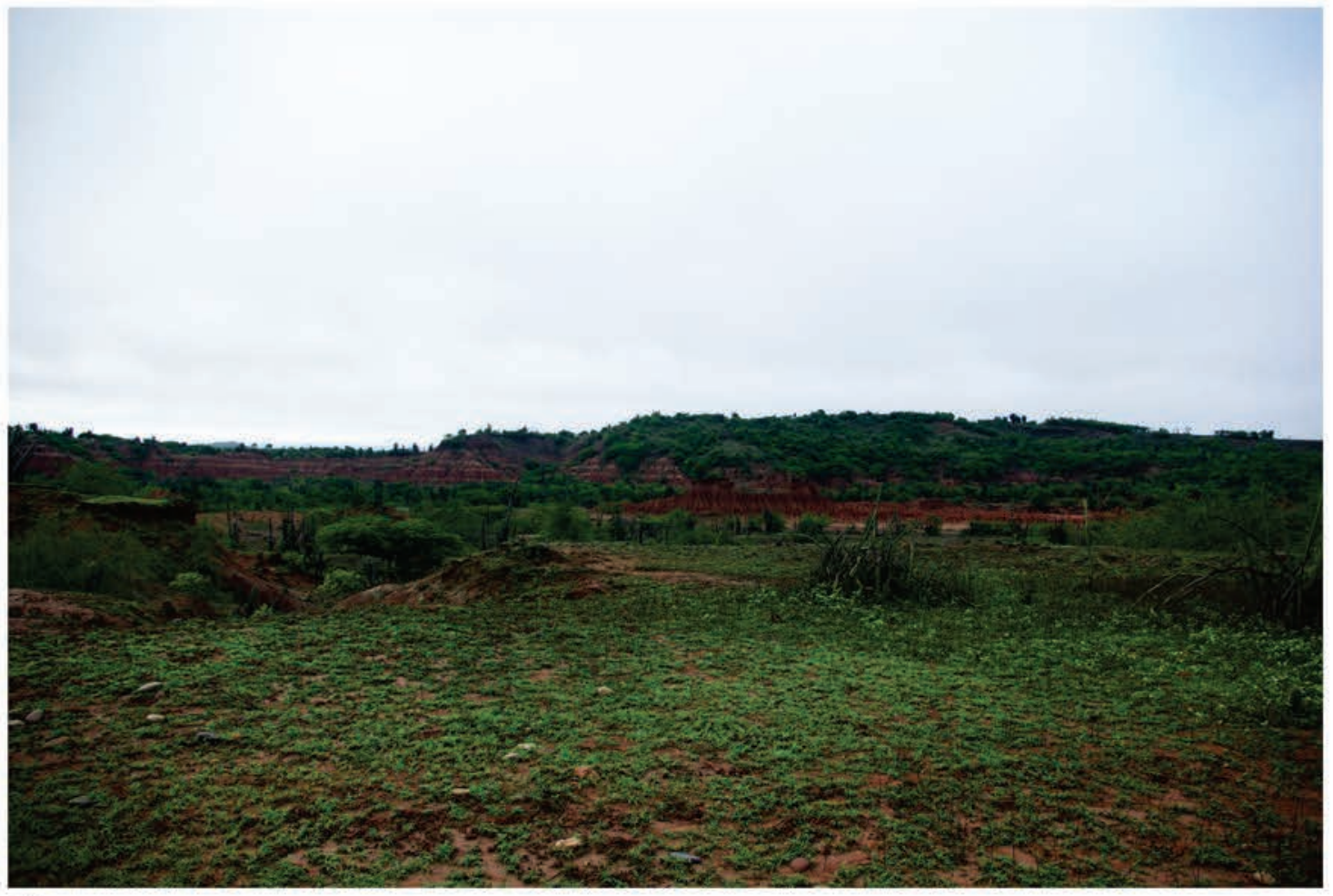

(b)

Figura 25. Matorrales abiertos, vegetación actual de la Formación Villavieja. Fotógrafo: Luis Norberto Parra-Sánchez. 


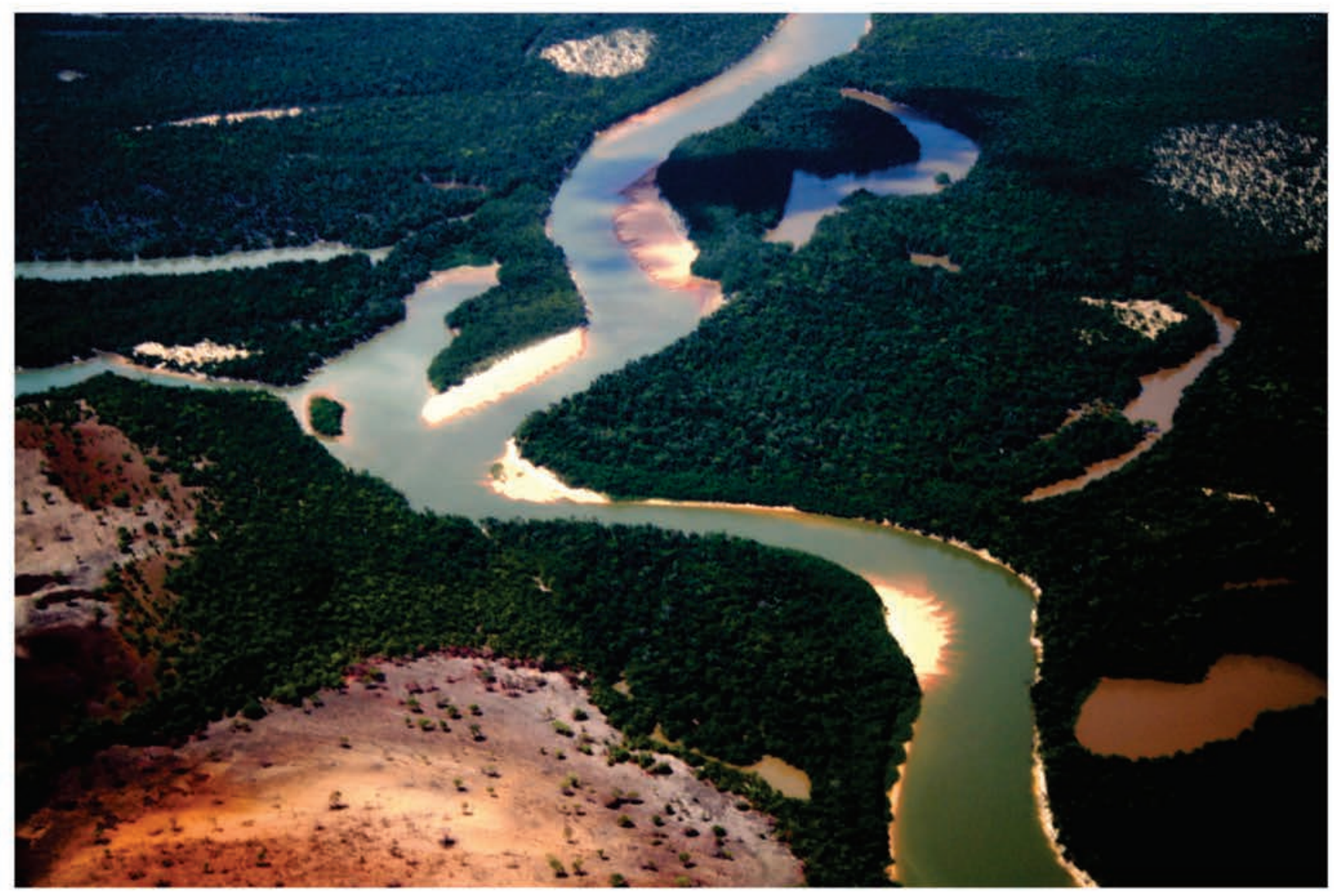

Figura 26. Vegetación actual, Río Bita, departamento del Vichada, Colombia; similar al paleohábitat de la Formación Villavieja. Fotógrafo: Francisco Castro. 


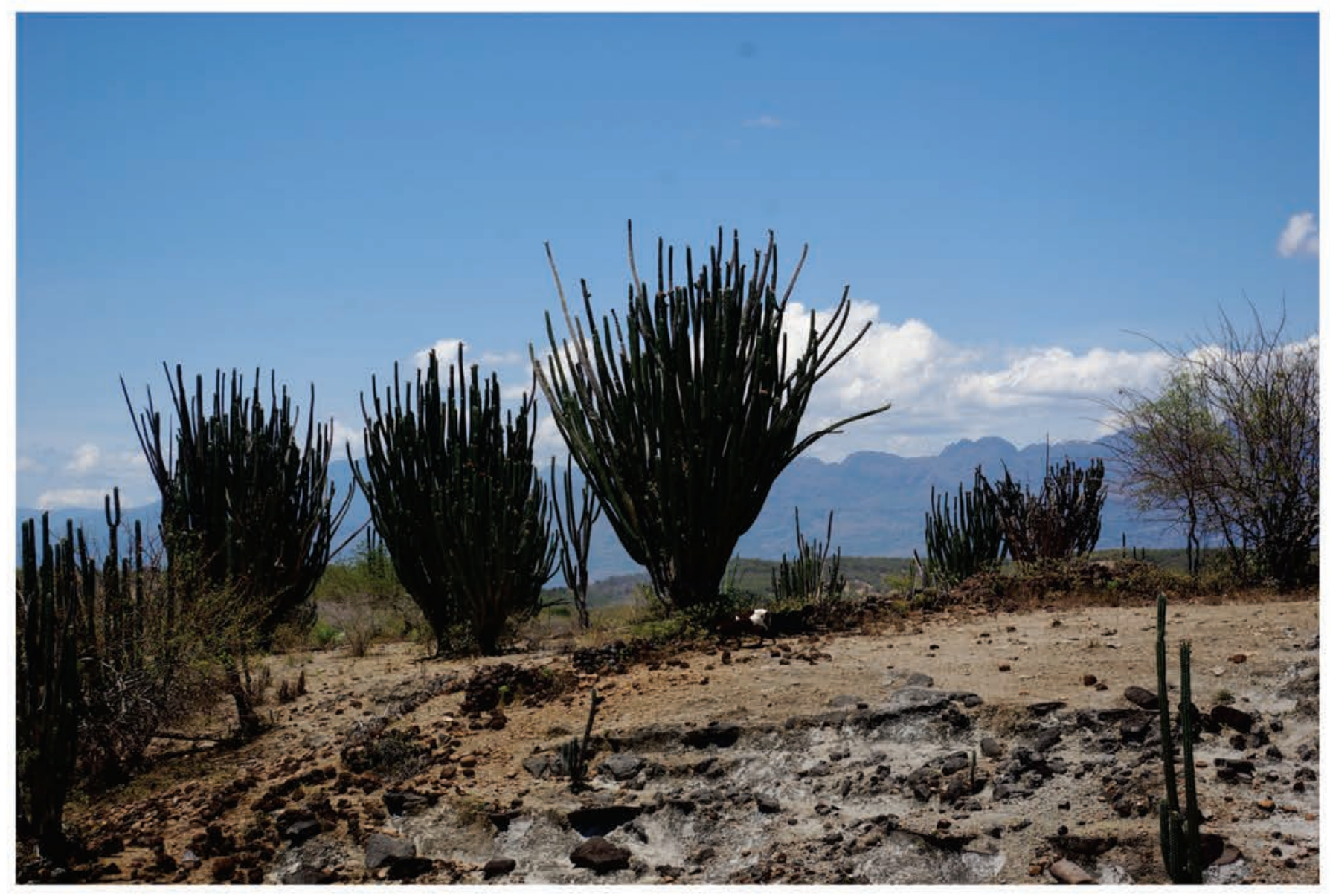

Figura 27. Bosque seco, vegetación actual de la Formación Las Mesitas. Fotógrafo: Luis Norberto Parra-Sánchez. 


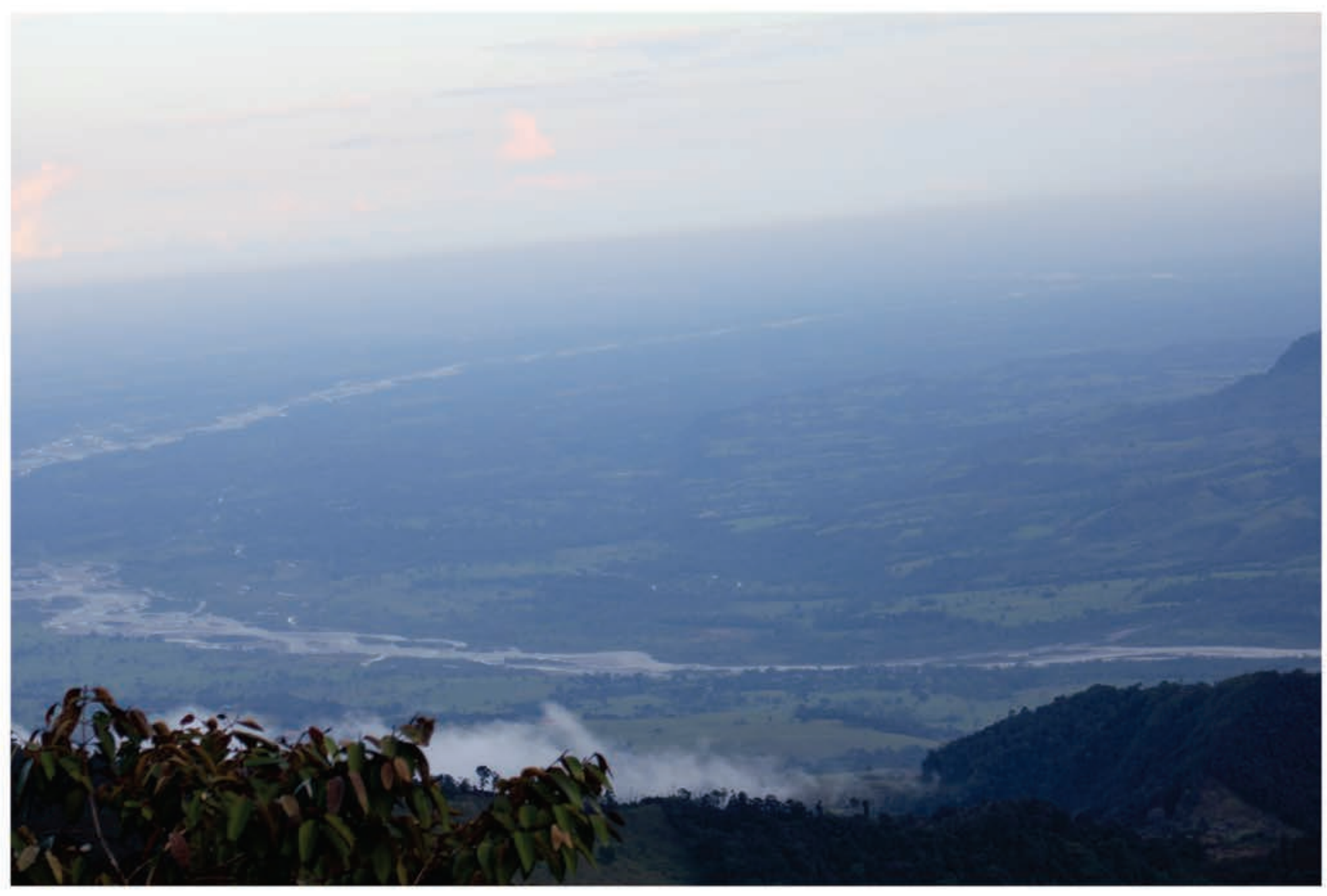

Figura 28. Vegetación actual, pie de monte llanero, Colombia; similar al paleohábitat de la Formación Las Mesitas. Fotógrafo: Francisco Castro. 


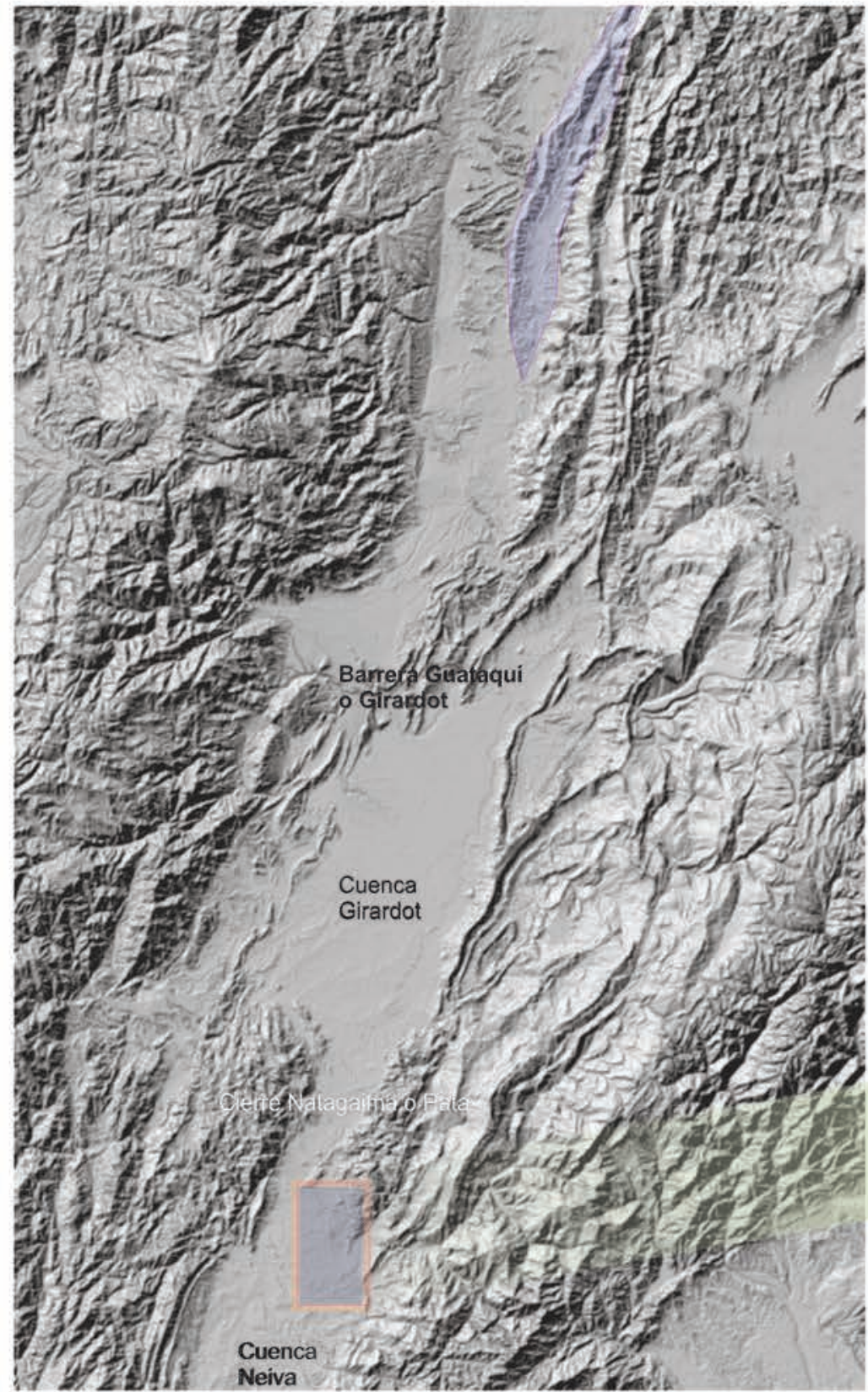

a. Modelo digital de elevación del terreno.

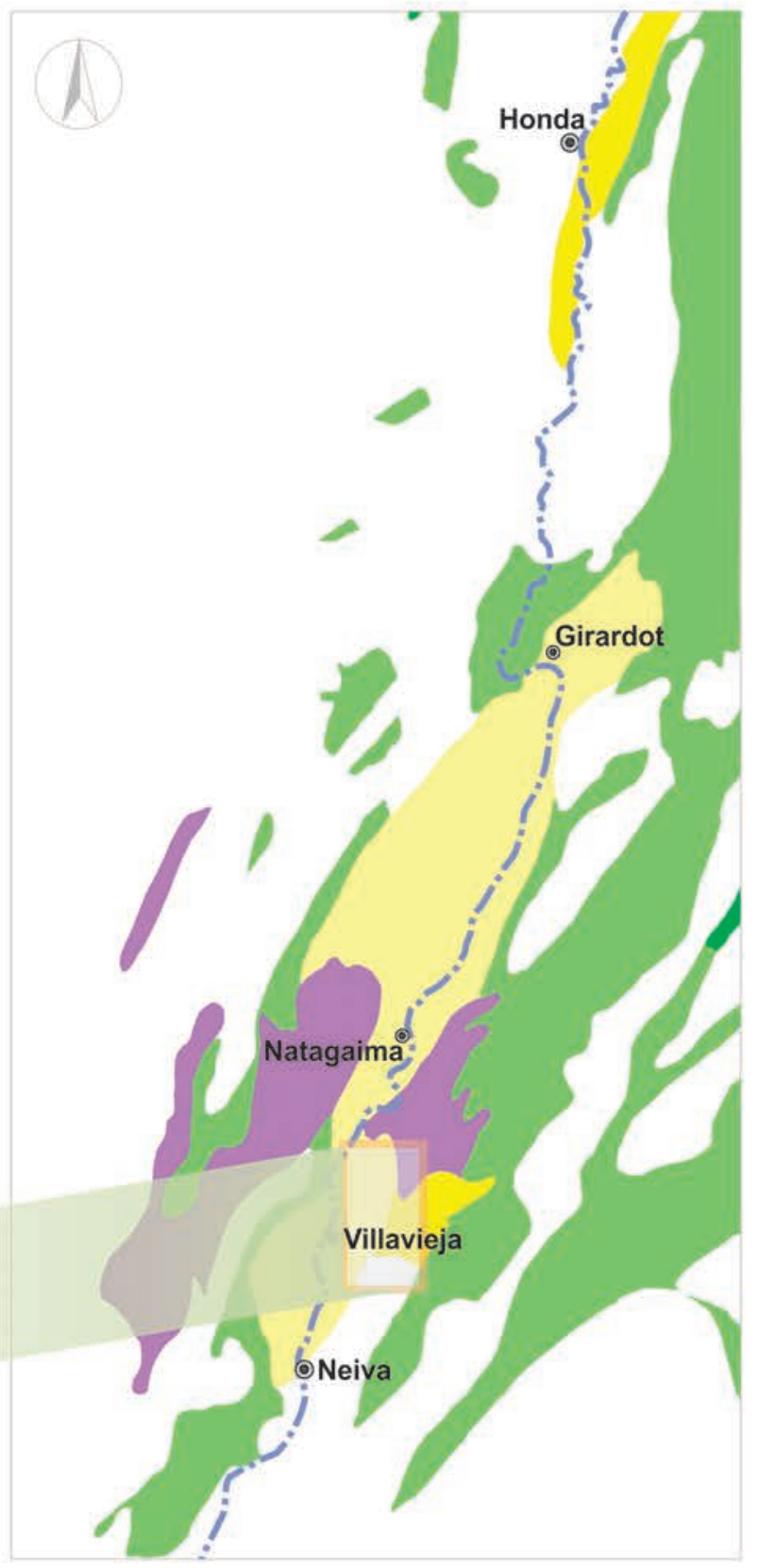

b. Mapa geológico generalizado.

Figura 29. Paleogeografia del Grupo La Venta.

Mapa elaborado por Luis Norberto Parra-Sánchez, Universidad Nacional de Colombia, Facultad de Ciencias,

CONVENCIONES

Medellin, 2016.

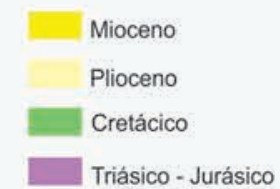




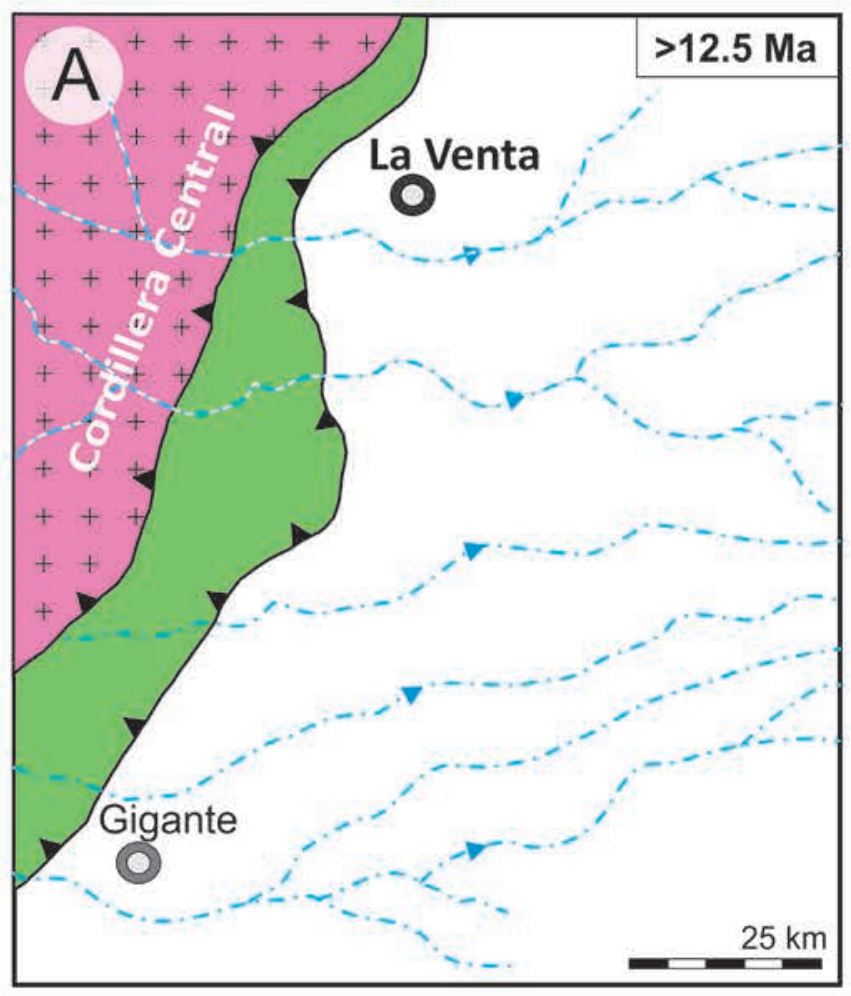

- Sistemas de drenajes dirigidos al Este.

- Formación de la Cordillera Central.

- Barrera topográfica contra el Este.

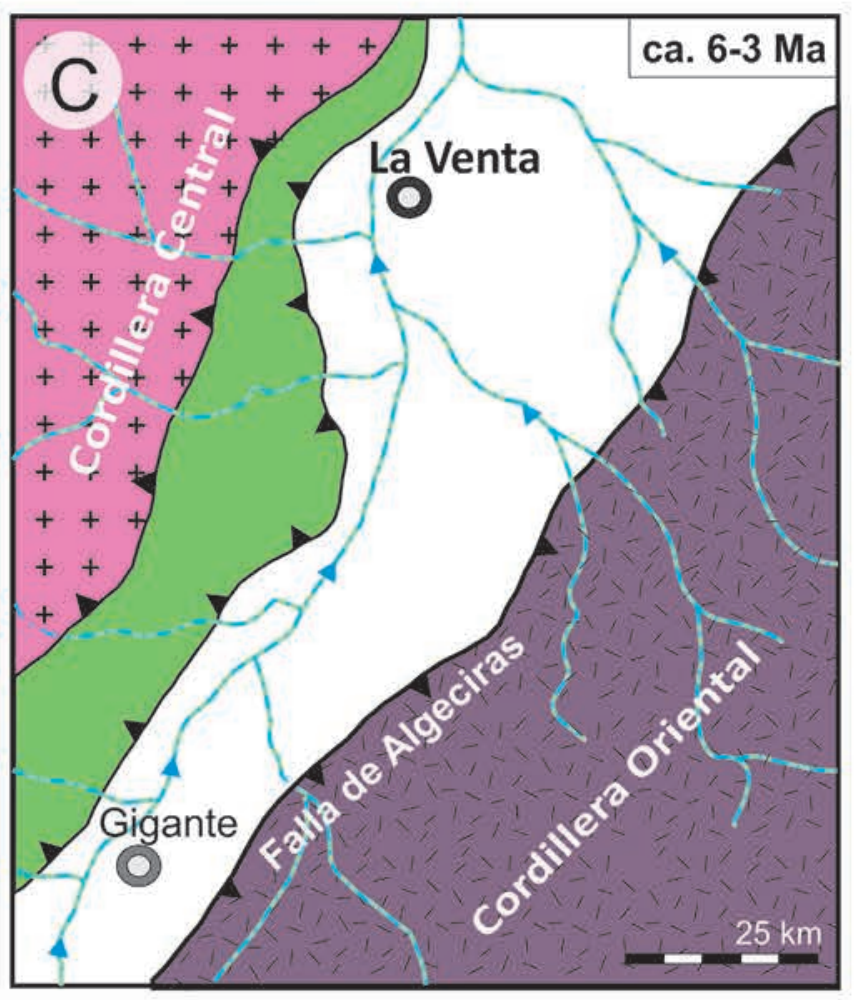

- Cabalgamiento y exhumación del Macizo de Garzón a través de la Falla de Algeciras.

- Surgimiento dominante de la Cordillera Oriental.

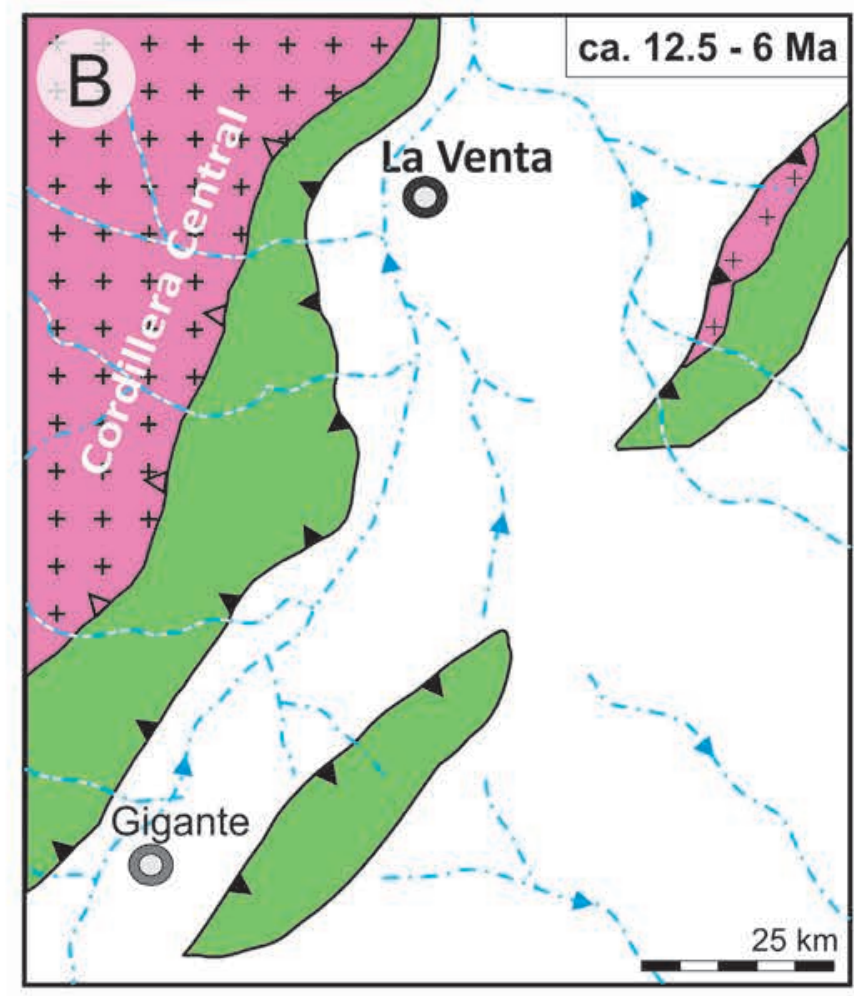

- Drenajes iniciales axiales (dirigidos al Norte).

- Surgimiento de la Cordillera Oriental y Central.

- Baja barrera topográfica al Este.

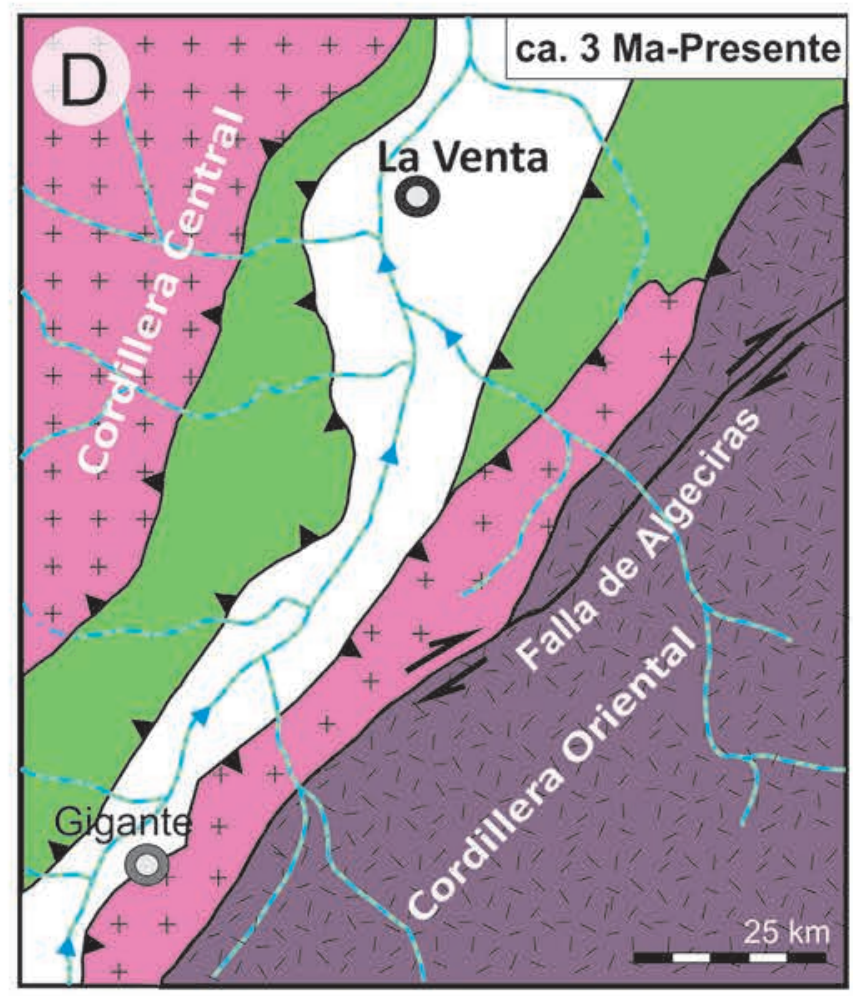

- Frente de cabalgamiento propagándose hacia el Oeste.

- Movimientos de rumbo iniciando a lo largo de la Falla de Algeciras.

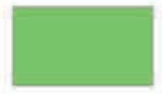

Unidades sedimentarias cretácico - paleógenas

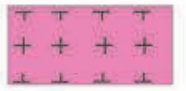

Unidades igneas Jurásico - Cenozóico
Basamento metamórfico de Garzón. 
Tabla 1. Información base (datos crudos) del análisis de polen fósil.

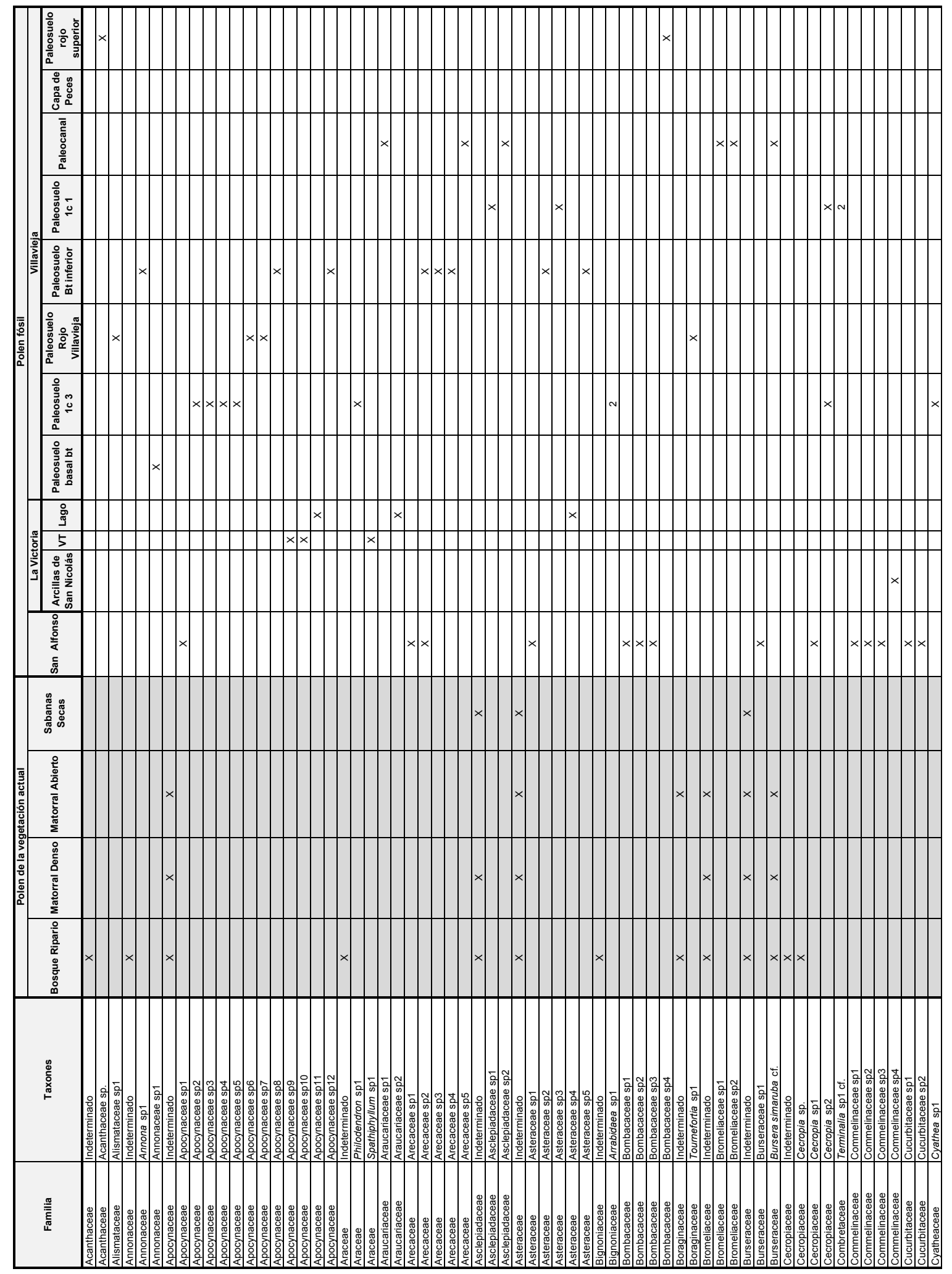




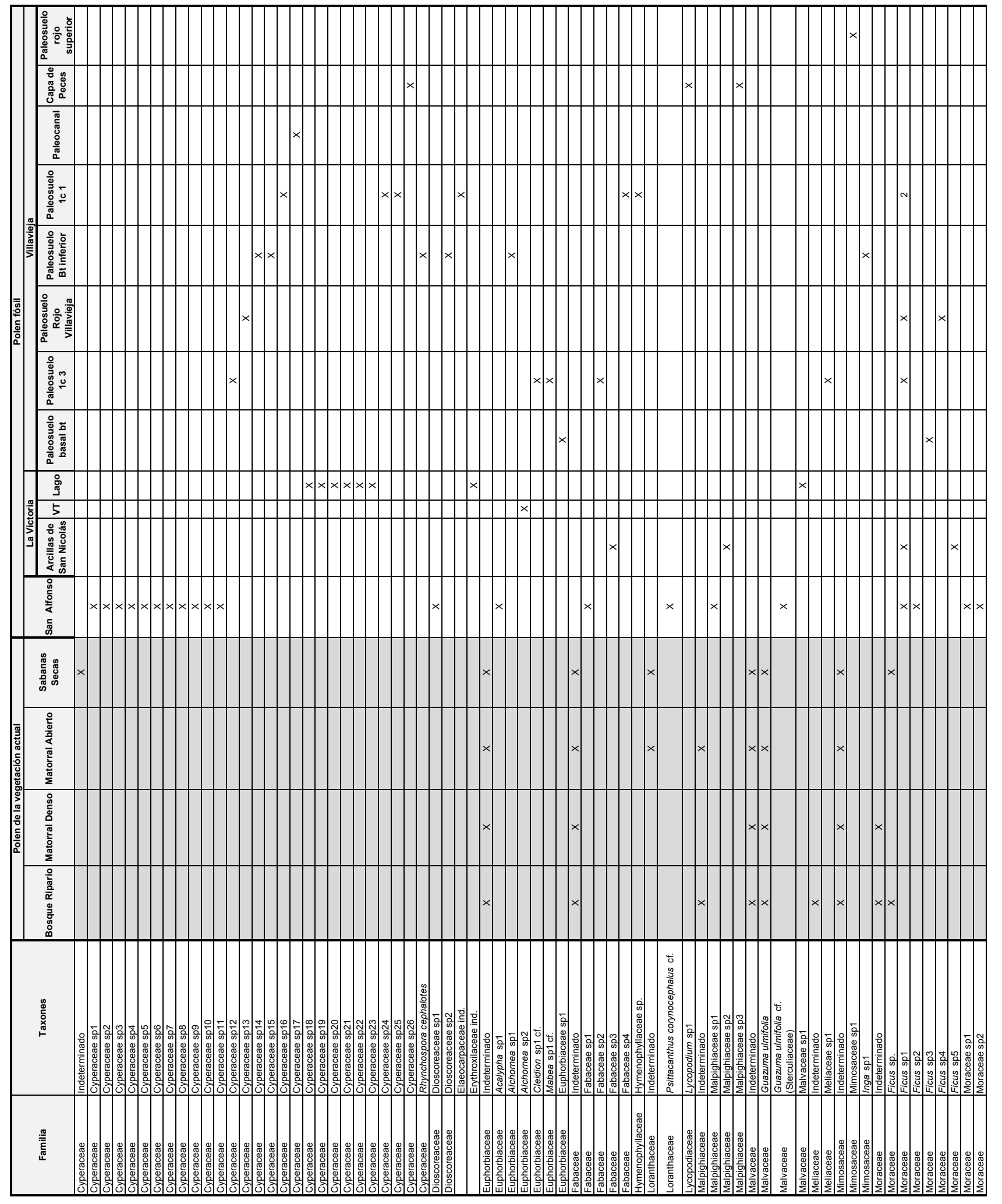




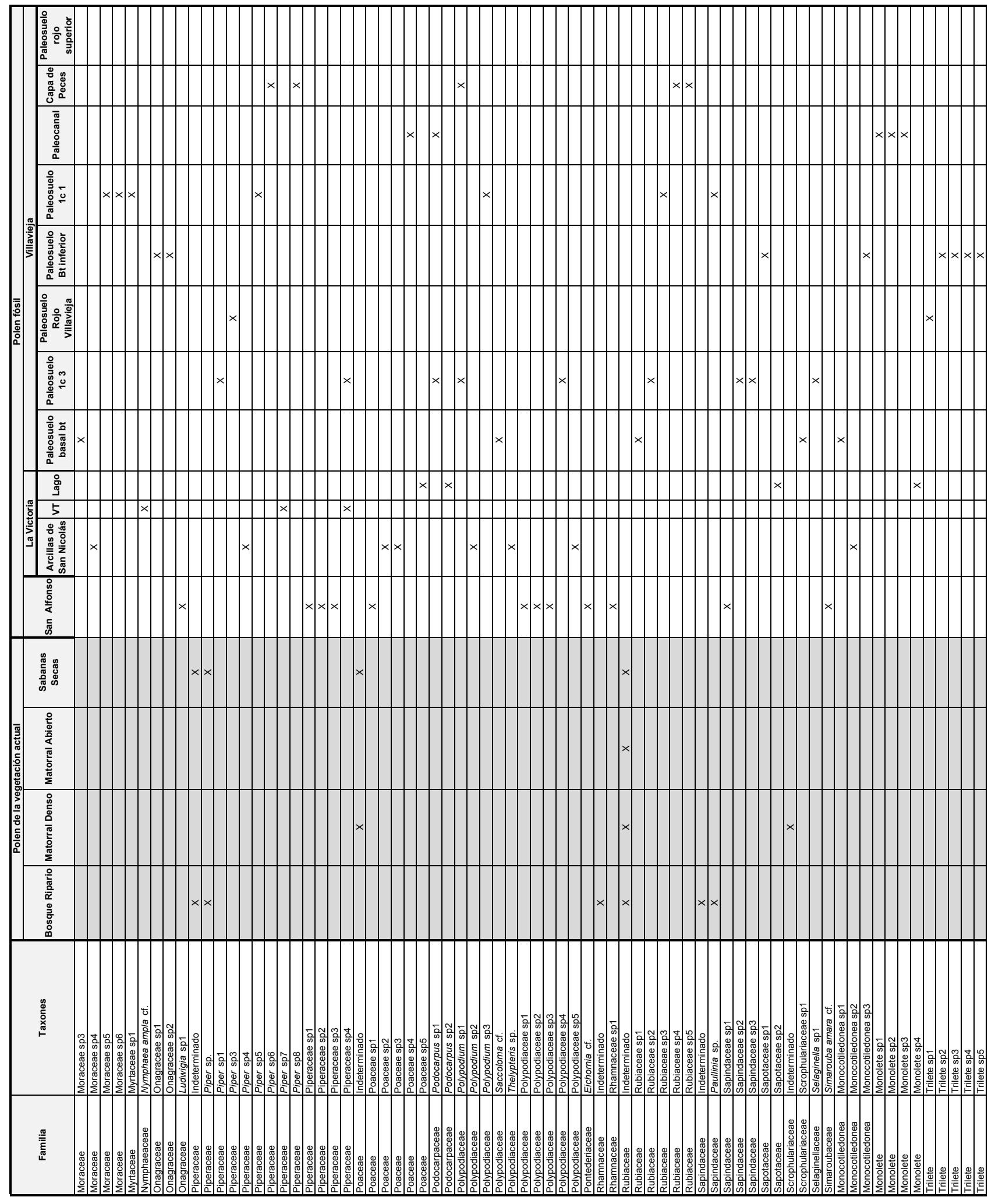




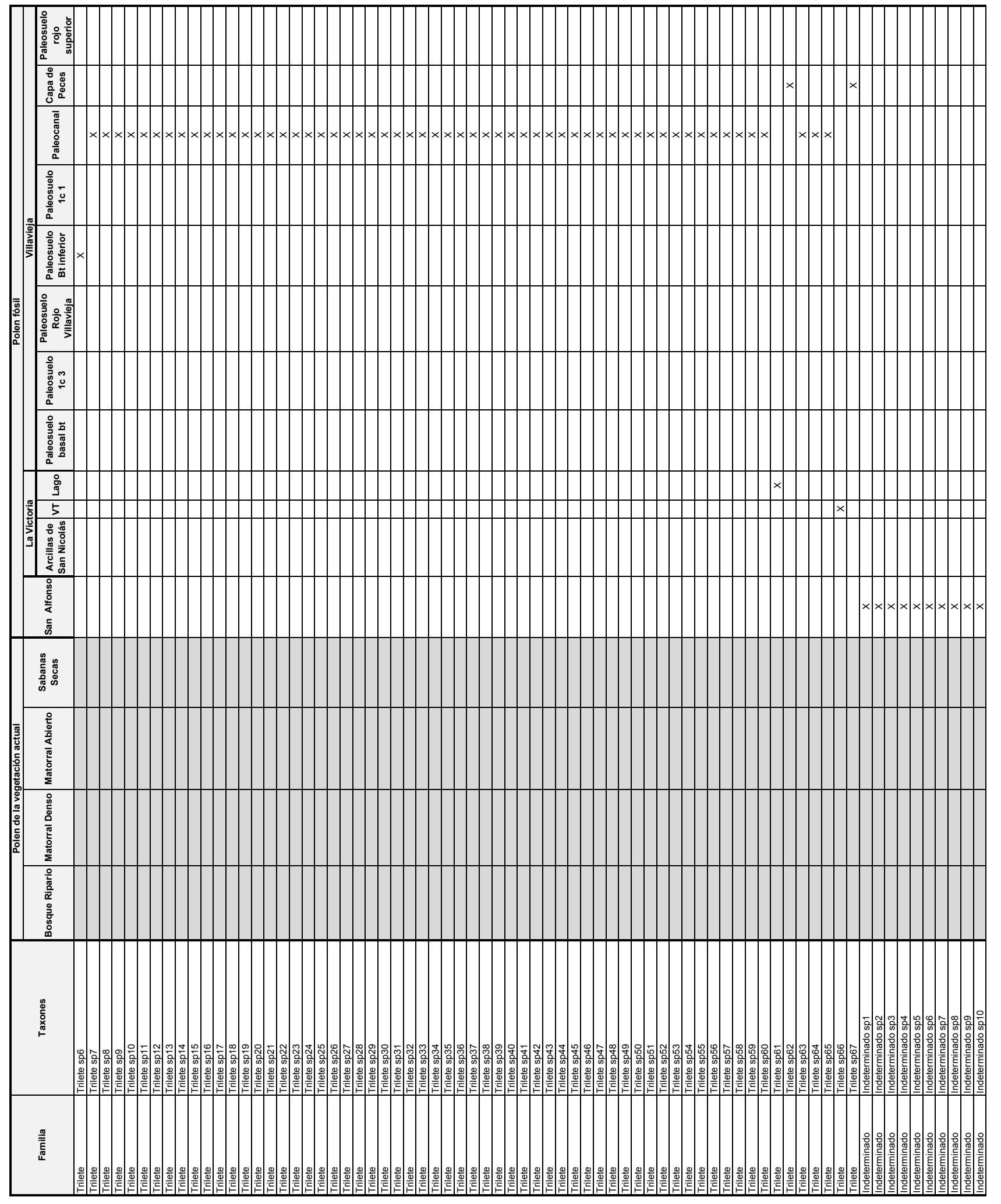




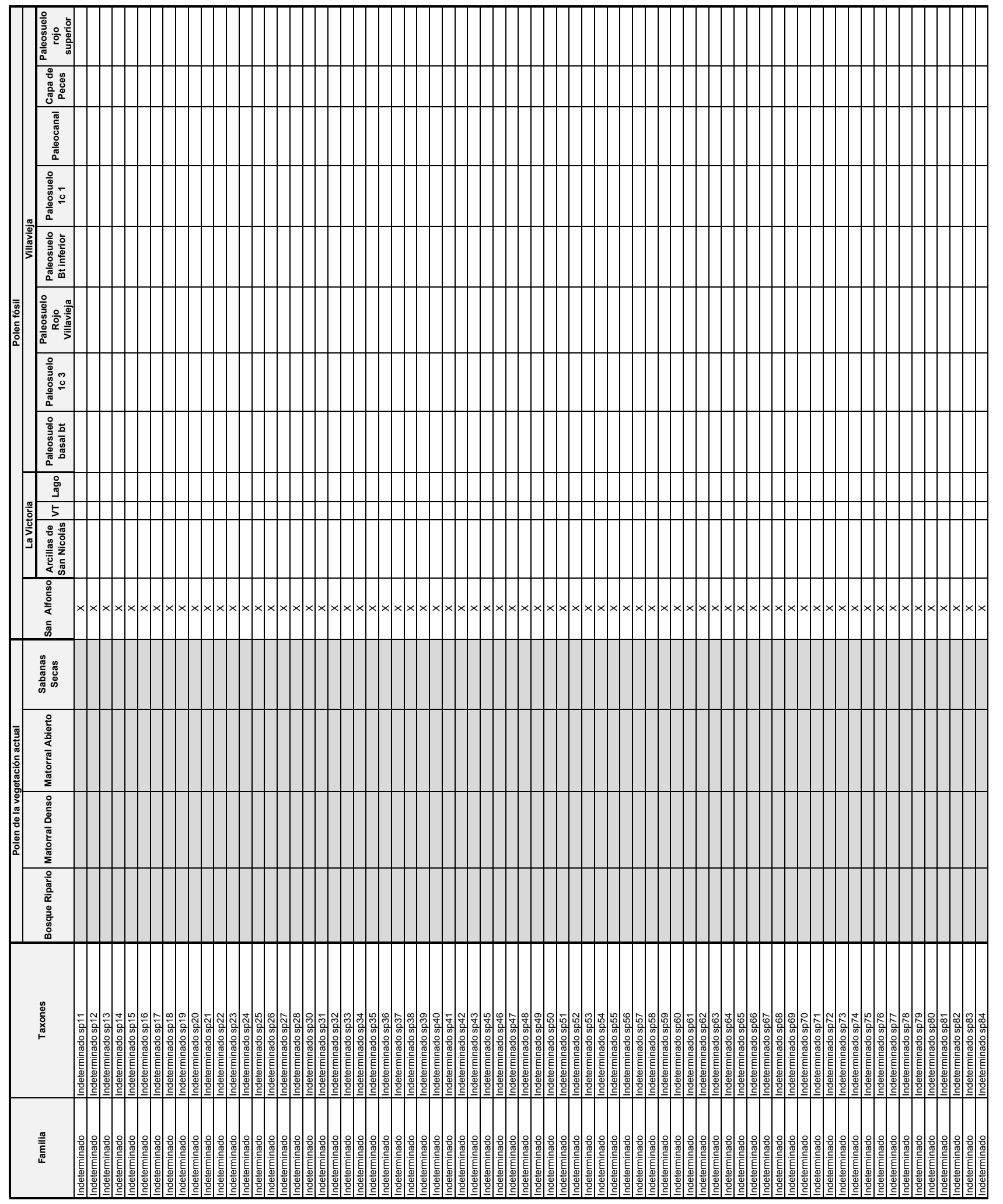




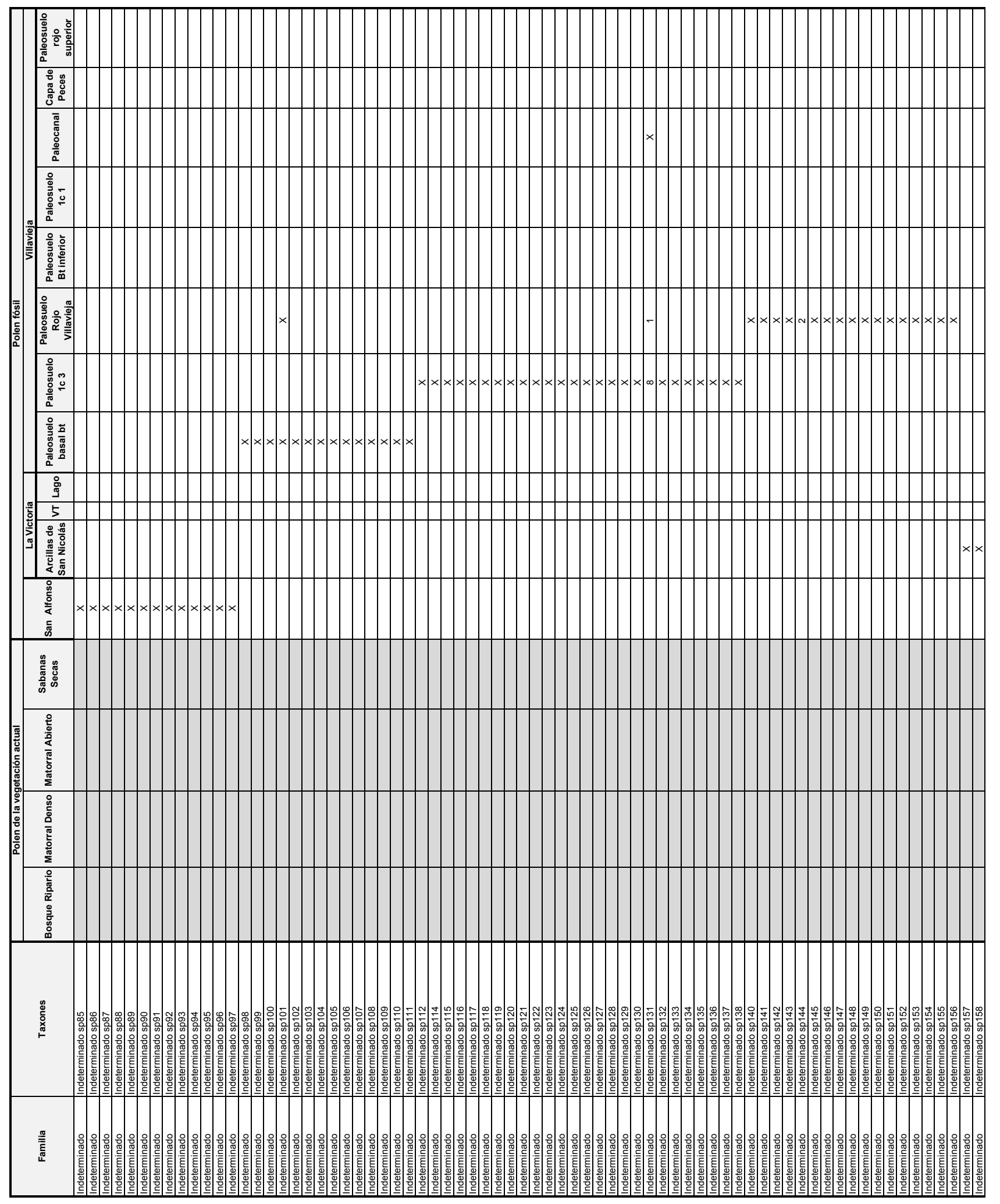




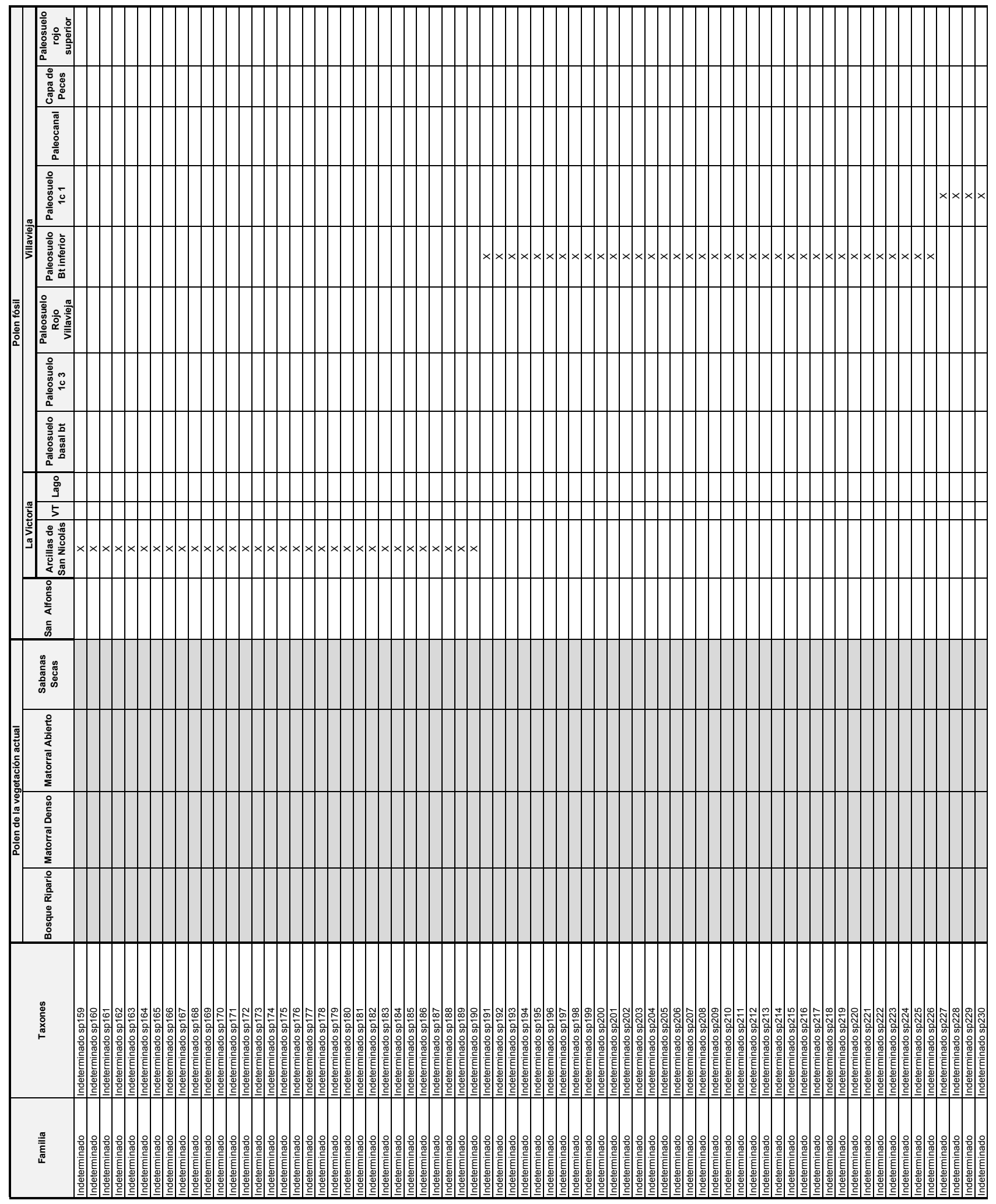




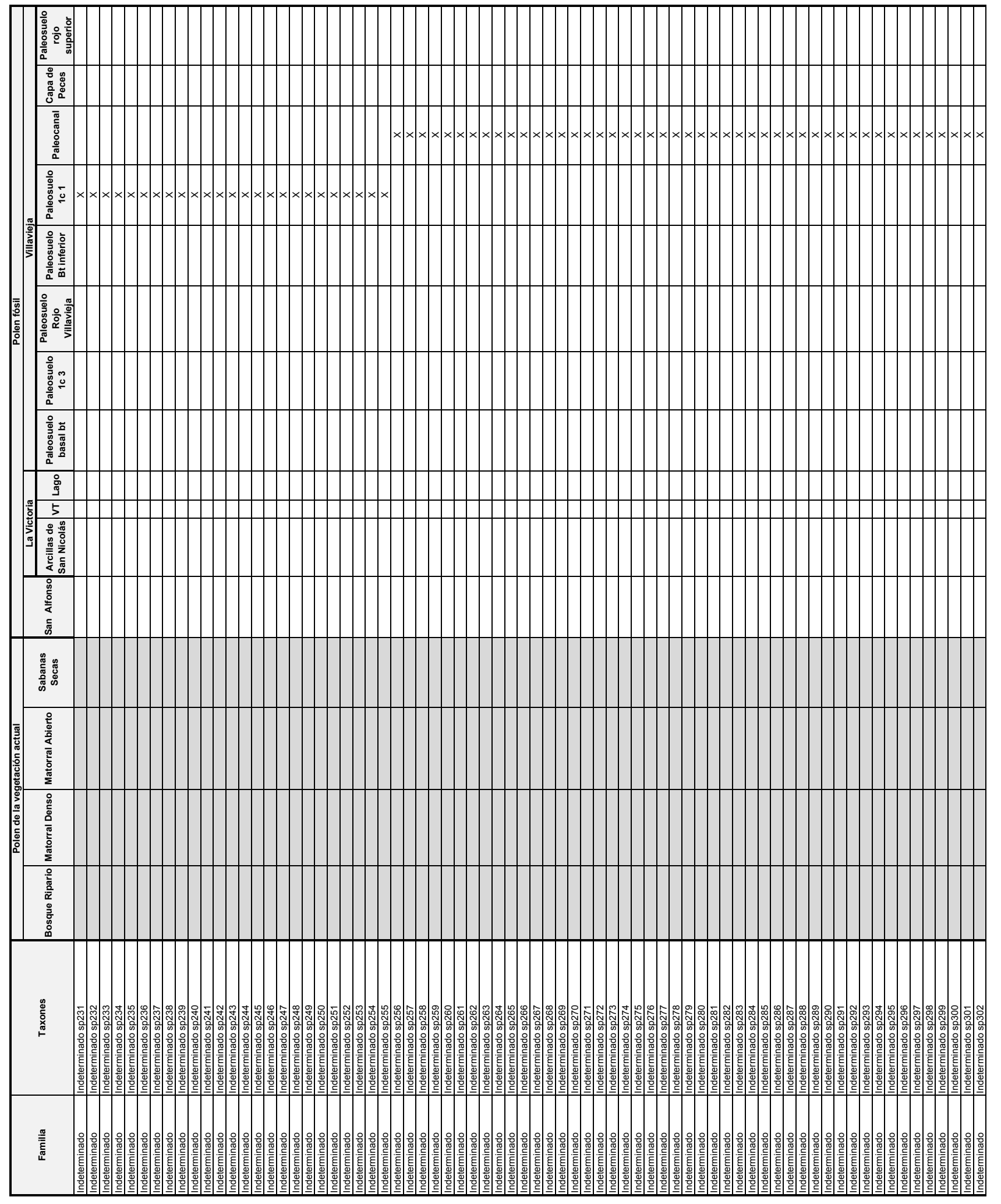




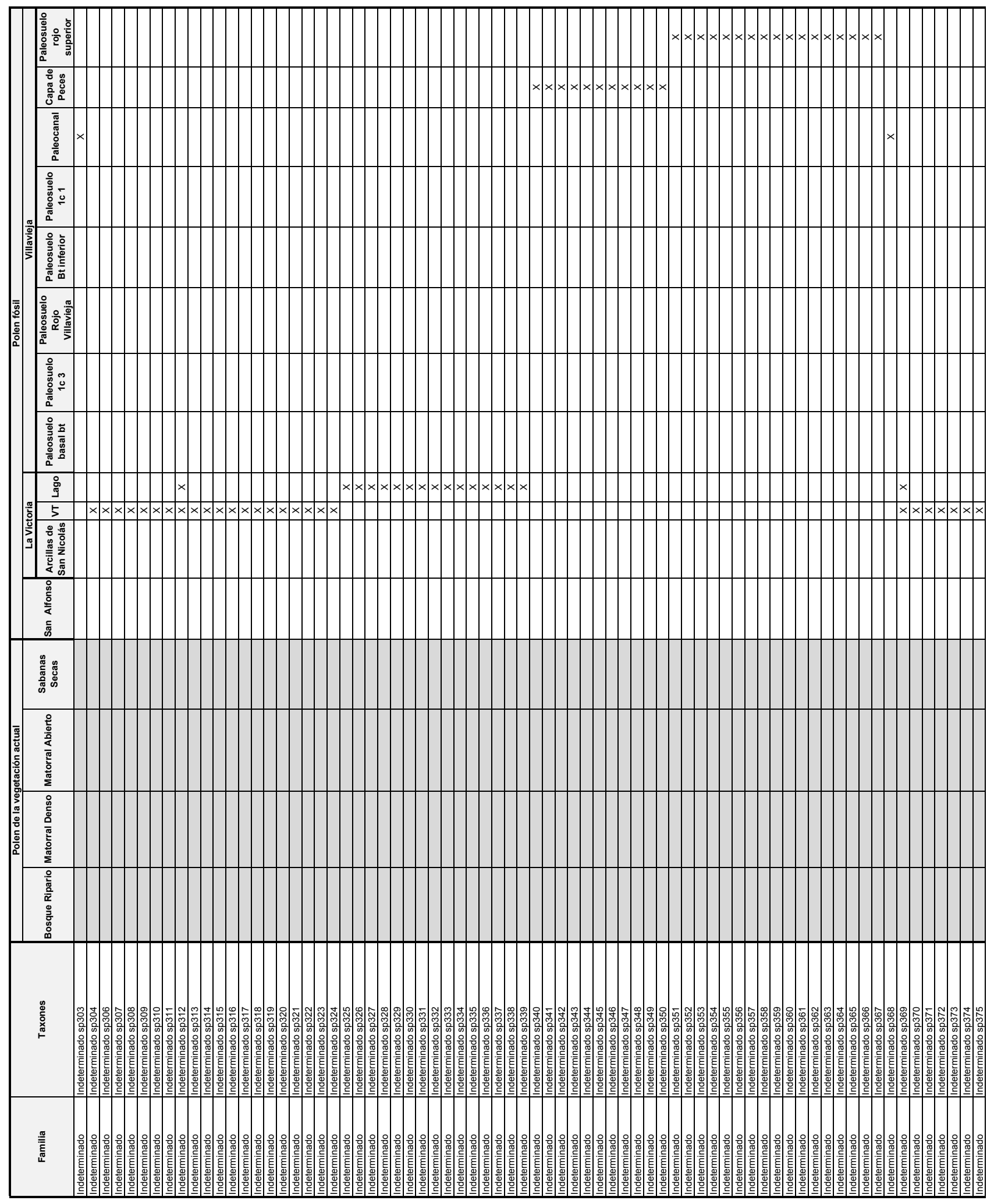




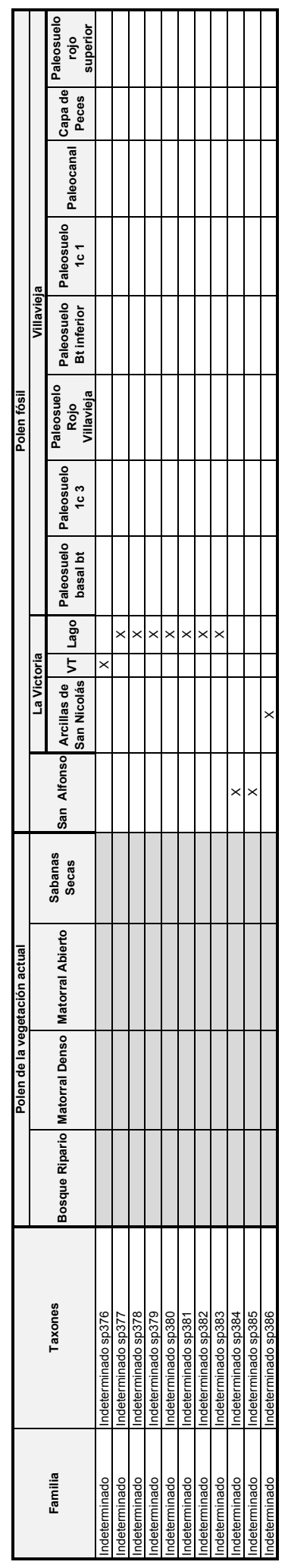




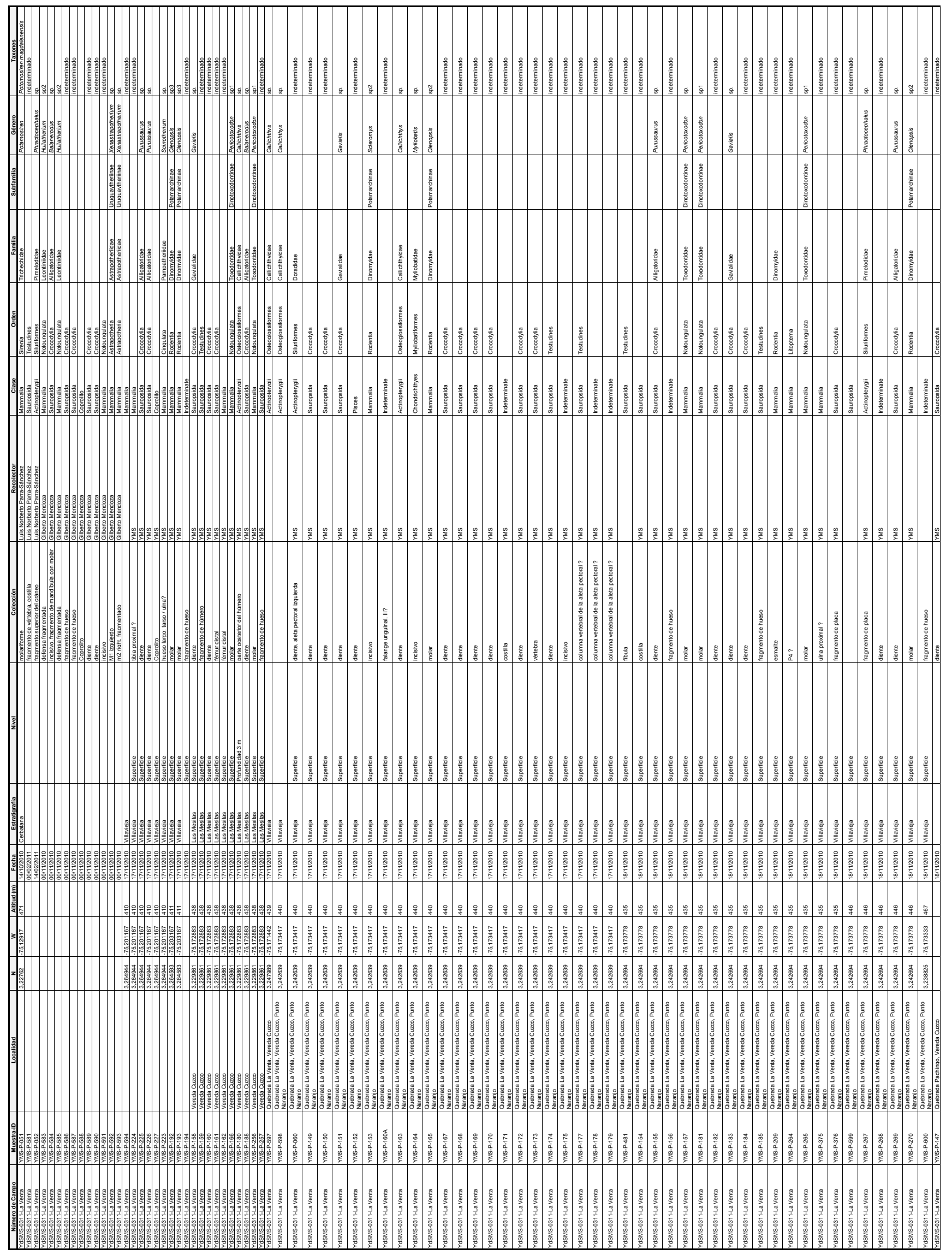




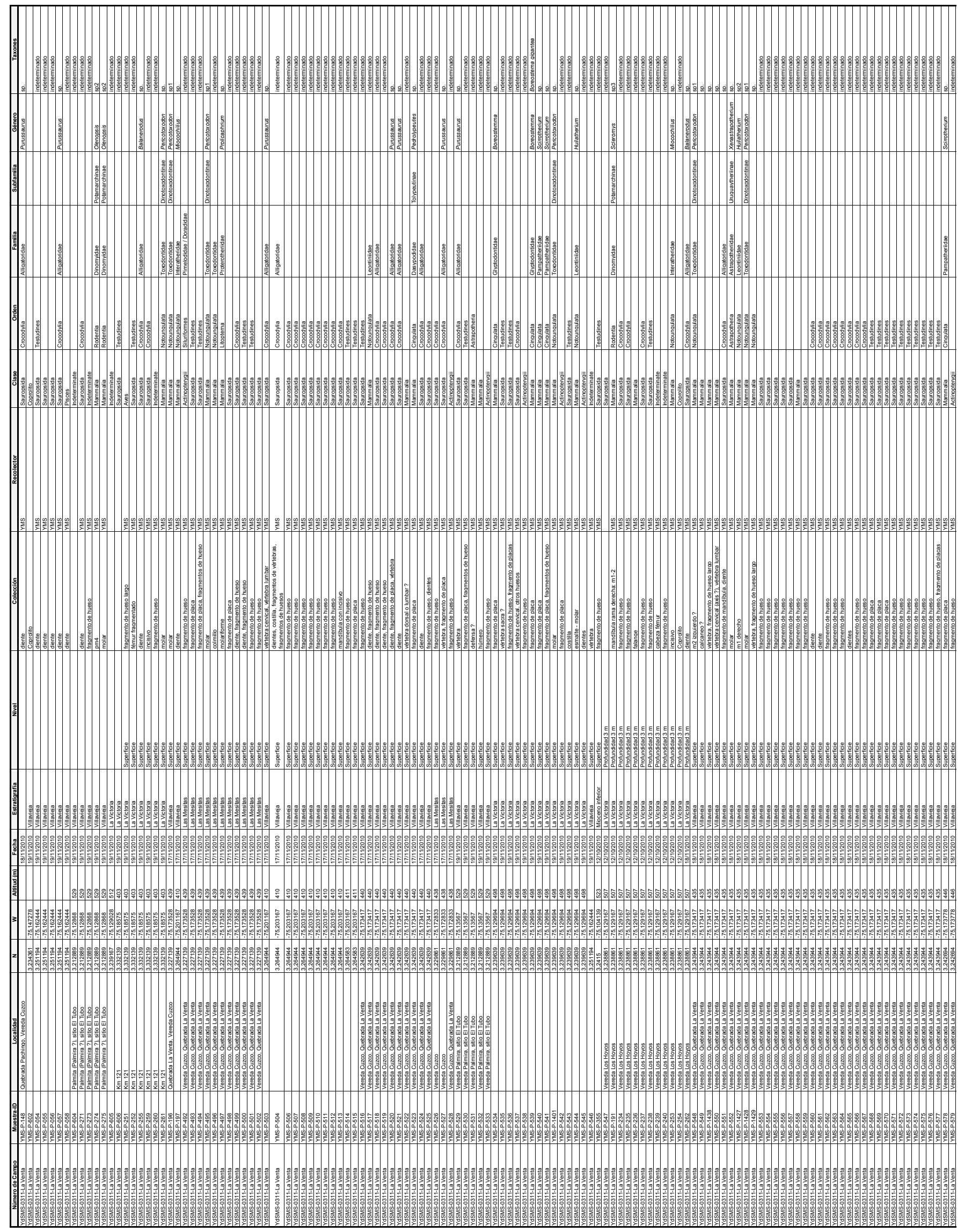




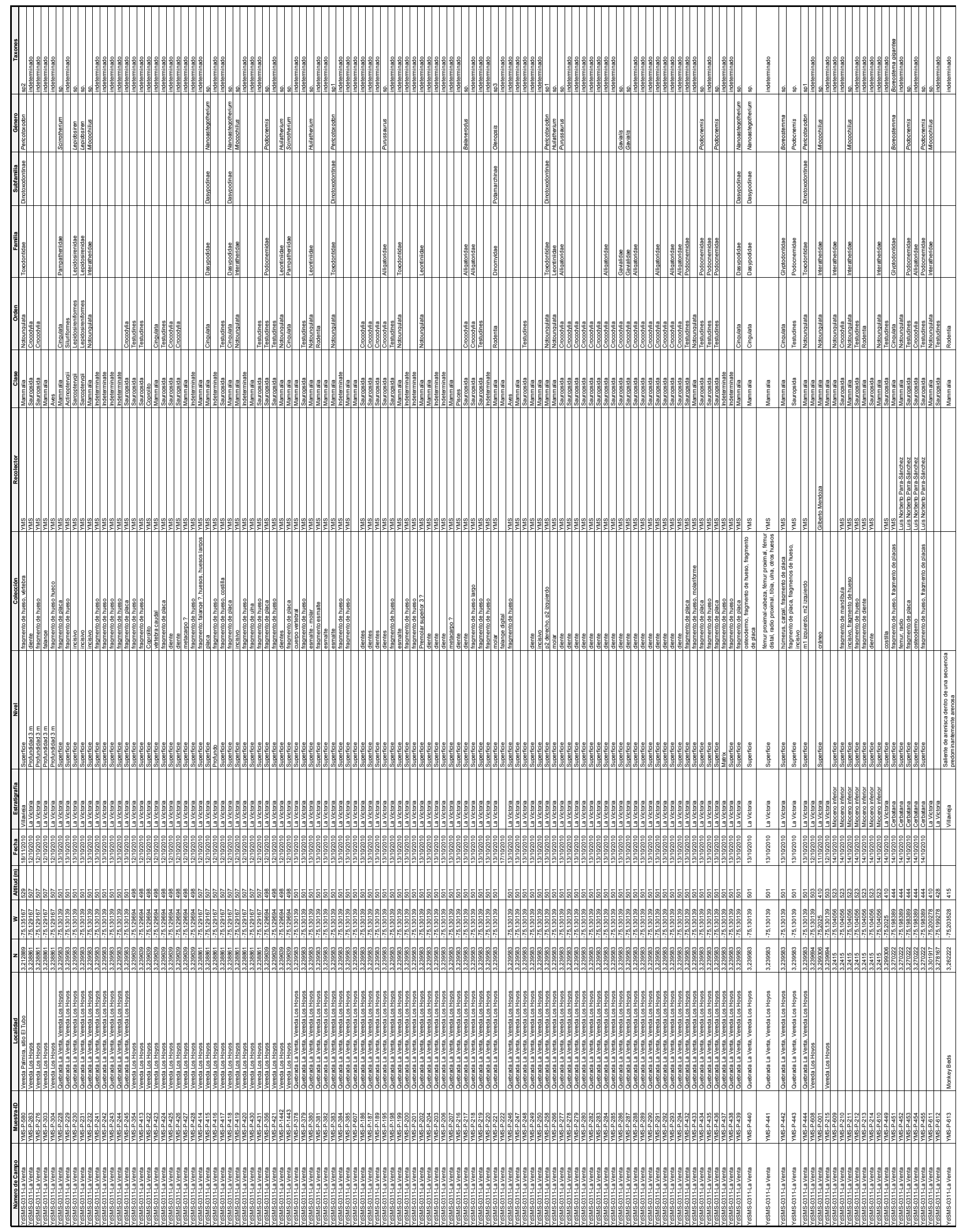




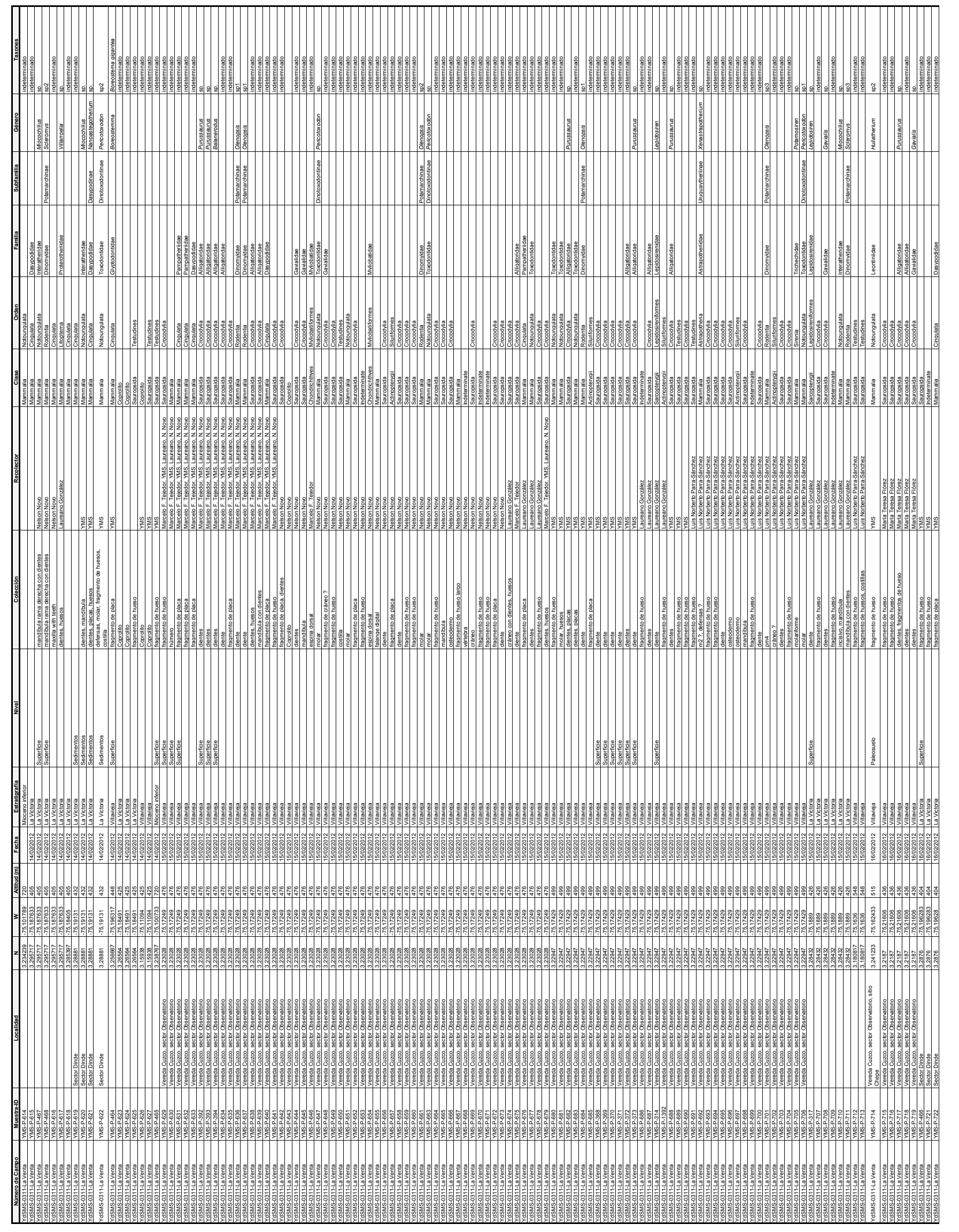




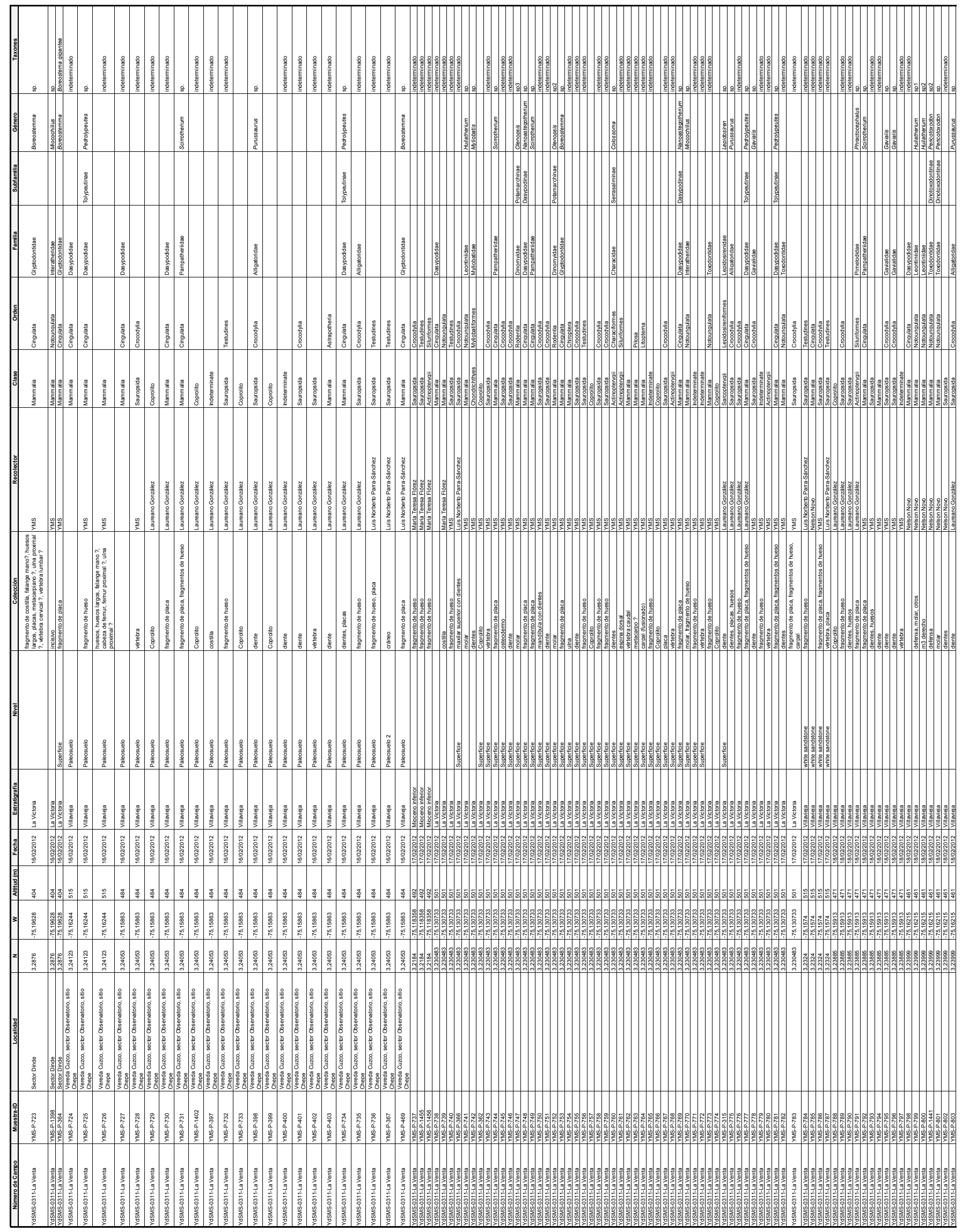




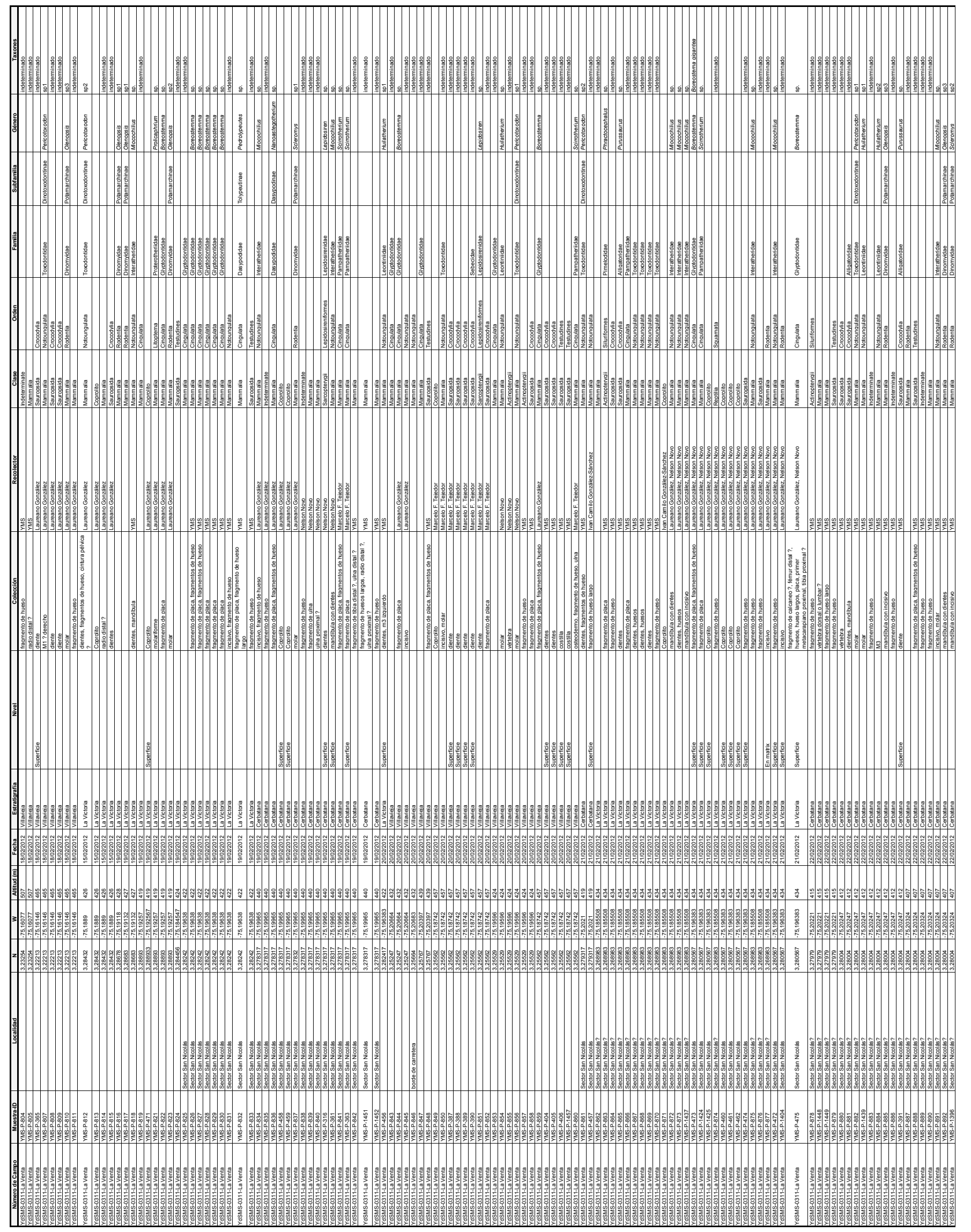




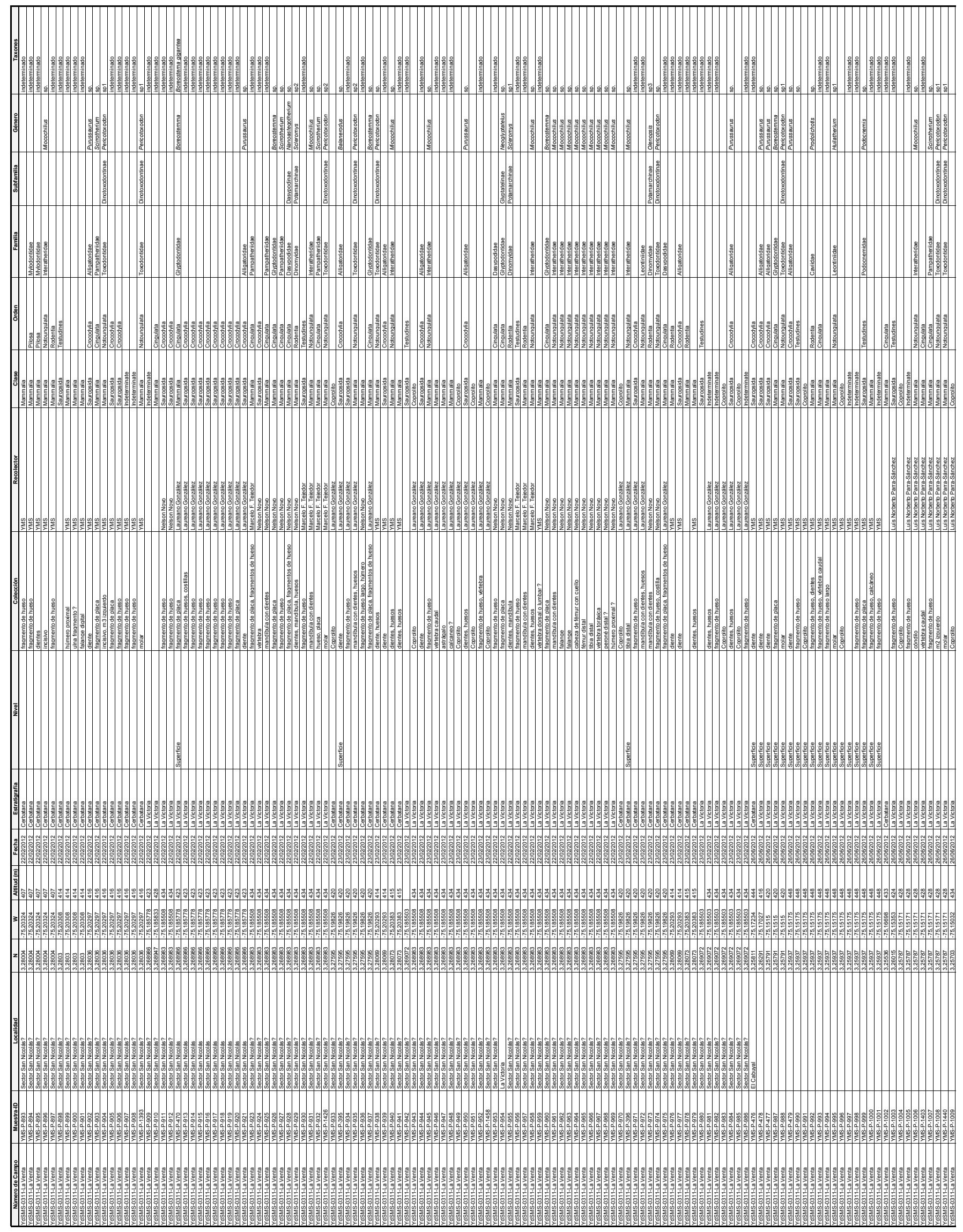




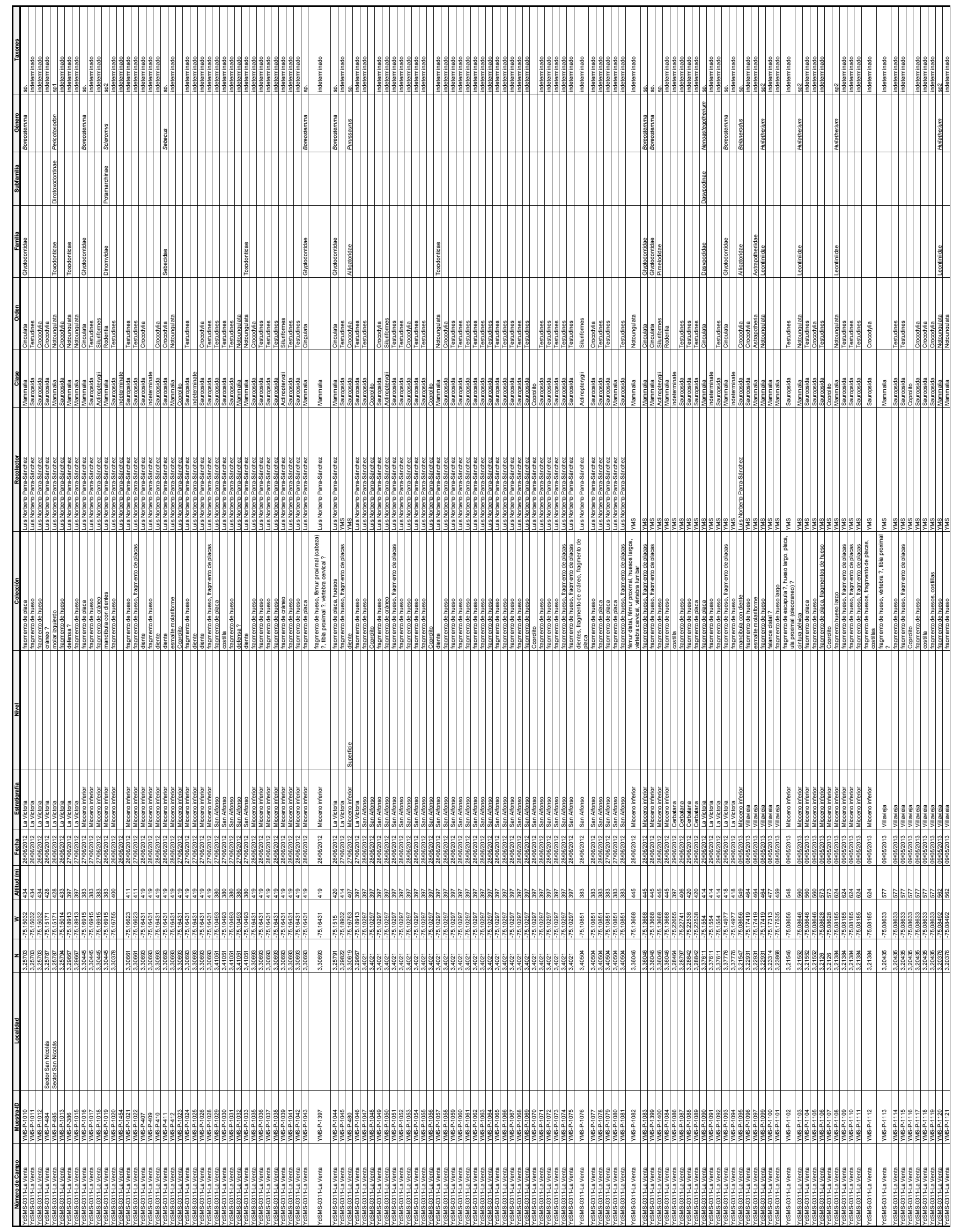




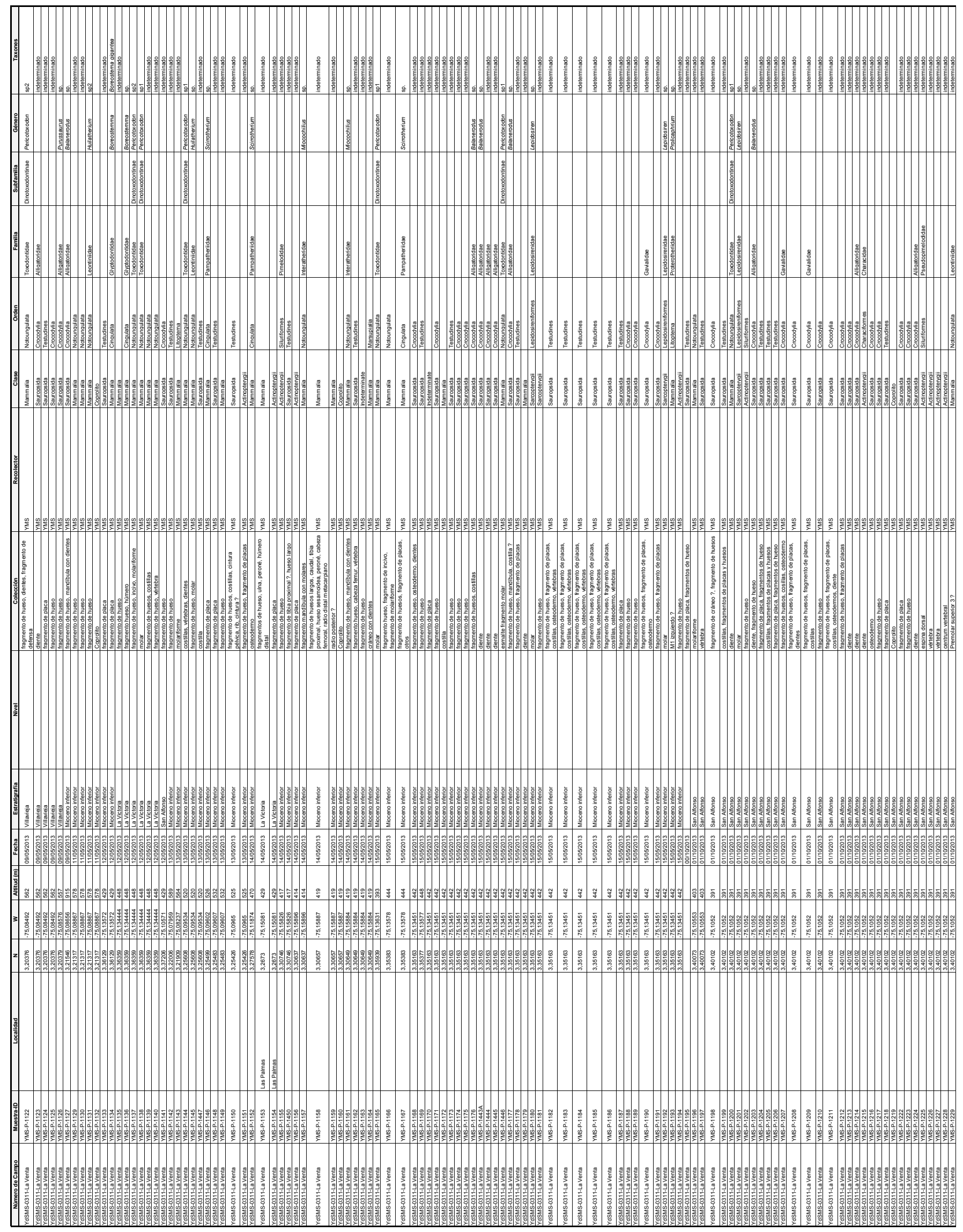




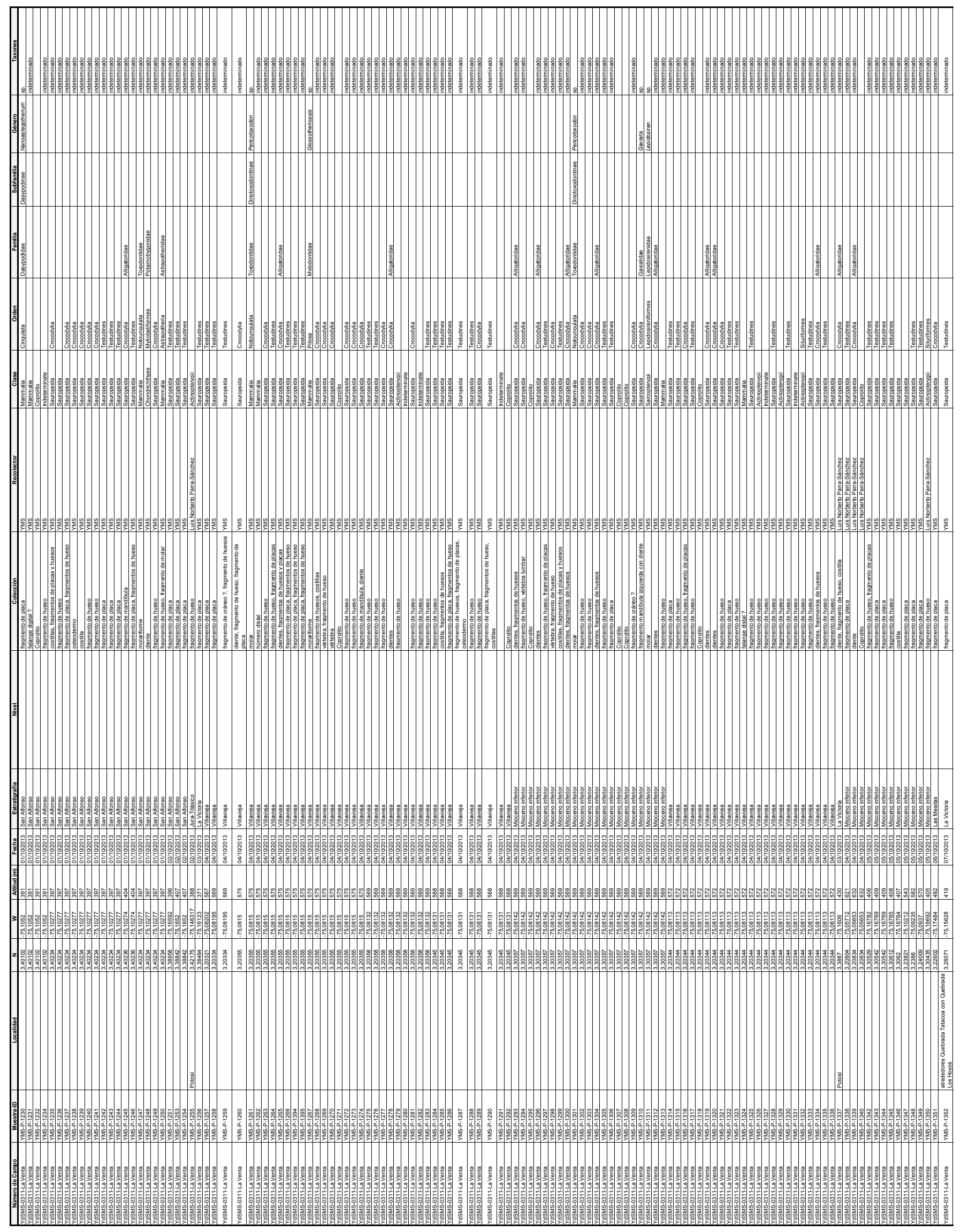




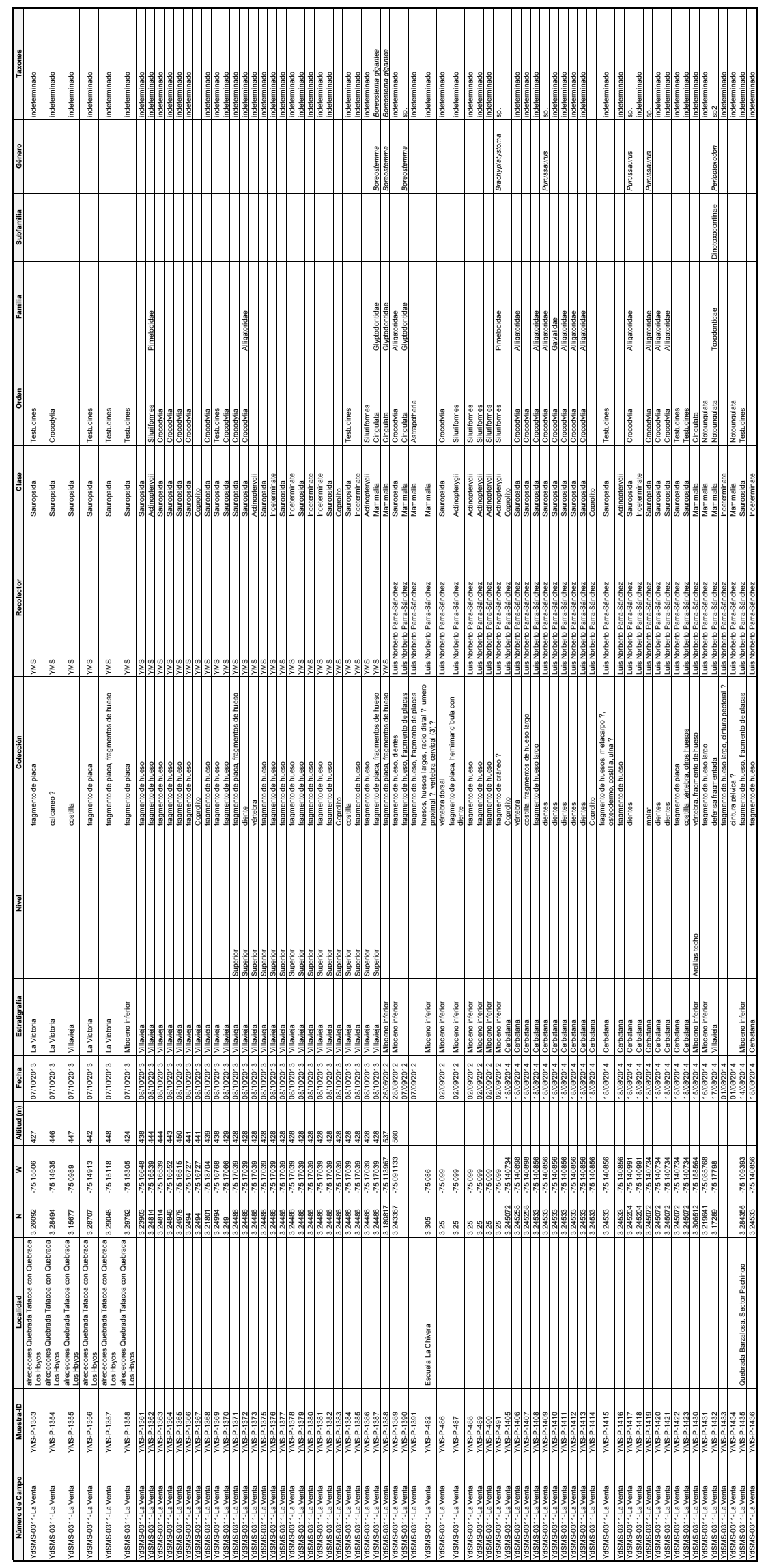


Tabla 3. Información base (datos crudos) del análisis de vertebrados. Información recopilada a partir de la literatura.

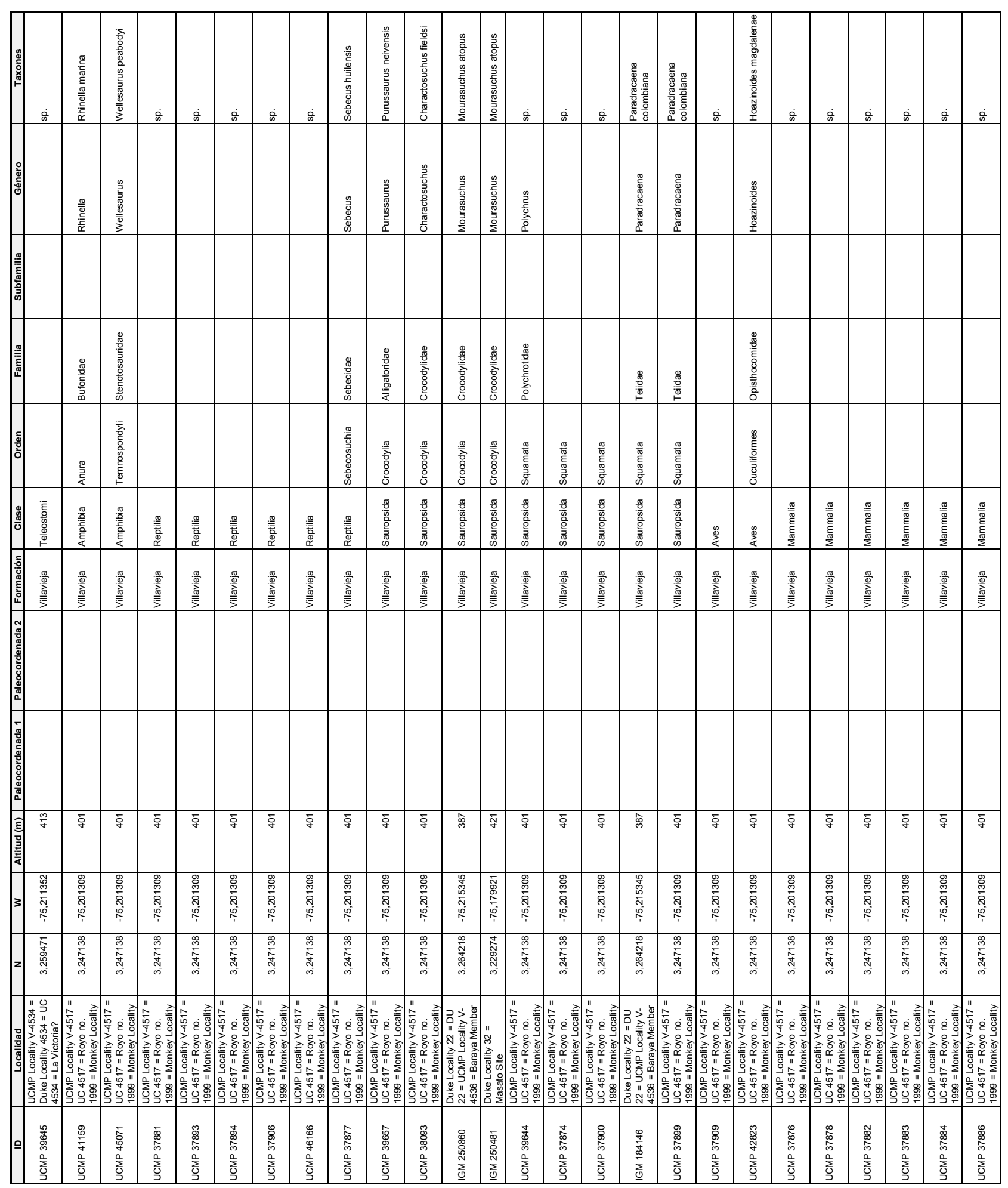




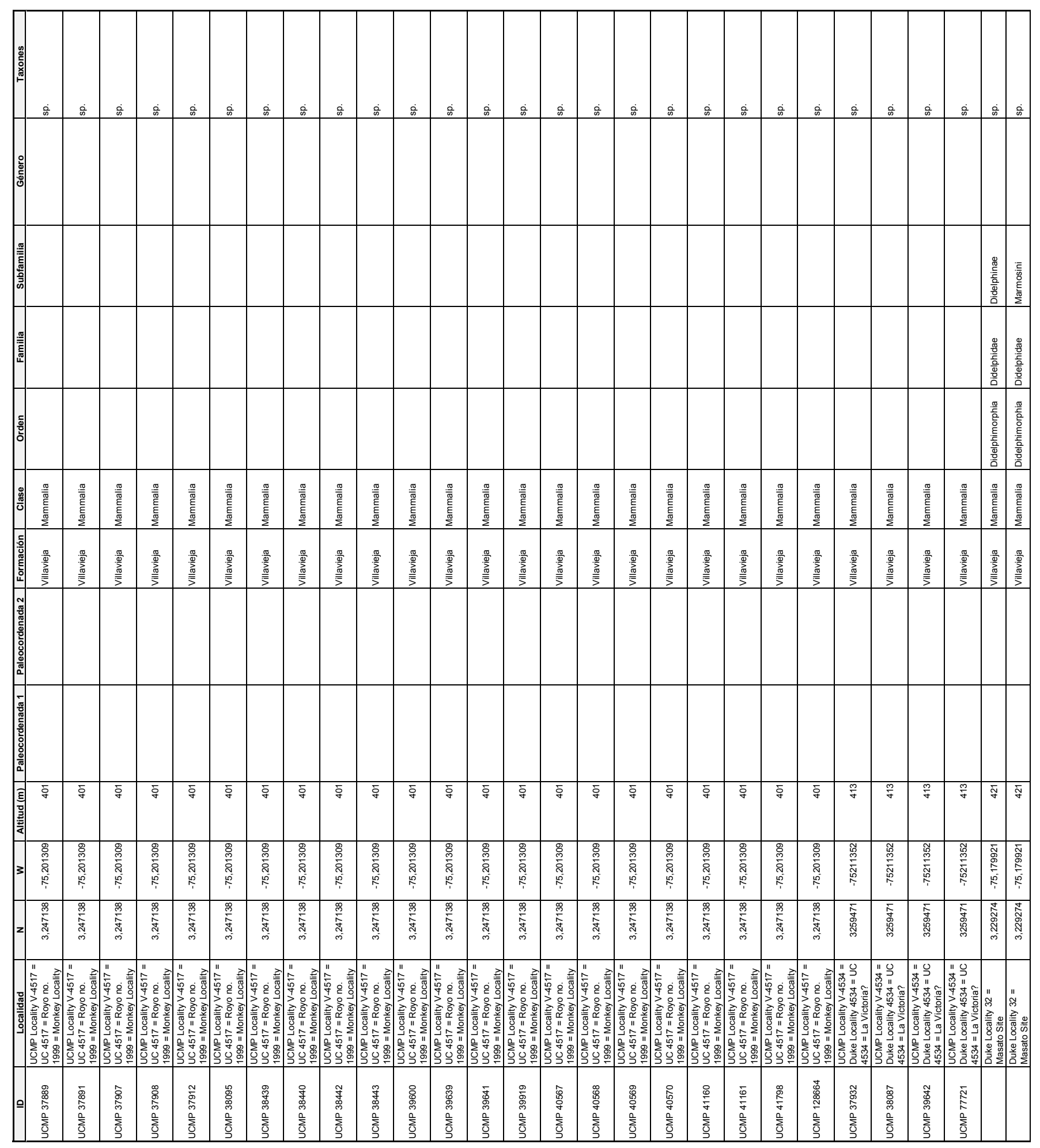




\begin{tabular}{|c|c|c|c|c|c|c|c|c|c|c|c|c|c|c|c|c|c|c|c|c|c|c|c|c|c|c|}
\hline & 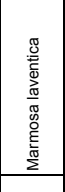 & 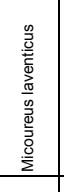 & 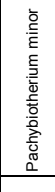 & 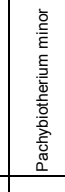 & 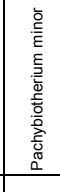 & 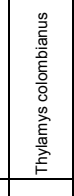 & 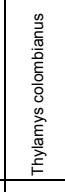 & 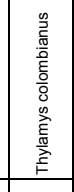 & 鲟 & 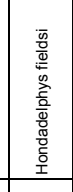 & 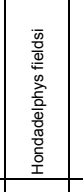 & & & & & $\dot{m}$ & $\frac{\dot{\omega}}{2}$ & $\frac{6}{6}$ & $\dot{\phi}$ & 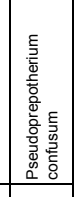 & & & 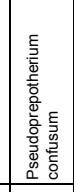 & $\div$ & 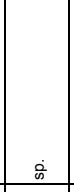 & 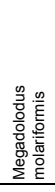 \\
\hline & $\begin{array}{l}\text { 总 } \\
\text { 高 } \\
\end{array}$ & 兴 & 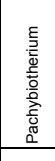 & 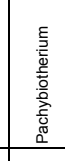 & 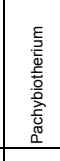 & 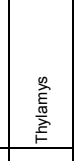 & 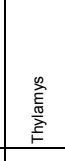 & 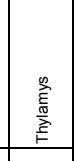 & 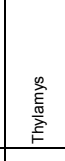 & 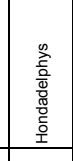 & 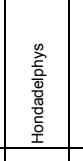 & & & 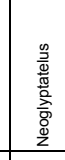 & 喜 & & & & & & & & $\frac{\sqrt{\frac{5}{5}}}{\overline{\frac{1}{2}}}$ & & 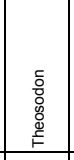 & 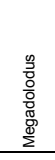 \\
\hline & & & & & & & & & & & & & & 0 & & & & & & & & & & $\frac{z}{2}$ & & \\
\hline & 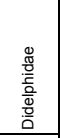 & 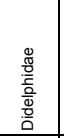 & 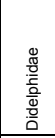 & 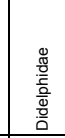 & 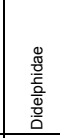 & 总 & 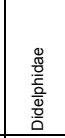 & 总 & 总 & 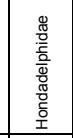 & 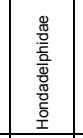 & & 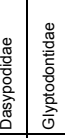 & 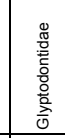 & 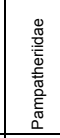 & & & 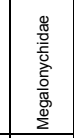 & 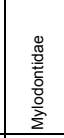 & 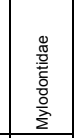 & 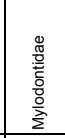 & 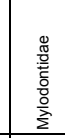 & 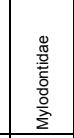 & 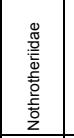 & 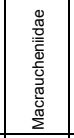 & 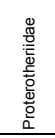 \\
\hline & 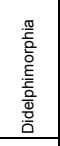 & 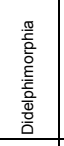 & 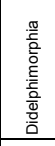 & 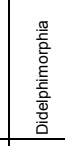 & 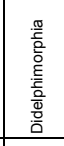 & 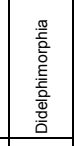 & 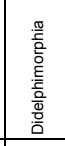 & 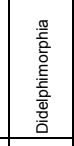 & 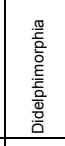 & 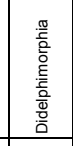 & 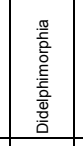 & & 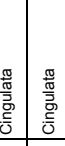 & 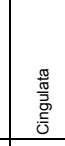 & 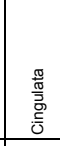 & 夠 & \begin{tabular}{|l}
$\frac{g}{2}$ \\
$\frac{a}{a}$
\end{tabular} & \begin{tabular}{|l|}
$\frac{g}{2}$ \\
$\frac{\partial}{2}$ \\
\end{tabular} & \begin{tabular}{|l|l}
$\frac{g}{2}$ \\
\end{tabular} & \begin{tabular}{|l}
$\frac{g}{\frac{g}{2}}$ \\
\end{tabular} & 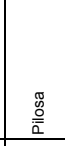 & $\mid \frac{\frac{g}{2}}{\frac{\delta}{2}}$ & \begin{tabular}{|l}
$\frac{g}{\frac{g}{2}}$ \\
\end{tabular} & $\begin{array}{c}\frac{\mathrm{g}}{\mathrm{a}} \\
\end{array}$ & 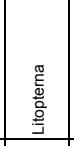 & 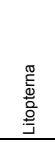 \\
\hline & 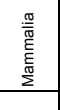 & 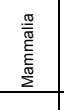 & 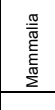 & 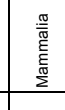 & 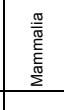 & 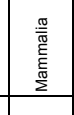 & 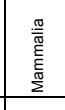 & 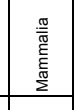 & 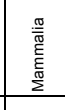 & 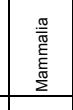 & 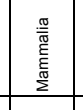 & & 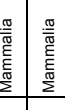 & 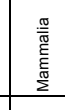 & 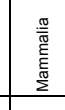 & 量 & 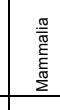 & 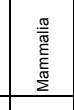 & 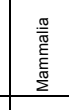 & 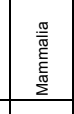 & 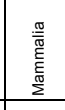 & 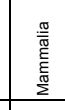 & 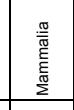 & 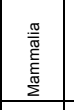 & 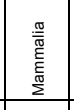 & 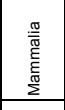 \\
\hline$\frac{\mathrm{m}}{\mathrm{g}}$ & 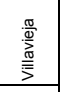 & 喜 & 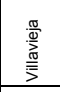 & 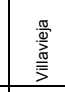 & 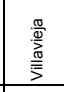 & 墨 & 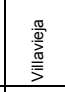 & 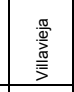 & 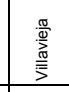 & 亳 & 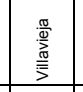 & & 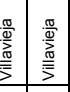 & 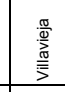 & 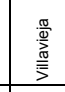 & 亳 & 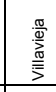 & 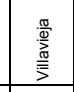 & 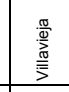 & 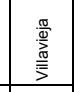 & 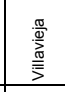 & 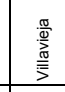 & 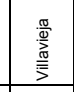 & 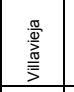 & 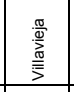 & 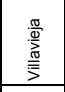 \\
\hline$\overline{\bar{y}}$ & $\overline{\bar{y}}$ & 吾 & 詥 & 弇 & \begin{tabular}{|l|l|} 
票 \\
\end{tabular} & 畣 & 畣 & $\overline{\mathrm{g}}$ & 总 & $\overline{\mathrm{D}}$ & $\overline{\bar{G}}$ & \begin{tabular}{|l|l|}
$\bar{y}$ & $\bar{s}$
\end{tabular} & $\overline{\bar{z}} \overline{\bar{z}}$ & 弇 & $\frac{m}{q}$ & $\overline{\bar{\alpha}}$ & $\frac{m}{q}$ & $\overline{\bar{\sigma}}$ & $\overline{\bar{\sigma}}$ & $\bar{\sigma}$ & 京 & $\overline{\bar{\sigma}}$ & $\overline{\bar{\sigma}}$ & $\frac{m}{q}$ & $\frac{m}{7}$ & $\mid \bar{q}$ \\
\hline 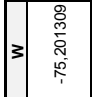 & 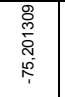 & 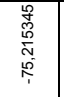 & 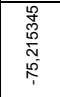 & 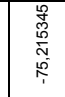 & 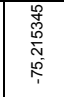 & 筩 & 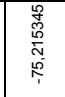 & 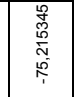 & 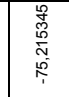 & 筩 & 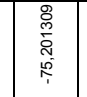 & 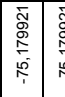 & 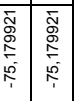 & 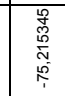 & 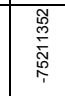 & 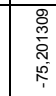 & 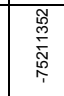 & 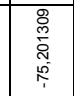 & 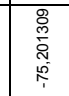 & 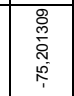 & 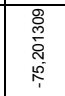 & 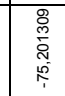 & 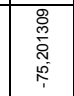 & 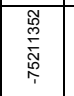 & 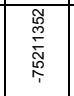 & 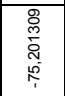 \\
\hline 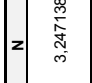 & 憵 & 离 & 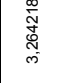 & 产 & 总 & 离 & 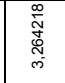 & 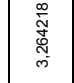 & 离 & 离 & 旁 & 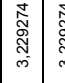 & 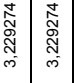 & 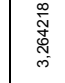 & 嘀 & 总 & 嘉 & 曾 & 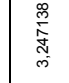 & 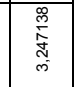 & 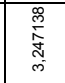 & 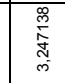 & 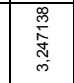 & \begin{tabular}{|l|l} 
蘦 \\
\end{tabular} & \begin{tabular}{|l|} 
莬 \\
\end{tabular} & 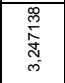 \\
\hline & & & & & & & & & & & & & & & & & & & & & & & & & & \\
\hline 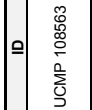 & 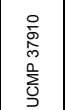 & 亳 & 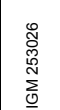 & 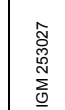 & 夢 & 商 & 㩊 & 喜 & 总 & 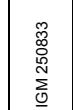 & $\begin{array}{l}\text { 总 } \\
\text { 譥 }\end{array}$ & 衰 & & & 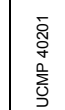 & 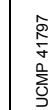 & 曾 & 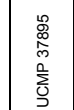 & 啹 & 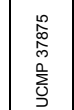 & 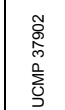 & 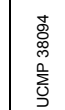 & 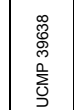 & 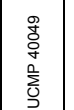 & 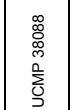 & 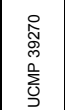 \\
\hline
\end{tabular}




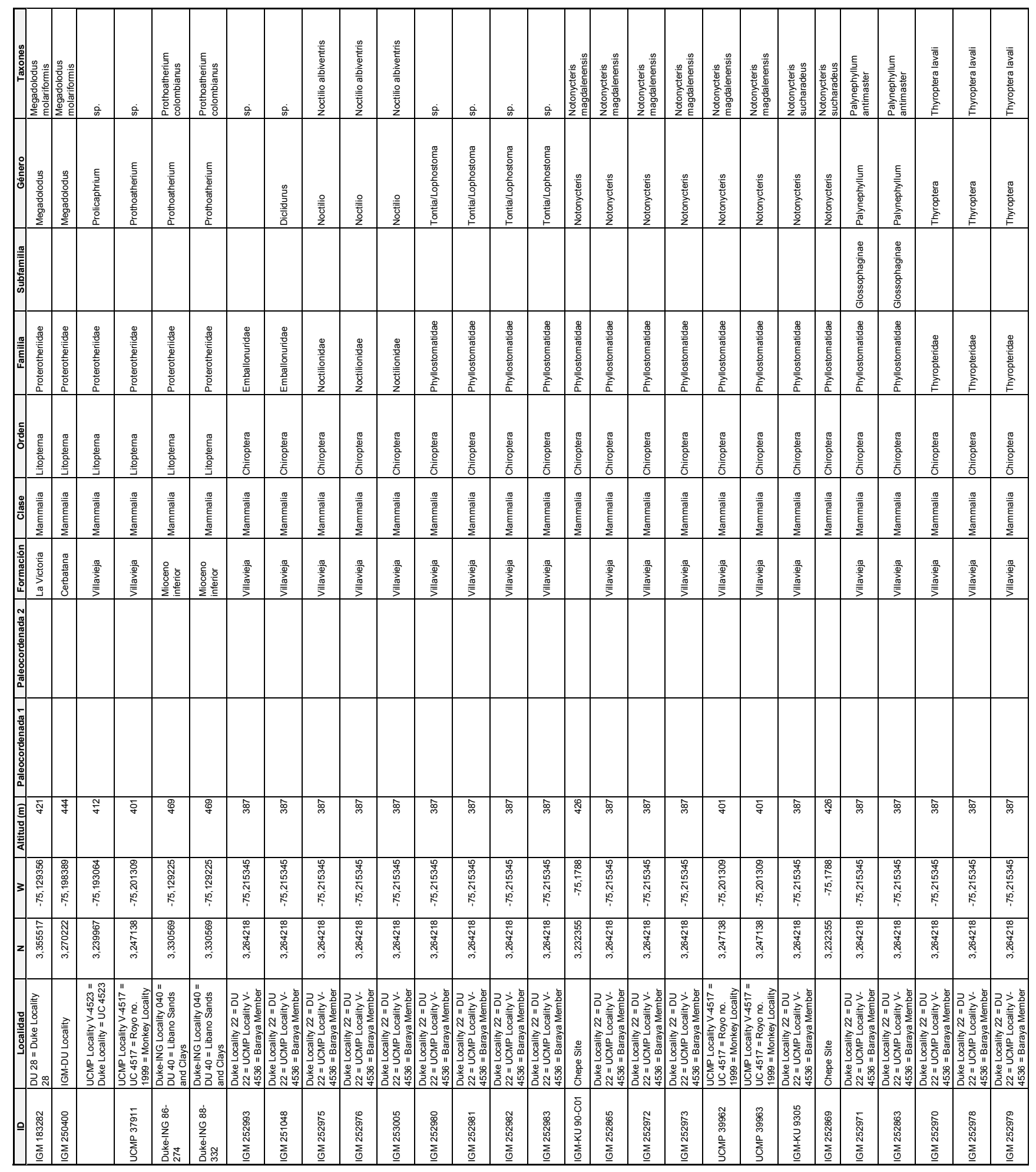




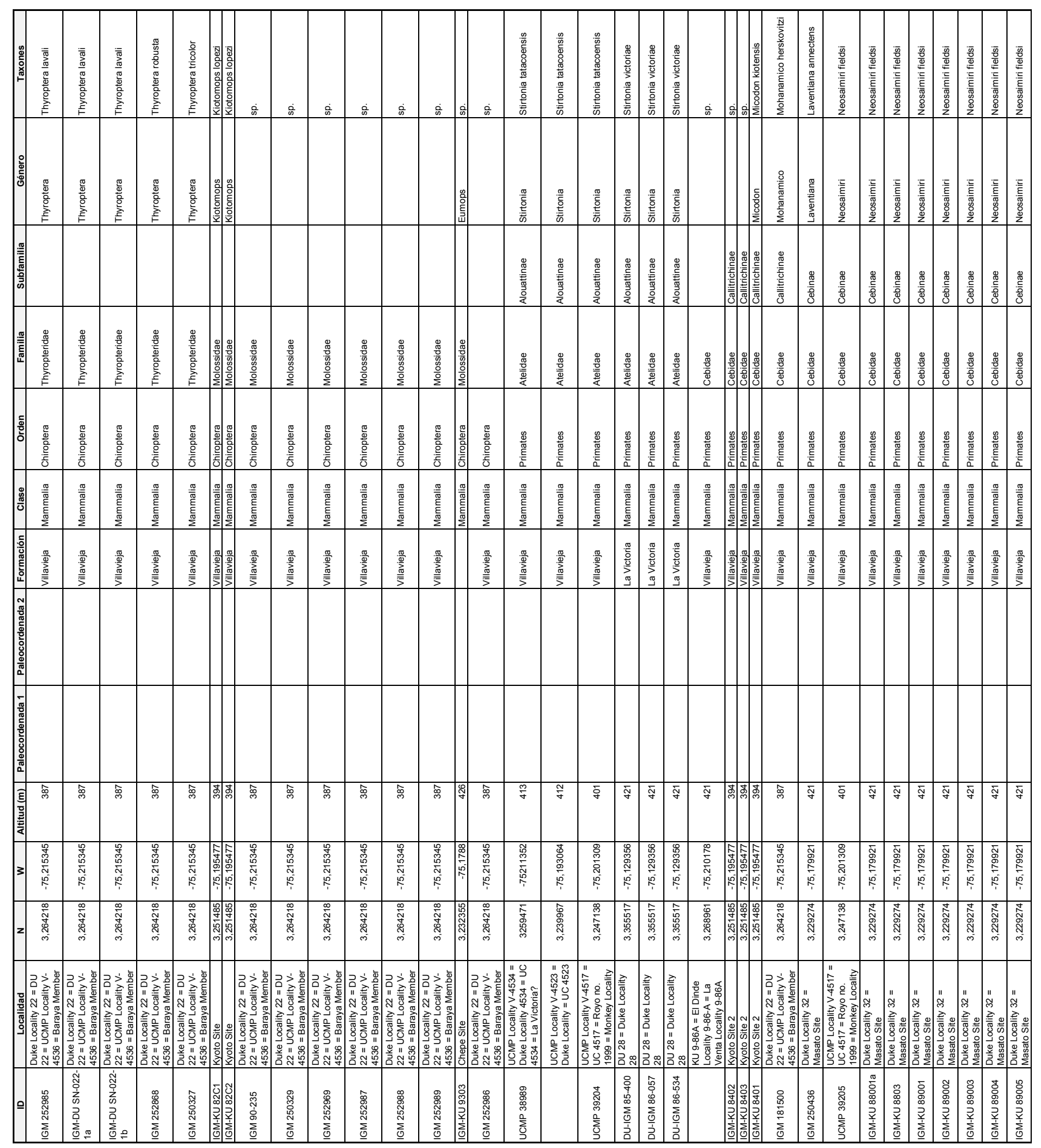




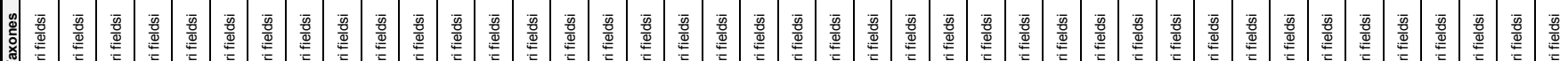

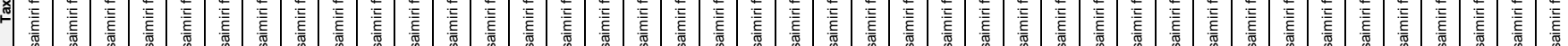

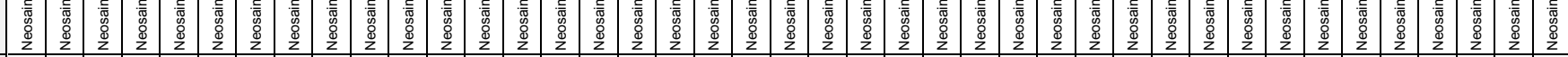

高

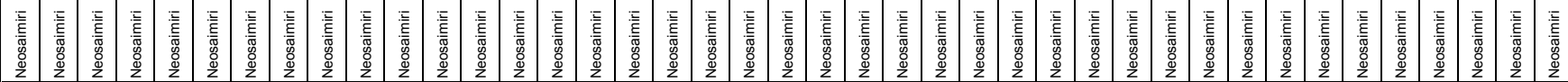

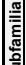

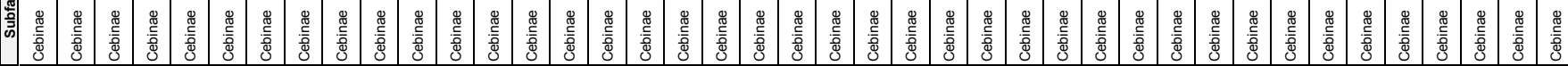

童

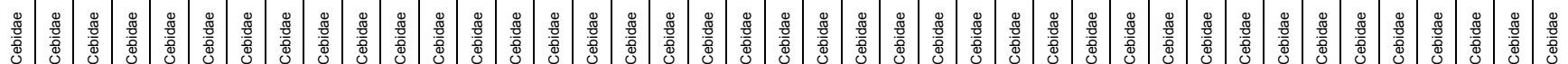

悹

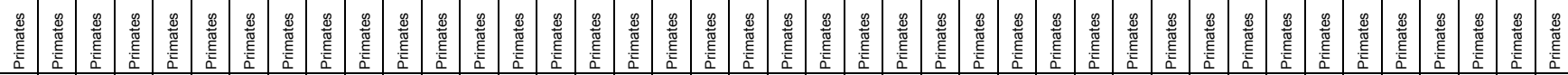

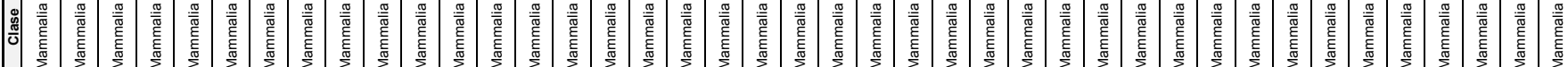

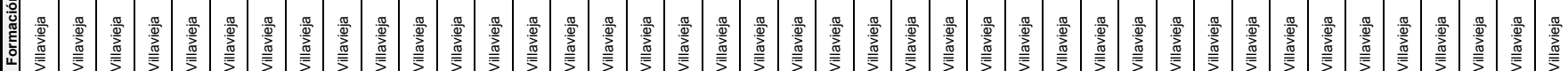

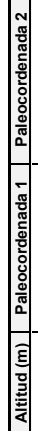

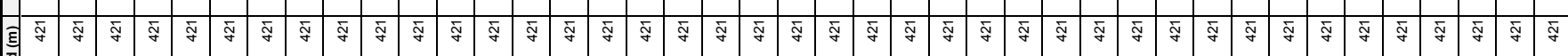

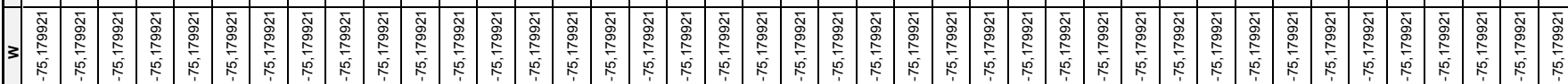

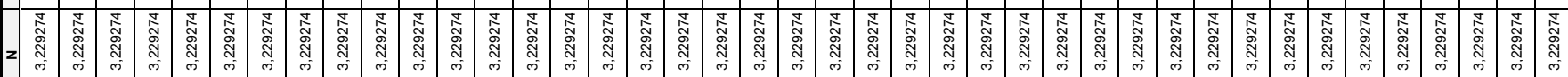

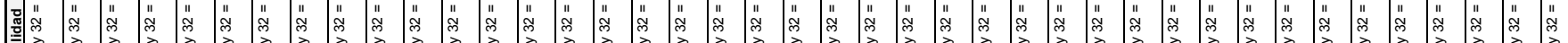

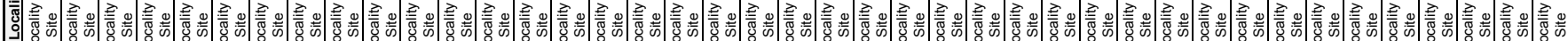

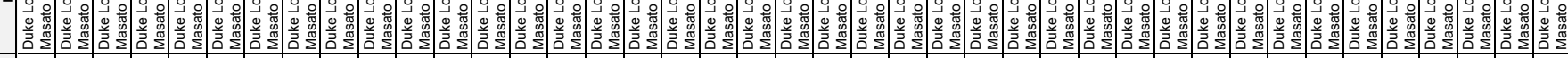

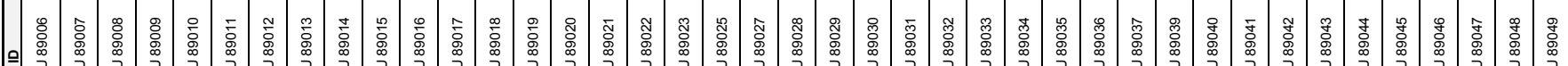

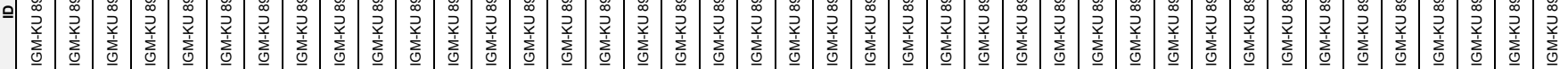




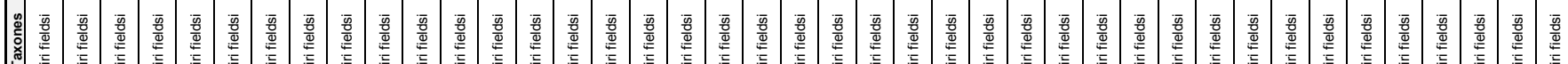

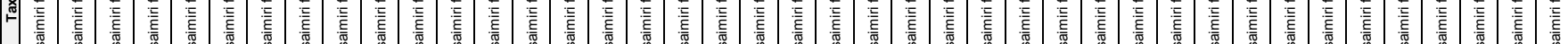

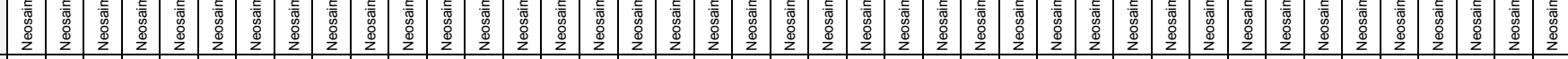
:

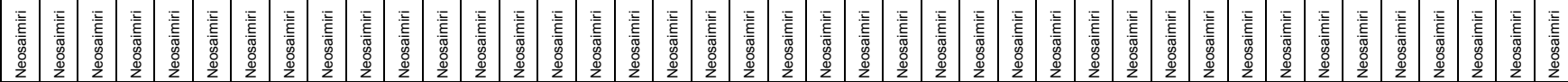
悹

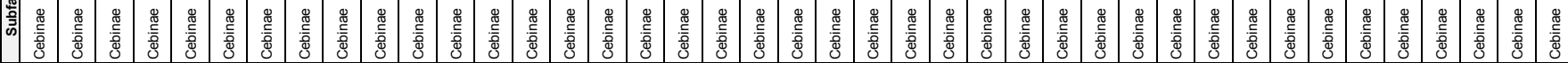
童

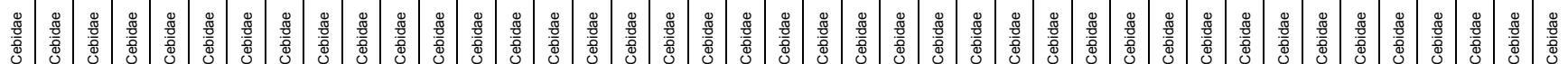

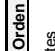

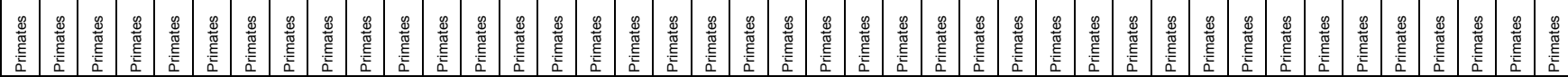

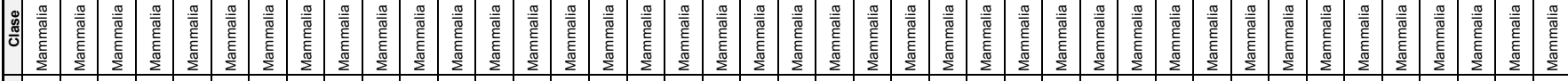

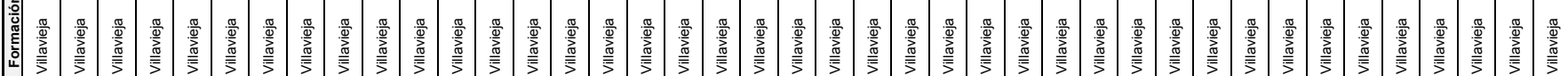
啇

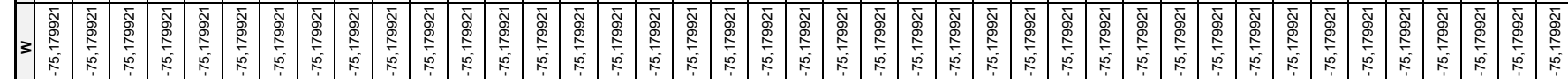

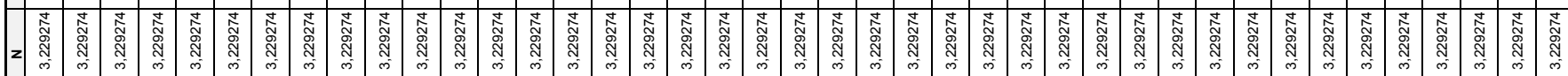

预

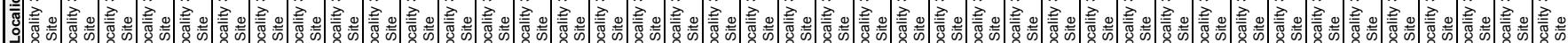

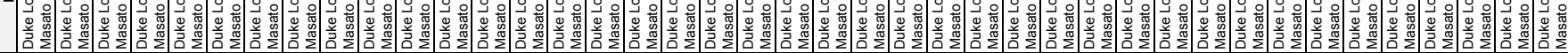

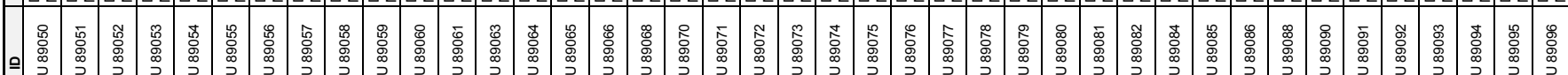

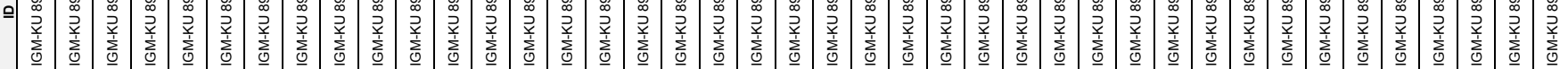




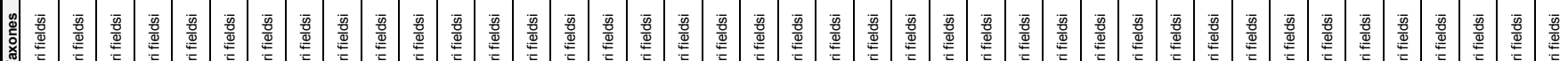

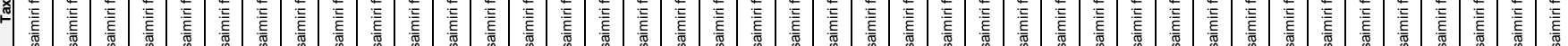

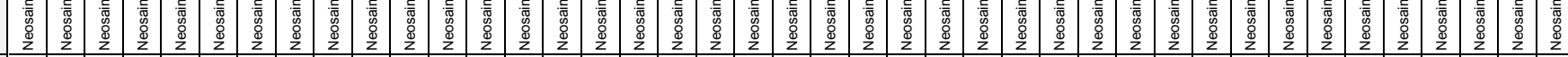

高

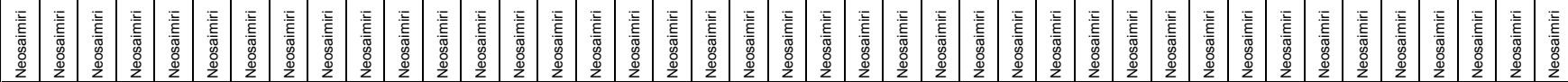

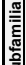

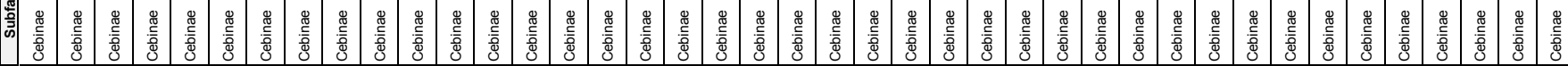

童

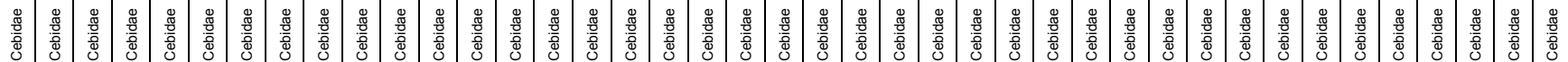

悹

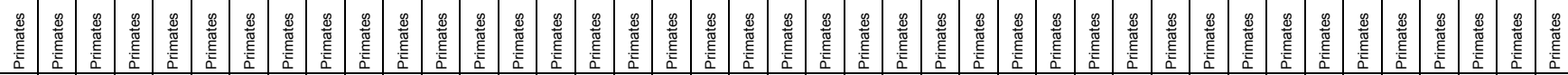

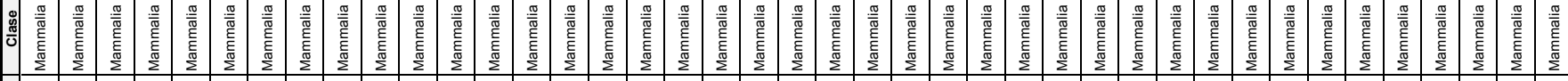

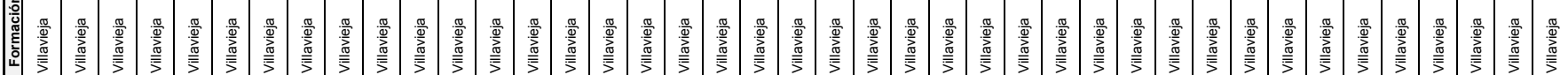

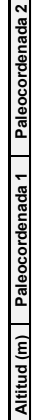

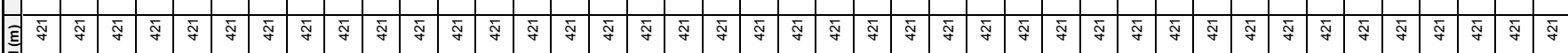

$\div$

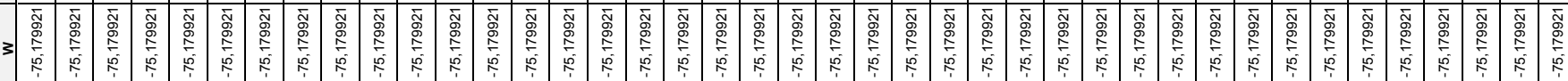

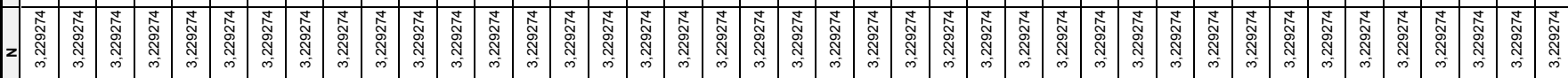

च

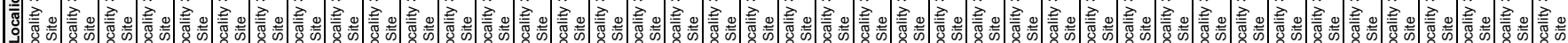

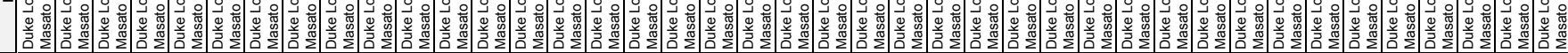

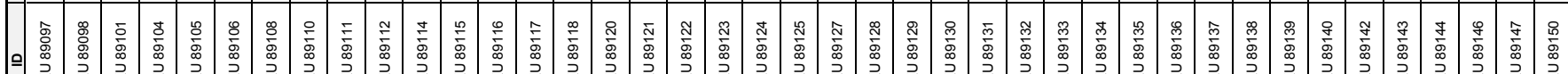

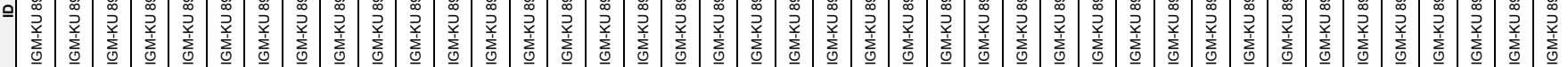




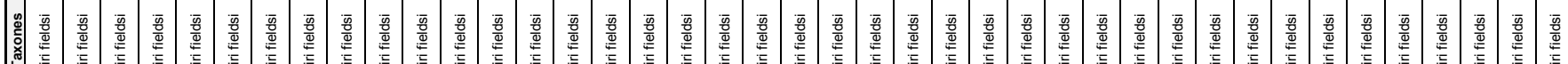

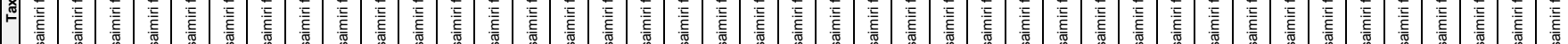

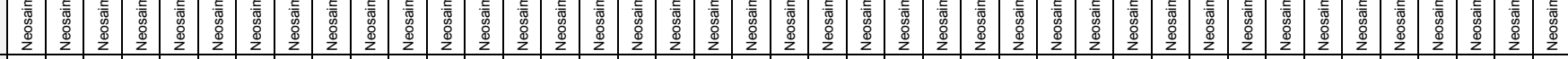
:

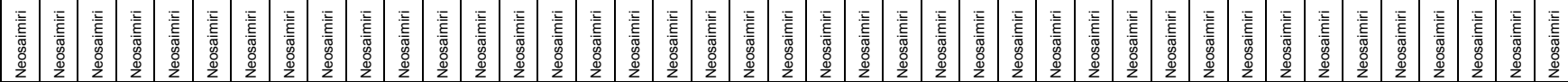
悹

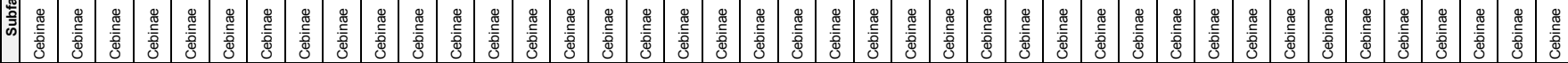
童

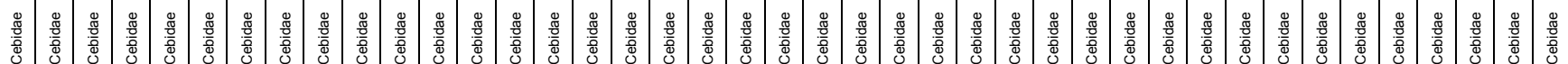

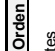

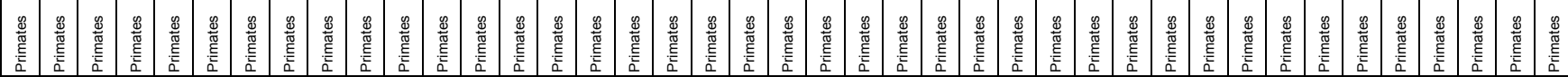

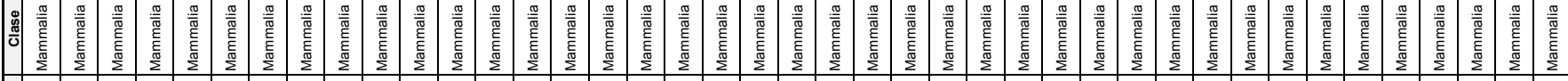

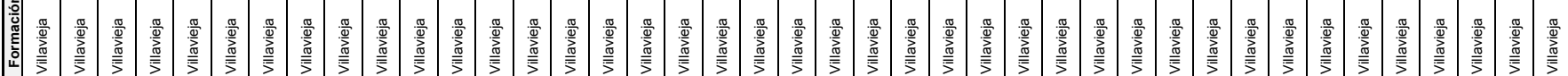
啇

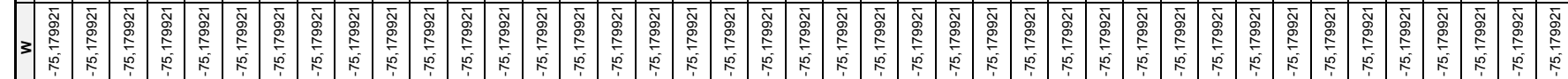

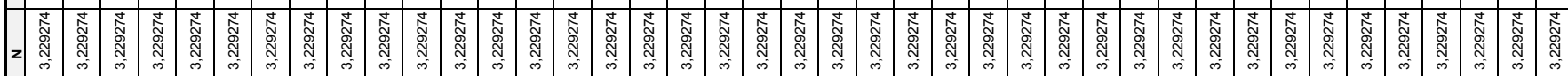

预

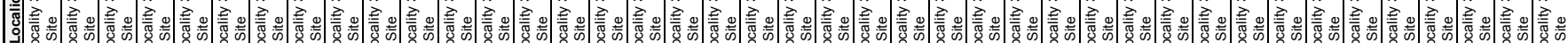

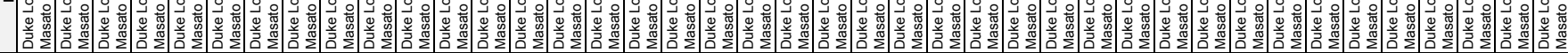

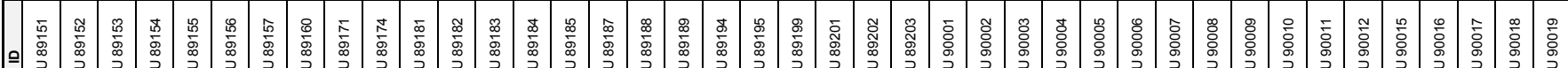

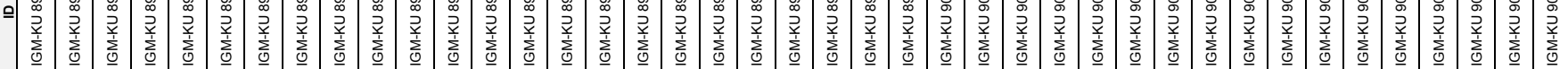




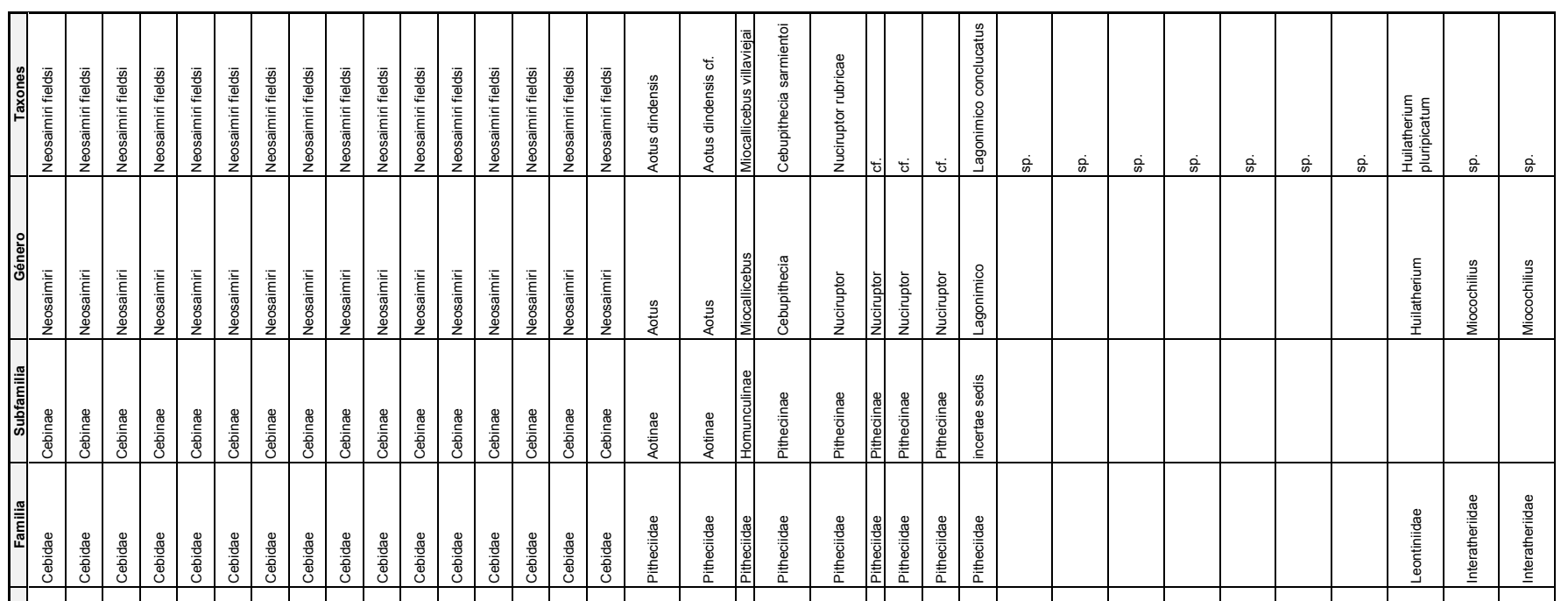

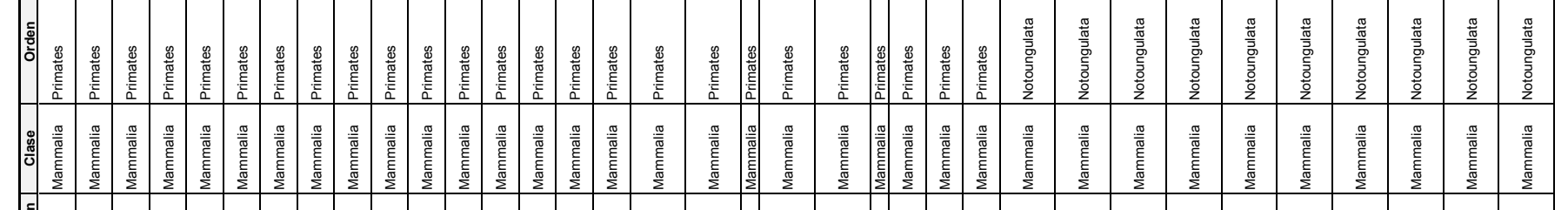

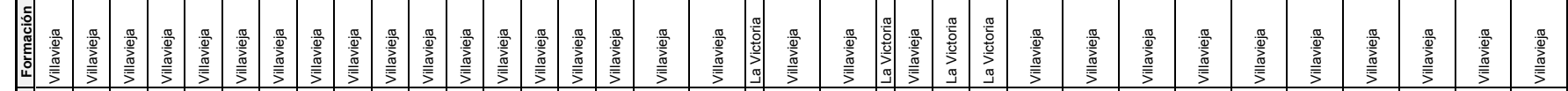
墒

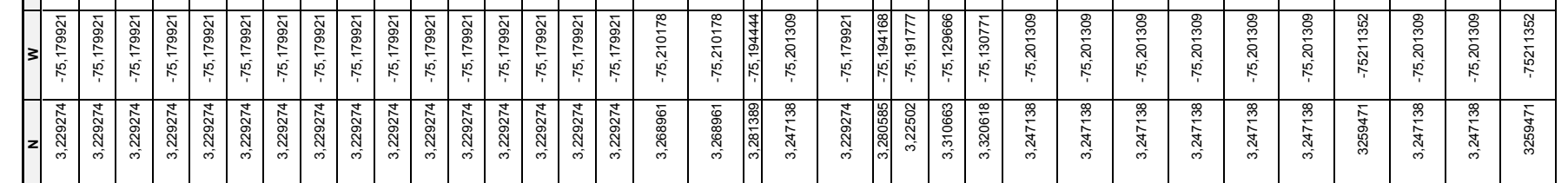

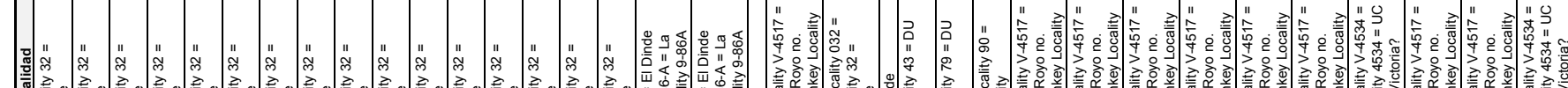

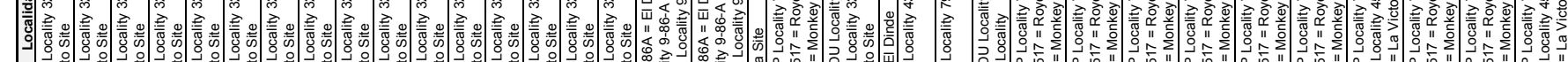

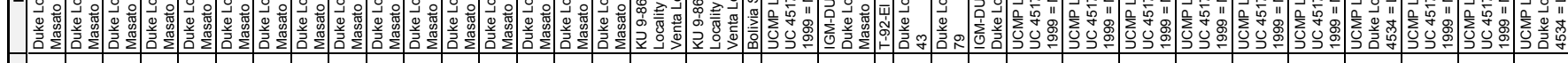

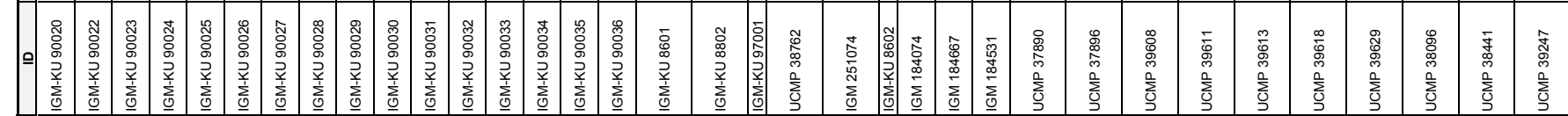




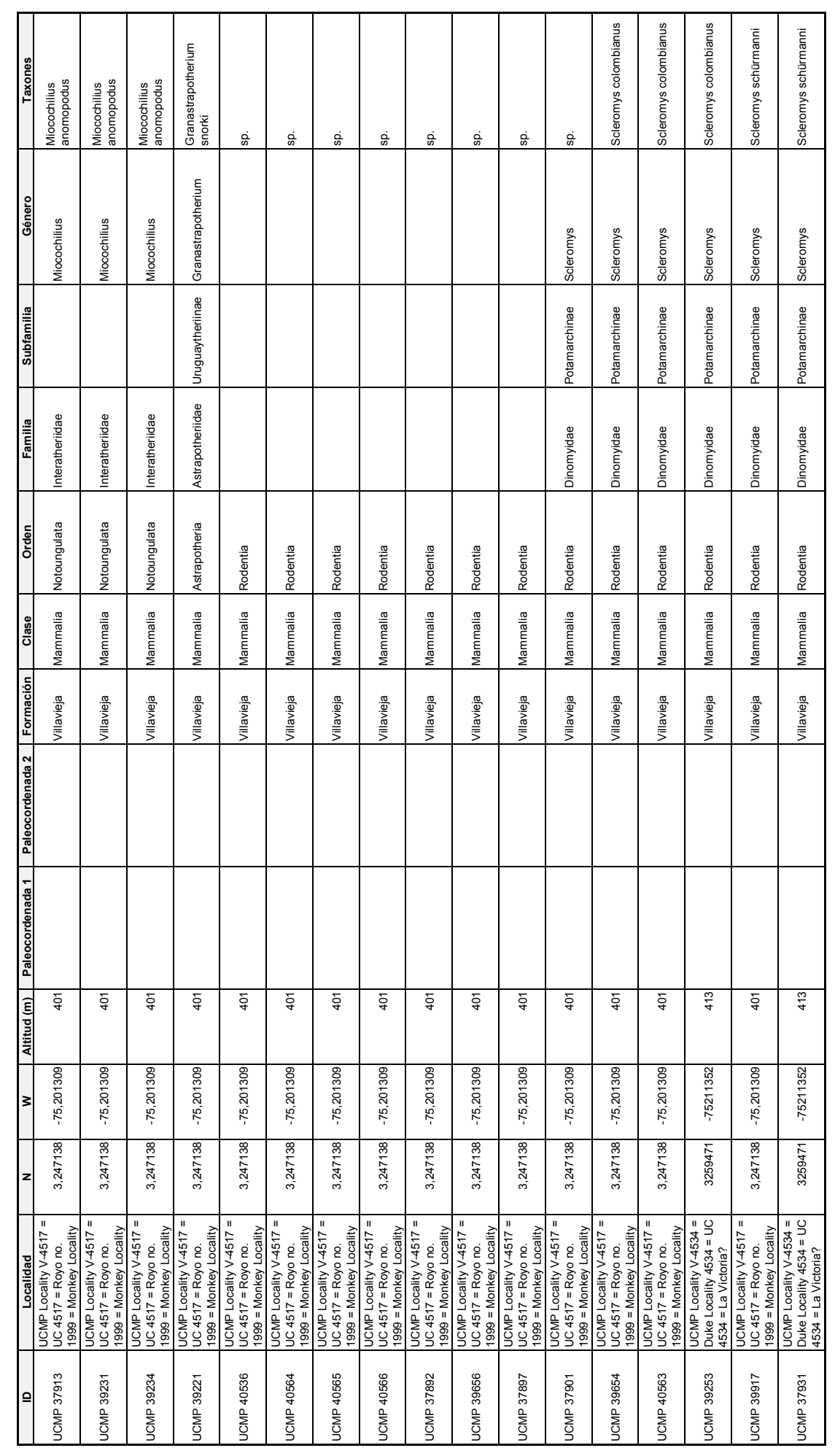


TABLA 4. Lista de vertebrados fósiles del Grupo La Venta registrados en la presente investigación y en literatura

\begin{tabular}{|c|c|c|c|c|c|c|c|c|c|}
\hline Clase & Orden & Familia & Género & Taxones & San Alfonso & La Victoria & Cerbatana & Villavieja & Las Mesitas \\
\hline & & & Total & 52 & 12 & 25 & 9 & 41 & 9 \\
\hline \multicolumn{4}{|l|}{ Pisces } & 1 & 0 & 1 & 0 & 1 & 0 \\
\hline Pisces & & & & sp. & & $\mathrm{X}$ & & $\mathrm{X}$ & \\
\hline \multicolumn{4}{|l|}{ Teleostomi } & 1 & 0 & 0 & 0 & 1 & 0 \\
\hline Teleostomi & & & & sp. & & & & $\mathrm{X}$ & \\
\hline \multicolumn{4}{|l|}{ Actinopterygii } & 11 & 4 & 4 & 1 & 7 & 3 \\
\hline \multirow{11}{*}{ Actinopterygii } & & & & sp. & $X$ & $\mathrm{X}$ & & $\mathrm{X}$ & $\mathrm{X}$ \\
\hline & Characiformes & Characidae & & sp. & $\mathrm{X}$ & & & & \\
\hline & Characiformes & Characidae & Colossoma & sp. & & $\mathrm{X}$ & & & \\
\hline & Osteoglossiformes & Callichthyidae & Callichthys & sp. & & & & $\mathrm{X}$ & $\mathrm{X}$ \\
\hline & Siluriformes & & & sp. & $\mathrm{X}$ & $\mathrm{X}$ & $X$ & $X$ & \\
\hline & Siluriformes & Doradidae & & sp. & & & & $\mathrm{X}$ & \\
\hline & Siluriformes & Pimelodidae & & sp. & & & & $X$ & \\
\hline & Siluriformes & Pimelodidae / Doradidae & & sp. & & & & & $\mathrm{X}$ \\
\hline & Siluriformes & Pimelodidae & Brachyplatystoma & Brachyplatystoma promagdalena & & & & $\mathrm{X}$ & \\
\hline & Siluriformes & Pimelodidae & Phractocephalus & sp. & & $\mathrm{X}$ & & $x$ & \\
\hline & Siluriformes & Pseudopimelodidae & & sp. & $X$ & & & & \\
\hline \multicolumn{4}{|l|}{ Chondrichthyes } & 3 & 1 & 1 & 0 & 2 & 0 \\
\hline \multirow{3}{*}{ Chondrichthyes } & Myliobatiformes & Myliobatidae & & sp. & & & & $\mathrm{X}$ & \\
\hline & Myliobatiformes & Myliobatidae & Myliobatis & sp. & & $\mathrm{X}$ & & $\mathrm{X}$ & \\
\hline & Myliobatiformes & Potamotrygonidae & & sp. & $\mathrm{X}$ & & & & \\
\hline \multicolumn{4}{|l|}{ Sarcopterygii } & 1 & 1 & 1 & 1 & 1 & 0 \\
\hline Sarcopterygii & Lepidosireniformes & Lepidosirenidae & Lepidosiren & $\mathrm{sp}$. & $\mathrm{X}$ & $X$ & $\mathrm{X}$ & $X$ & \\
\hline \multicolumn{4}{|l|}{ Amphibia } & 2 & 0 & 0 & 0 & 2 & 0 \\
\hline \multirow{2}{*}{ Amphibia } & Anura & Bufonidac & Rhinella & Rhinella marina & & & & $\mathrm{X}$ & \\
\hline & Temnospondyli & Stenotosauridae & Wellesaurus & Wellesaurus peabodyi & & & & $\mathrm{X}$ & \\
\hline \multicolumn{4}{|l|}{ Reptilia } & 5 & 0 & 1 & 0 & 5 & 0 \\
\hline \multirow{5}{*}{ Reptilia } & & & & sp. & & & & $\mathrm{X}$ & \\
\hline & Eusuchia & & & sp. & & $X$ & & $X$ & \\
\hline & Sebecosuchia & & & sp. & & & & $\mathrm{X}$ & \\
\hline & Sebecosuchia & Sebecidae & & sp. & & & & $\mathrm{X}$ & \\
\hline & Sebecosuchia & Sebecidae & Sebecus & Sebecus huilensis & & & & $\mathrm{X}$ & \\
\hline \multicolumn{4}{|l|}{ Sauropsida } & 25 & 6 & 16 & 7 & 20 & 6 \\
\hline & & & & sp. & $X$ & $X$ & $X$ & $x$ & $x$ \\
\hline & Crocodylia & & & sp. & $\mathrm{X}$ & $\mathrm{X}$ & $\mathrm{X}$ & $\mathrm{X}$ & $\mathrm{X}$ \\
\hline & Crocodylia & Alligatoridae & & sp. & $\mathrm{X}$ & $x$ & $\mathrm{X}$ & $X$ & \\
\hline & Crocodylia & Alligatoridae & Balanerodus & sp. & $x$ & $\mathrm{X}$ & $X$ & $\mathrm{X}$ & $\mathrm{X}$ \\
\hline & Crocodylia & Alligatoridae & Balamerodus logimus & & & $X$ & & & \\
\hline & Crocodylia & Alligatoridae & Caiman & Caiman lutescens & & & & $X$ & \\
\hline & Crocodylia & Alligatoridae & Purussaurzus & sp. & & $X$ & $\mathrm{X}$ & $x$ & $X$ \\
\hline & Crocodylia & Alligatoridae & Purnssaurus & Purussaurus neivensis & & & & $\mathrm{X}$ & \\
\hline & Crocodylia & Crocodylidae & & sp. & & & & $\mathrm{X}$ & \\
\hline & Crocodylia & Crocodylidae & Charactosuchus & Charactosuchus fieldsi & & & & $\mathrm{X}$ & \\
\hline & Crocodylia & Crocodylidae & Gryposuchus & Gryposuchus colombiamus & & $\mathrm{X}$ & & & \\
\hline & Crocodylia & Crocodylidac & Mourasuchus & Mourasuchtus atopus & & & & $\mathrm{X}$ & \\
\hline Sauropsida & Crocodylia & Gavialidae & & sp. & $X$ & $\mathrm{X}$ & & $\mathrm{X}$ & \\
\hline & Crocodylia & Gavialidae & Gavialis & sp. & & $\mathrm{X}$ & & $X$ & $\mathrm{X}$ \\
\hline & Squamata & & & sp. & & $\mathrm{X}$ & & $X$ & \\
\hline & Squamata & Ophidia & & & & & & $\mathrm{X}$ & \\
\hline & Squarmata & Polychritudae & Polychrus & sp. & & & & $\mathrm{X}$ & \\
\hline & Squamata & Serpentes & & & & $\mathrm{X}$ & & & \\
\hline & Squamata & Teiidae & Paradracaena & Paradracaena colombiana & & $X$ & & $\mathrm{X}$ & \\
\hline & Squamata & Teiidae & Tupinambis & Tupinambis teguixin & & & & $\mathrm{X}$ & \\
\hline & Testudines & & & sp. & $\mathrm{X}$ & $X$ & $\mathrm{X}$ & $\mathrm{X}$ & $\mathrm{X}$ \\
\hline & Testudines & Chelidae & Chelus & Cheltus colombianus & & & & $x$ & \\
\hline & Testudines & Podocnemidae & & sp. & & $\mathrm{X}$ & & & \\
\hline & Testudines & Podocnemidae & Podocnemis & sp. & & $\mathrm{X}$ & $\mathrm{X}$ & & \\
\hline & Testudines & Podocnemidac & Podocnemis & Podocnemis pritchardi & & $\mathrm{X}$ & & & \\
\hline & Testudines & Testudinidae & Geochelone & Geochelone hesterna & & & & $\mathrm{X}$ & \\
\hline Aves & & & & 2 & 0 & $\mathrm{I}$ & 0 & 2 & 0 \\
\hline Aves & & & & sp. & & $X$ & & $X$ & \\
\hline & Cuculiformes & Opisthocomidae & Hoazinoides & Hoazinoides magdalenae & & & & $\mathrm{X}$ & \\
\hline Coprolito & & & & & $\mathrm{X}$ & $X$ & $X$ & $X$ & $\mathrm{X}$ \\
\hline Indeterminante & & & & & $x$ & $\mathrm{X}$ & $\mathrm{X}$ & $\mathrm{X}$ & $\mathrm{X}$ \\
\hline
\end{tabular}


Tabla 5. Taxones de polen fósil identificados en las formaciones del Grupo La Venta y coberturas de vegetación actual del Desierto de La Tatacoa departamento del Huila, Colombia. Datos sobre los cuales se realizó el índice de similitud de Simpson.
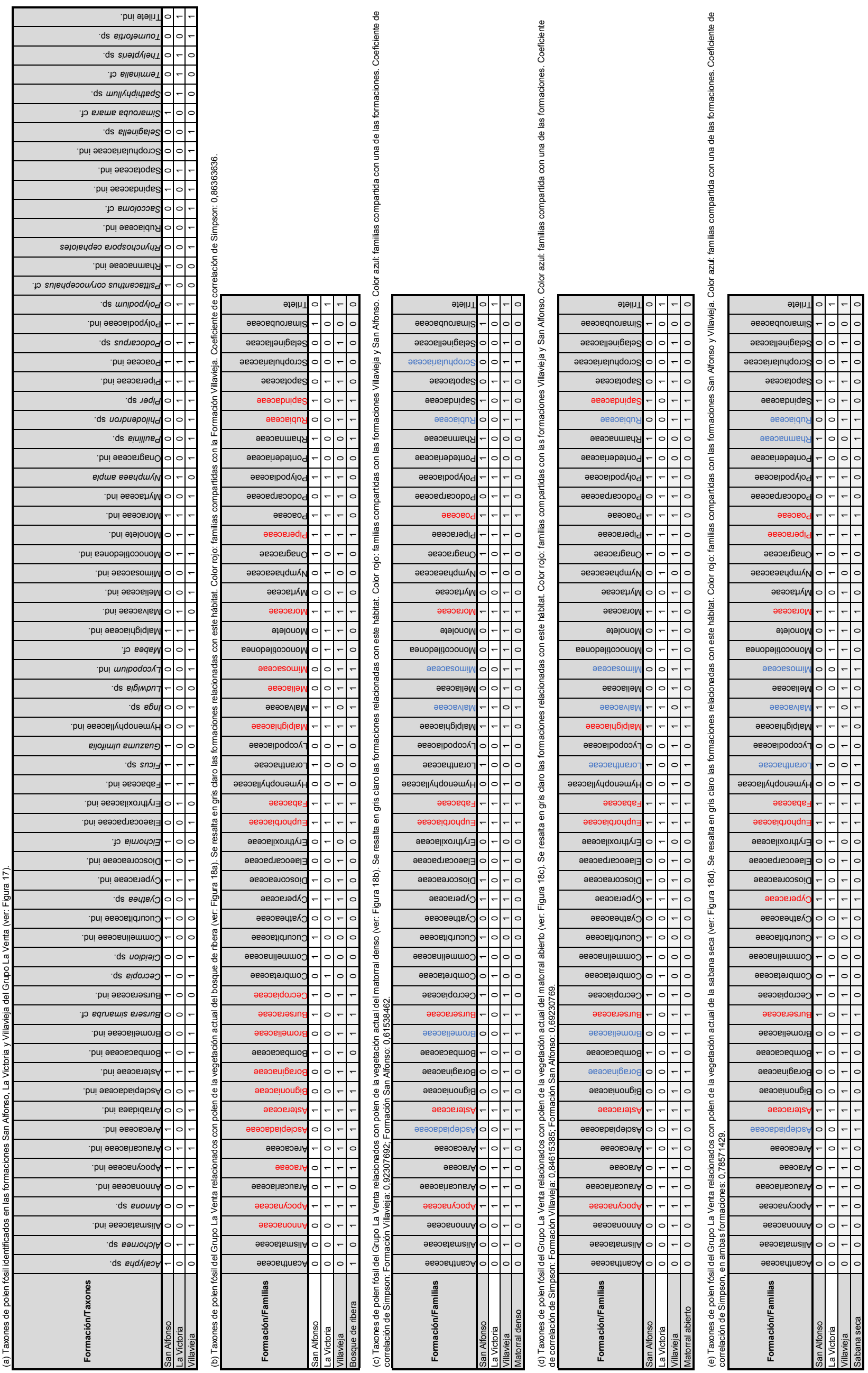
Tabla 6. Índice de similitud de Simpson, teniendo en cuenta el polen fósil, los paleohábitats propuestos y las formaciones del Grupo La Venta.

(a) Similitud entre las formaciones San Alfonso, La Victoria y Villavieja del Grupo La Venta (ver: Figura 17).

\begin{tabular}{|c|c|c|c|}
\hline & San Alfonso & La Victoria & Villavieja \\
\hline San Alfonso & 1 & 0,40 & 0,60 \\
\hline La Victoria & & 1 & 0,76 \\
\hline Villavieja & & & 1 \\
\hline
\end{tabular}

(b) Similitud entre las formaciones del Grupo La Venta y la cobertura vegetal denominada bosque de ribera (ver: Figura 18a).

\begin{tabular}{|c|c|c|c|c|}
\hline & San Alfonso & La Victoria & Villavieja & Bosque de ribera \\
\hline San Alfonso & 1 & 0,52380952 & 0,70833333 & 0,54545455 \\
\hline La Victoria & & 1 & 0,80952381 & 0,42857143 \\
\hline Villavieja & & & 1 & 0,86363636 \\
\hline Bosque de ribera & & & & 1 \\
\hline
\end{tabular}

(c) Similitud entre las formaciones del Grupo La Venta y la cobertura vegetal denominada matorral denso (ver: Figura 18b).

\begin{tabular}{|l|c|c|c|c|}
\cline { 2 - 5 } \multicolumn{1}{c|}{} & San Alfonso & La Victoria & Villavieja & Matorral denso \\
\hline San Alfonso & 1 & 0,52380952 & 0,70833333 & $\mathbf{0 , 6 1 5 3 8 4 6 2}$ \\
\hline La Victoria & & 1 & 0,80952381 & 0,53846154 \\
\hline Villavieja & & 1 & $\mathbf{0 , 9 2 3 0 7 6 9 2}$ \\
\hline Matorral denso & & & & 1 \\
\hline
\end{tabular}

(d) Similitud entre las formaciones del Grupo La Venta y la cobertura vegetal denominada matorral abierto (ver: Figura 18c).

\begin{tabular}{|l|c|c|c|c|}
\cline { 2 - 5 } \multicolumn{1}{c|}{} & San Alfonso & La Victoria & Villavieja & Matorral abierto \\
\hline San Alfonso & 1 & 0,52380952 & 0,70833333 & $\mathbf{0 , 6 9 2 3 0 7 6 9}$ \\
\hline La Victoria & & 1 & 0,80952381 & 0,46153846 \\
\hline Villavieja & & 1 & $\mathbf{0 , 8 4 6 1 5 3 8 5}$ \\
\hline Matorral abierto & & & & 1 \\
\cline { 4 - 5 } & & & &
\end{tabular}

(e) Similitud entre las formaciones del Grupo La Venta y la cobertura vegetal denominada sabana seca (ver: Figura 18d).

\begin{tabular}{|l|c|c|c|c|}
\cline { 2 - 5 } \multicolumn{1}{c|}{} & San Alfonso & La Victoria & Villavieja & Sabana seca \\
\hline San Alfonso & 1 & 0,52380952 & 0,70833333 & $\mathbf{0 , 7 8 5 7 1 4 2 9}$ \\
\hline La Victoria & & 1 & $\underline{0,80952381}$ & 0,57142857 \\
\hline Villavieja & & 1 & $\mathbf{0 , 7 8 5 7 1 4 2 9}$ \\
\hline Sabana seca & & & & 1 \\
\hline
\end{tabular}


Tabla 7. Taxones de paleofauna de vertebrados identificados en las formaciones del Grupo La Venta. Datos sobre los cuales se realizó el índice de similitud de Simpson.

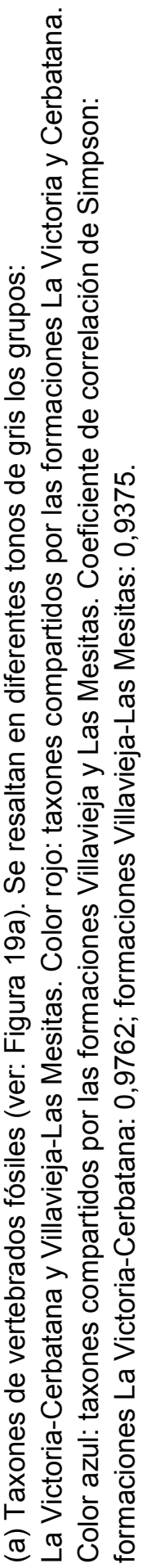

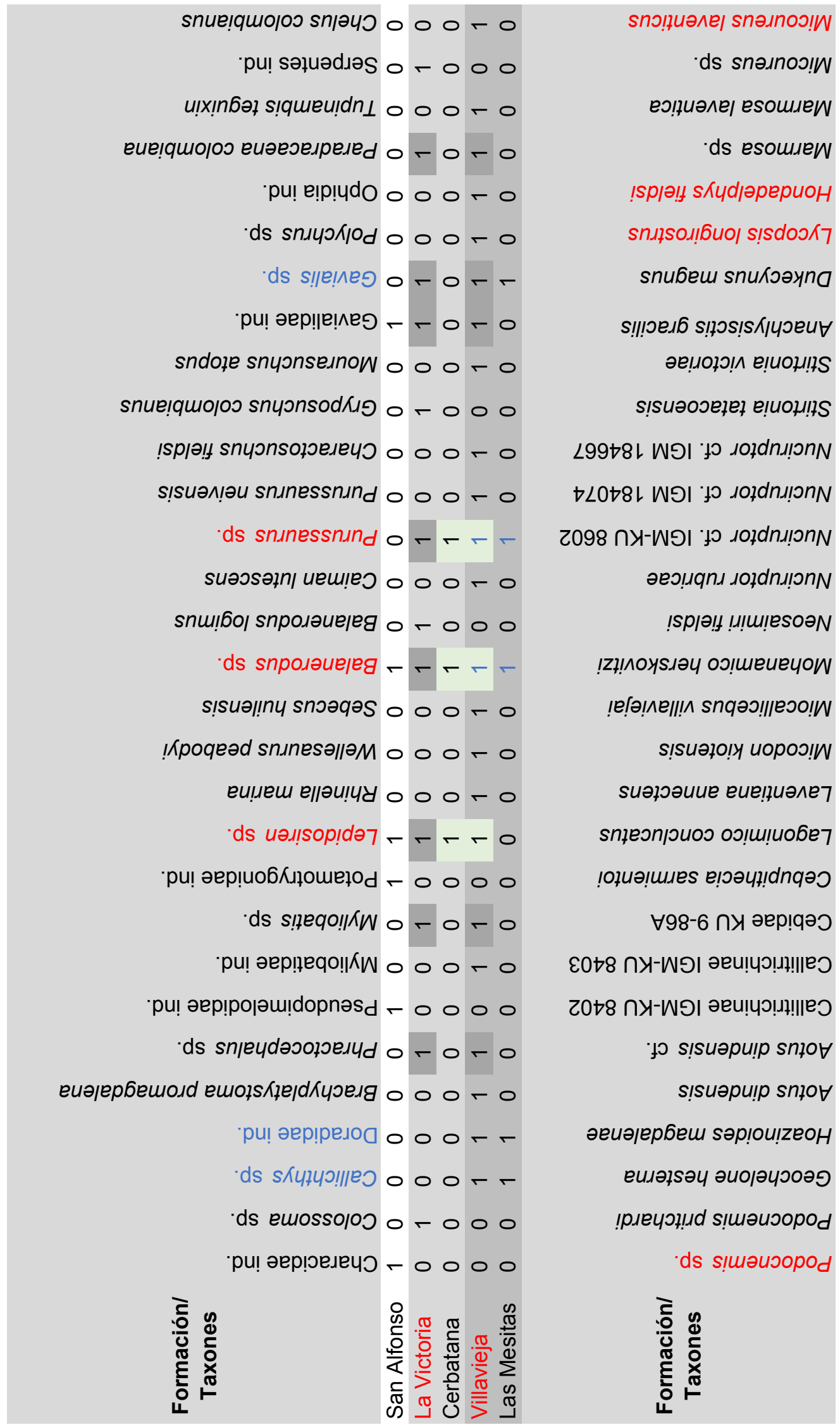




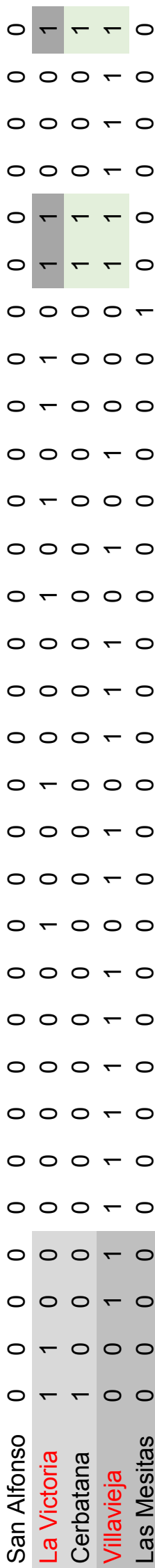

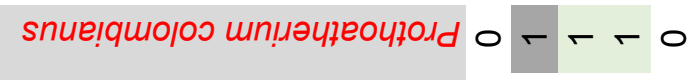

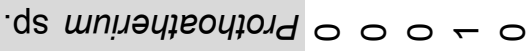

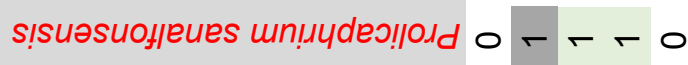

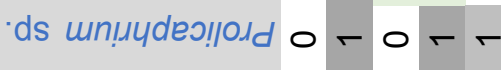
sәшиоц!иеош snројоребәW о $-\leftarrow \circ$

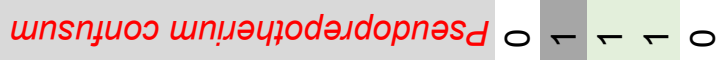

'pu! әер!!ләцІолЧҢОN ० s!ןеәлоq еприешедоәN о о

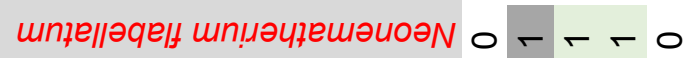

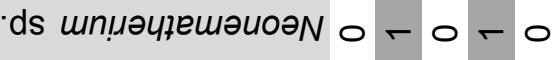

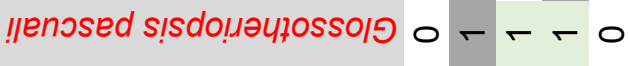

-ds sisdo!nәціоssolo o 0 o s!suәриәле sкрелqелә!и о - $о 00$

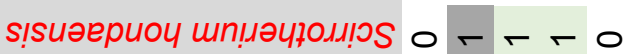

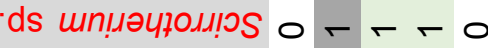
ıоsınәәелd sәдnәdК/олрәd о $\leftarrow$ -

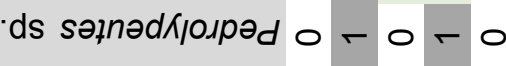

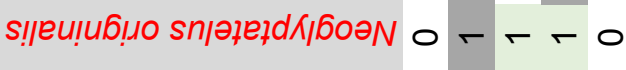

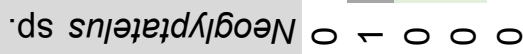

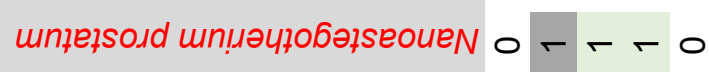

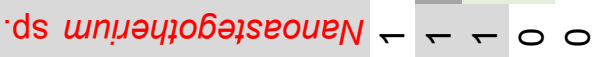

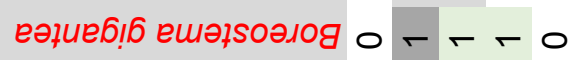
әетлоле ешәльолод ог

ds ешиндsоглоg ог snuepuoy sndКsepeu $\forall$ ○ $-\leftarrow \circ$

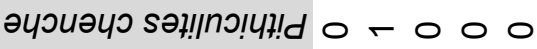
лореzео sәјиәчдерион о о $о-\circ$

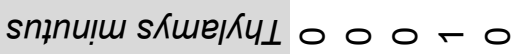

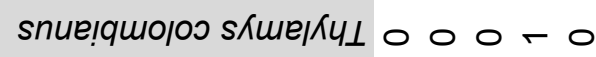

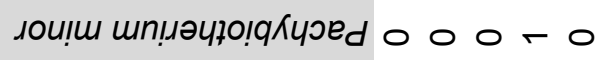

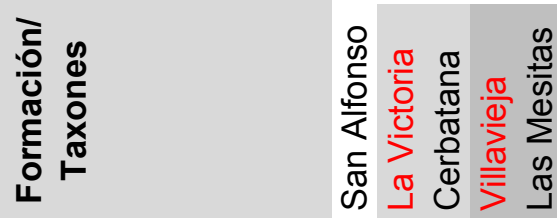

dds uәиाsomejod o -

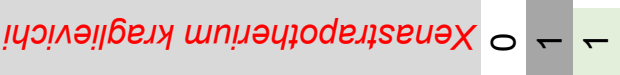

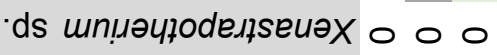

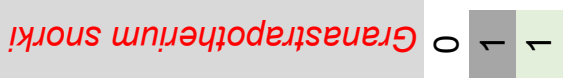

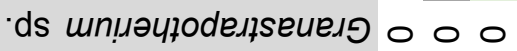
'pu! әер!!ıәцाоdeגıs $\forall-\circ 0$

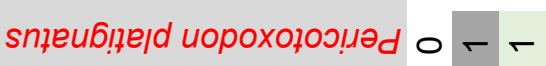
乙ds иорохоројцәd о -

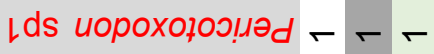

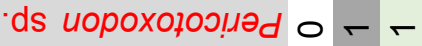
snpodomoue sn!!!јооо!W ○ -ds sn!!!чวоэо!W ० - -

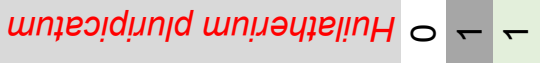
zds ши!ләчер!nн о о lds un!нәцाе!!nн о - -

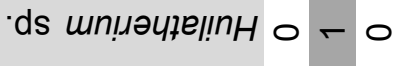
'ds emolsoydo7/e!peuol ○

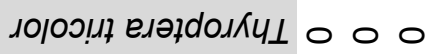

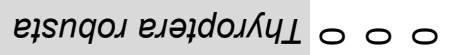
!елер еләдdолКЧ о о

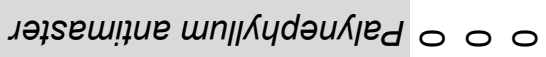

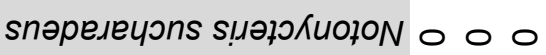
s!suәиәлербеш s!ләркиодоN о $о$ o s!นинл!qןе o!!! 'pu! әер!ssolow $\circ$ ○ !zədol sdowolo!Y ○ $\circ 0$ -ds sninp!j! ○ $\bigcirc \circ$

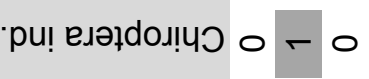

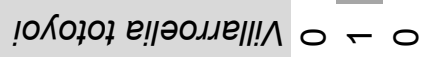

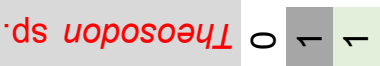

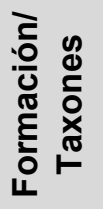

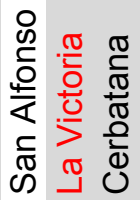



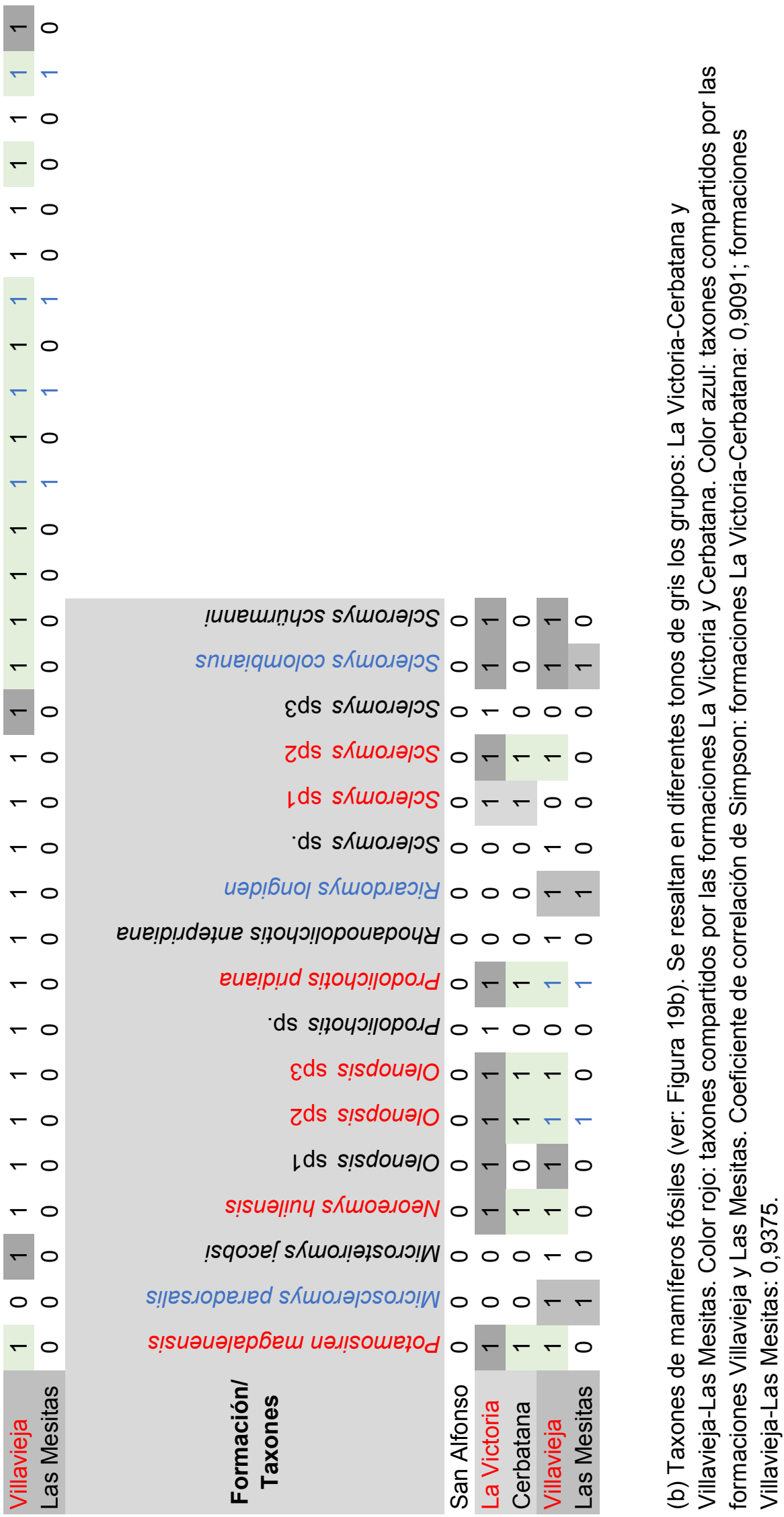

ıореzео sәұиәчұерион о

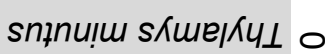

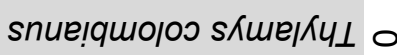
лоч!ш шп!әәцо!qКчред о snо!ฺนәле snәлnоэ!W о ds snəגnoग!W o еопџилег еsошлеW о dds esomiew o !sp/ə!! sКцd/әрерион о

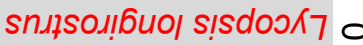
snuбeш snикэәуnа о

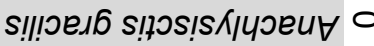
әе!лоџग! е!иоц!!S о s!suәоэеје е!иоц!!s о

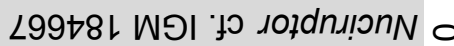

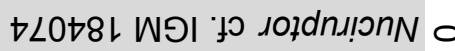

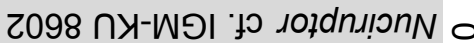

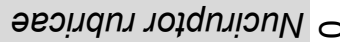
!sp/ә! ! !!щ!еsoәN о

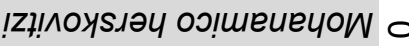

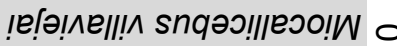
S!suәно!y иороग!W o sиәрэәиие еие!Һиәле7 о

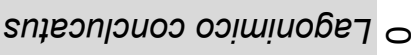
!оұиә!шие е!эәчџ!dnqәว о

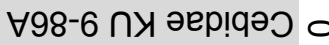

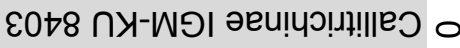

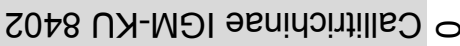
·॰ s!suәрu!p snıo sısuәри!p snı๐

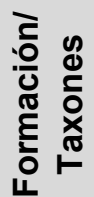




\begin{tabular}{|c|c|c|c|c|c|c|c|c|c|c|c|c|}
\hline & & & & & & & & & & & & \\
\hline ○ & 0 r & -0 & ·ds sninp!|ग! & & 0 & $0-$ & p & s!suә!ny sরயщоәлоәN & 10 & 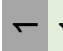 & - & $\tau$ \\
\hline 0 & $0 r$ & -0 & ·pu! eıәાdoג!५ว & 0 & $r c$ & $0 \vdash$ & -0 & !sqoэе! sкщод!әјsолэ!W & 10 & 0 & 0 & $\tau$ \\
\hline 0 & $0 \mathrm{r}$ & -0 & !оКоро е! еәомеш!^ & 0 & $-c$ & 00 & 0 & 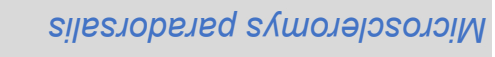 & 10 & 0 & 0 & - \\
\hline ○ & $0 r$ & -0 & ds uороsоәчц & ○. & $r$ & $r-$ & -0 & s!suәиәјербеш иәи!somełod & 0 & $\leftarrow$ & $r$ & $\leftarrow$ \\
\hline - & $r$ & -0 & 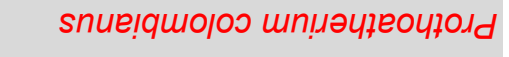 & ○ & $r$ & $r-$ & -0 & 'ds иәл!somełod & 10 & 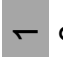 & 0 & - \\
\hline ○ & 0 - & -0 & -ds uп!ләчұеочролd & $\circ$ & $0 c$ & $0-$ & -0 & 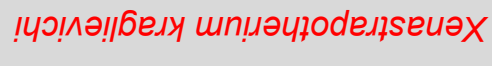 & o. & $\leftarrow$ & - & 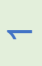 \\
\hline 0 & 0 & -0 & sәшиоц!иејош snројоребәW & ○. & $r$ & $r-$ & -0 & 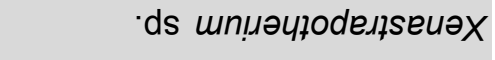 & o & $\circ$ & 0 & - \\
\hline 0 & $0 r$ & -0 & s!̣uәsuofleues mi!ıudeग!ןold & ○. & $r$ & $r-$ & -0 & 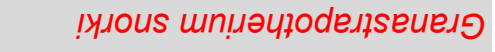 & 0 & $r$ & - & $\leftarrow$ \\
\hline$\leftarrow$ & $r$ & -0 & ds un!̣ydeo!ןold & o & $-c$ & 0 & $-\leftarrow$ & 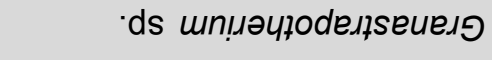 & o & $\circ$ & 0 & $\leftarrow$ \\
\hline$\leftarrow$ & $r$ & -0 & 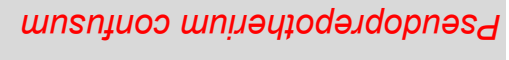 & ○ & $r$ & $-r$ & -0 & 'рu! әер!!ләчцоdeגıS & $1-$ & $\circ$ & 0 & $\leftarrow$ \\
\hline 0 & $\circ c$ & $0-$ & ·pu! әер!!дәцұоццоN & 0 & $r c$ & 0 & - 0 & snұеuб!ıеןd иорохоюоэ!әд & O & - & 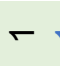 & $\leftarrow$ \\
\hline 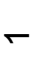 & 00 & 00 & s!ןеәлоq еприешејоәN & 0 & $0 c$ & $0-$ & -0 & zds иорохороэ!әәd & & $\leftarrow$ & - & $\leftarrow$ \\
\hline$\leftarrow$ & $0 c$ & 00 & шпџе\|әqе| шп!ләчұешәиоәN & 0 . & $r$ & $r \sigma$ & -0 & Lds иорохороэ! & - & $\leftarrow$ & - & $\tau$ \\
\hline 0 & $\circ$ r & -0 & 'ds шп!ләчұешәиоәN & 0 & $-c$ & $0-$ & -0 & -ds иорохороэ!лдd & o. & $\leftarrow$ & 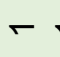 & $\leftarrow$ \\
\hline$\leftarrow$ & 00 & 00 & !ןenosed s!sdo!ıәчłossol૭ & 0 & $r$ & $r-$ & -0 & snpodouоue sn!!!৩оэо!W & 10 & 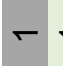 & - & $\leftarrow$ \\
\hline 0 & 0 r & -0 & 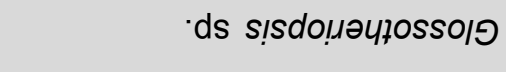 & 0 & 0 & $0-$ & -0 & ds sn!!!૫оэо!W & & 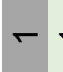 & - & $\leftarrow$ \\
\hline$r$ & 0 & 00 & s!suәłuәле| sরрелqелә!ıg & 0 & $-c$ & 00 & 0 & unıеэ!d!ınıd uп!ıәчұе!!nн & 10. & - & $\leftarrow$ & $\leftarrow$ \\
\hline 0 & 0 r & -0 & s!̨иәериоч шп!әуцом!्ड & 0 . & $r$ & $r-$ & -0 & 乙ds ши!ләчғе!!nн & 10 & 0 & - & $\leftarrow$ \\
\hline 0 & 0 r & -0 & 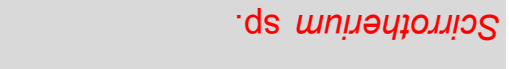 & 0 & $r$ & $-r$ & -0 & Lds uп!پәчұе!!nн & 10 & $\leftarrow$ & - & $\leftarrow$ \\
\hline 0 & 0 r & -0 & ıоsınวәеıd sәłnәdК/олрәd & ○ & $r$ & $r-$ & -0 & ·ds ши!ләчұе!!nн & 10 & 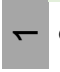 & 0 & $\sigma$ \\
\hline$\leftarrow$ & $0 c$ & 00 & ·ds sәłnәdК/одрәd & ○. & $-c$ & 0 & -0 & 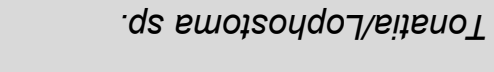 & 0 & 0 & 0 & $\leftarrow$ \\
\hline 0 & 0 r & -0 & s!ןeu!uб!ı snןәједdКןбоәN & 0 & $r$ & $r$ & -0 & 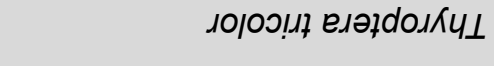 & 0 & 0 & 0 & $\sigma$ \\
\hline 0 & 0 - & -0 & -ds snןәједdКןбоәN & 0 r & $-c$ & 00 & 0 & ерsnqoı еләрdолКчц & 0 & 0 & 0 & $\sigma$ \\
\hline$r$ & $0 c$ & 00 & 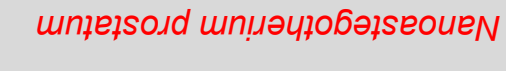 & ○ & $r$ & $\leftarrow$ & -0 & ! еле| еләғdоıкчц & o & 0 & 0 & $\sigma$ \\
\hline 0 & 0 - & -0 & 'ds uп!әчұобәғsеочеN & - & $r$ & -0 & 0 & 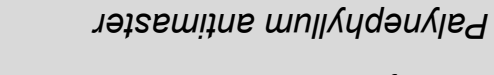 & 10 & 0 & 0 & - \\
\hline 0 & 0 - & 50 & еәұиеб!б ешәјรоәлоя & 0 & $r$ & $-r$ & -0 & snәрелечоns s!̣әроКиоюо & 10 & 0 & 0 & 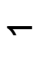 \\
\hline 0 & 0 & -0 & әеґรоэе ещәџรоәлоя & 0 & $r$ & $r \sigma$ & -0 & s!suәиәјербеш s!ләјоКиојоN & 10 & 0 & 0 & $\sigma$ \\
\hline 0 & 0 r & -0 & dds ешщәұsоәю口 & 0 . & $r$ & $r-$ & -0 & s!ฺұนәм!qןe о!!!ฺ००N & 10 & 0 & 0 & $\sigma$ \\
\hline 0 & 0 & -0 & snuepuou sndКsepeu & 0 & $r$ & $\sigma-$ & -0 & ·pu! әер!ssolow & No & $\circ$ & 0 & $\leftarrow$ \\
\hline 0 & 0 & -0 & әцગиәчว sә!!|nગ!પ!!d & 0 & $-c$ & 00 & 0 & !zədol sdowolo!y & 10 & 0 & & $\sigma$ \\
\hline 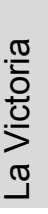 & 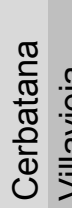 & 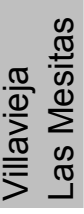 & 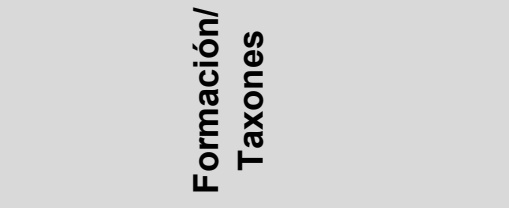 & 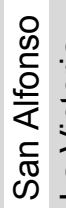 & 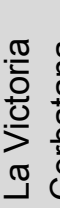 & 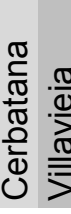 & 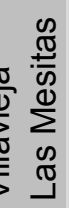 & 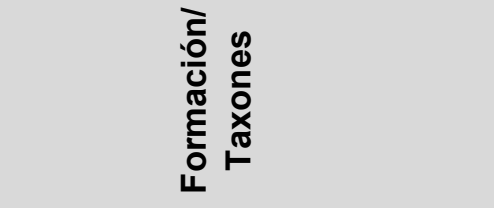 & 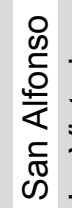 & 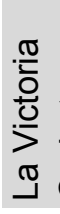 & 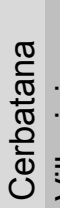 & $\frac{\frac{\sigma}{0}}{\frac{0}{\infty}}$ \\
\hline
\end{tabular}




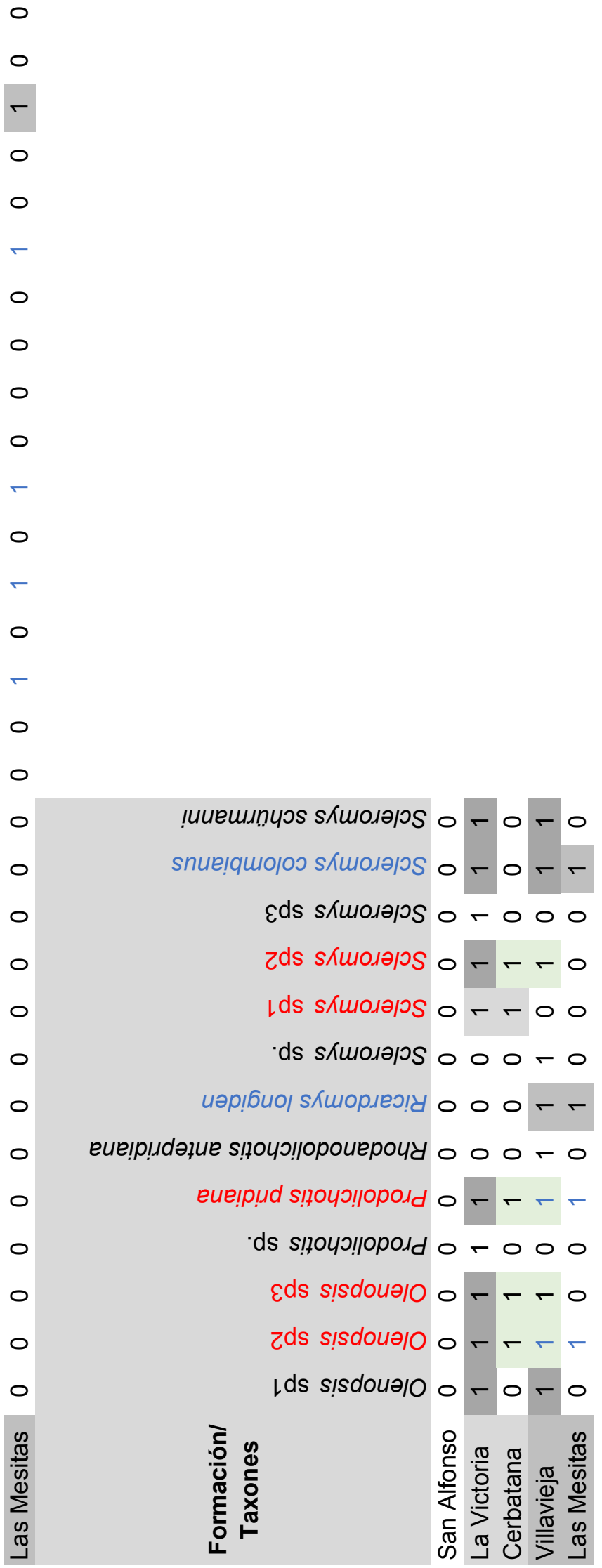


Tabla 8. Índice de similitud de Simpson, teniendo en cuenta los paleovertebrados de las diferentes formaciones del Grupo La Venta.

(a) Similitud de vertebrados fósiles (ver: Figura 19a).

\begin{tabular}{|c|c|c|c|c|c|}
\hline & San Alfonso & La Victoria & Cerbatana & Villavieja & Las Mesitas \\
\hline San Alfonso & 1 & 0,66666667 & 0,66666667 & 0,66666667 & 0,33333333 \\
\hline La Victoria & & 1 & 0,97368421 & $\underline{0,76271186}$ & 0,72727273 \\
\hline Cerbatana & & & 1 & $\underline{0,94736842}$ & 0,54545455 \\
\hline Villavieja & & & & 1 & 0,90909091 \\
\hline Las Mesitas & & & & & 1 \\
\hline
\end{tabular}

(b) Similitud de mamíferos fósiles (ver: Figura 19b).

\begin{tabular}{|c|c|c|c|c|c|}
\hline & San Alfonso & La Victoria & Cerbatana & Villavieja & Las Mesitas \\
\hline San Alfonso & 1 & 0,55555556 & 0,44444444 & 0,55555556 & 0,22222222 \\
\hline La Victoria & & 1 & 0,97619048 & $\underline{0,7260274}$ & 0,6875 \\
\hline Cerbatana & & & 1 & 0,92857143 & 0,5 \\
\hline Villavieja & & & & 1 & 0,9375 \\
\hline Las Mesitas & & & & & 1 \\
\hline
\end{tabular}


Anexo 1. Estratigrafía del Grupo Honda.

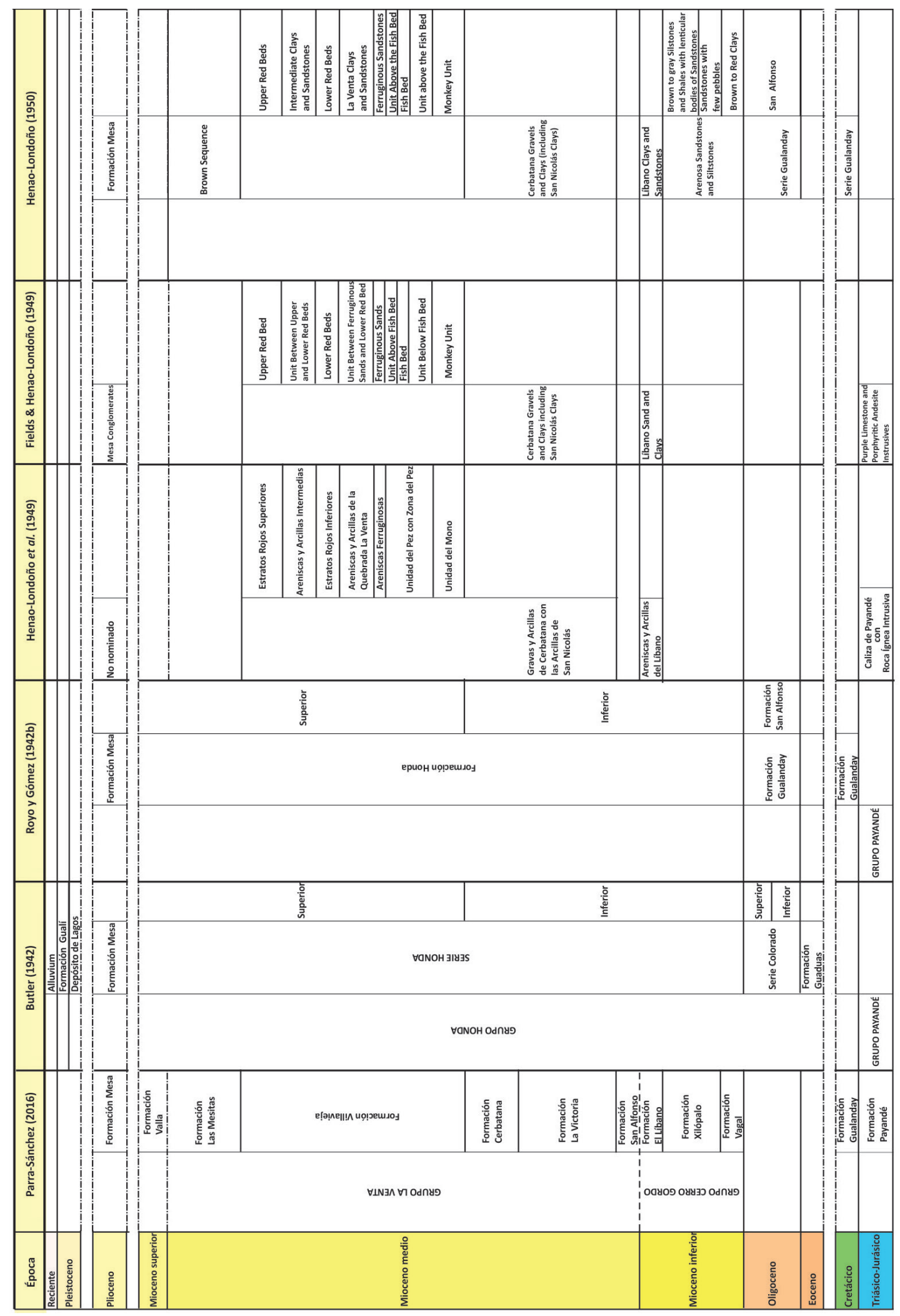




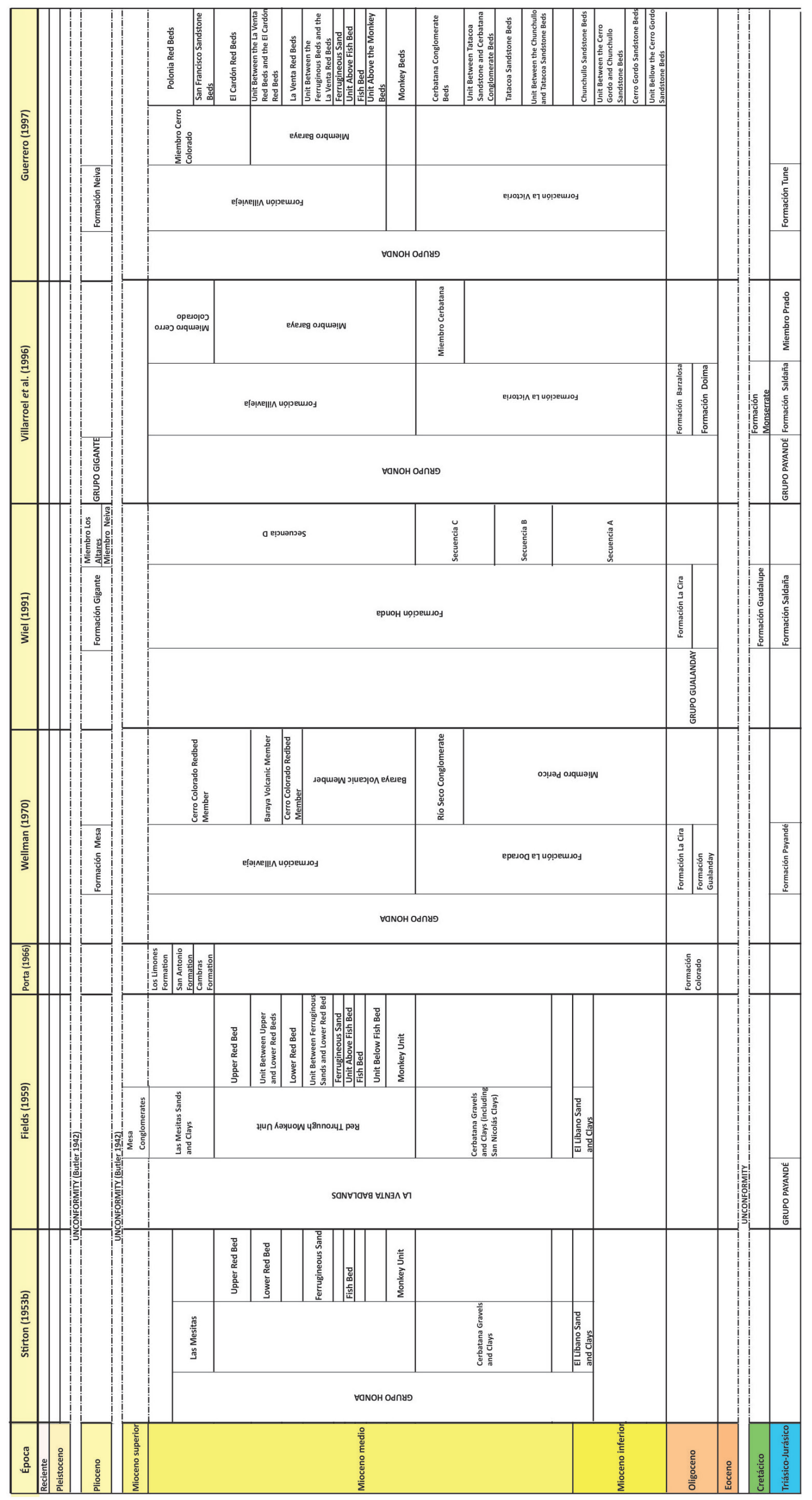




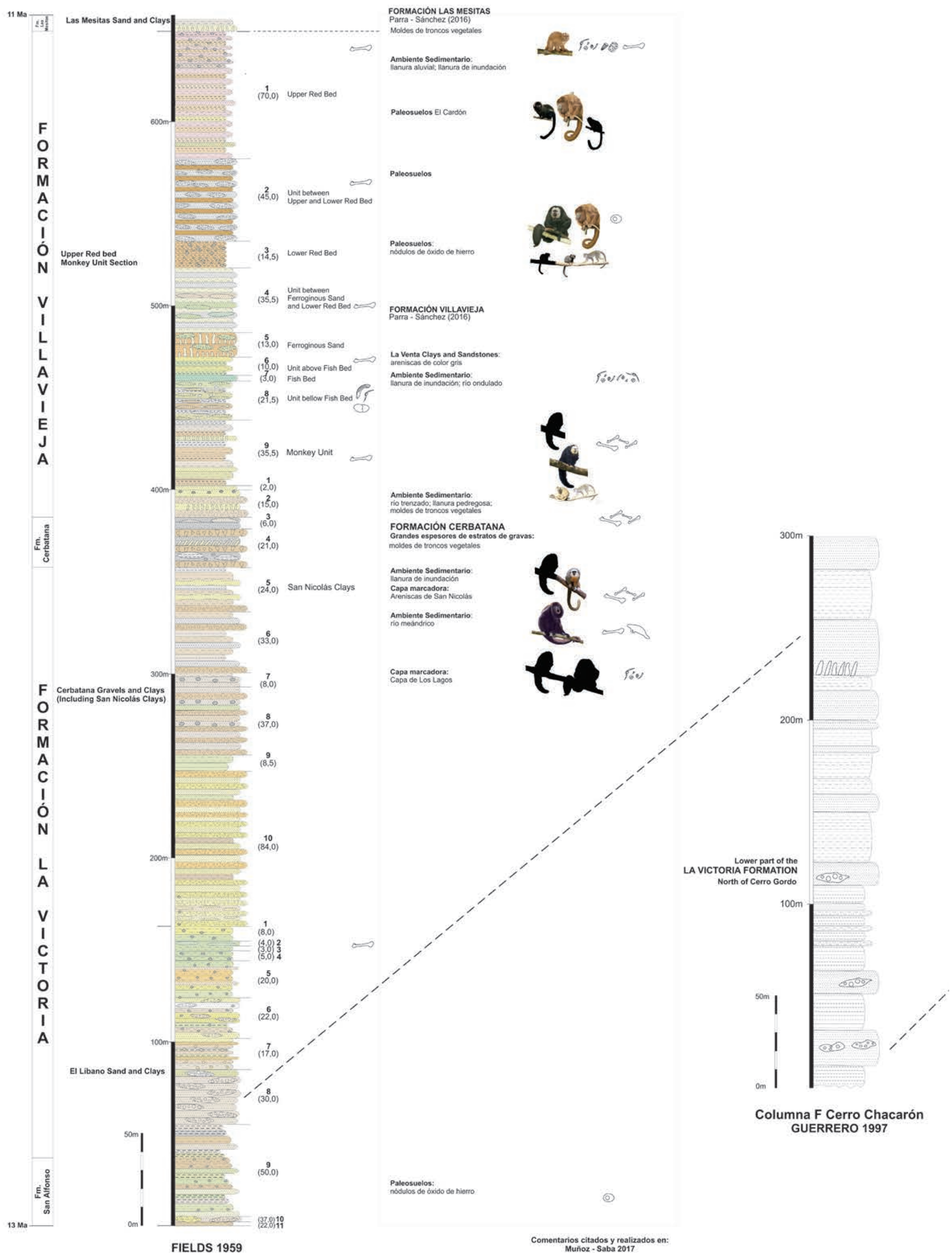


Anexo 2. Sección estratigráfica del Grupo La Venta.

Fields 1959, Guerrero 1997, Parra - Sánchez 2016, comentarios Muñoz - Saba 2017
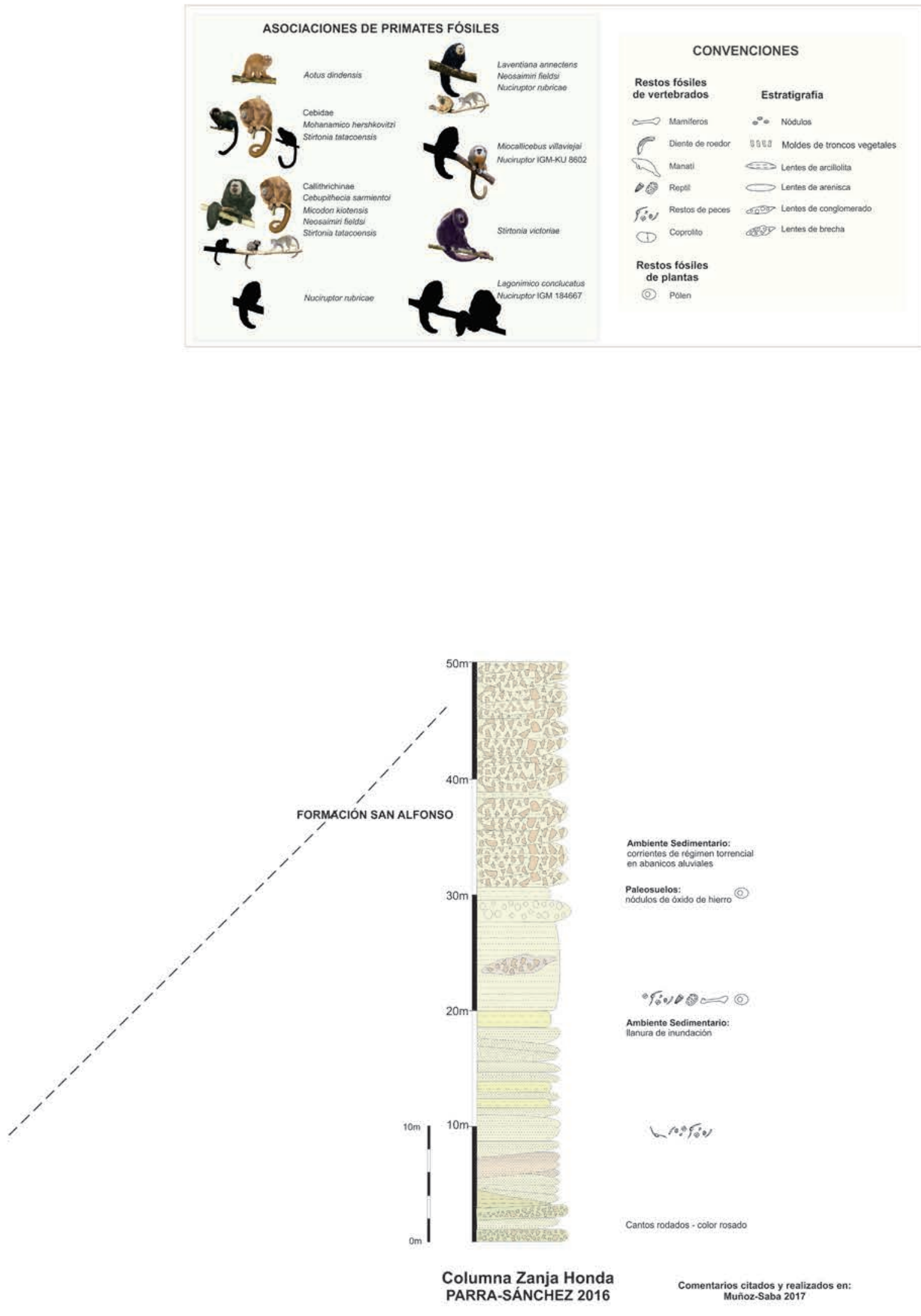
Anexo 3. Ambiente sedimentario. Formación San Alfonso, Grupo La Venta.

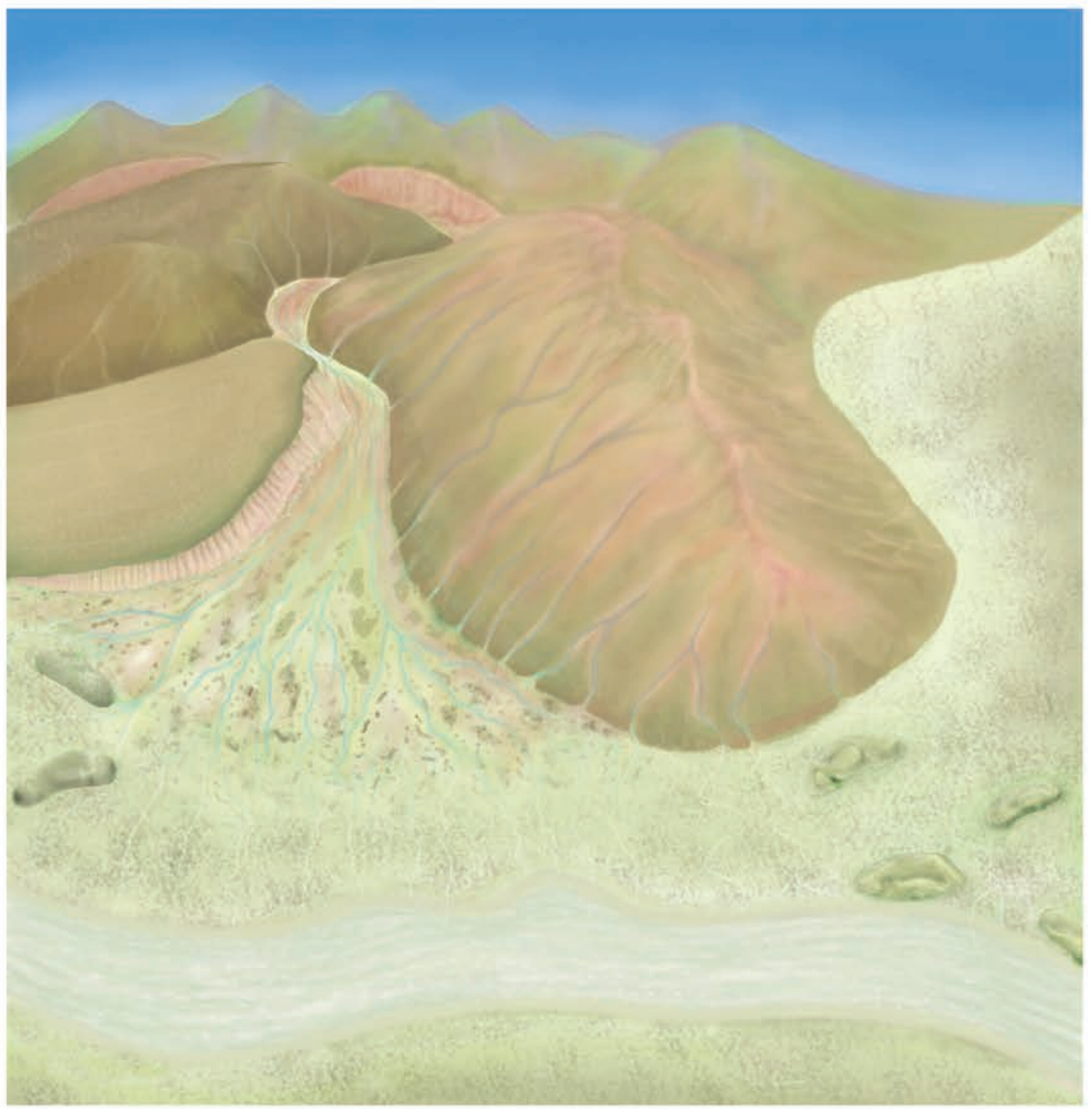

Ilustración: Marie Joëlle Giraud López, 2017. 
Anexo 4. Ambiente sedimentario. Formación La Victoria, Grupo La Venta.

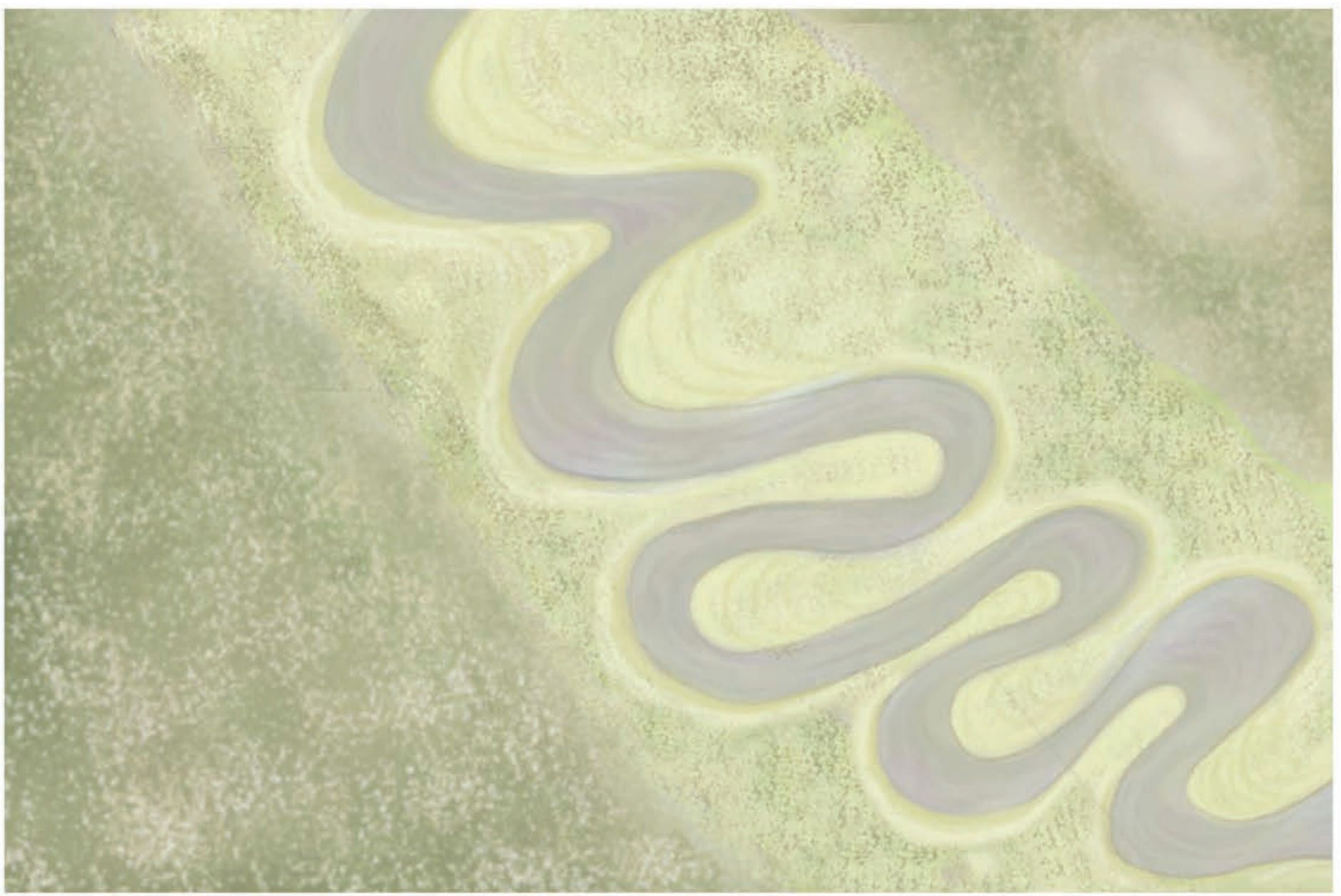

Ilustración: Marie Joëlle Giraud López, 2017. 
Anexo 5. Ambiente sedimentario. Formación Cerbatana, Grupo La Venta.

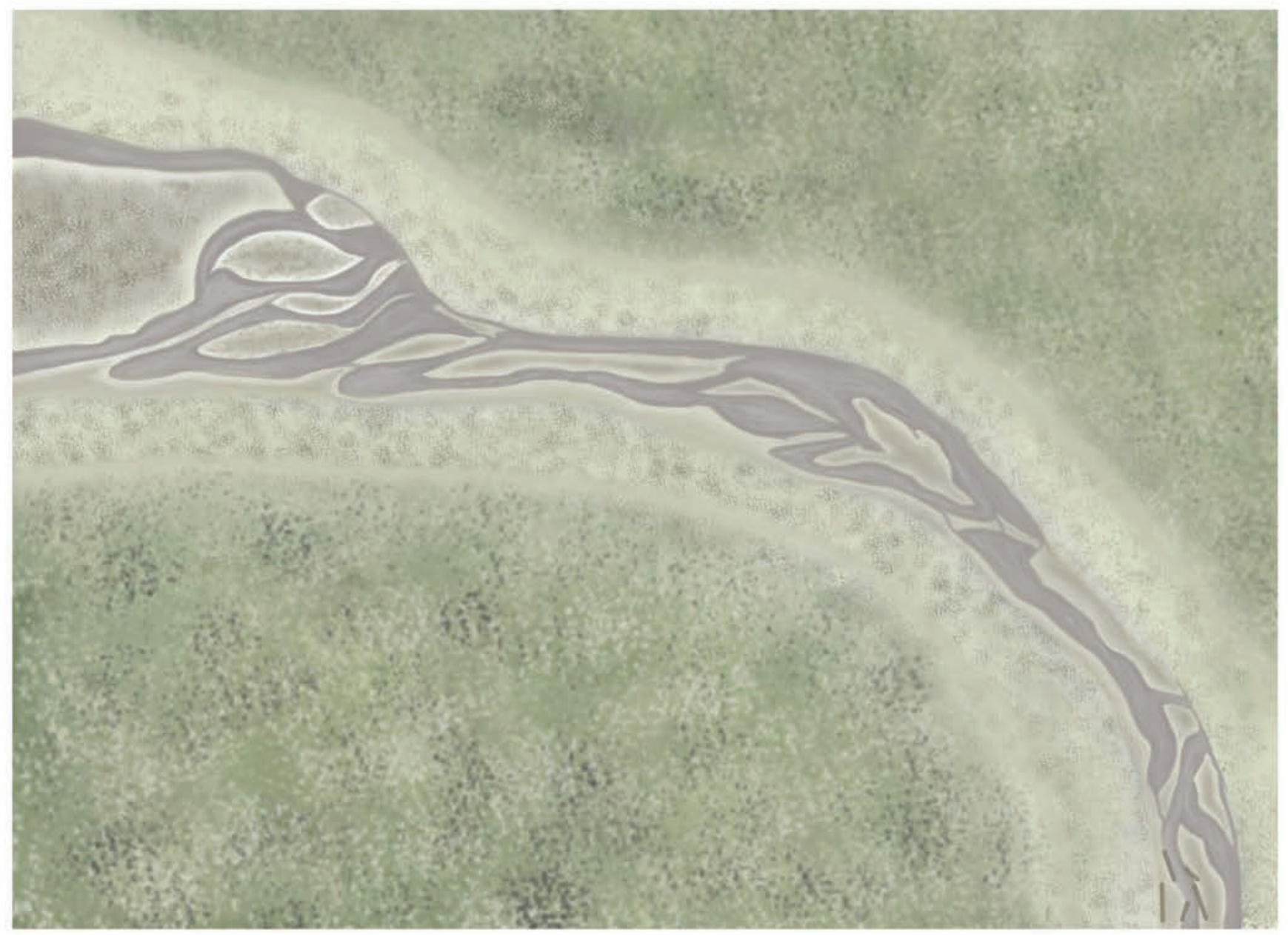

Ilustración: Marie Joëlle Giraud López, 2017. 
Anexo 6. Ambiente sedimentario. Formación Villavieja, Grupo La Venta.

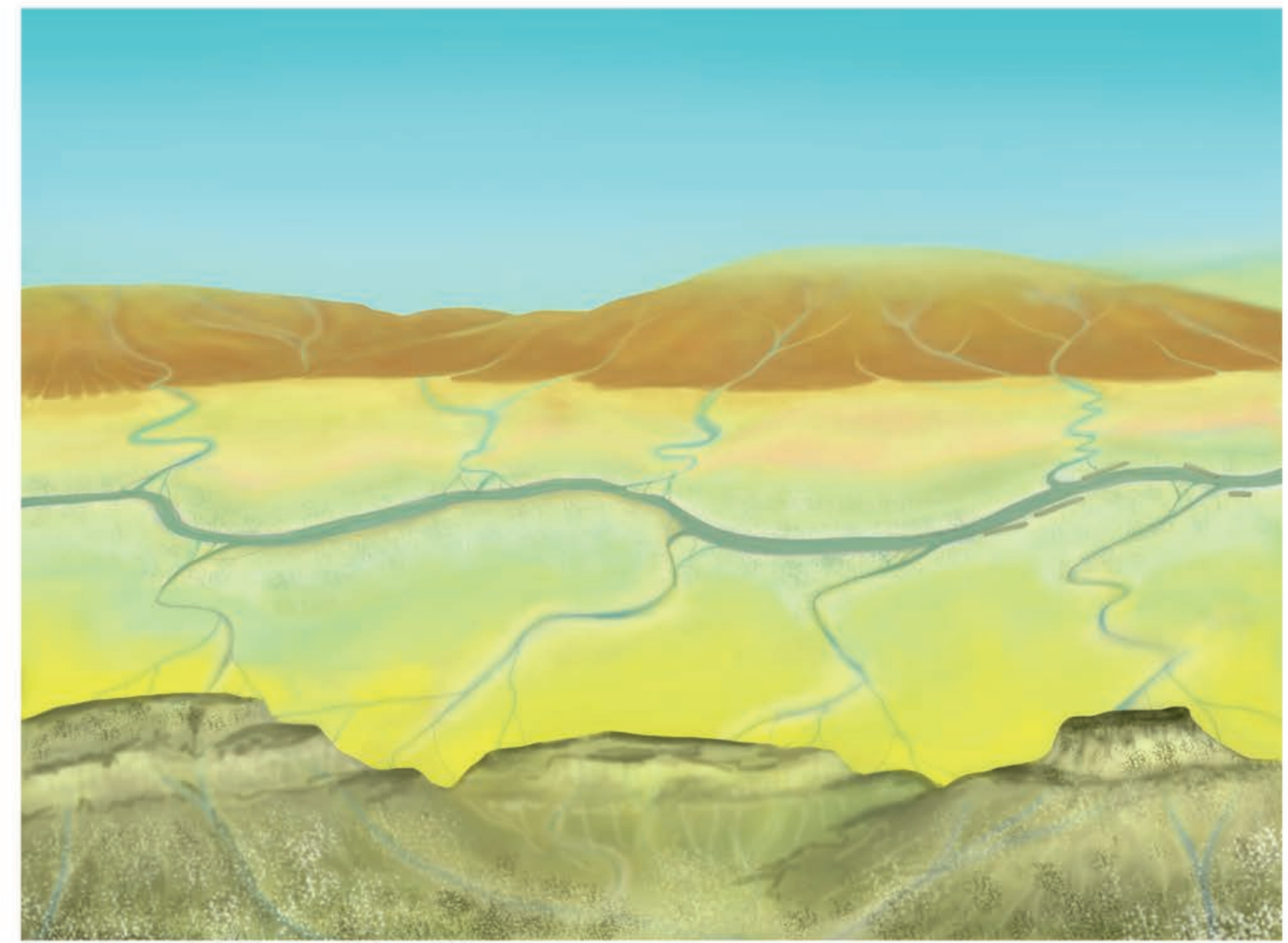

Ilustración: Marie Joëlle Giraud López, 2017. 
Anexo 7. Ambiente sedimentario. Formación Las Mesitas, Grupo La Venta.

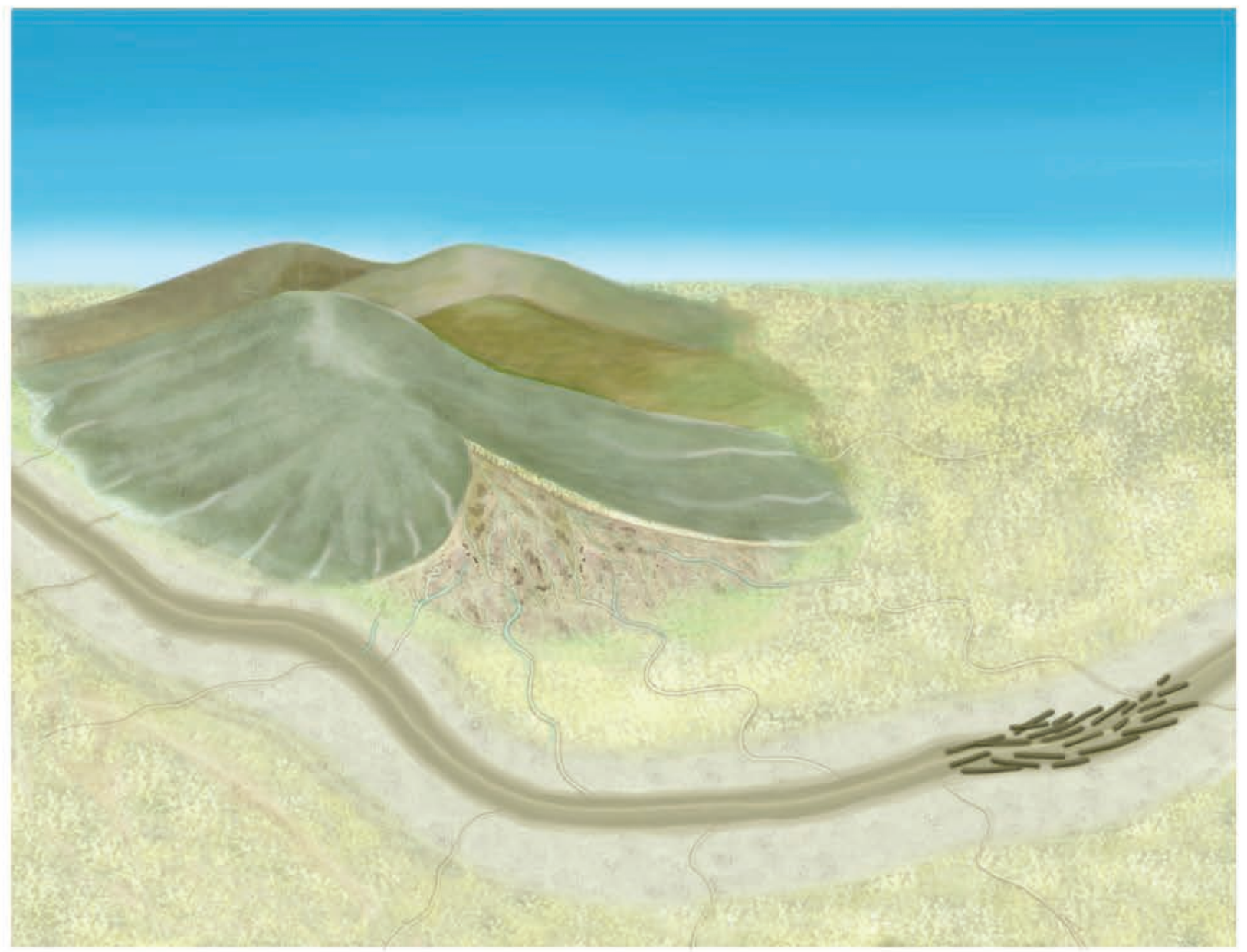

Ilustración: Marie Joëlle Giraud López, 2017. 


\begin{tabular}{|c|c|c|c|c|c|c|c|c|}
\hline \multirow[b]{2}{*}{ FAMILIA } & \multirow[b]{2}{*}{ TAXONES } & \multicolumn{3}{|c|}{ POLEN FÓSIL } & \multicolumn{4}{|c|}{ VEGETACIÓN ACTUAL } \\
\hline & & San Alfonso & La Victoria & Villavieja & $\begin{array}{c}\text { Bosque } \\
\text { de Ribera }\end{array}$ & $\begin{array}{c}\text { Matorral } \\
\text { Denso }\end{array}$ & $\begin{array}{l}\text { Matorral } \\
\text { Abierto }\end{array}$ & $\begin{array}{l}\text { Sabana } \\
\text { Seca }\end{array}$ \\
\hline \multicolumn{2}{|l|}{ Total } & 144 & 121 & 357 & & & & \\
\hline Acanthaceae & Acanthaceae sp. & & & $x$ & $x$ & & & \\
\hline Acanthaceae & Turbergia erecta & & & $x$ & & & & \\
\hline Alismataceae & Alismataceae sp. & & & $x$ & & & & \\
\hline Annonaceae & & & & $\mathrm{X}$ & $x$ & & & \\
\hline Annonaceae & Annonaceae sp. & & & $x$ & & & & \\
\hline Annonaceae & Annona sp. & & & $x$ & & & & \\
\hline \multicolumn{2}{|l|}{ Apocynaceae } & $\mathrm{x}$ & $\mathrm{X}$ & $\mathrm{x}$ & $x$ & $\mathrm{x}$ & $\mathrm{x}$ & \\
\hline Apocynaceae & Apocynaceae spl & $x$ & & & & & & \\
\hline Apocynaceae & Apocynaceae sp2 - sp8 & & & $x$ & & & & \\
\hline Apocynaceae & Apocynaceae sp9 - sp11 & & $x$ & & & & & \\
\hline Apocynaceae & Apocynaceae sp 12 & & & $x$ & & & & \\
\hline \multicolumn{2}{|l|}{ Araceae } & $x$ & $x$ & $x$ & $x$ & & & \\
\hline Araceae & Philodendron sp. & & & $\mathrm{X}$ & & & & \\
\hline Araceae & Spathiphyllum sp. & & $x$ & & & & & \\
\hline \multicolumn{2}{|l|}{ Araucariaceae } & & $x$ & $x$ & & & & \\
\hline Araucariaceae & Araucariaceae sp1 & & & $x$ & & & & \\
\hline Araucariaceae & Araucariaceae $\mathrm{sp} 2$ & & $x$ & & & & & \\
\hline \multicolumn{2}{|l|}{ Arecaceae } & $\mathrm{X}$ & & $\mathrm{X}$ & & & & \\
\hline Arecaceae & Arecaceae spl & $x$ & & & & & & \\
\hline Arecaceae & Arecaceae sp2 & $x$ & & $X$ & & & & \\
\hline Arecaceae & Arecaceae sp3 - sp 5 & & & $x$ & & & & \\
\hline \multicolumn{2}{|l|}{ Asclepiadaceae } & & & $x$ & $x$ & $\mathrm{x}$ & & $x$ \\
\hline Asclepiadaceae & Asclepiadaceae sp1 - sp2 & & & $x$ & & & & \\
\hline \multicolumn{2}{|l|}{ Asteraceae } & $x$ & $x$ & $x$ & $x$ & $\mathrm{x}$ & $\mathrm{X}$ & $\mathrm{X}$ \\
\hline Asteraceae & Asteraceae sp1 & $x$ & & & & & & \\
\hline Asteraceae & Asteraceae $\mathrm{sp} 2$ - $\mathrm{sp} 3$ & & & $x$ & & & & \\
\hline Asteraceae & Asteraceae sp4 & & $x$ & & & & & \\
\hline Asteraceae & Asteraceae sp5 & & & $x$ & & & & \\
\hline Bignoniaceae & & & & $x$ & $x$ & & & \\
\hline Bignoniaceae & Arrabidaea sp. & & & $x$ & & & & \\
\hline Bombacaceae & & $x$ & & $x$ & & & & \\
\hline Bombacaceae & Bombacaceae spl - $\mathrm{sp} 3$ & $x$ & & & & & & \\
\hline Bombacaceae & Bombacaceae sp4 & & & $\mathrm{X}$ & & & & \\
\hline Boraginaceae & & & & $x$ & $x$ & & $x$ & \\
\hline Boraginaceae & Tournerfortia sp1 & & & $\mathrm{x}$ & & & & \\
\hline Bromeliaceae & & & & $x$ & $x$ & $x$ & $x$ & \\
\hline Bromeliaceae & Bromeliaceae sp1 - sp2 & & & $\mathrm{X}$ & & & & \\
\hline Burseraceae & & $\mathrm{x}$ & & $\mathrm{x}$ & & & & \\
\hline Burseraceae & Burseraceae sp. & $x$ & & & & & & \\
\hline Burseraceae & Bursera simaruba cf. & & & $\mathrm{x}$ & $\mathrm{X}$ & $\mathrm{X}$ & $\mathrm{X}$ & $x$ \\
\hline Cecropiaceae & & $\mathrm{X}$ & & $x$ & $x$ & & & \\
\hline Cecropiaceae & Cecropia sp. & & & & $x$ & & & \\
\hline Cecropiaceae & Cecropia spl & $x$ & & & & & & \\
\hline Cecropiaceae & Cecropia sp2 & & & $\mathrm{x}$ & & & & \\
\hline Combretaceae & Terminalia sp. $c f$. & & & $x$ & & & & \\
\hline Commelinaceae & & $\mathrm{X}$ & $x$ & & & & & \\
\hline Commelinaceae & Commelinaceae sp1 - sp3 & $x$ & & & & & & \\
\hline Commelinaceae & Commelinaceae sp4 & & $x$ & & & & & \\
\hline Cucurbitaceae & Cucurbitaceae sp1 - sp2 & $x$ & & & & & & \\
\hline Cyatheaceae & Cyathea sp. & & & $\mathrm{X}$ & & & & \\
\hline Cyperaceae & & $x$ & $x$ & $x$ & & & & $x$ \\
\hline Cyperaceae & Cyperaceae spl - spll & $\mathrm{x}$ & & & & & & \\
\hline Cyperaceae & Cyperaceae sp12-sp17 & & & $x$ & & & & \\
\hline Cyperaceae & Cyperaceae sp18 - sp23 & & $x$ & & & & & \\
\hline Cyperaceae & Cyperaceae sp24 - sp26 & & & $x$ & & & & \\
\hline Cyperaceae & Rhynchospora cephalotes & & & $x$ & & & & \\
\hline Dioscoreaceae & & $x$ & & $x$ & & & & \\
\hline Dioscoreaceae & Dioscoreaceae sp1 & $x$ & & & & & & \\
\hline Dioscoreaceae & Dioscoreaceae sp2 & & & $\mathrm{X}$ & & & & \\
\hline Elaeocarpaceae & Elaeocarpaceae sp. & & & $\mathrm{x}$ & & & & \\
\hline Erythroxilaceae & Erythroxilaceae sp. & & $x$ & & & & & \\
\hline Euphorbiaceae & & $x$ & $x$ & $x$ & $x$ & $x$ & $x$ & $x$ \\
\hline Euphorbiaceae & Acalypha sp. & $x$ & & & & & & \\
\hline Euphorbiaceae & Alchornea sp1 & & & $x$ & & & & \\
\hline
\end{tabular}




\begin{tabular}{|c|c|c|c|c|c|c|c|c|}
\hline Euphorbiaceae & Alchornea sp2 & & $\mathrm{x}$ & & & & & \\
\hline Euphorbiaceae & Cleidion sp. $c f$. & & & $\mathrm{x}$ & & & & \\
\hline Euphorbiaceae & Mabea sp. cf. & & & $\mathrm{x}$ & & & & \\
\hline Euphorbiaceae & Euphorbiaceae sp. & & & $\mathrm{x}$ & & & & \\
\hline \multicolumn{2}{|l|}{ Fabaceae } & $x$ & $x$ & $x$ & $x$ & $x$ & $\mathrm{x}$ & $x$ \\
\hline Fabaceae & Fabaceae spl & $\mathrm{x}$ & & & & & & \\
\hline Fabaceae & Fabaceae sp2 & & & $\mathrm{x}$ & & & & \\
\hline Fabaceae & Fabaceae sp3 & & $\mathrm{x}$ & & & & & \\
\hline Fabaceae & Fabaceae sp4 & & & $x$ & & & & \\
\hline Hymenophyllaceae & Hymenophyllaceae sp. & & & $\mathrm{x}$ & & & & \\
\hline \multicolumn{2}{|l|}{ Loranthaceae } & $x$ & & & & & $x$ & $x$ \\
\hline Loranthaceae & Psittacanthus corynocephalus cf. & $x$ & & & & & & \\
\hline Lycopodiaceae & Lycopodium sp. & & & $\mathrm{x}$ & & & & \\
\hline \multicolumn{2}{|l|}{ Malpighiaceae } & $x$ & $x$ & $x$ & $\mathrm{x}$ & & $x$ & \\
\hline Malpighiaceae & Malpighiaceae spl & $\mathrm{x}$ & & & & & & \\
\hline Malpighiaceae & Malpighiaceae sp2 & & $x$ & & & & & \\
\hline Malpighiaceae & Malpighiaceae sp3 & & & $\mathrm{x}$ & & & & \\
\hline \multicolumn{2}{|l|}{ Malvaceae } & $\mathrm{x}$ & $x$ & & $\mathrm{x}$ & $\mathrm{X}$ & $X$ & $x$ \\
\hline Malvaceae & Guazuma ulmifolia cf. (Sterculiaceae) & $\mathrm{x}$ & & & & & & \\
\hline Malvaceae & Malvaceae sp. & & $x$ & & & & & \\
\hline Meliaceae & Meliaceae sp. & & & $x$ & $x$ & & & \\
\hline \multicolumn{2}{|l|}{ Mimosaceae } & & & $x$ & $x$ & $x$ & $x$ & $x$ \\
\hline Mimosaceae & Mimosaceae sp. & & & $x$ & & & & \\
\hline Mimosaceae & Inga sp. & & & $x$ & & & & \\
\hline \multicolumn{2}{|l|}{ Moraceae } & $x$ & $x$ & $\mathrm{x}$ & $x$ & $x$ & & $x$ \\
\hline Moraceae & Ficus sp. & & & & $x$ & & & $\mathrm{x}$ \\
\hline Moraceae & Ficus sp1 & $x$ & $\mathrm{X}$ & $x$ & & & & \\
\hline Moraceae & Ficus sp2 & $x$ & & & & & & \\
\hline Moraceae & Ficus sp3 - sp4 & & & $x$ & & & & \\
\hline Moraceae & Ficus sp5 & & $x$ & & & & & \\
\hline Moraceae & Moraceae sp1 - sp2 & $x$ & & & & & & \\
\hline Moraceae & Moraceae sp3 & & & $x$ & & & & \\
\hline Moraceae & Moraceae sp4 & & $x$ & & & & & \\
\hline Moraceae & Moraceae sp5 - sp6 & & & $x$ & & & & \\
\hline Myrtaceae & Myrtaceae sp. & & & $x$ & & & & \\
\hline Nymphaeaceae & Nymphaea ampla cf. & & $x$ & & & & & \\
\hline \multicolumn{2}{|l|}{ Onagraceae } & $x$ & & $x$ & & & & \\
\hline Onagraceae & Onagraceae sp1 - sp2 & & & $x$ & & & & \\
\hline Onagraceae & Ludwigia sp. & $x$ & & & & & & \\
\hline \multicolumn{2}{|l|}{ Piperaceae } & $x$ & $x$ & $x$ & $x$ & & & $x$ \\
\hline Piperaceae & Piper sp. & & & & $x$ & & & $x$ \\
\hline Piperaceae & Piper $\mathrm{spl}$ - sp3 & & & $x$ & & & & \\
\hline Piperaceae & Piper sp4 & & $x$ & & & & & \\
\hline Piperaceae & Piper sp5 - sp6 & & & $x$ & & & & \\
\hline Piperaceae & Piper sp7 & & $x$ & & & & & \\
\hline Piperaceae & Piper $\mathrm{sp} 8$ & & & $x$ & & & & \\
\hline Piperaceae & Piperaceae sp1 - sp3 & $\mathrm{x}$ & & & & & & \\
\hline Piperaceae & Piperaceae sp4 & & $x$ & $x$ & & & & \\
\hline \multicolumn{2}{|l|}{ Poaceae } & $x$ & $x$ & $\mathrm{x}$ & & $x$ & & $x$ \\
\hline Poaceae & Poaceae spl & $\mathrm{x}$ & & & & & & \\
\hline Poaceae & Poaceae sp2 - sp3 & & $x$ & & & & & \\
\hline Poaceae & Poaceae sp4 & & & $x$ & & & & \\
\hline Poaceae & Poaceae sp5 & & $x$ & & & & & \\
\hline \multicolumn{2}{|l|}{ Podocarpaceae } & & $x$ & $x$ & & & & \\
\hline Podocarpaceae & Podocarpus spl & & & $x$ & & & & \\
\hline Podocarpaceae & Podocarpus sp2 & & $x$ & & & & & \\
\hline Polypodiaceae & & $x$ & $x$ & $x$ & & & & \\
\hline Polypodiaceae & Polypodium sp1 & & & $x$ & & & & \\
\hline Polypodiaceae & Polypodium sp2 & & $x$ & & & & & \\
\hline Polypodiaceae & Polypodium sp3 & & & $x$ & & & & \\
\hline Polypodiaceae & Saccoloma sp. $c f$. & & & $x$ & & & & \\
\hline Polypodiaceae & Thelypteris sp. & & $x$ & & & & & \\
\hline Polypodiaceae & Polypodiaceae sp1 - sp3 & $x$ & & & & & & \\
\hline Polypodiaceae & Polypodiaceae sp4 & & & $x$ & & & & \\
\hline Pontederiaceae & Eichornia sp.cf. & $x$ & & & & & & \\
\hline Rhamnaceae & Rhamnaceae sp. & $x$ & & & $x$ & & & \\
\hline Rubiaceae & & & & $x$ & $x$ & $x$ & $x$ & $\mathrm{X}$ \\
\hline Rubiaceae & Rubiaceae spl - sp5 & & & $x$ & & & & \\
\hline Sapindaceae & & $x$ & & $x$ & $x$ & & & \\
\hline
\end{tabular}




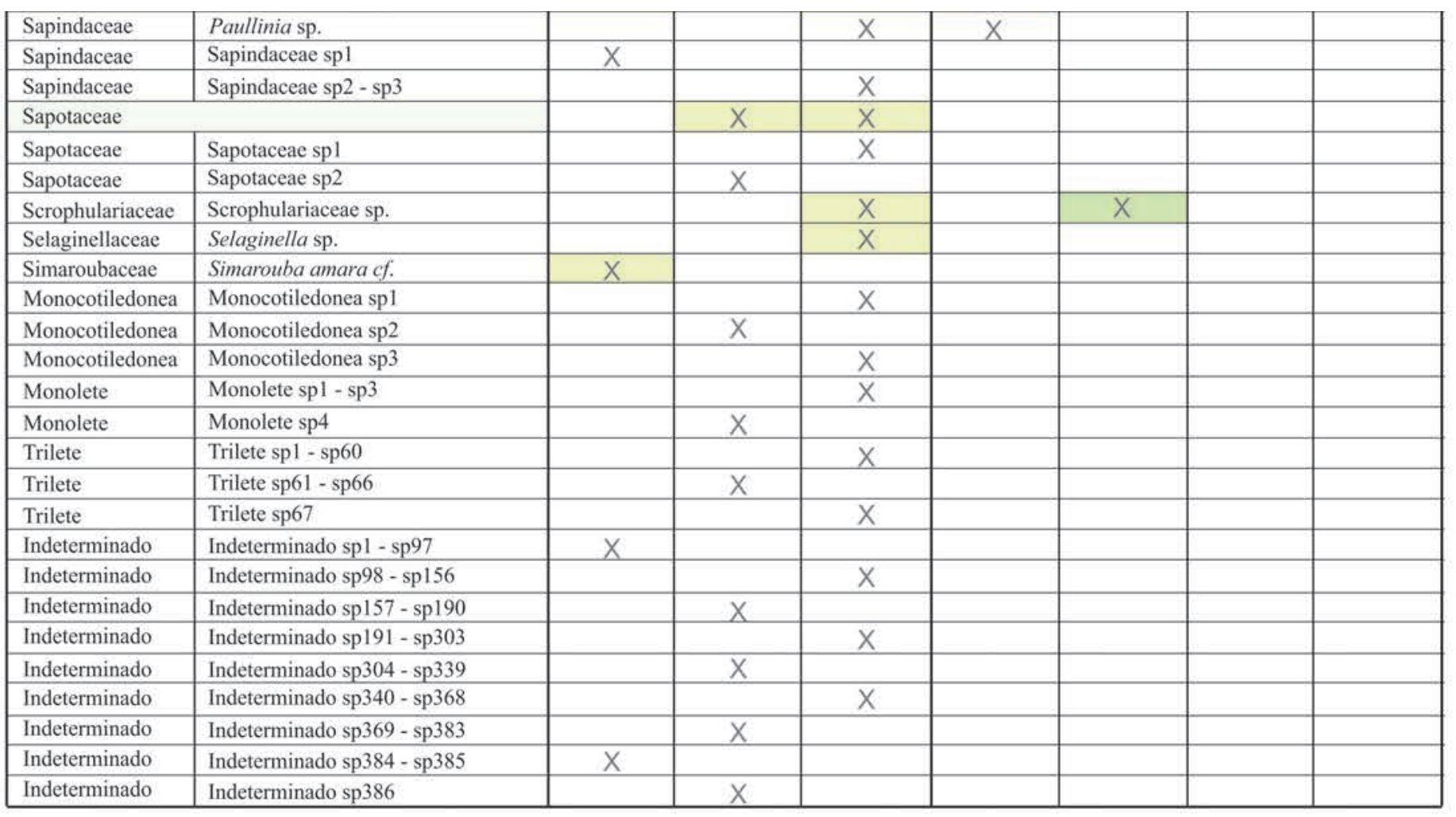


Anexo 9. Atlas del polen fósil de la Formación San Alfonso, Grupo La Venta.

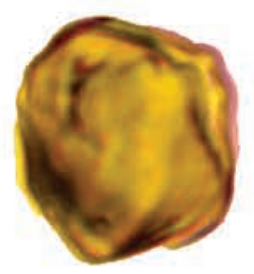

(a)

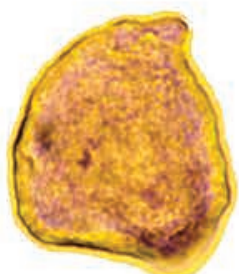

(b)
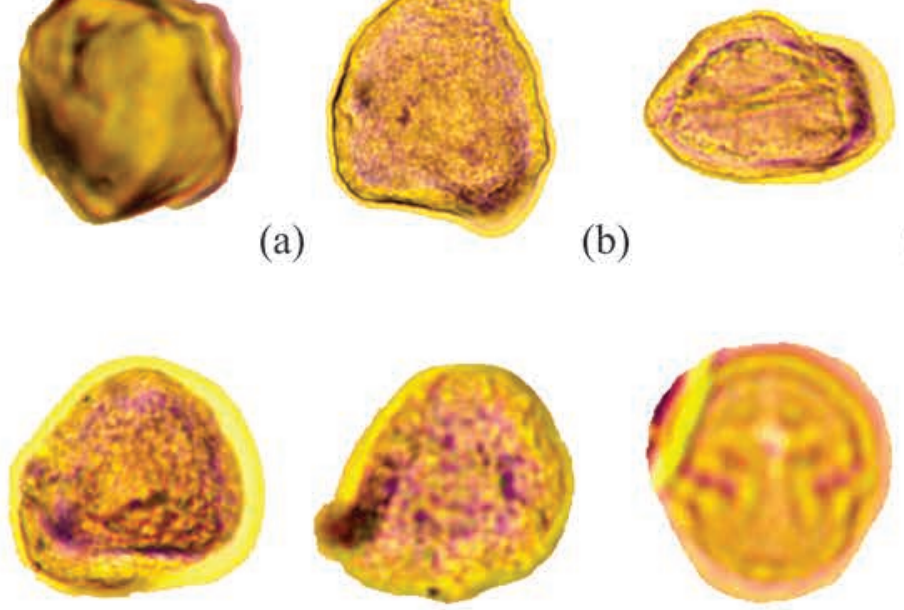

(f)

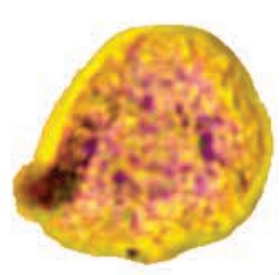

(g)

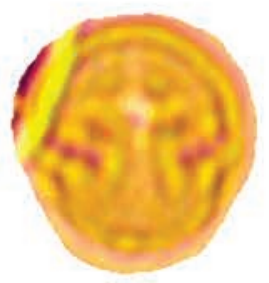

(h)

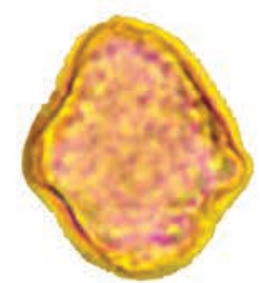

(c)

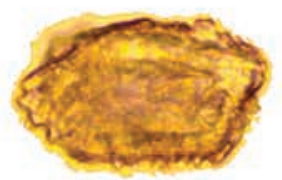

(d)

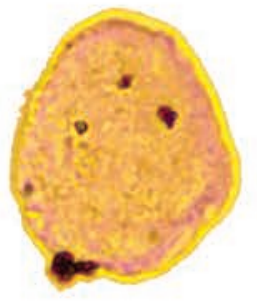

(e)

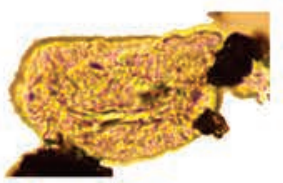

(i)

(j)

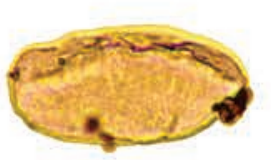

(k)

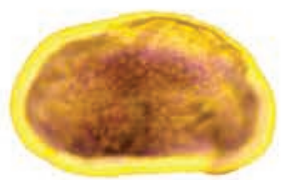

(1)

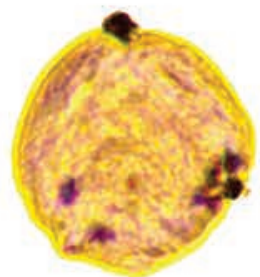

(m)

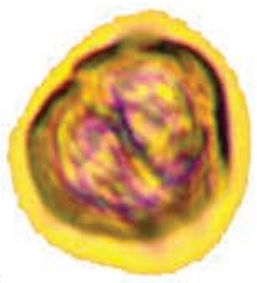

(n)

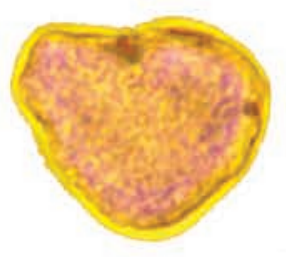

(r)

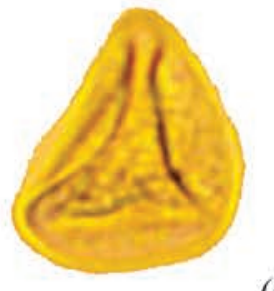

(q)

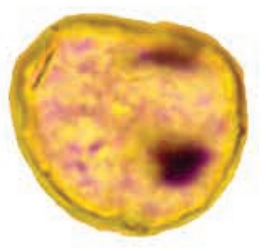

(u)

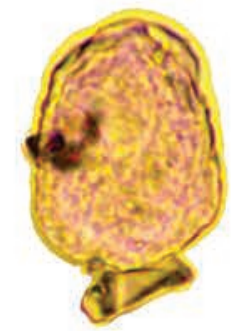

(v)

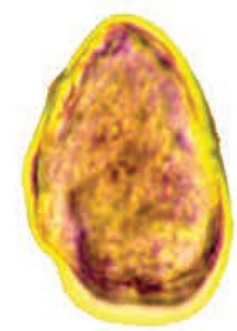

(w)

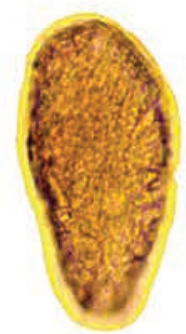

(s)
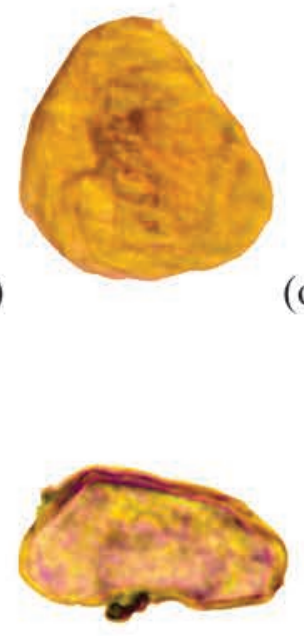

(o)

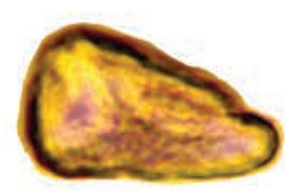

$(\mathrm{x})$

(y)

(a) Acalypha sp.; (b) Apocynaceae sp1; (c) Arecaceae sp1; (d) Asteraceae sp1; (e) Bombacaceae sp1; (f) Bombacaceae sp2; (g) Bombacaceae sp3; (h) Burseraceae sp. (i) Cecropia sp1; (j) Commelinaceae sp1; (k) Commelinaceae sp2; (l) Commelinaceae sp3; (m) Cucurbitaceae sp1; (n) Cucurbitaceae sp2; (o) Cyperaceae sp1; (p) Cyperaceae sp2; (q) Cyperaceae sp3; (r) Cyperaceae sp4; (s) Cyperaceae sp5; (t) Cyperaceae sp6; (u) Cyperaceae sp7; (v) Cyperaceae sp8; (w) Cyperaceae sp9; (x) Cyperaceae sp10; (y) Cyperaceae sp11.

Fotografía: Luz Victoria Correa. 


\section{Continuación Anexo 9.}
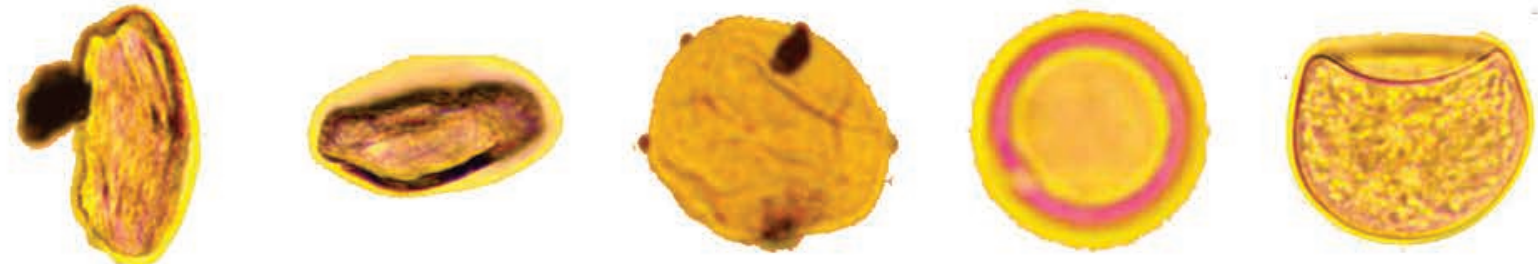

$(z)$

(aa)

(ab)

(ac)

(ad)
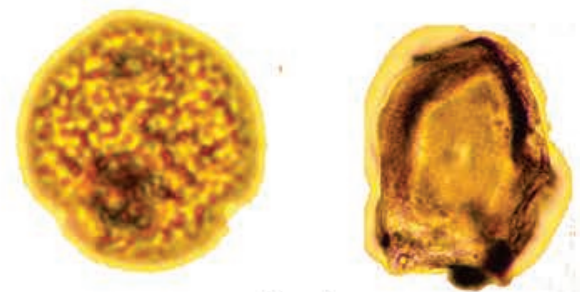

(ae)

(af)

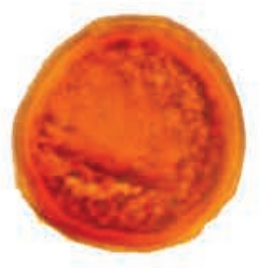

(ag)

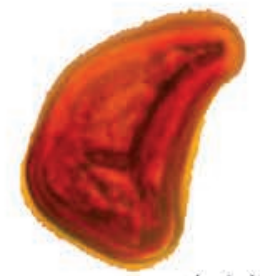

(ah)

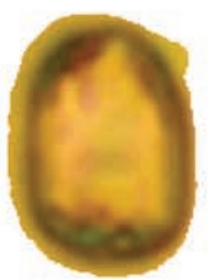

(ai)

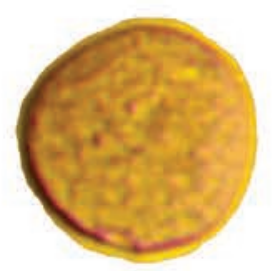

(aj)
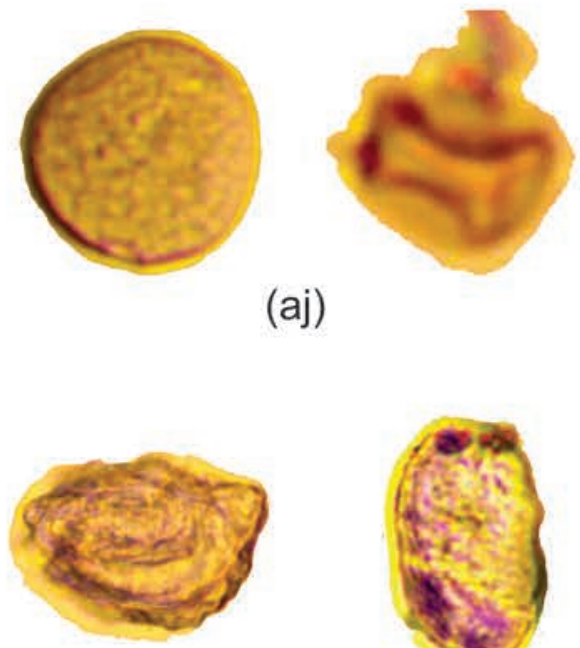

(ao)

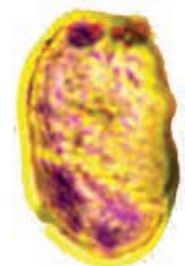

(ak)

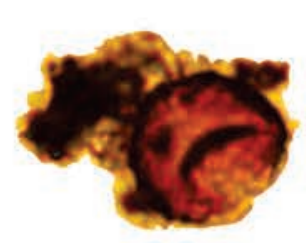

(al)

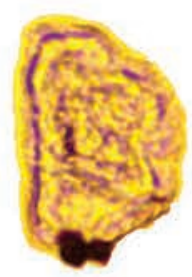

(am)

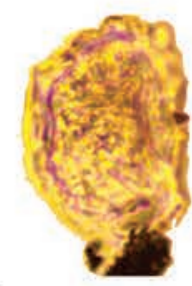

(an)

(ap)

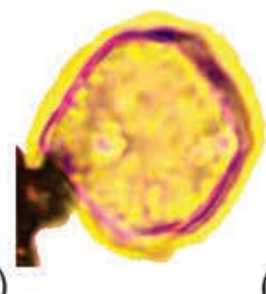

(aq)
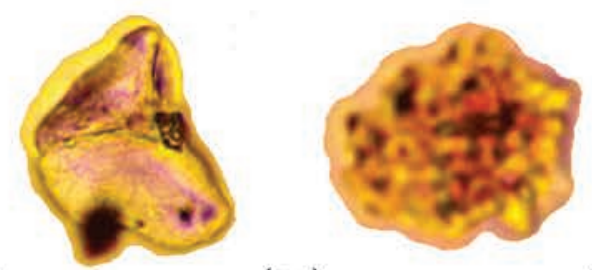

(ar)

(as)

(z) Dioscoreaceae sp1; (aa) Eichornia sp.cf.; (ab) Fabaceae sp1; (ac)Ficus sp2;(ad) Gramineae sp1: (ae) Gusmania ulmifolia cf.; (af) Ludwigia sp.; (ag) Malpighiaceae sp1, (ah) Malpighiaceae sp2; (ai) Moraceae sp1; (aj) Moraceae sp2; (ak) Piper sp1; (al) Piper sp2; (am) Polypodiaceae sp1; (an) Polypodiaceae sp2; (ao) Polypodiaceae sp3; (ap) Rhamnaceae sp.; (aq) Sapindaceae sp1; (ar) Simaouruba amara.

Fotografía: Luz Victoria Correa. 
Anexo 10. Atlas del polen fósil de la Formación La Victoria, Grupo La Venta.

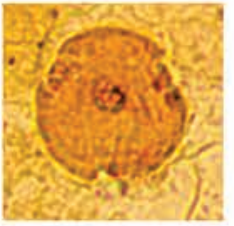

(a)

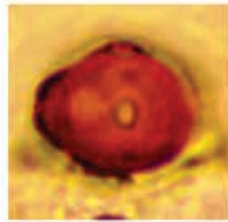

(b)

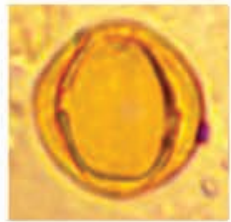

(c)

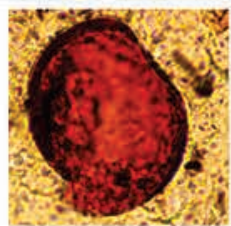

(1)

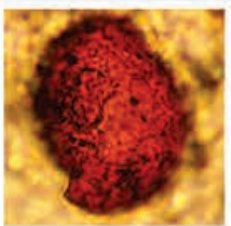

(2)

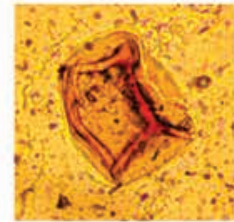

(e)

(d)

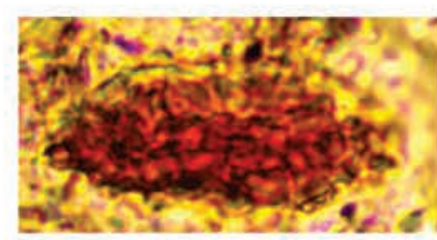

(f)

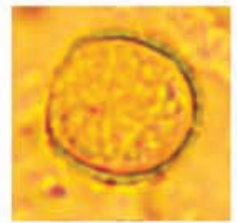

(g)

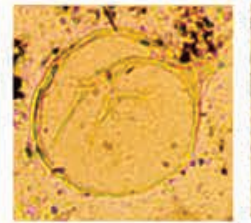

(h)

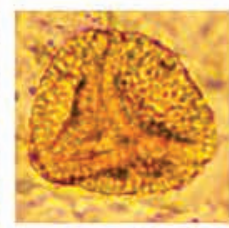

(m)

(n)

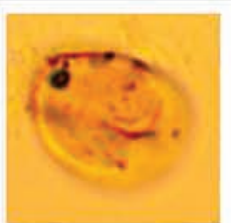

(1)

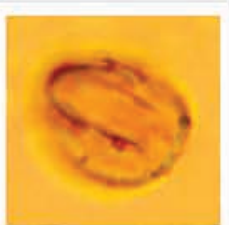

(2)

(o)

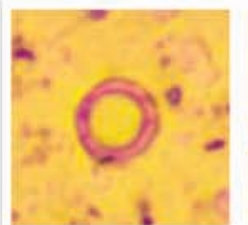

(p)

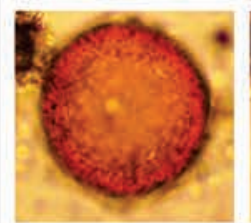

(1)

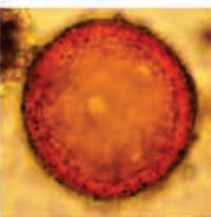

(2)

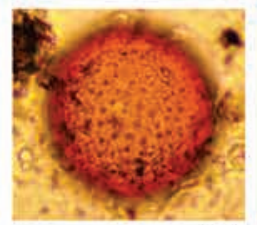

(3)

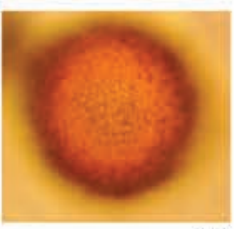

(4)

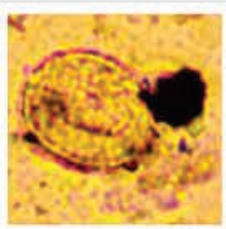

(1)

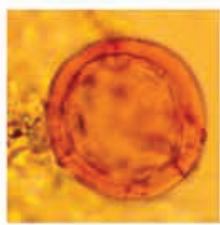

(q)

(k)

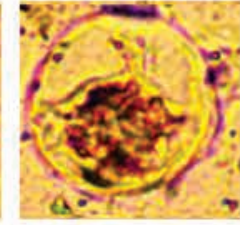

(j)

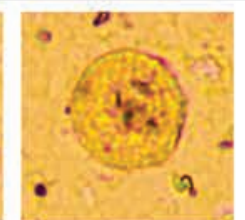

(2)

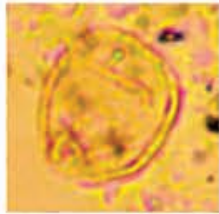

(t)

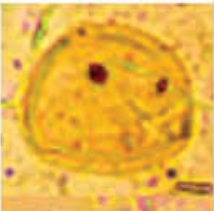

(u)

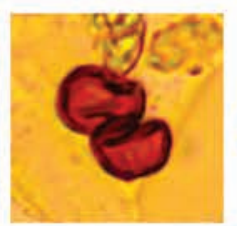

(v)

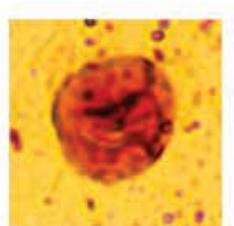

(w)

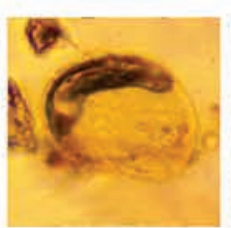

(x)

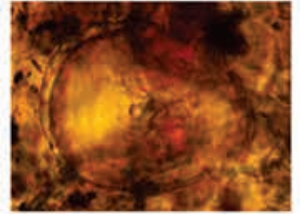

(y)

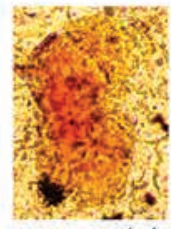

(z)

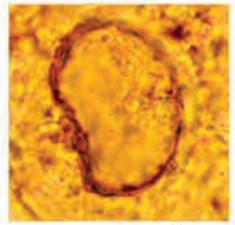

(aa)

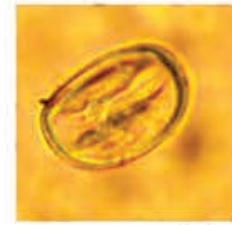

(ab)

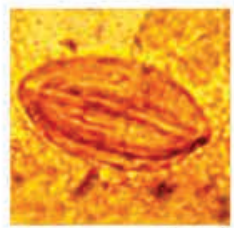

(ac)

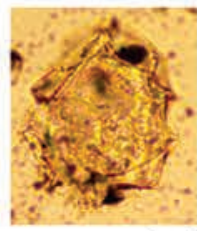

(ad)

(a) Alchornea sp2; (b) Apocynaceae sp9; (c) Apocynaceae sp10; (d) Apocynaceae sp11: 1 - 2;(e) Aracauriaceae sp2; (f) Asteraceae sp4; (g) Commelinaceae sp4; (h) Cyperaceae sp18; (i) Cyperaceae sp19; (j) Cyperaceae sp20; (k) Cyperaceae sp21; (I) Cyperaceae sp22; (m) Cyperaceae sp23; (n) Erythroxylaceae sp. (o) Fabaceae sp3: 1 - 2; (p) Ficus sp5; (q) Malpighiaceae sp2; (r) Malvaceae sp: 1 - 4; (s) Monocotiledonea sp2: 1 - 2; (t) Moraceae sp4; (u) Nymohaea ampla cf.; (v) Piper sp4; (w) Piper sp7; (x) Poaceae sp2; (y) Poaceae sp3; (z) Podocarpus sp2; (aa) Polypodium sp2; (ab) Sapotaceae sp2; (ac) Spathiphyllum sp9; (ad) Thelypteris sp1. 
Anexo 11. Atlas del polen fósil de la Formación Villavieja, Grupo La Venta.

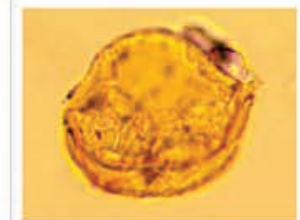

(1)

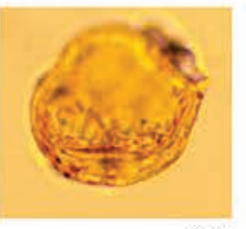

(2)

(a)

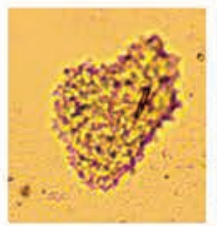

(1)

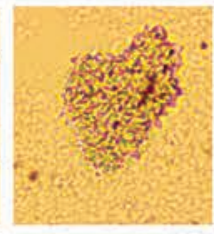

(2)

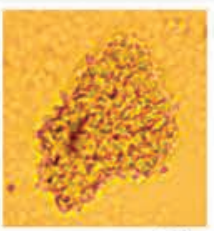

(3)

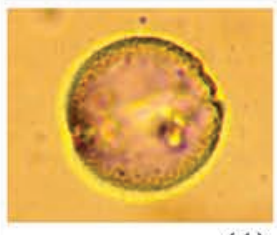

(1)

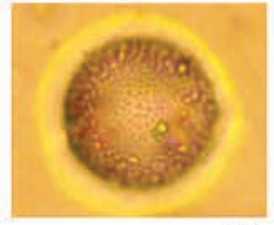

(2)

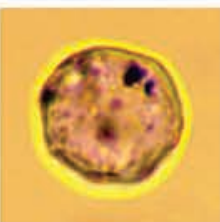

(1)

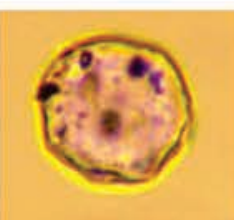

(2)

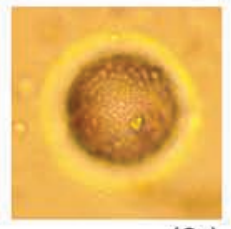

(3)

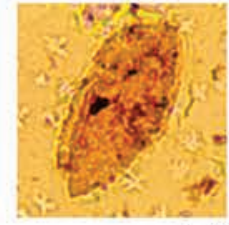

(c)

(b)

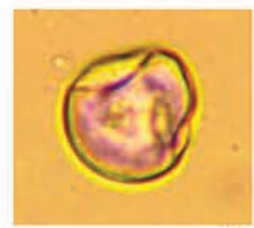

(f)

(d)

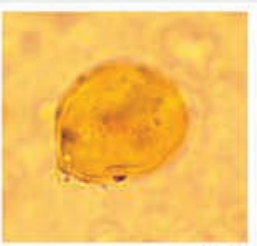

(1)

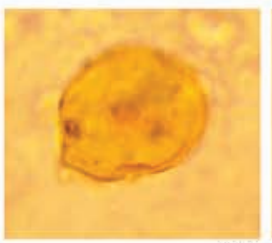

(2)

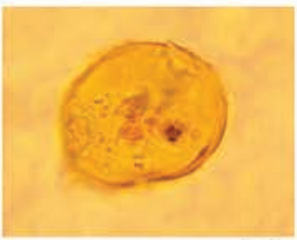

(3)

(g)

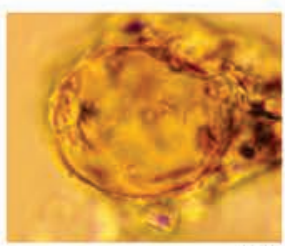

(h)

(e)

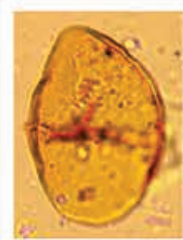

(1)

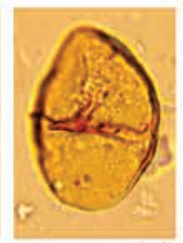

(2)

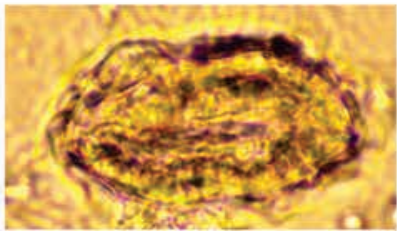

(1)

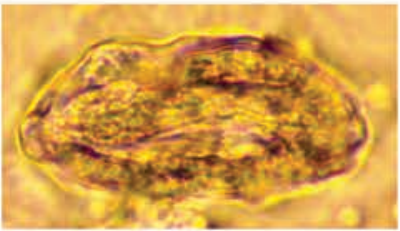

(2)

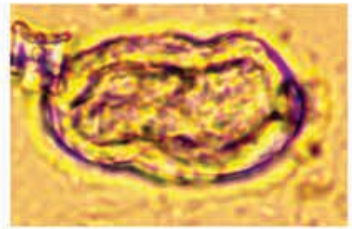

(1)

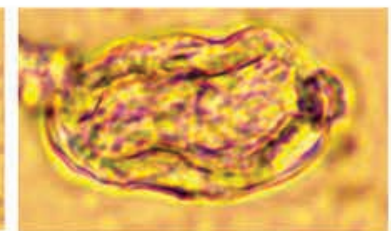

(2)

(j)

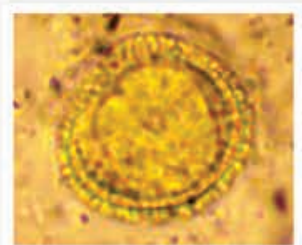

(1)

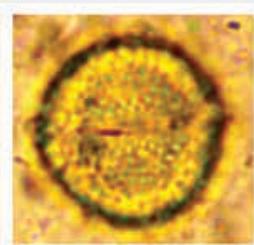

(2)

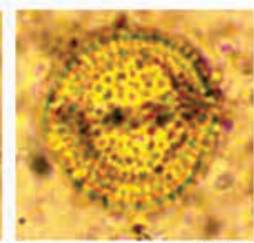

(3)

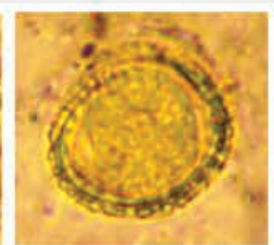

(4)

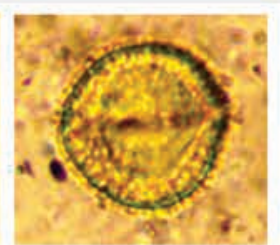

(5)

(a) Alchornea sp1: 1 - 2; (b) Alismataceae sp.: 1 - 3; (c) Annona sp.; (d) Annonaceae sp.: 1- 3; (e) Apocynaceae sp2: 1 - 2; (f) Apocynaceae sp7; (g) Apocynaceae sp8: 1 - 3; (h) Apocynaceae sp12; (i) Araucariaceae sp1:1 - 2; (j)Arecaceae sp3: 1-2; (k)Arecaceae sp4:1 - 2; (I) Bursera simaruba cf.: 1 - 5.

Fotógrafo: Luz Victoria Correa. 


\section{Continuación Anexo 11.}

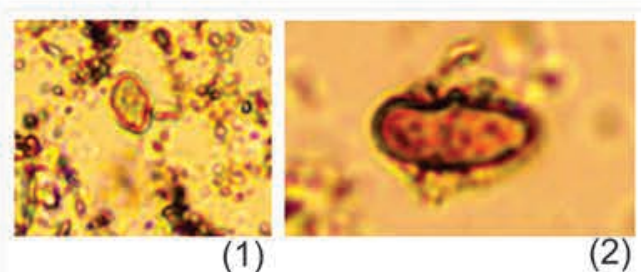

(m)

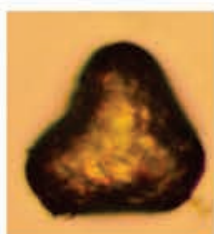

(1)

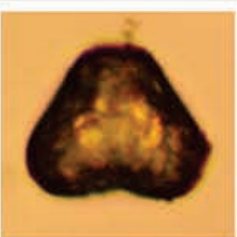

(2)

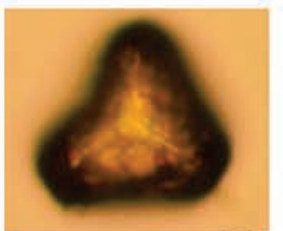

(3)

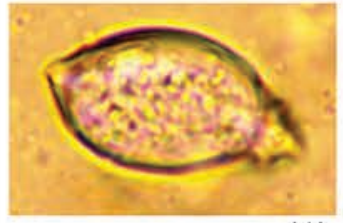

(1)

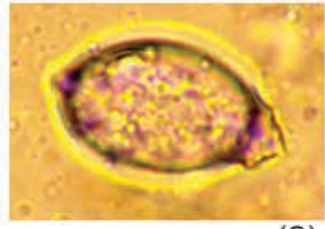

(2)

(n)

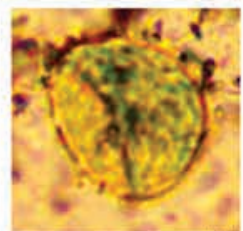

(1)

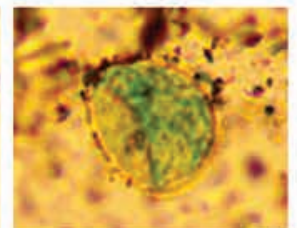

(2)

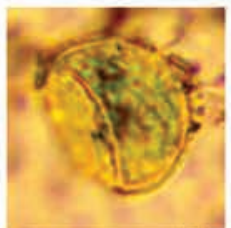

(3)

(o)

(p)

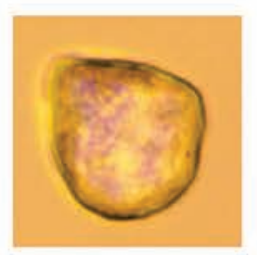

(q)

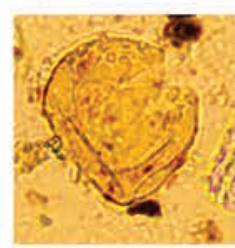

(r)

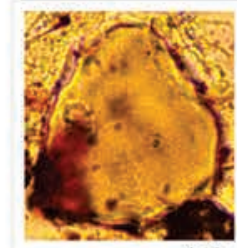

(1)

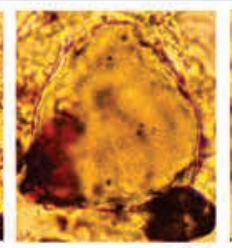

(2)

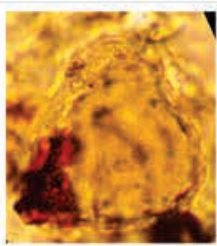

(3)

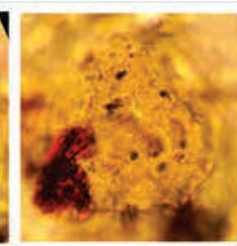

(4)

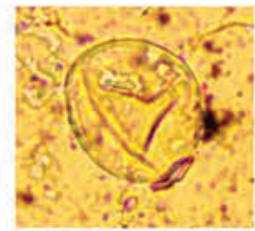

(t)

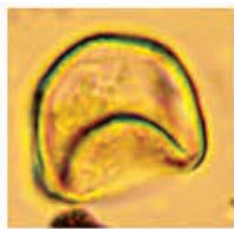

(1)

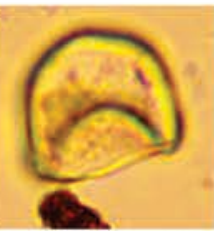

(2)

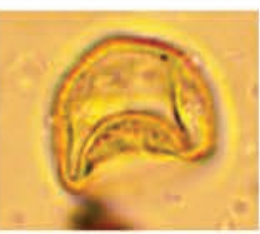

(3)

(u)

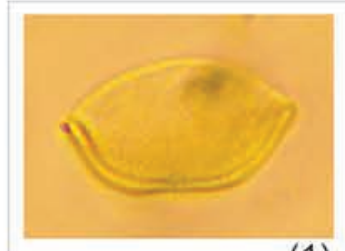

(1)

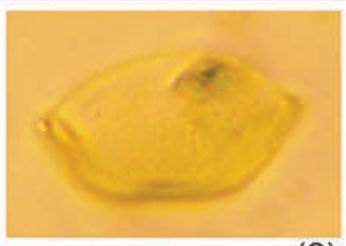

(2)

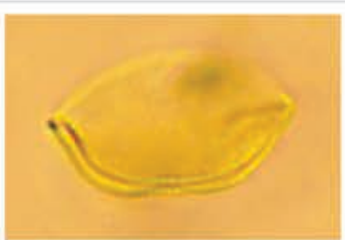

(3)

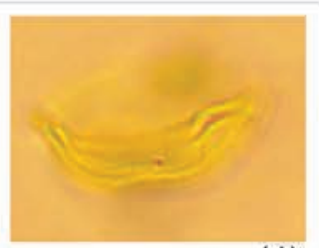

(4)

(m) Cecropia sp2: 1 - 2; (n) Cleidon sp. cf.: 1 - 2; (o) Cyathea sp.: 1 - 3; (p) Cyperaceae sp12: 1 - 3; (q) Cyperaceae sp13; (r) Cyperaceae sp14; (s) Cyperaceae sp15: 1 - 4; (t) Cyperaceae sp16; (u) Cyperaceae sp17: 1-3; (v) Cyperaceae sp24:1-4.

Fotógrafo: Luz Victoria Correa. 


\section{Continuación Anexo 11.}

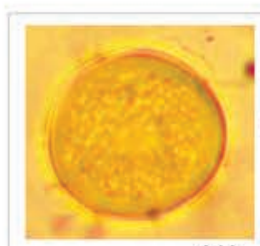

(1)

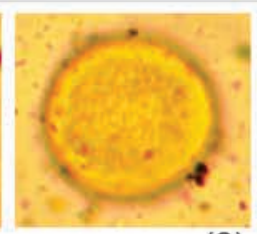

(2)

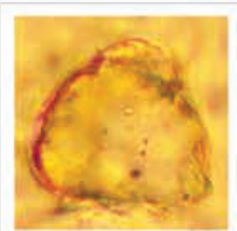

(1)

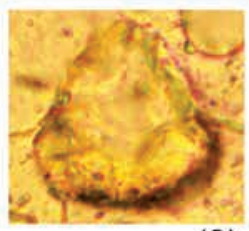

(2)

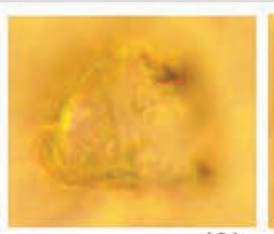

(3)

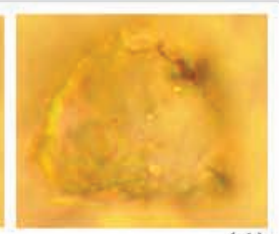

$(4)$

(x)

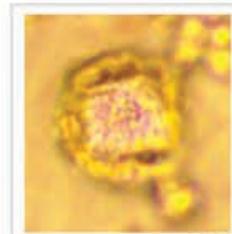

(1)

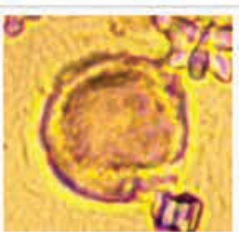

(2)

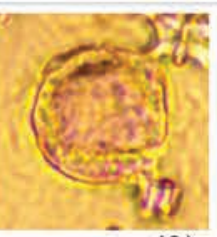

(3)

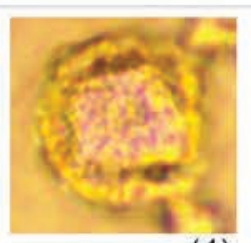

(4)

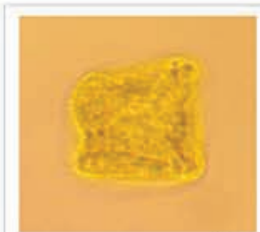

(1)

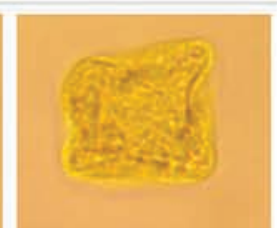

(2)

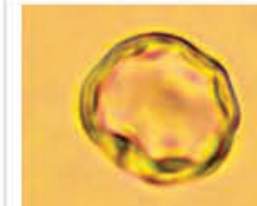

(1)

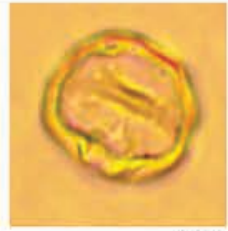

(2)

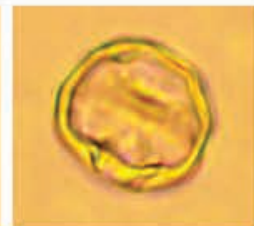

(3)

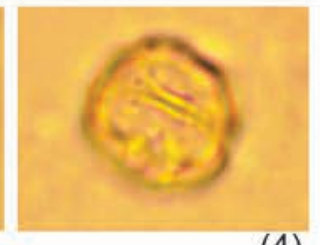

(4)

(aa)

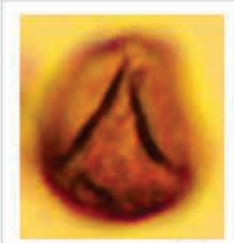

(1)

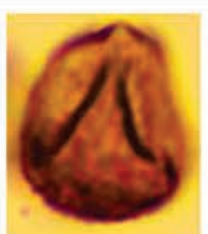

(2)

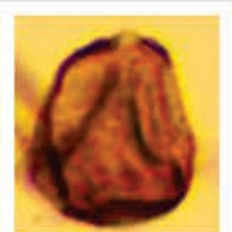

(3)

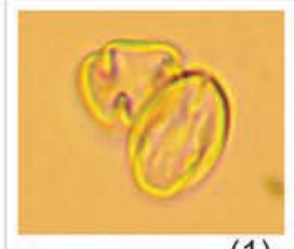

(1)

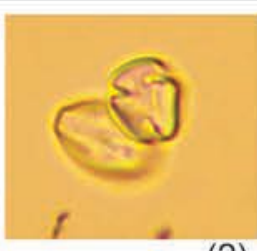

(2)

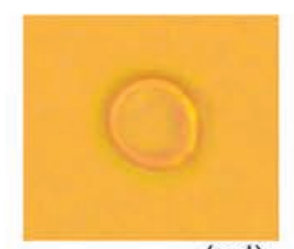

(ad)

$(a b)$

(ac)

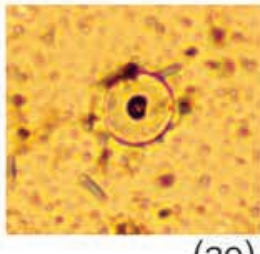

(ae)

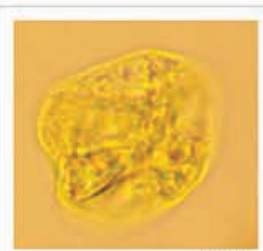

(1)

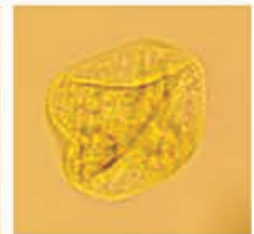

(2)

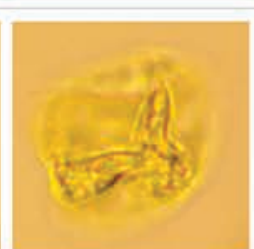

(3) 


\section{Continuación Anexo 11.}

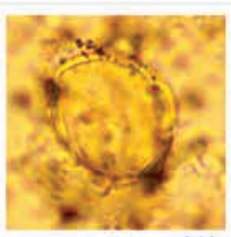

(1)

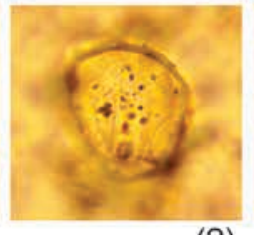

(2)

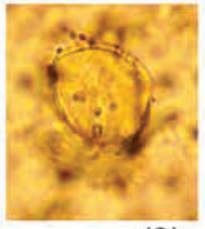

(3)

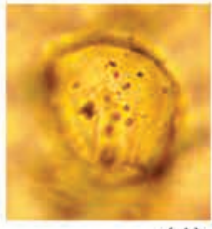

(4)

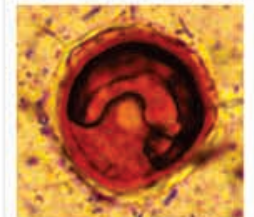

(1)

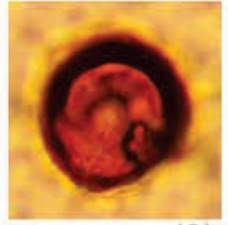

(2)

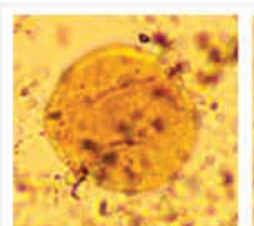

(1)

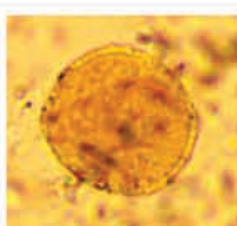

(2)

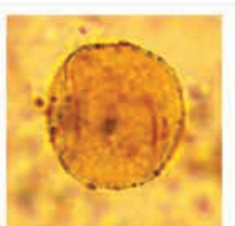

(3)

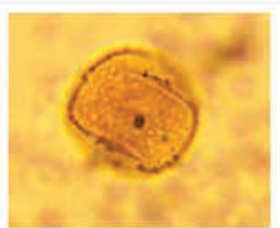

(4)

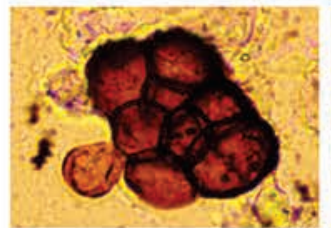

(1)

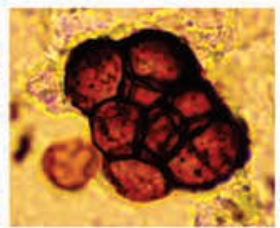

(2)

(aj)

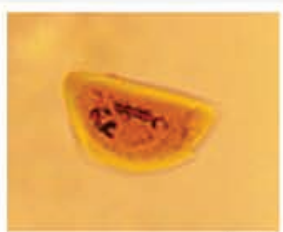

(1)

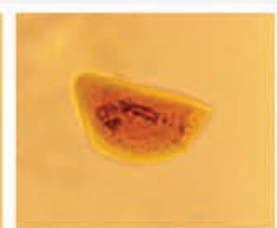

(2)

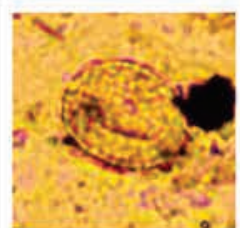

(1)

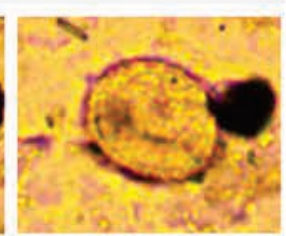

(2)

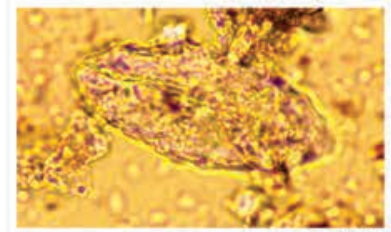

(1)

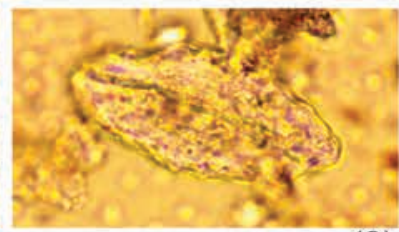

(2)

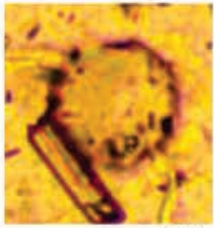

(1) (an)

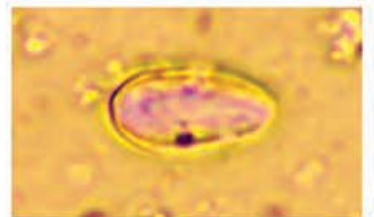

(1)

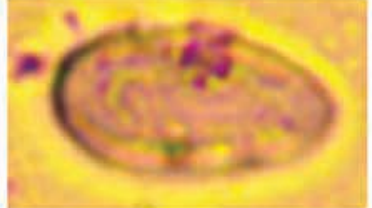

(2)

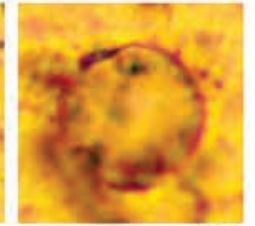

(2)

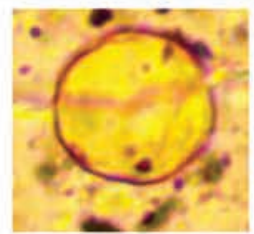

(1)

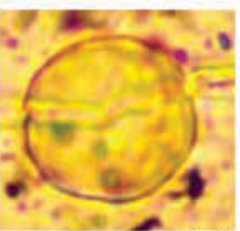

(2)

(ap)

(3)

(aq)

(ah) Mabea sp. cf.: 1 - 4; (ai) Malpighiaceae sp3: 1-2; (aj) Meliaceae sp.: 1 - 4; (ak) Mimosaceae sp.: 1 - 2; (al) Monocotiledonea sp1: 1 - 2; (am) Monocotiledonea sp2: 1 - 2; (an) Monocotiledonea sp3:1 - 2; (ao) Moraceae sp3: 1-2; (ap) Moraceae sp5: 1-2; (aq) Moracea sp6:1-3.

Fotógrafo: Luz Victoria Correa. 


\section{Continuación Anexo 11.}

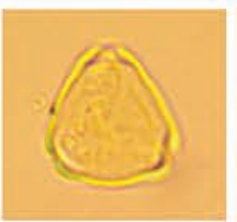

(1)

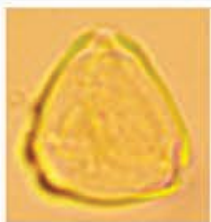

(2)

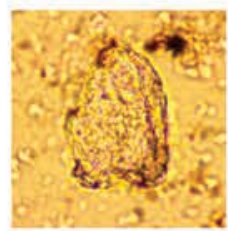

(as)

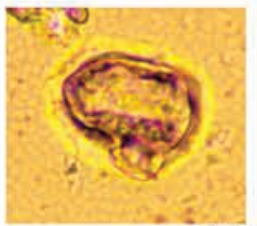

(1)

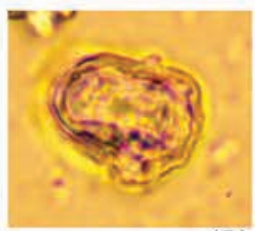

(2)

(at)

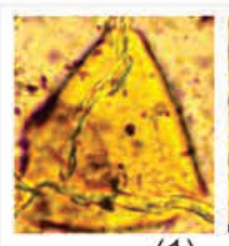

(1)

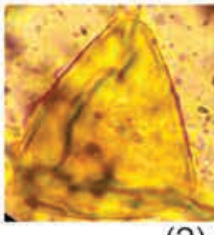

(2)

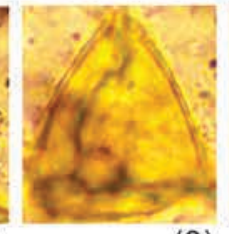

(3)

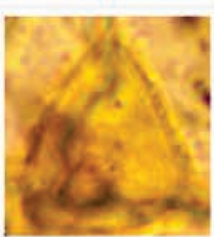

(4)

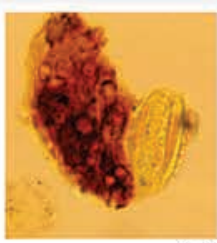

(1)

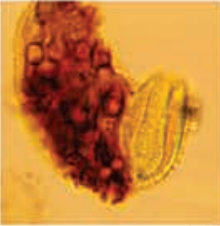

(2)

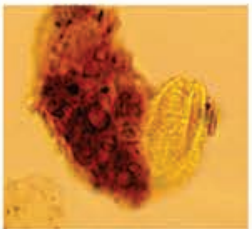

(3)

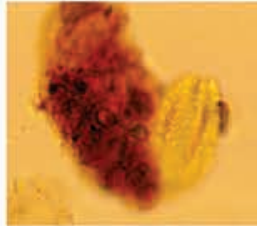

(4)

(av)

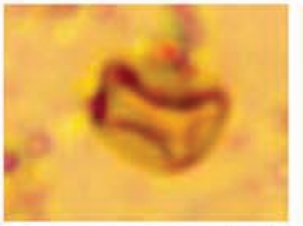

(aw)

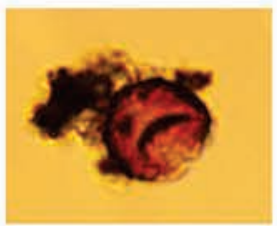

(ax)

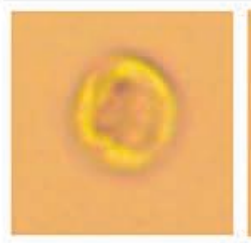

(1)

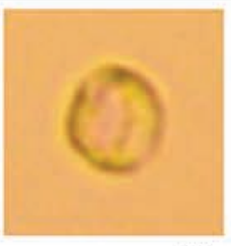

(2)

(ay)

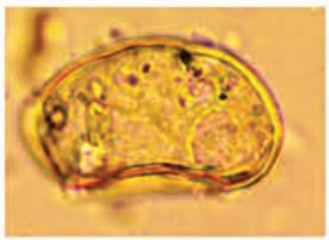

(1)

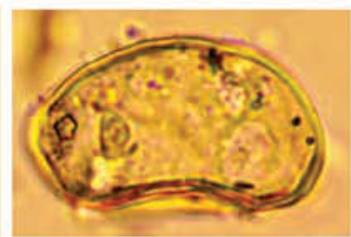

(2)

(bb)

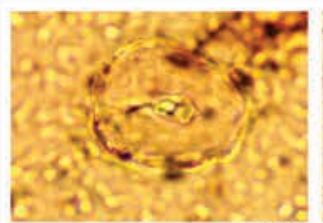

(1)

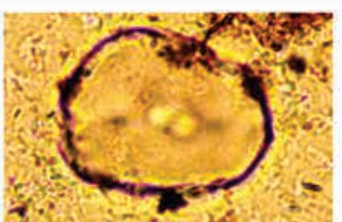

(2)

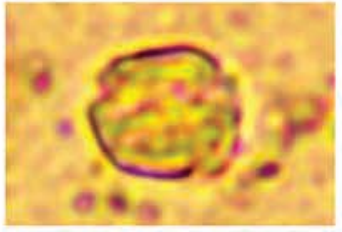

(az)

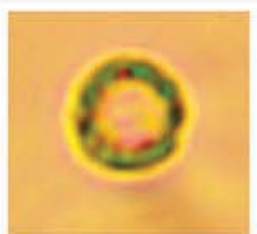

(1)

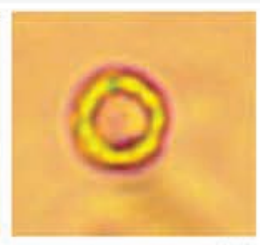

(2)

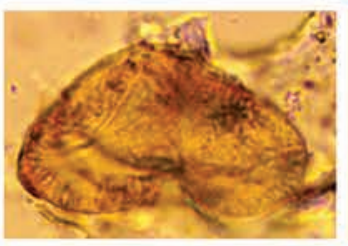

(1)

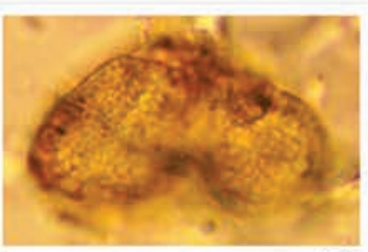

(2)

(bd)

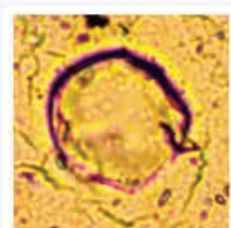

(1)

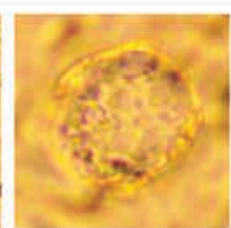

(2)

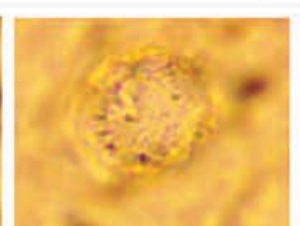

(3)

(ar) Myrtaceae sp.: 1 - 2; (as) Onagraceae sp1; (at) Onagraceae sp2: 1 - 2; (au) Paullinia sp.: 1 - 4; (av) Philodendron sp.: 1 - 4; (aw) Pipersp1; (ax) Pipersp3; (ay) Pipersp5: 1 - 2; (az) Pipersp6; (ba) Pipersp8: 1 2; (bb) Poaceae sp4: 1 - 2; (bc) Podocarpus sp1: 1 - 2; (bd) Rhynchospora cephalotes: 1 - 2; (be) Rubiaceae sp1:1-3.

Fotógrafo: Luz Victoria Correa. 


\section{Continuación Anexo 11.}

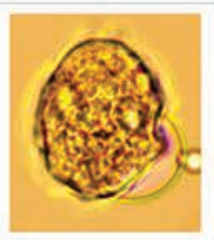

(1)

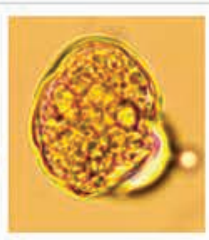

(2)

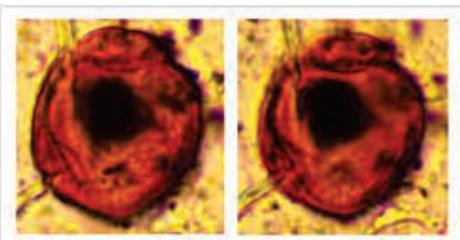

(1)
(2)

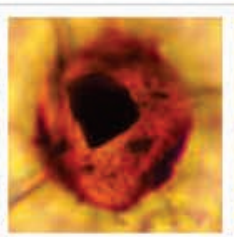

(3)

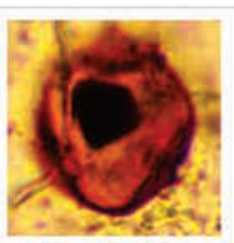

(4)

(bf)

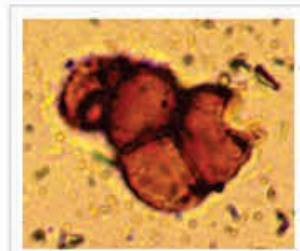

(1)

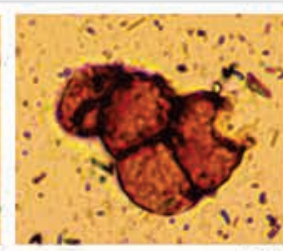

(2)

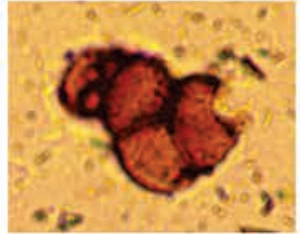

(3)

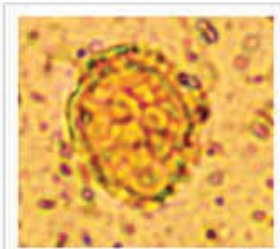

(1)

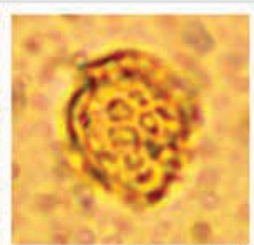

(2)

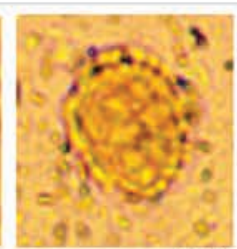

(3)

(bh)

(bi)

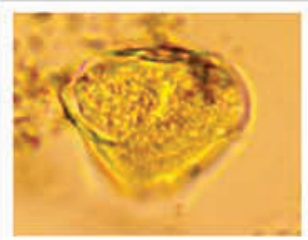

(1)

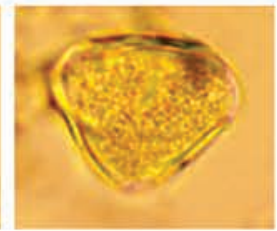

(2)

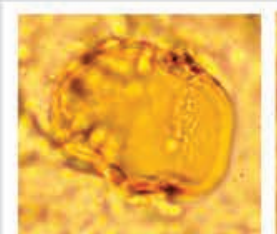

(1)

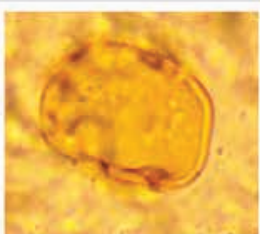

(2)

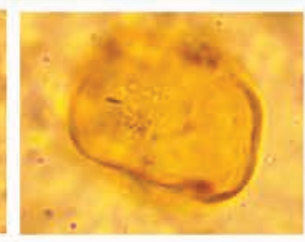

(3)

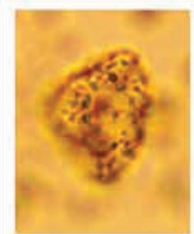

(1)

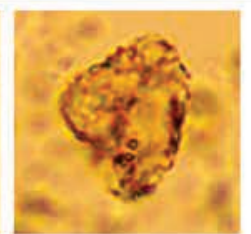

(2)

(bk)

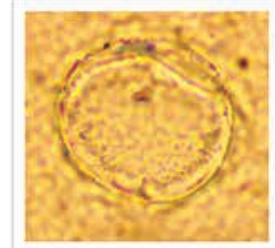

(1)

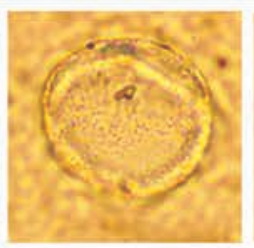

(2)

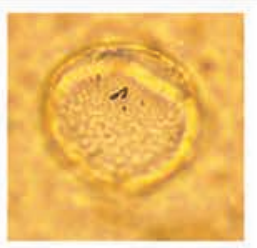

(3)

(bl)

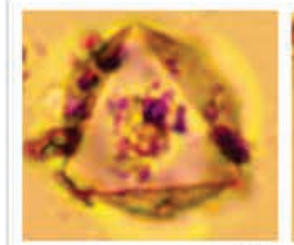

(1)

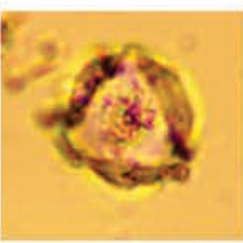

(2)

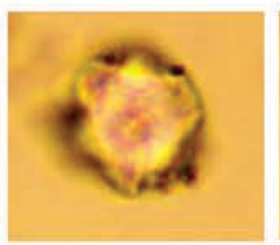

(3)

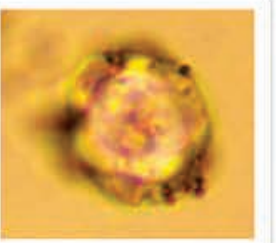

(4)

(bn)

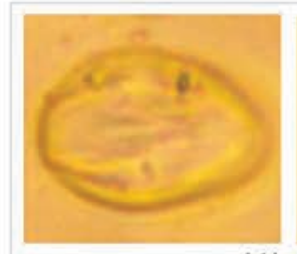

(1)

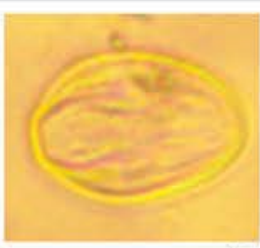

(2)

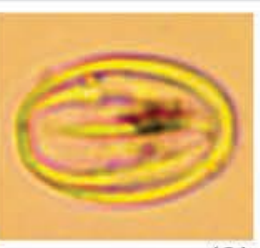

(3)

(bo)

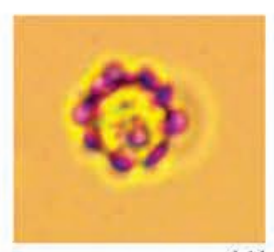

(1)

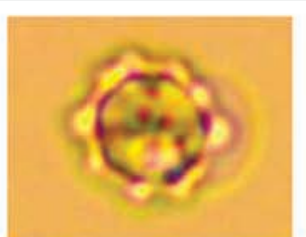

(2)

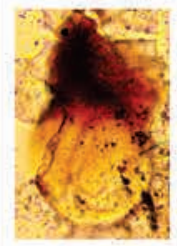

(bq)

(bp)

(bf) Rubiaceae sp2: 1 - 2; (bg) Rubiaceae sp3: 1 - 4; (bh) Rubiaceae sp4: 1 - 3; (bi) Rubiaceae sp5: 1 - 3; (bj) Sapindaceae sp2: 1 - 2; (bk) Sapindaceae sp3: 1 - 2; (bl) Sapotaceae sp1: 1 - 3; (bm) Scrophulariaceae sp.: 1-3; (bn) Selaginella sp.: 1-4; (bo) Terminalia sp. cf.:1 - 3; (bp) Tournefortia sp.: 1-2; (bq) Tumbergia erecta.

Fotógrafo: Luz Victoria Correa. 
Anexo 12. Lista de mamíferos fósiles del Grupo La Venta registrados en la presente investigación y en literatura.

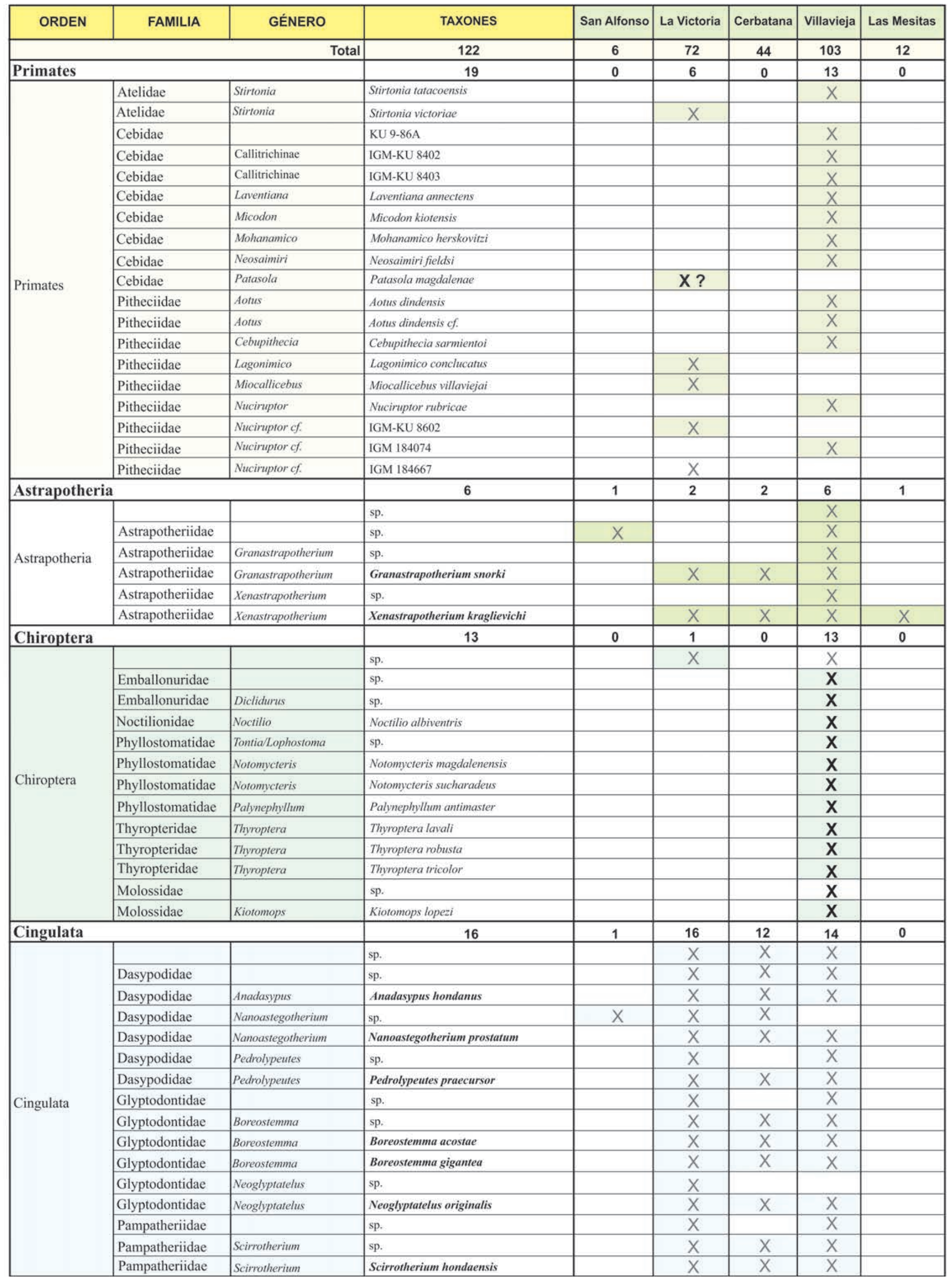




\begin{tabular}{|c|c|c|c|c|c|c|c|c|}
\hline \multicolumn{3}{|l|}{ Didelphimorphia } & 9 & 0 & 2 & 2 & 9 & 0 \\
\hline \multirow{7}{*}{ Didelphimorphia } & Didelphidae & & sp. & & & & $\mathrm{X}$ & \\
\hline & Didelphidae & Marmosa & sp. & & & & $X$ & \\
\hline & Didelphidae & Marmosa & Marmosa laventica & & & & $\mathbf{x}$ & \\
\hline & Didelphidae & Micoureus & sp. & & & & $\mathrm{X}$ & \\
\hline & Didelphidae & Micoureus & Micoureus laventicus & & $X$ & $\mathrm{X}$ & $\mathrm{X}$ & \\
\hline & Didelphidae & Pachybiotherium & Pachybiotherium minor & & & & $\mathrm{X}$ & \\
\hline & Hondadelphidae & Hondadelphys & Hondadelphys fieldsi & & $\mathrm{X}$ & $\mathrm{X}$ & $x$ & \\
\hline \multicolumn{3}{|l|}{ Litopterna } & 10 & 0 & 9 & 4 & 7 & 1 \\
\hline \multirow{6}{*}{ Litopterna } & & & sp. & & $\mathrm{X}$ & & $x$ & \\
\hline & Macraucheniidae & Theosodon & sp. & & $\mathrm{X}$ & $\mathrm{X}$ & $x$ & \\
\hline & Proterotheriidae & & sp. & & $\mathrm{X}$ & & & \\
\hline & Proterotheriidae & Prothoatherium & Prothoatherium colombianus & & $X$ & $x$ & $x$ & \\
\hline & Proterotheriidae & Villarroelia & sp. & & $\mathrm{X}$ & & & \\
\hline & Proterotheriidae & Villarroelia & Villarroelia totoyoi & & $\mathrm{X}$ & & & \\
\hline \multicolumn{3}{|l|}{ Notoungulata } & 13 & 4 & 12 & 11 & 13 & 4 \\
\hline \multirow[b]{7}{*}{ Notoungulata } & & & sp. & $\mathrm{X}$ & $\mathrm{X}$ & $\mathrm{X}$ & $\mathrm{X}$ & \\
\hline & Leontiniidae & & sp. & $X$ & $\mathrm{X}$ & $x$ & $\mathrm{X}$ & \\
\hline & Leontiniidae & Huilatherium & sp. & & $\mathrm{X}$ & & $\mathrm{X}$ & \\
\hline & Leontiniidae & Huilatherium & sp1 & & $X$ & $x$ & $x$ & \\
\hline & Leontiniidae & Huilatherium & $\mathrm{sp} 2$ & & & $x$ & $x$ & \\
\hline & Leontiniidae & Huilatherium & Huilatherium pluripicatum & & $\mathrm{X}$ & $X$ & $x$ & \\
\hline & Toxodontidae & & sp. & $\mathrm{X}$ & $\mathrm{X}$ & & $\mathrm{X}$ & $\mathrm{X}$ \\
\hline \multirow{2}{*}{ Paucituberculata } & Abderitidae & Pithiculites & Pithiculites chenche & & $\mathbf{x}$ & & & \\
\hline & Paleonthentidae & Hondathentes & Hondathentes cazador & & & & $\mathrm{X}$ & \\
\hline \multicolumn{3}{|l|}{ Pilosa } & 11 & 0 & 7 & 4 & 9 & 0 \\
\hline \multirow{11}{*}{ Pilosa } & & & sp. & & $\mathrm{X}$ & & $\mathrm{X}$ & \\
\hline & Megalonychidae & & sp. & & & & $X$ & \\
\hline & Mylodontidae & & sp. & & & $\mathrm{X}$ & & \\
\hline & Mylodontidae & Brievabradys & Brievabradys laventensis & & $X$ & & & \\
\hline & Mylodontidae & Glossotheriopsis & sp. & & & & $x$ & \\
\hline & Mylodontidae & Glossotheriopsis & Glossotheriopsis pascuali & & $\mathrm{X}$ & $\mathrm{X}$ & $x$ & \\
\hline & Mylodontidae & Neonematherium & sp. & & $X$ & & $x$ & \\
\hline & Mylodontidae & Neonematherium & Neonematherium flabellatum & & $\mathrm{X}$ & $x$ & $x$ & \\
\hline & Mylodontidae & Pseudoprepotherium & Pseudoprepotherium confusum & & $\mathrm{X}$ & $X$ & $\mathrm{X}$ & \\
\hline & Nothrotheriidae & & sp. & & $X$ & & $x$ & \\
\hline & Myrmecophagidae & Neotamandua & Neotamandua borealis & & & & $\mathrm{X}$ & \\
\hline
\end{tabular}




\begin{tabular}{|c|c|c|c|c|c|c|c|c|}
\hline \multicolumn{3}{|l|}{ Rodentia } & \multirow{2}{*}{18} & \multirow[t]{2}{*}{0} & \multirow{2}{*}{$\frac{12}{x}$} & \multirow{2}{*}{$\frac{7}{x}$} & \multirow{2}{*}{$\frac{15}{x}$} & \multirow[t]{2}{*}{5} \\
\hline \multirow{18}{*}{ Rodentia } & & & & & & & & \\
\hline & Caviidae & Prodolichotis & sp. & & $X$ & & & \\
\hline & Caviidae & Prodolichotis & Prodolichotis pridiana & & $\mathrm{X}$ & $X$ & $\mathrm{X}$ & $\mathrm{X}$ \\
\hline & Caviidae & Rhodanodolichotis & Rhodanodolichotis antepridiana & & & & $\mathbf{X}$ & \\
\hline & Dasyproctidae & Microscleromys & Microscleromys paradorsalis & & & & $\mathrm{X}$ & $\mathrm{X}$ \\
\hline & Dasyproctidae & Neoreomys & Neoreomys huilensis & & $X$ & $X$ & $x$ & \\
\hline & Dinomyidae & & sp. & & & & $\mathrm{X}$ & \\
\hline & Dinomyidae & Olenopsis & sp1 & & $\mathrm{X}$ & & $\mathrm{X}$ & \\
\hline & Dinomyidae & Olenopsis & sp2 & & $X$ & $X$ & $\mathrm{X}$ & $\mathrm{X}$ \\
\hline & Dinomyidae & Olenopsis & sp3 & & $X$ & $\mathrm{X}$ & $\mathrm{X}$ & \\
\hline & Dinomyidae & Scleromys & sp. & & & & $\mathrm{X}$ & \\
\hline & Dinomyidae & Scleromys & sp1 & & $X$ & $X$ & & \\
\hline & Dinomyidae & Scleromys & sp2 & & $\mathrm{X}$ & $X$ & $X$ & \\
\hline & Dinomyidae & Scleromys & $\mathrm{sp} 3$ & & $\mathbf{X}$ & & & \\
\hline & Dinomyidae & Scleromys & Scleromys colombianus & & $\mathrm{X}$ & & $\mathrm{X}$ & $\mathrm{X}$ \\
\hline & Dinomyidae & Scleromys & Scleromys schürmanni & & $X$ & & $X$ & \\
\hline & Erethizontidae & Microsteiromys & Microsteiromys jacobsi & & & & $\mathbf{X}$ & \\
\hline & Erethizontidae & Ricardomys & Ricardomys longiden & & & & $\mathrm{X}$ & $\mathrm{X}$ \\
\hline \multicolumn{3}{|l|}{ Sirenia } & 2 & 0 & 2 & 1 & 2 & 0 \\
\hline \multirow[t]{2}{*}{ Sirenia } & Trichechidae & Potamosiren & sp. & & $X$ & & $\mathrm{X}$ & \\
\hline & Trichechidae & Potamosiren & Potamosiren magdalenensis & & $\mathrm{X}$ & $\mathrm{X}$ & $\mathrm{X}$ & \\
\hline \multicolumn{3}{|l|}{ Sparassodonta } & 3 & 0 & 2 & 1 & 1 & 1 \\
\hline \multirow{3}{*}{ Sparassodonta } & Prothylacynidae & Dukecymus & Dukecymus magnus & & & & & $\mathbf{X}$ \\
\hline & Prothylacynidae & Lycopsis & Lycopsis longirostrus & & $X$ & $X$ & $\mathrm{X}$ & \\
\hline & Thylacosmilidae & Anachlysisctis & Anachlysisctis gracilis & & $\mathbf{X}$ & & & \\
\hline
\end{tabular}


Anexo 13. Atlas de vertebrados fósiles del Grupo La Venta.
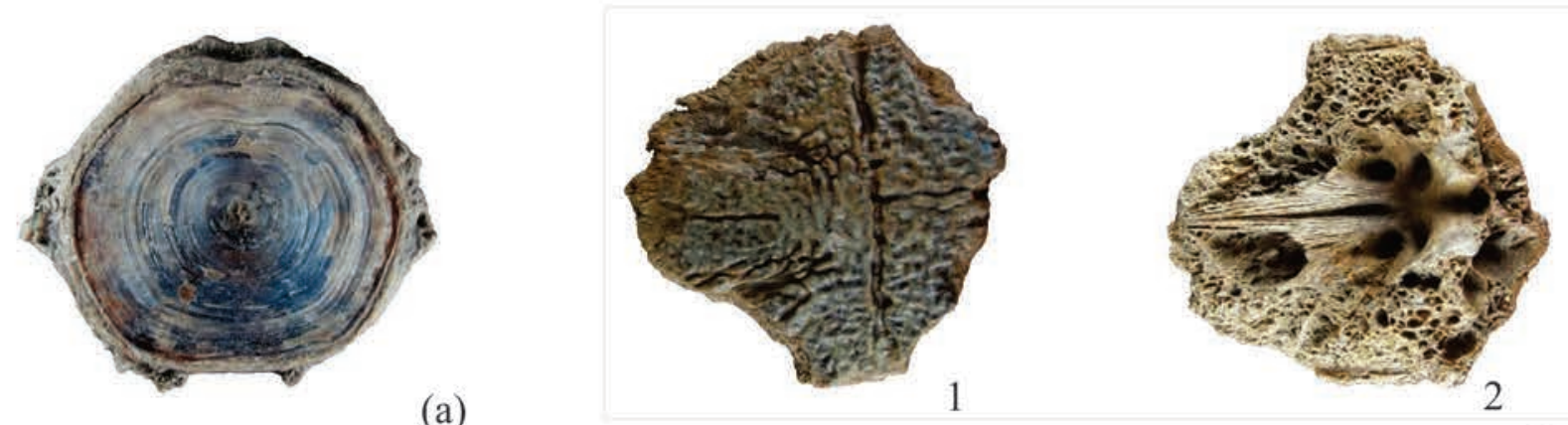

(a)

(b)

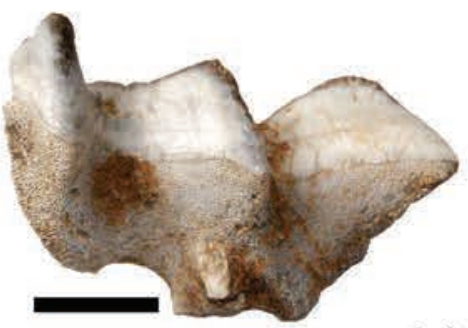

(c)

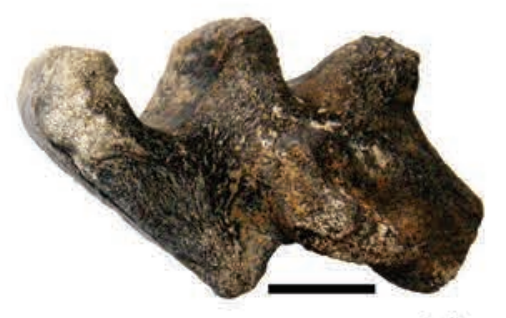

(d)

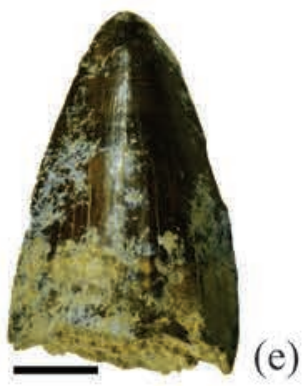

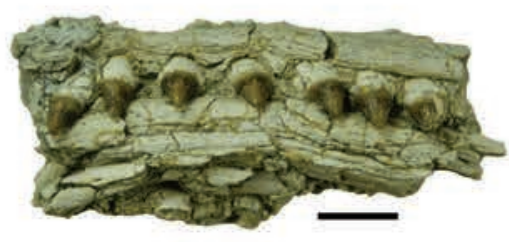

(f)

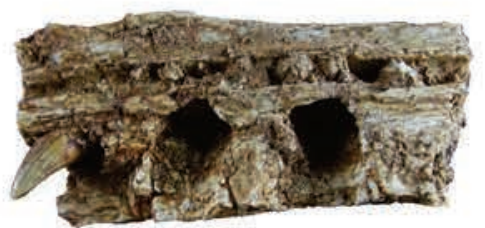

(g)
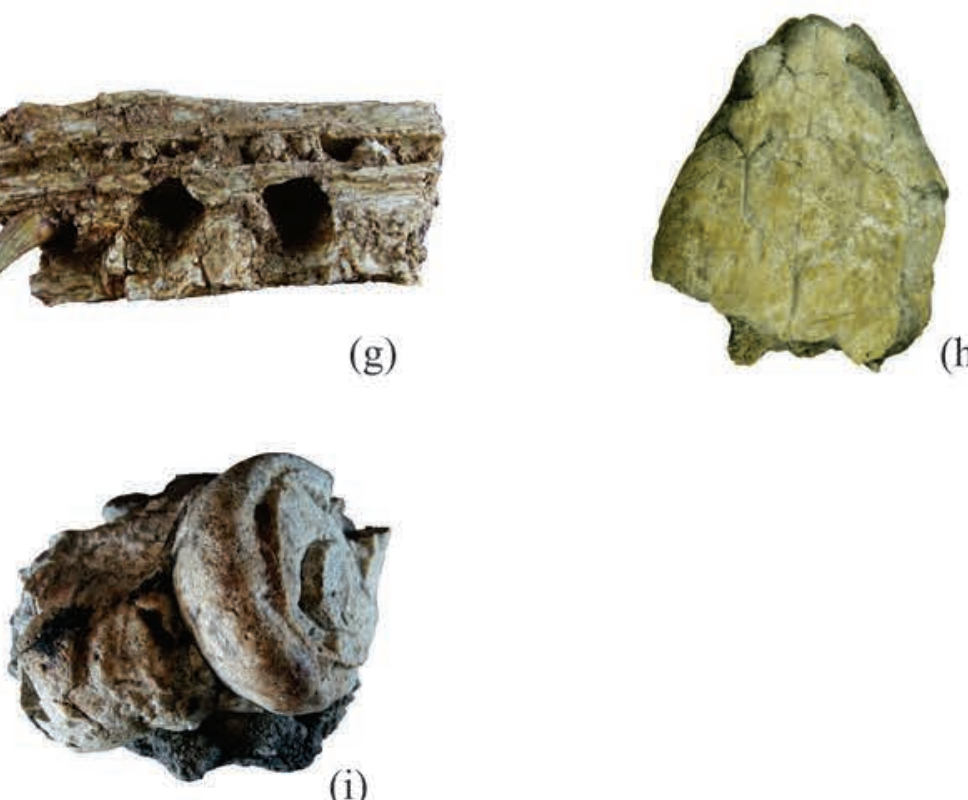

(h)

(a) Actinopterygii, YMS-P 021, F. La Victoria; (b) Phractocephalus (Actinopterygii), YMS-P 052, F. Villavieja 1-2; (c) Lepidosiren (Sarcopterygii), YMS-P 315, F. La Victoria; (d) Lepidosiren (Sarcopterygii), YMS-P 316, F. Cerbatana; (e) Purussaurus (Alligatoridae: Crocodylia), YMS-P057, F. Villavieja; (f) Gavialis (Gavialidae: Crocodylia), YMS-P 366, F. La Victoria; (g) Gavialis (Gavialidae: Crocodylia), YMS-P 1310, F. Villavieja; (h) Podocnemidae (Testudines), YMS-P 367, F. Villavieja; (i) Coprolito, YMS-P471, F. La Victoria.

Fotógrafo: Grupo de Investigación Evolución y Ecología de Mamíferos Neotropicales (EEMN). 
Anexo 14. Atlas de mamíferos fósiles del Grupo La Venta.

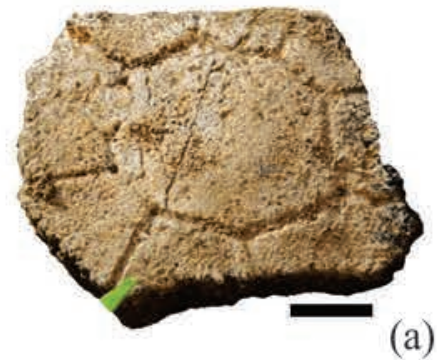

(a)

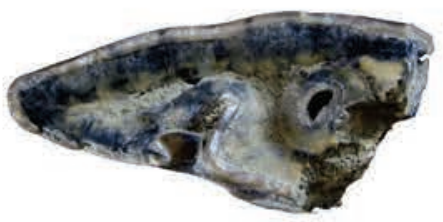

(d)

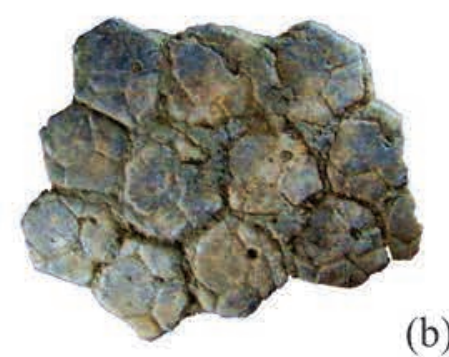

(b)

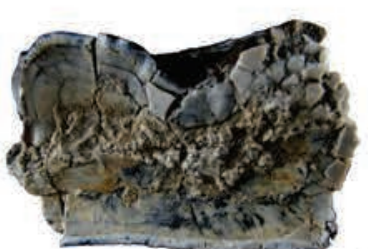

(1)
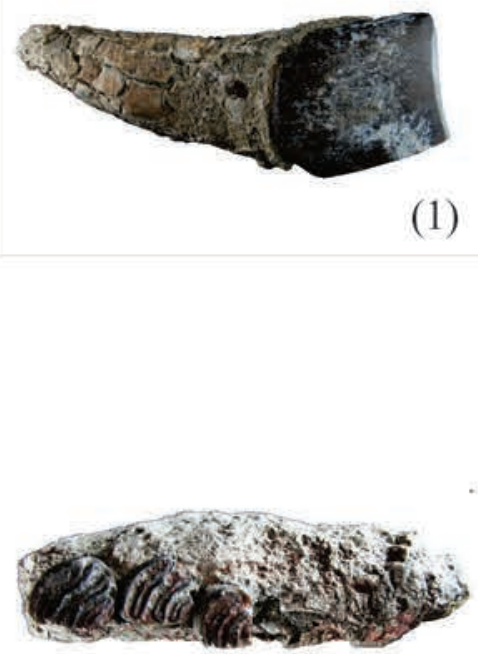

(g)

(c)
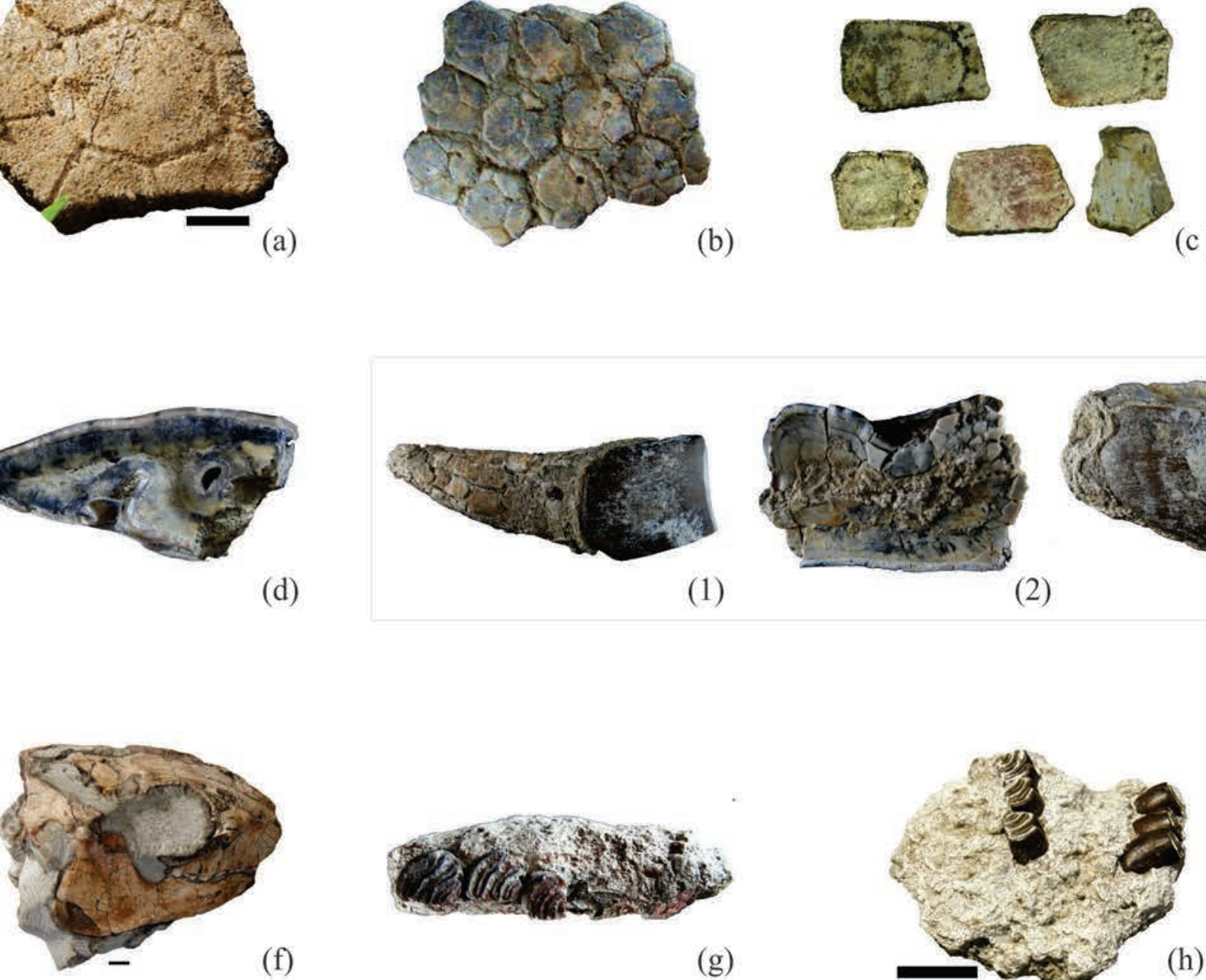

(f)

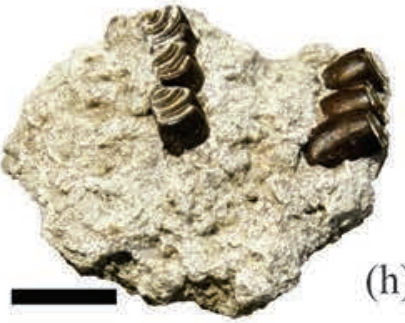

$(3$

(e)

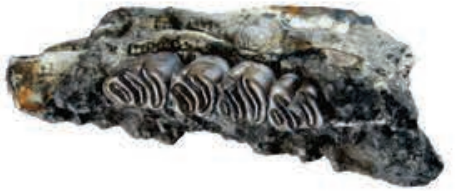

(i)

Cingulata: (a) Boreostema gigantea (Glyptodontidae), YMS-P 364, F. La Victoria; (b) Neoglyptatelus (Glyptodontidae), YMS-P 954, F. La Victoria (c). Scirrotherium (Pampatheriidae), YMSP-P 363, F. Cerbatana; Notoungulata: (d) Huilatherium (Leontiniidae), YMS-P 1439, F. Cerbatana; (e) Pericotoxodon (Toxodontidae), YMS-P 444, F. La Victoria; (f) Miocochilius (Interatheridae), YMS-P001, F. La Victoria; Rodentia: (g) Olenopsis (Dinomyidae), YMS-P 973, F. Cerbatana; (h) Scleromys (Dinomyidae), YMS-P 711, F. La Victoria; (i) Scleromys (Dinomyidae), YMS-P 1019, F. Cerbatana.

Fotógrafo: Grupo de Investigación Evolución y Ecología de Mamíferos Neotropicales(EEMN). 
Anexo 15. Primates fósiles del Grupo La Venta.
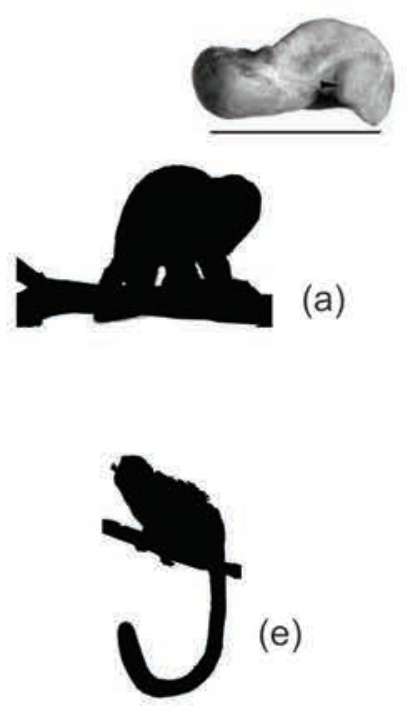

(e)

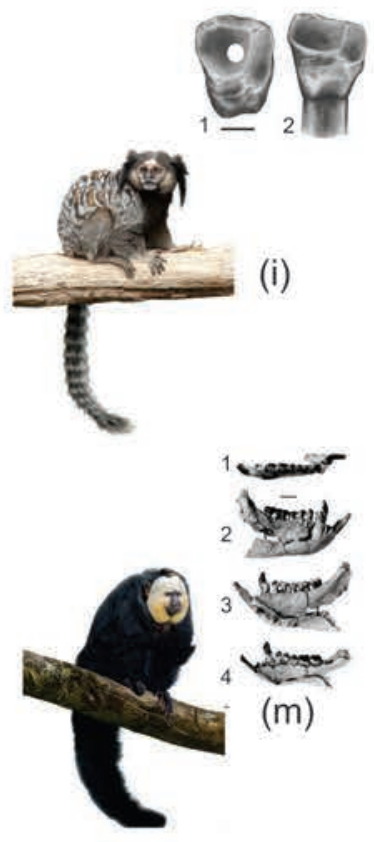

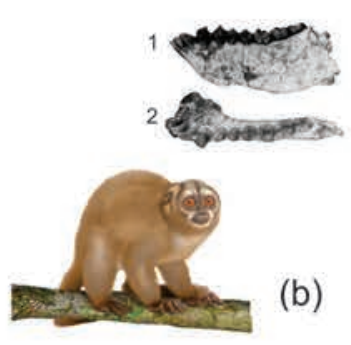
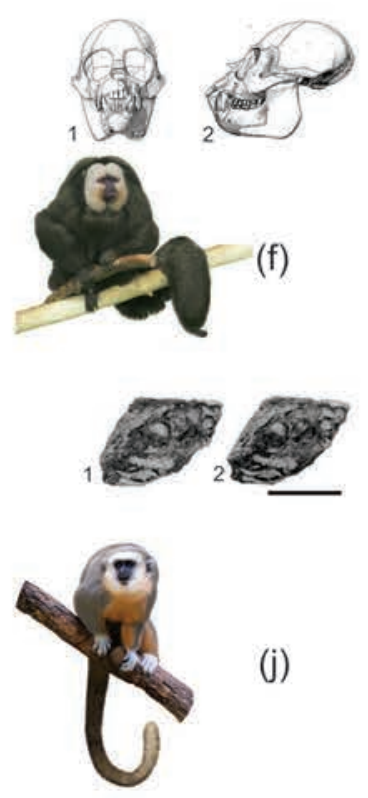

(j)

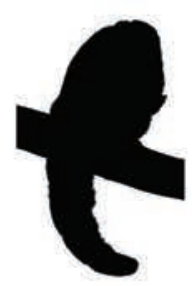

(n)

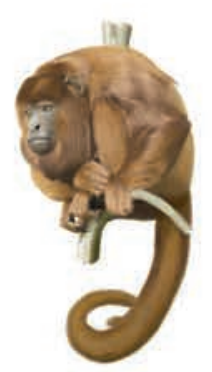

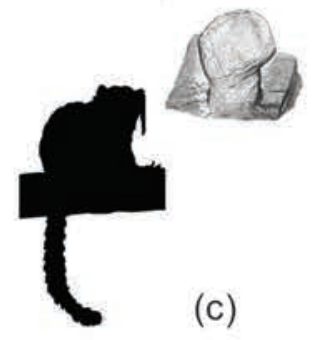
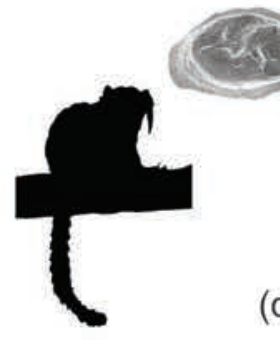

(d)
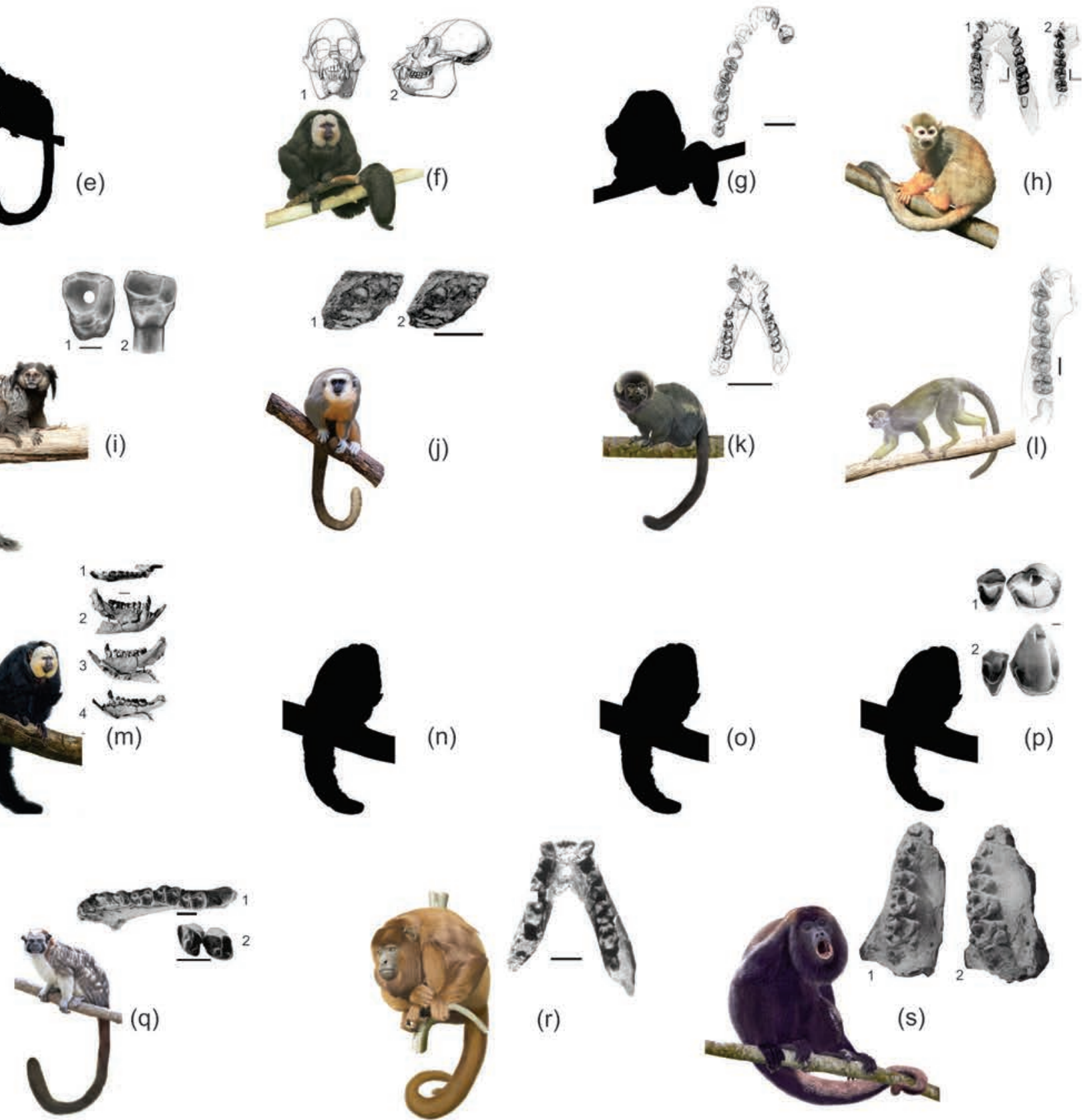

(r)

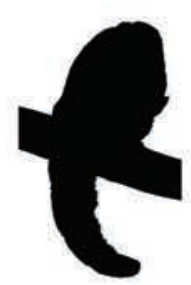

(o)

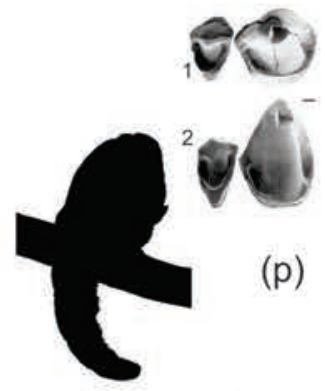

(p)

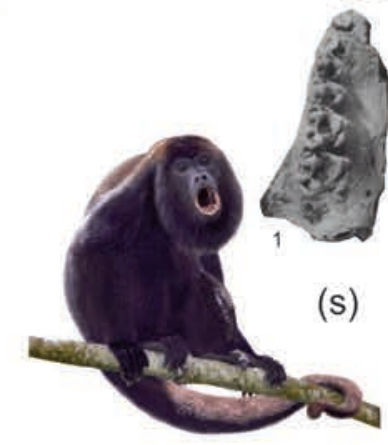

(a) Aotus cf. dindensis, registro fósil IGM-KU 8802, astrágalo (Gebo et al. 1990, P: 739); (b) Aotus dindensis, (1) registro fósil IGM-KU 8601, (2) fragmento mandibular izquierdo (Setoguchi \& Rosenberg 1987, P: 692); (c) Callitrichinae, registro fósil IGM-KU 8402, I1 derecho vista lingual (Setoguchi \& Rosenberg 1985, P: 620); (d) Callitrichinae, registro fósil IGM-KU 8403, P4 izquierdo vista oclusal (Setoguchi \& Rosenberg 1985, P: 620); (e) Cebidae, vista lateral KU 9-86A (Setoguchi \& Rosenberger 1985); (f) Cebupithecia sarmientoi, registro fósil UCMP 38762, cráneo (1) vista frontal, (2) vista lateral (Stirton \& Savage 1951, P: 359); (g) Lagonimico conclucatus, (1) registro fósil IGM 184531, (2) fragmento mandibular izquierdo (Kay 1994, P: 340); (h) Laventiana annectens: (1) mandíbula, vista oclusal del registro fósil IGM-KU 8801a, (2) mandibula, rama derecha, vista oclusal del registro fósil UCMP 39205; (i) Micodon kiotensis, registro fósil IGM-KU 8401, (1) M1 izquierdo vista oclusal, (2) vista labial (Setoguchi \& Rosenberg 1985, P: 618); (j) Miocallicebus villaviejai, registro fósil IGM-KU 97001: (1) M2 fragmento maxilar derecho, (2) fragmento de M1 y M3 (Takai et al. 2001, P: 293); (k) Mohanamico hershkovitzi, registro fósil IGM 181500, mandibula (Luchterhand et al. 1986, P: 1755); (I) Neosaimiri fieldsi, registro fósil UCMP 39205, fragmento mandíbula izquierda (Takai 1993, P: 333); (m) Nuciruptor rubricae, registro fósil IGM 251074, fragmento mandibular derecho (1) vista oclusal, (2) vista bucal, (3) vista lingual, (4) vista ocluso-lingual (Meldrum \& Kay 1997, P: 411); (n) cf. Nuciruptor, registro fósil IGM 184074 (Ford et al. 1991, P: 73); (o) cf. Nuciruptor, registro fósil IGM 184667 (Meldrum \& Kay 1997, P: 418); (p) cf. Nuciruptor, registro fósil IGM KU 8602, canino y P2: (1) vista oclusal, (2) vista lingual (Meldrum \& Kay 1997, P: 419); (q) Patasola magdalenae, registro fósil IGM 184332: (1) fragmento mandibular derecho, (2) P3-P4 (Kay \& Meldrum 1997, P: 443); (r) Stirtonia tatacoensis, (1) registro fósil UCMP 38989, (2) mandibula (Hershkovitz 1984, P: 273); (s) Stirtonia victoriae, registro fósil DU-IGM 85-400, fragmento de maxila derecha (Kay et al. 1987, P: 180). 
Anexo 16. Paleohábitat, Formación San Alfonso, Grupo La Venta.

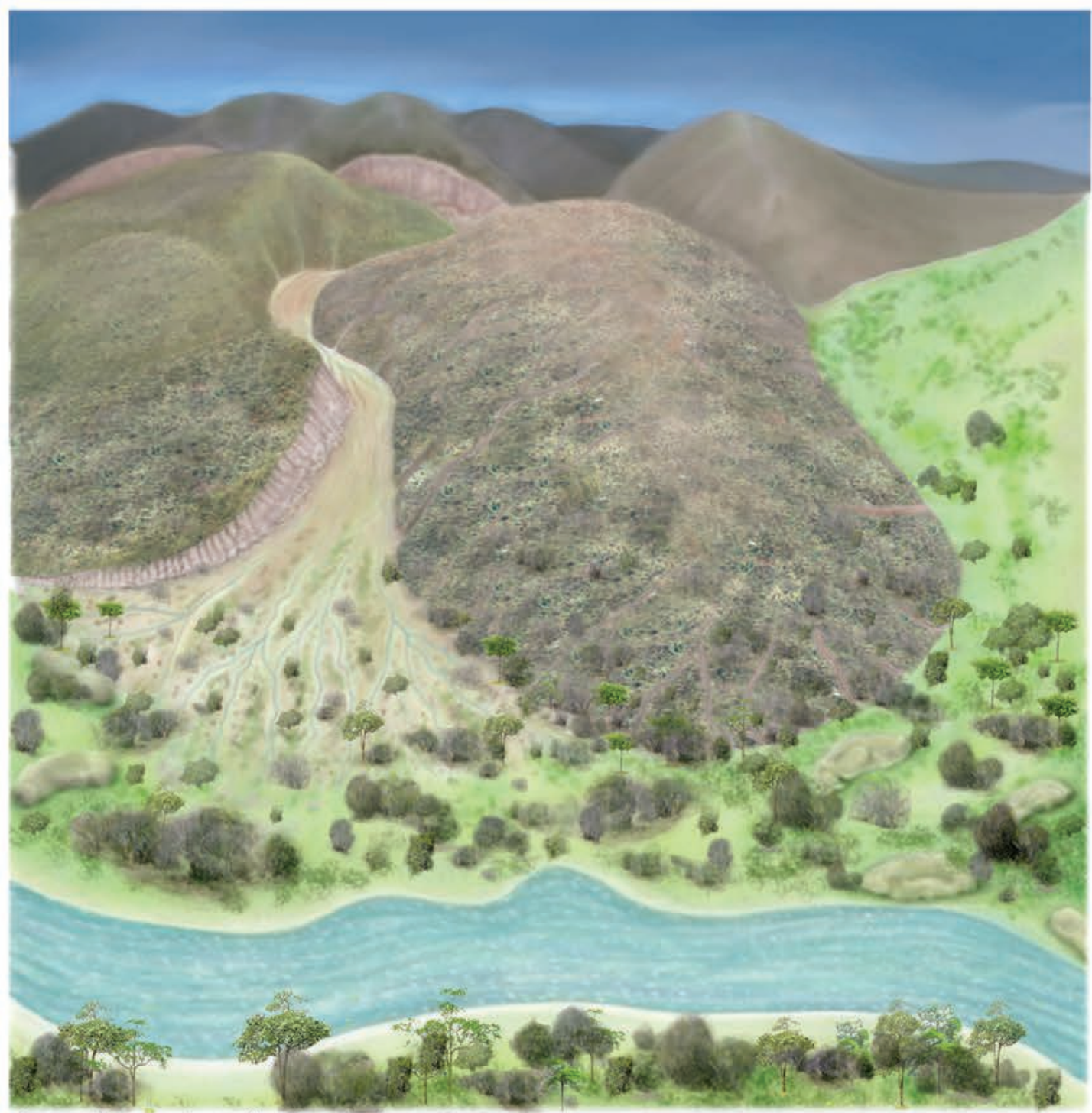

Ilustración: Marie Joëlle Giraud López, 2017. 
Anexo 17. Paleohábitat, Formación La Victoria, Grupo La Venta.

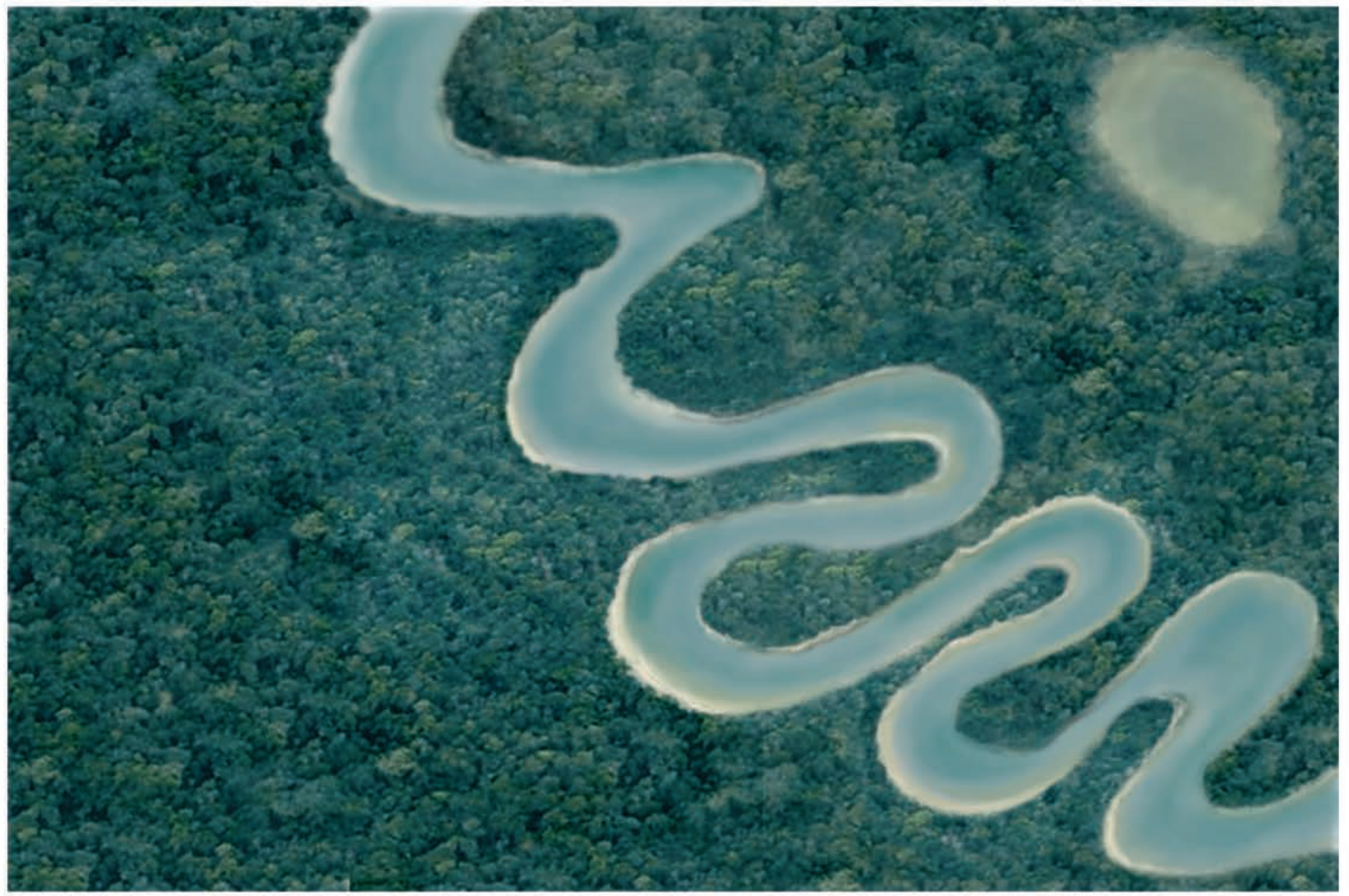

Ilustración: Marie Joëlle Giraud López, 2017. 
Anexo 18. Paleohábitat, Formación Cerbatana, Grupo La Venta.

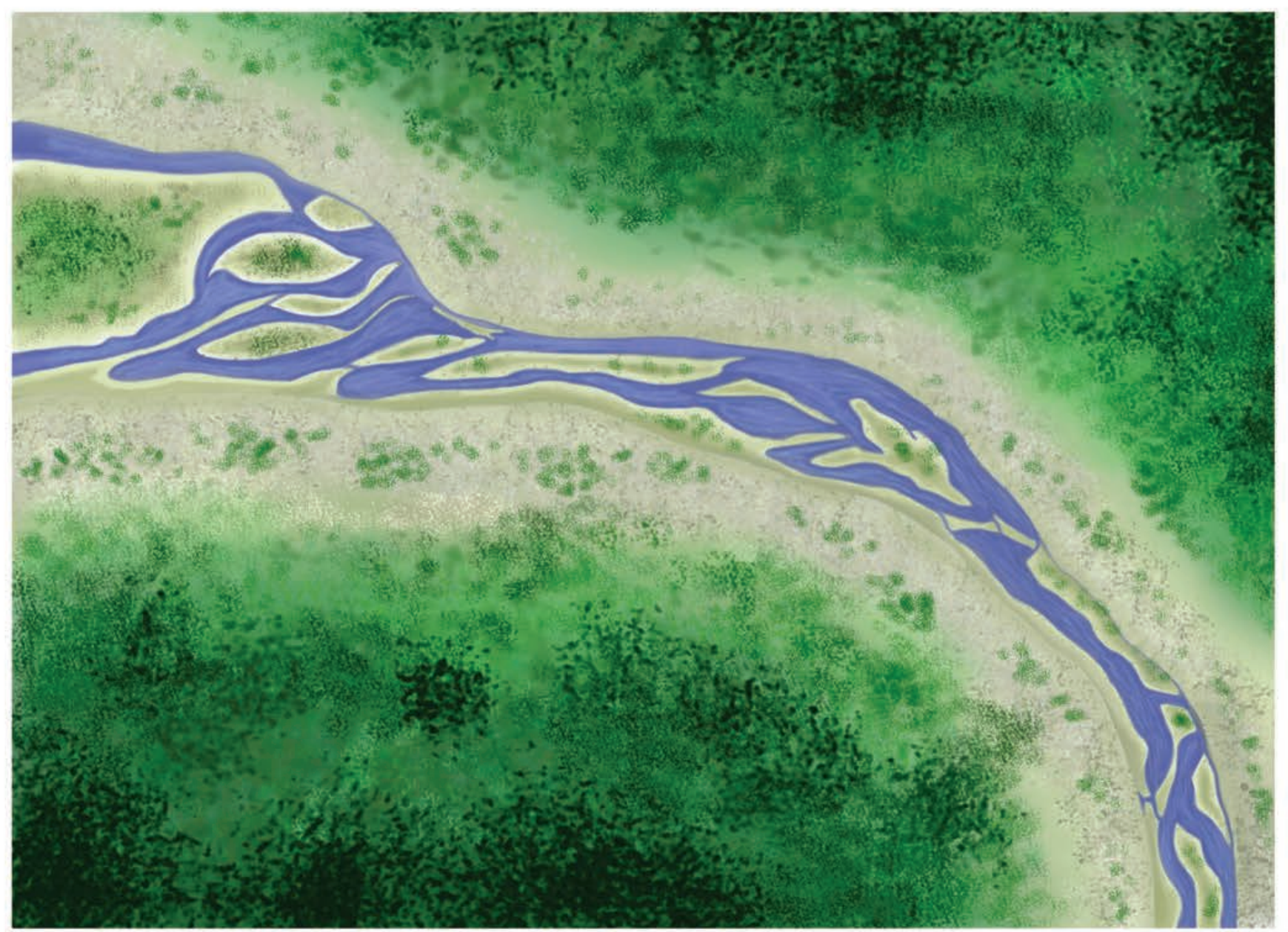

Ilustración: Marie Joëlle Giraud López, 2017. 
Anexo 19. Paleohábitat, Formación Villavieja, Grupo La Venta.

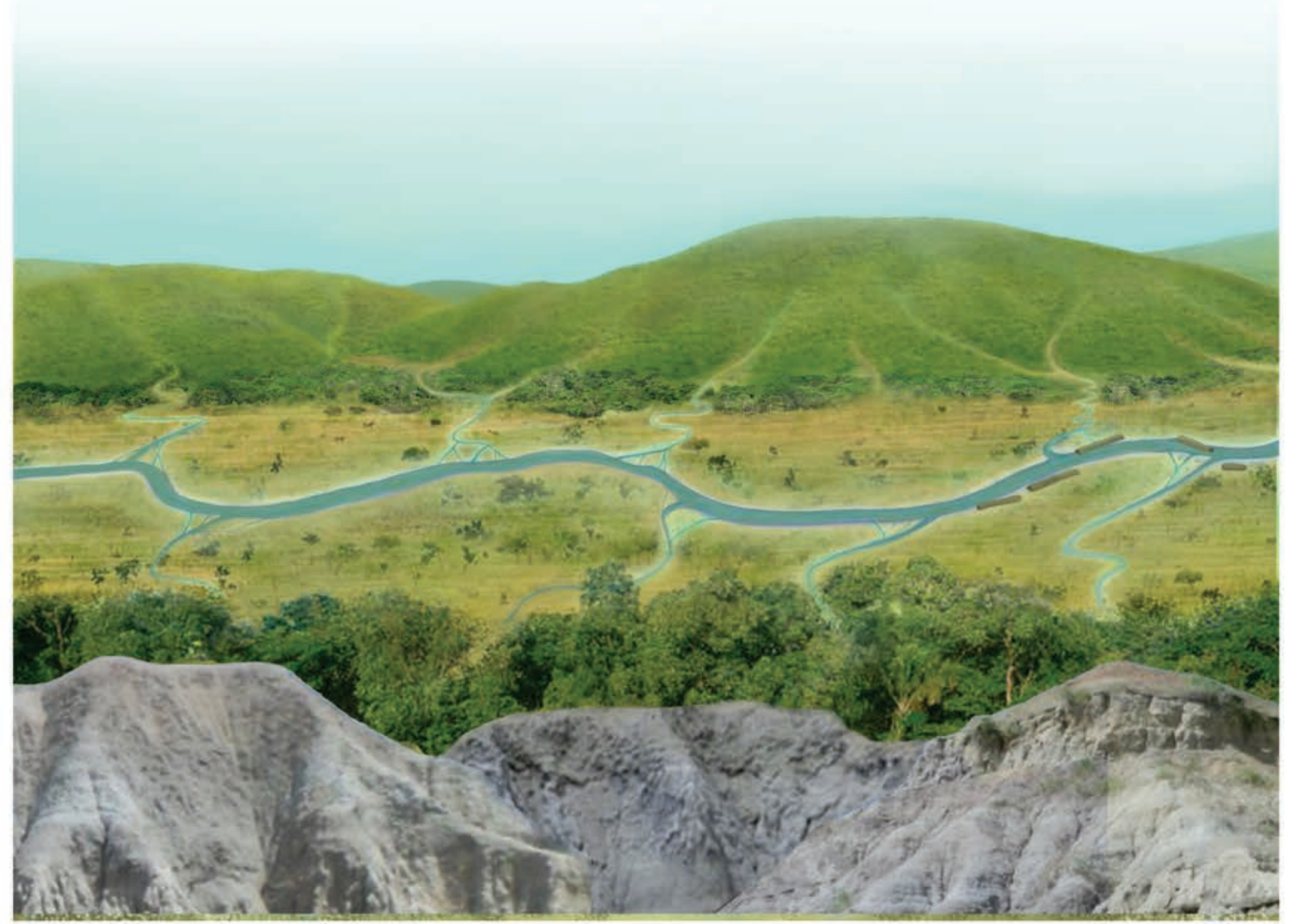

Ilustración: Marie Joëlle Giraud López, 2017. 
Anexo 20. Paleohábitat, Formación Las Mesitas, Grupo La Venta.

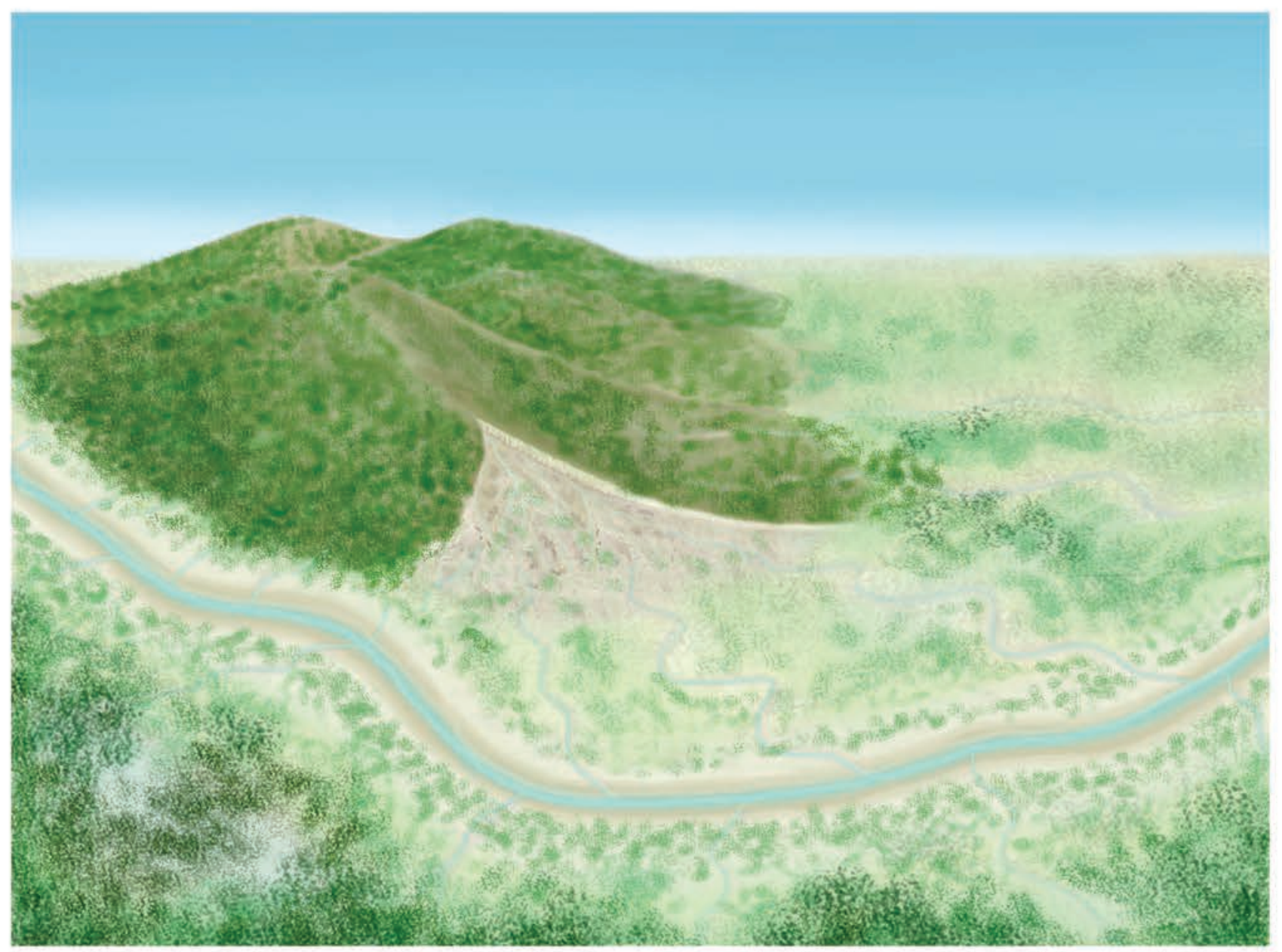

Ilustración: Marie Joëlle Giraud López, 2017. 

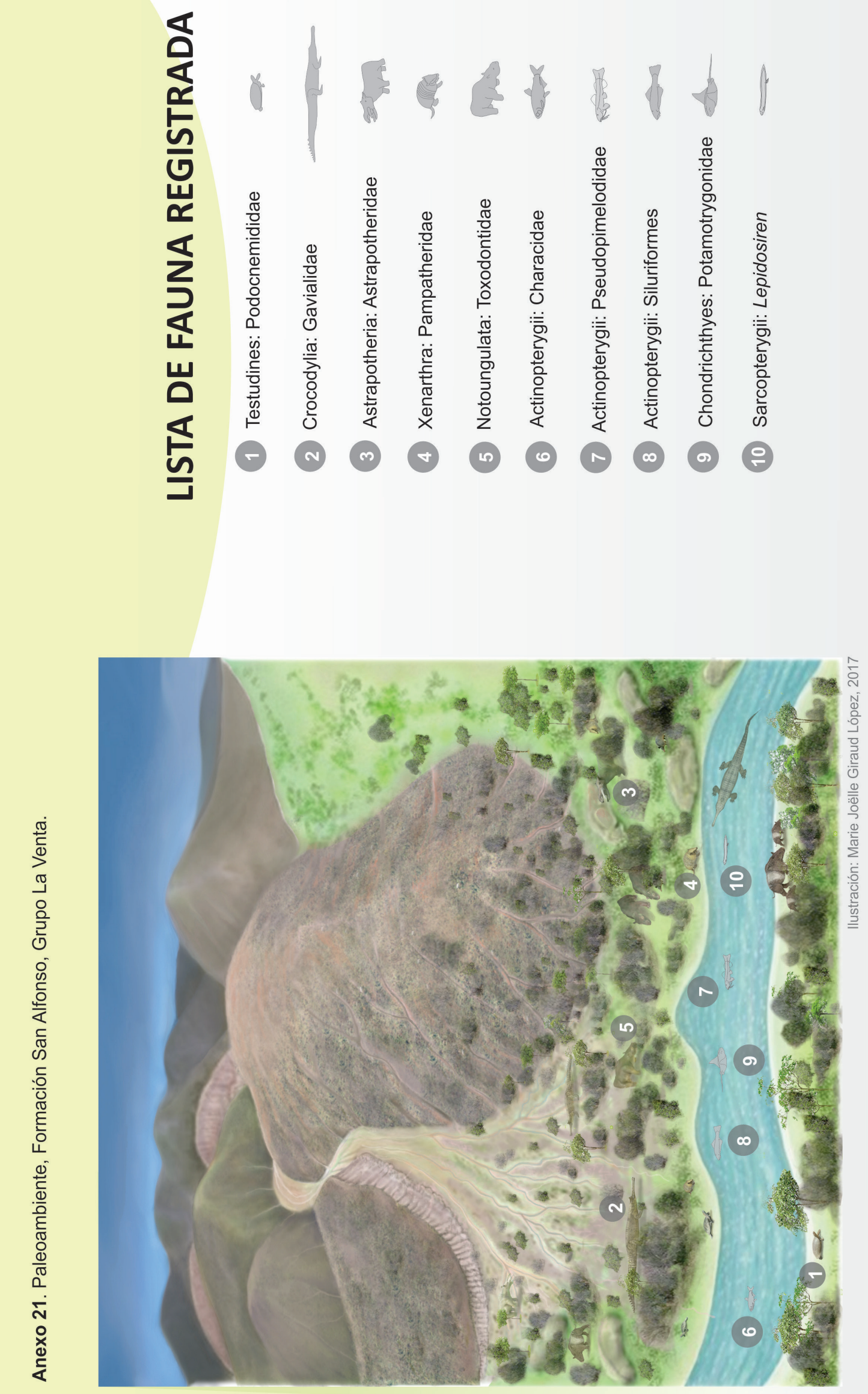


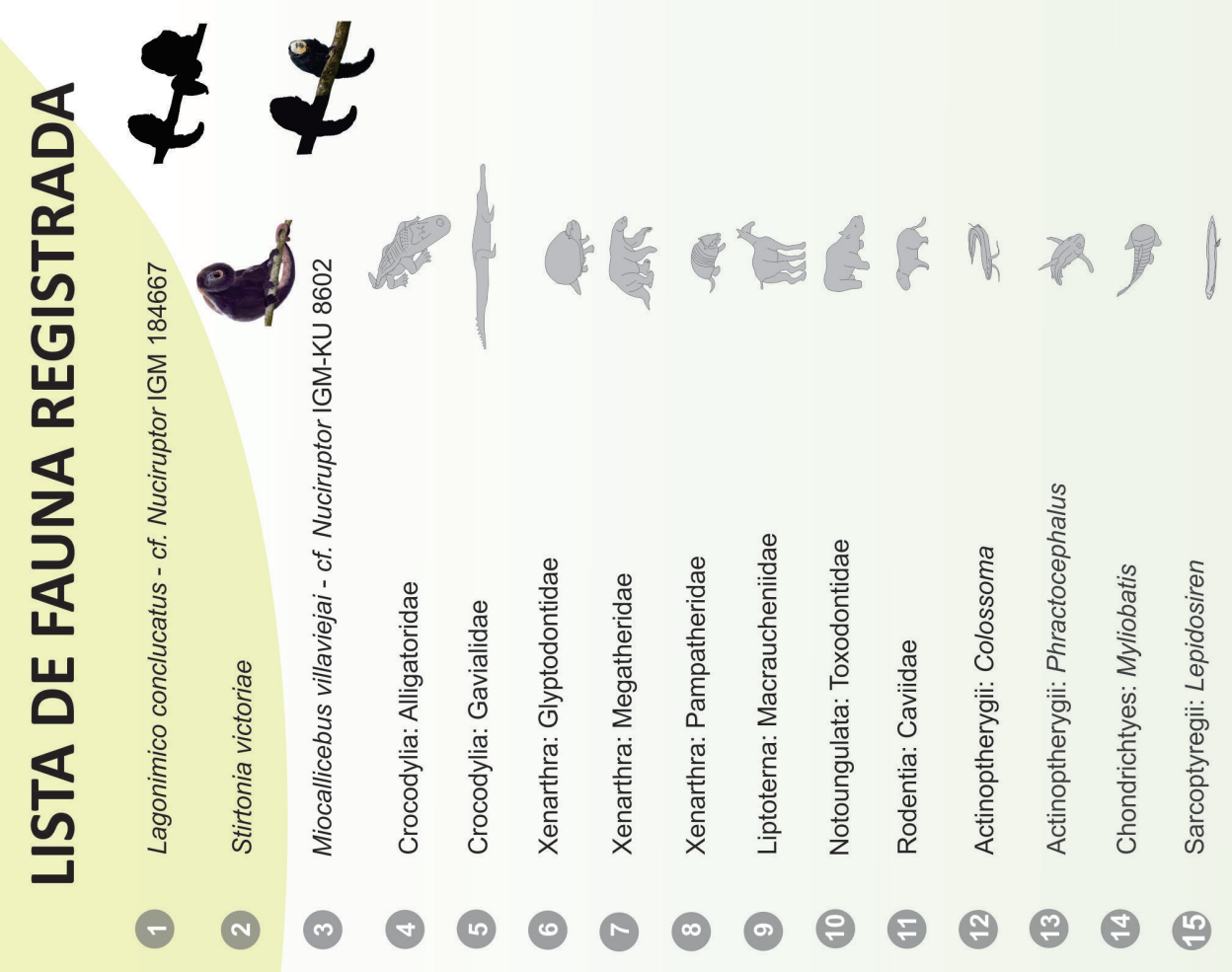

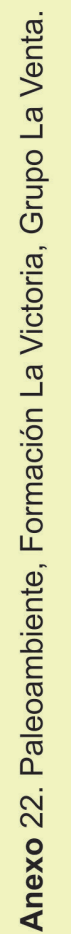

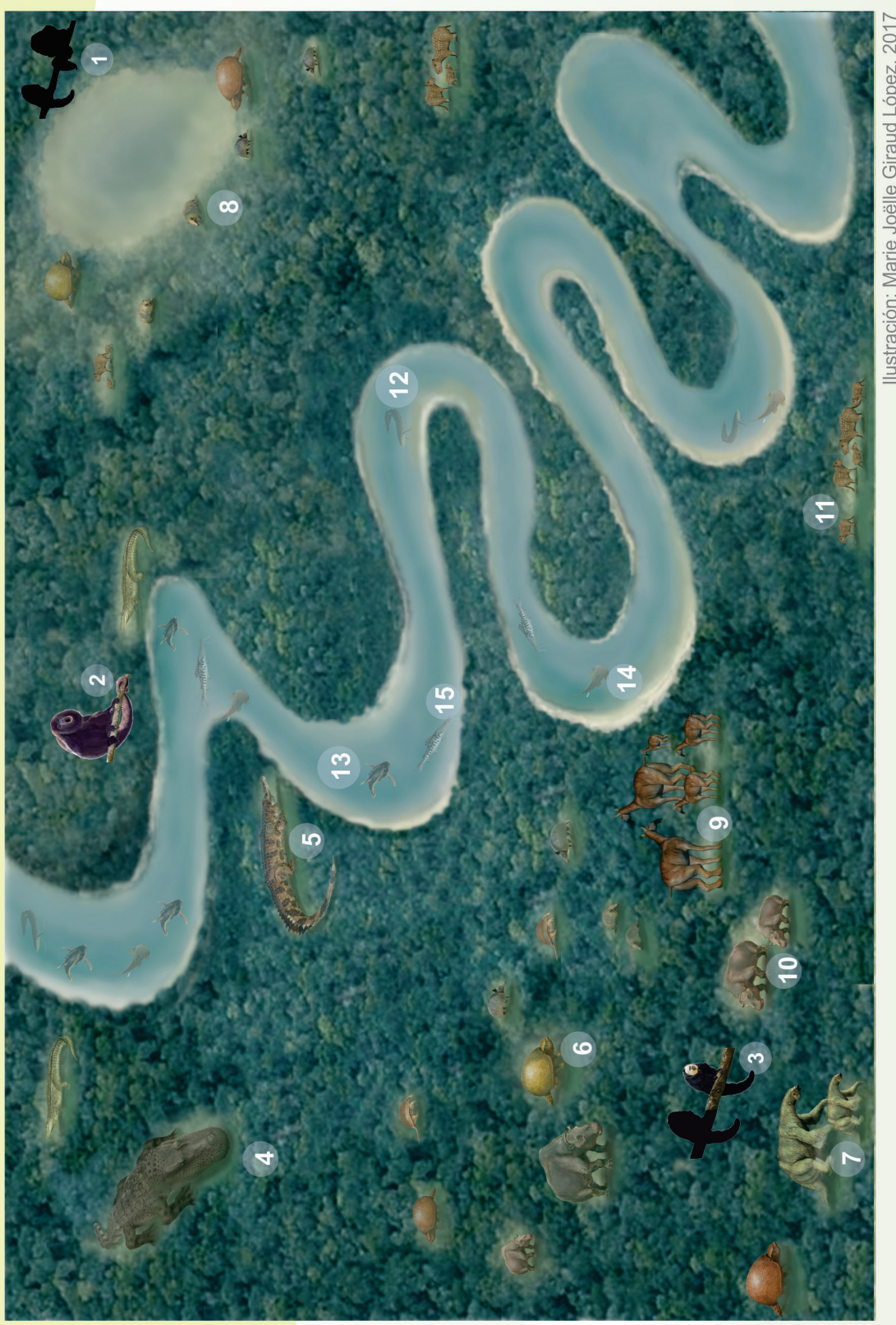

$\Sigma-0 \cup ய z 0 \quad \Sigma m 0-0$

$\Sigma-00 ш \mathbf{z O} \quad-\mathbf{z}$ นं

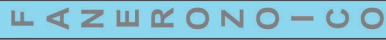



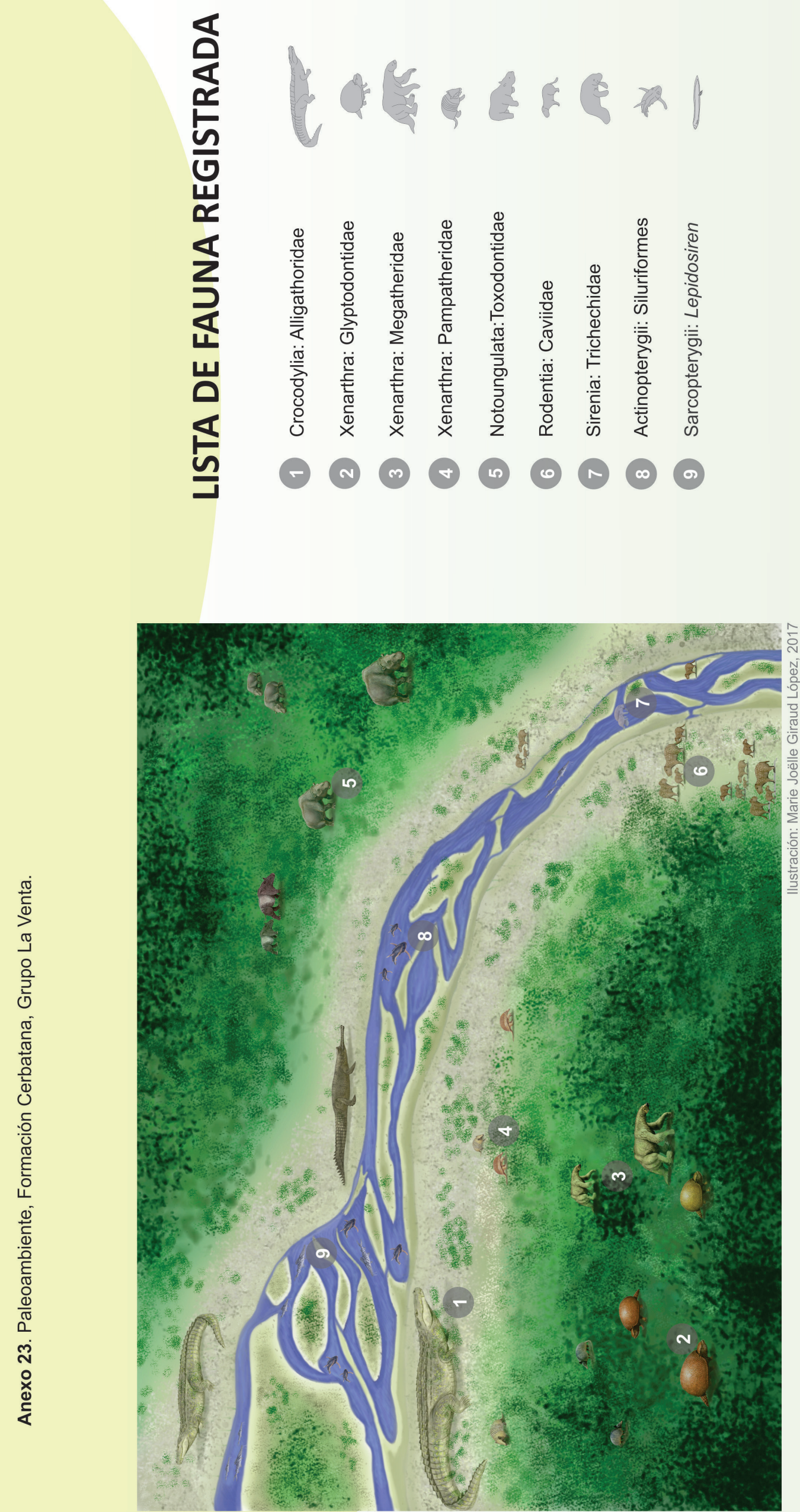


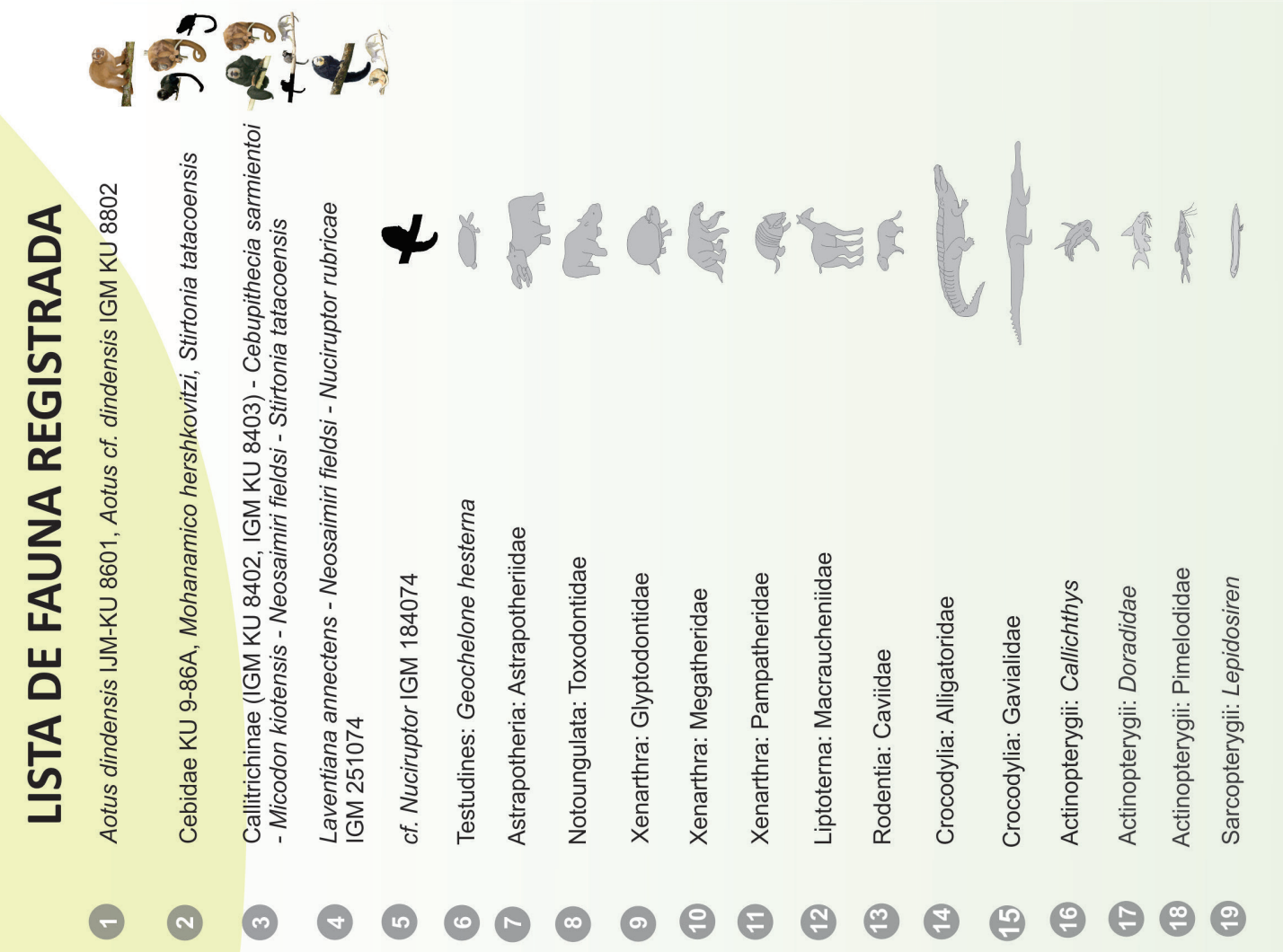

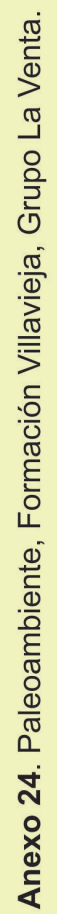

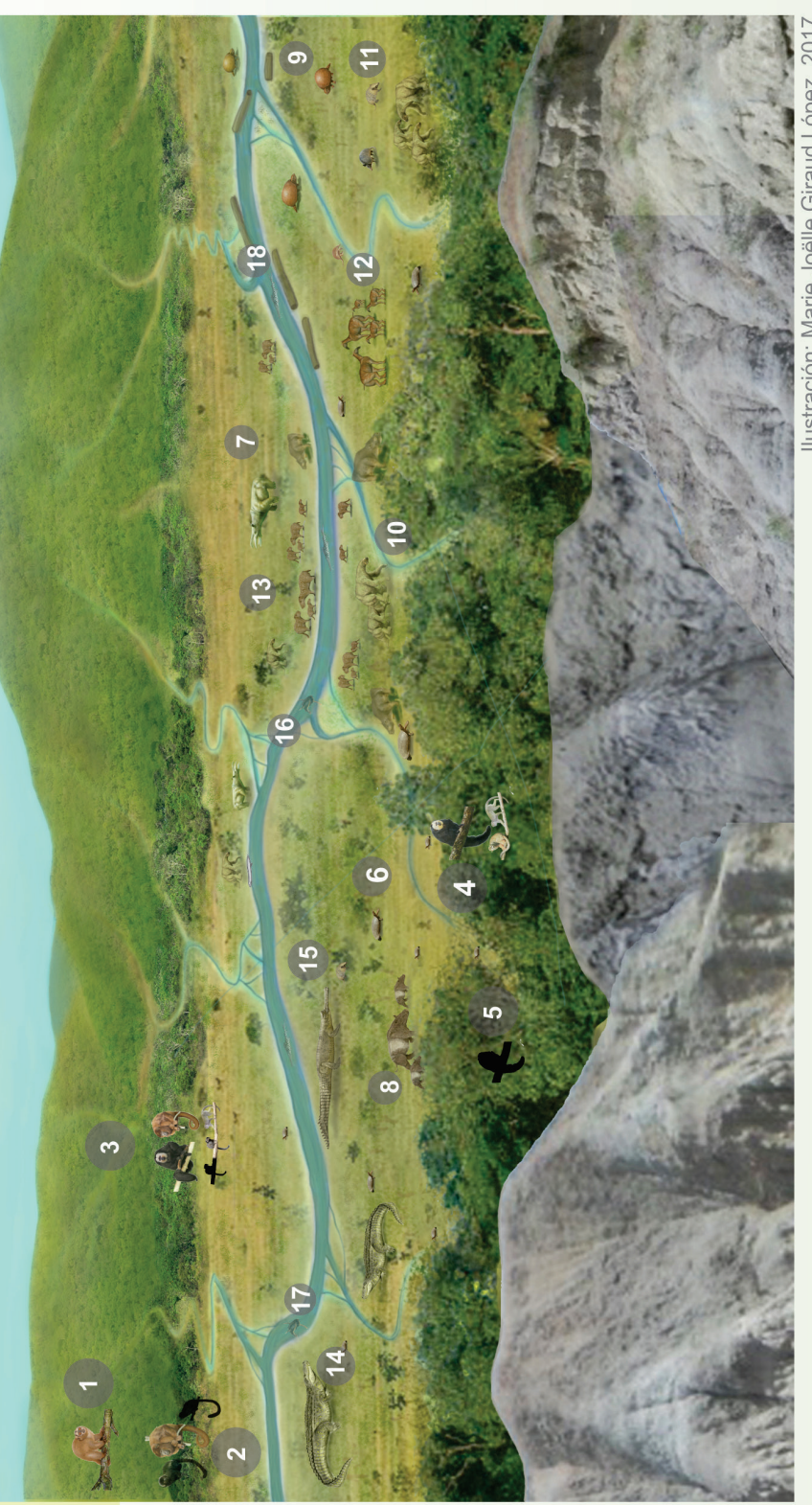

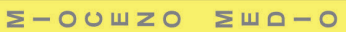

$\Sigma-00 ш \mathbf{z O} \quad-\mathbf{z}$ $\Sigma-0 \cup \amalg \geq 0$ 


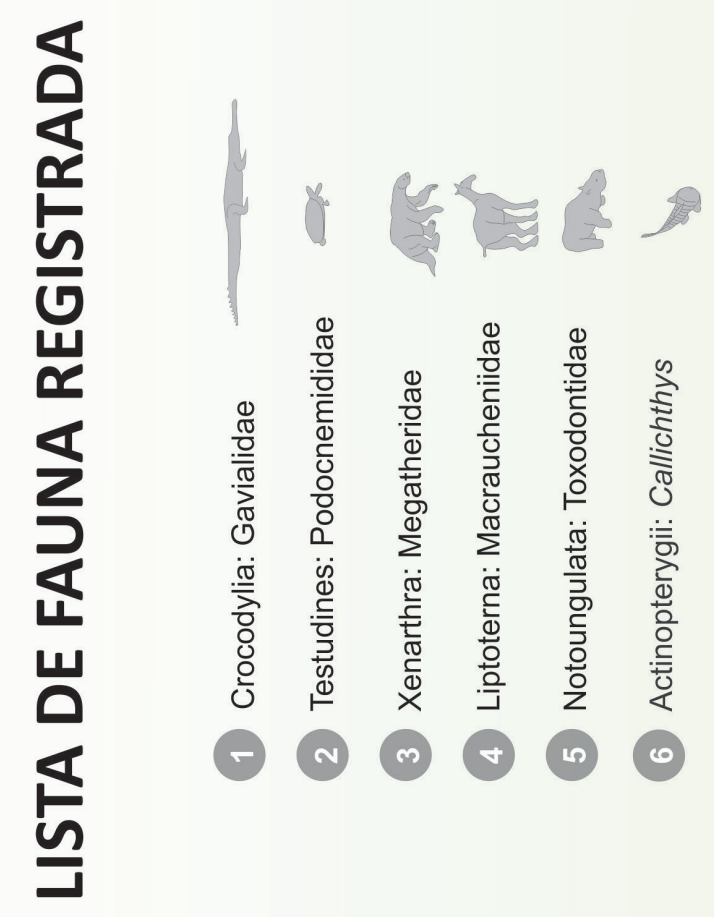

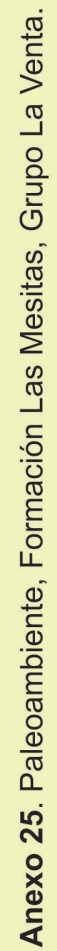

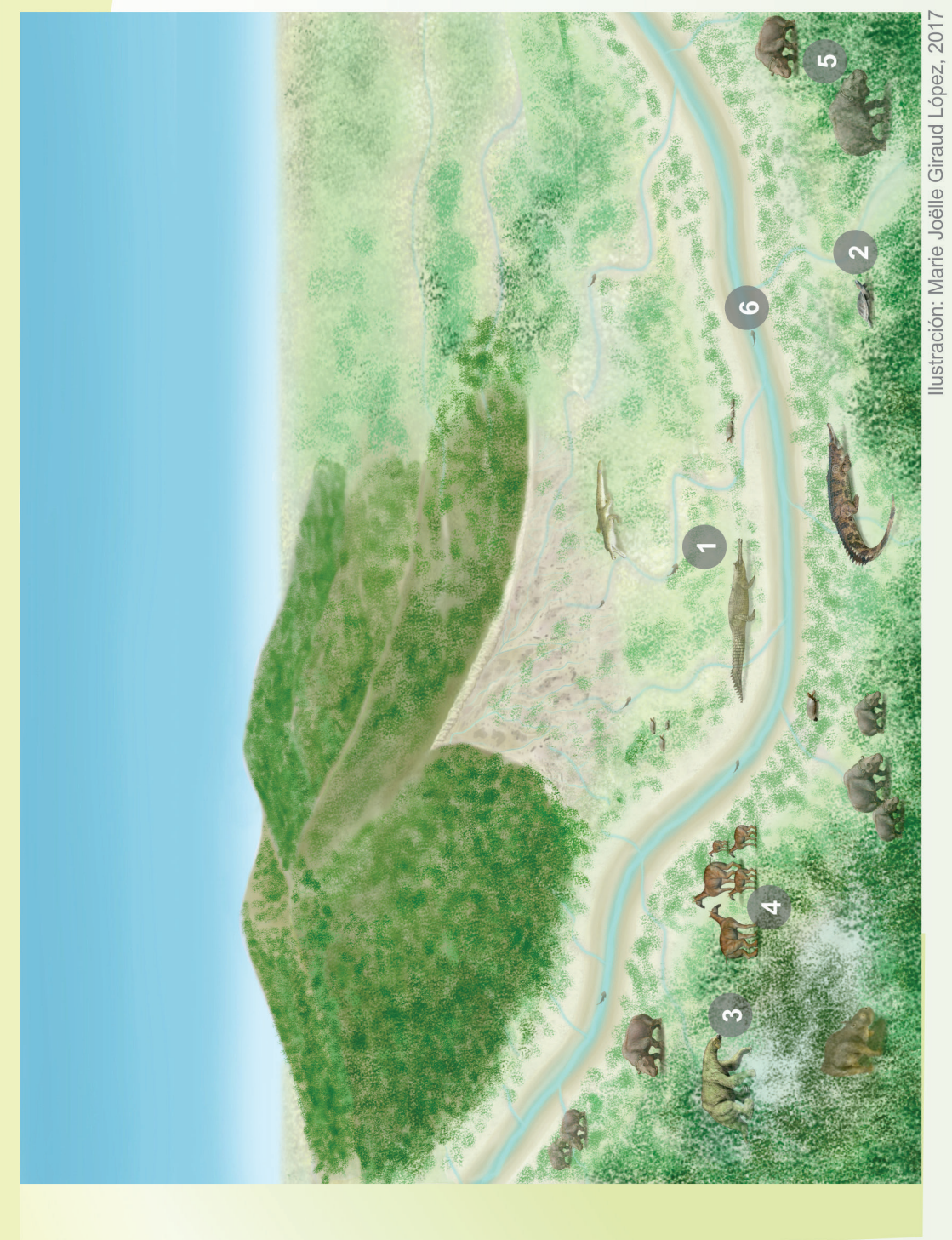


Anexo 26. Asociaciones propuestas de los Primates fósiles, Grupo La Venta.

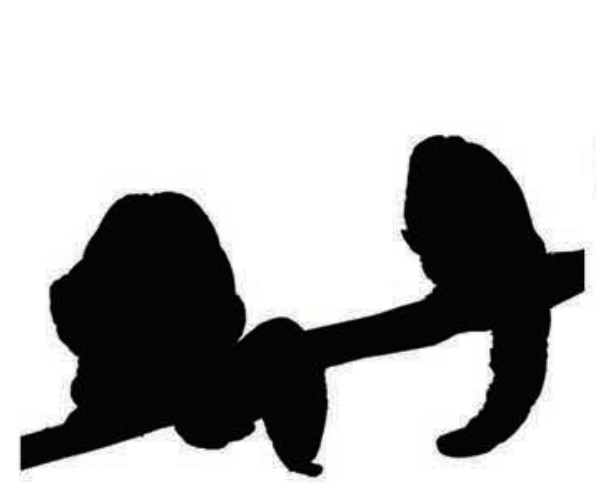

(a)

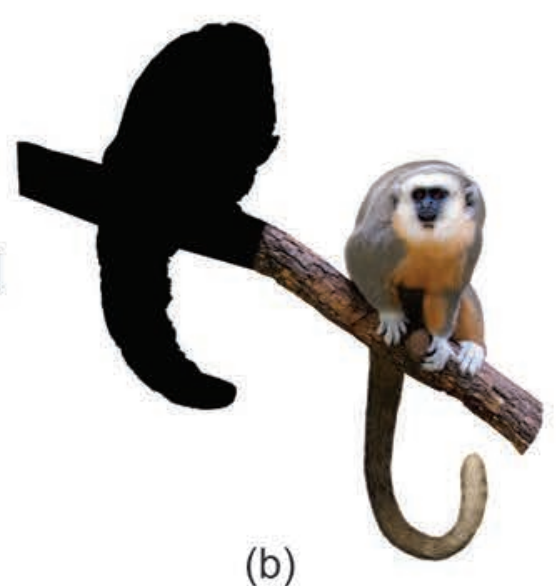

(b)

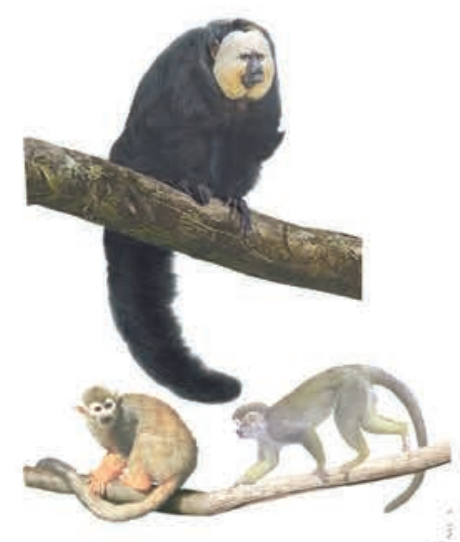

(c)
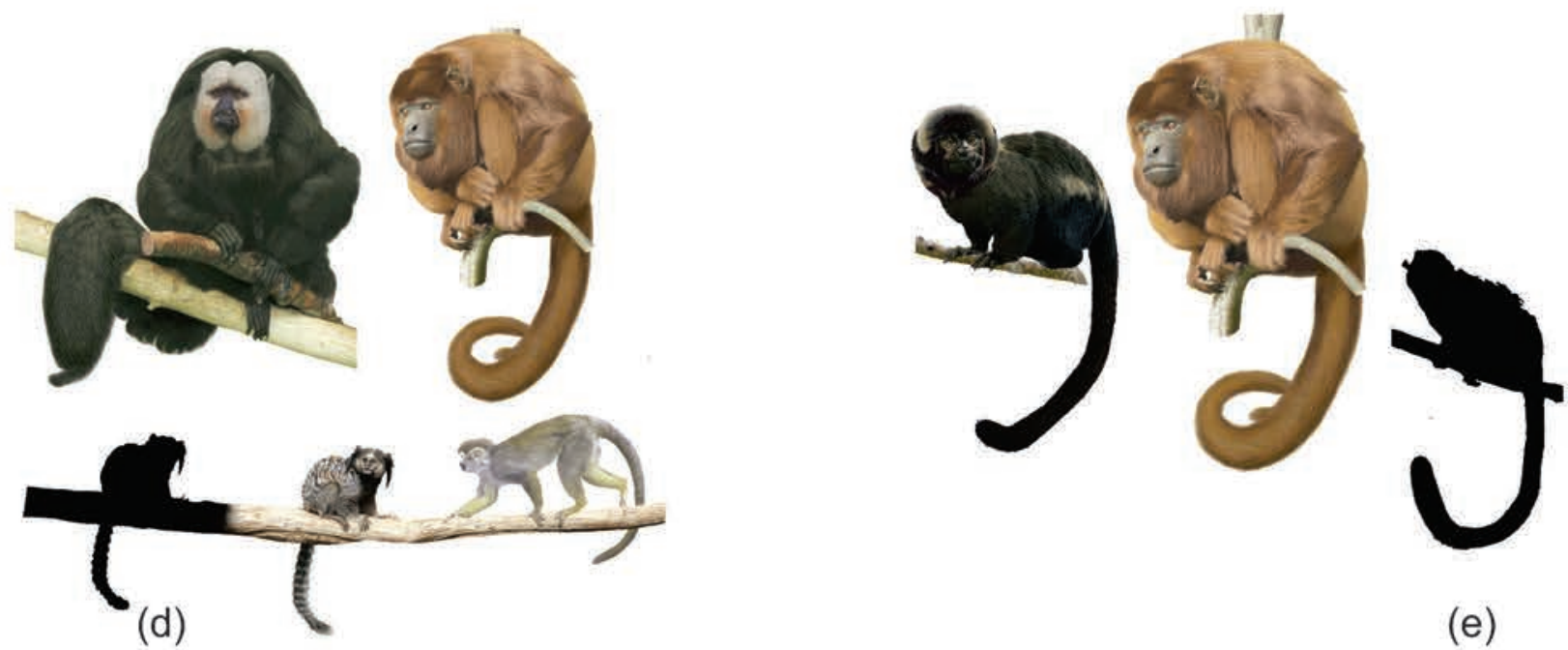

(e)

(a) Lagonimico conclucatus - cf. Nuciruptor IGM 184667. Capa Los Lagos, Formación La Victoria, Grupo La Venta; (b) Miocallicebus villaviejai - cf. Nuciruptor IGM-KU 8602. Areniscas de San Nicolás, Formación La Victoria, Grupo La Venta; (c) Laventiana annectens - Neosaimiri fieldsi - Nuciruptor rubricae IGM 251074. Monkey Unit, Formación Villavieja, Grupo La Venta; (d) Callitrichinae (IGM-KU 8402, IGM-KU 8403) - Cebupithecia sarmientoi - Micodon kiotensis - Neosaimirifieldsi - Stirtonia tatacoensis. Lower Red Bed, Formación Villavieja, Grupo La Venta; (e) Cebidae KU 9-86A-Mohanamico hershkovitzi - Stirtonia tatacoensis. Upper Red Bed, Formación Villavieja, Grupo La Venta.

Ilustraciones: Marie Joélle Giraud López, 2017. 


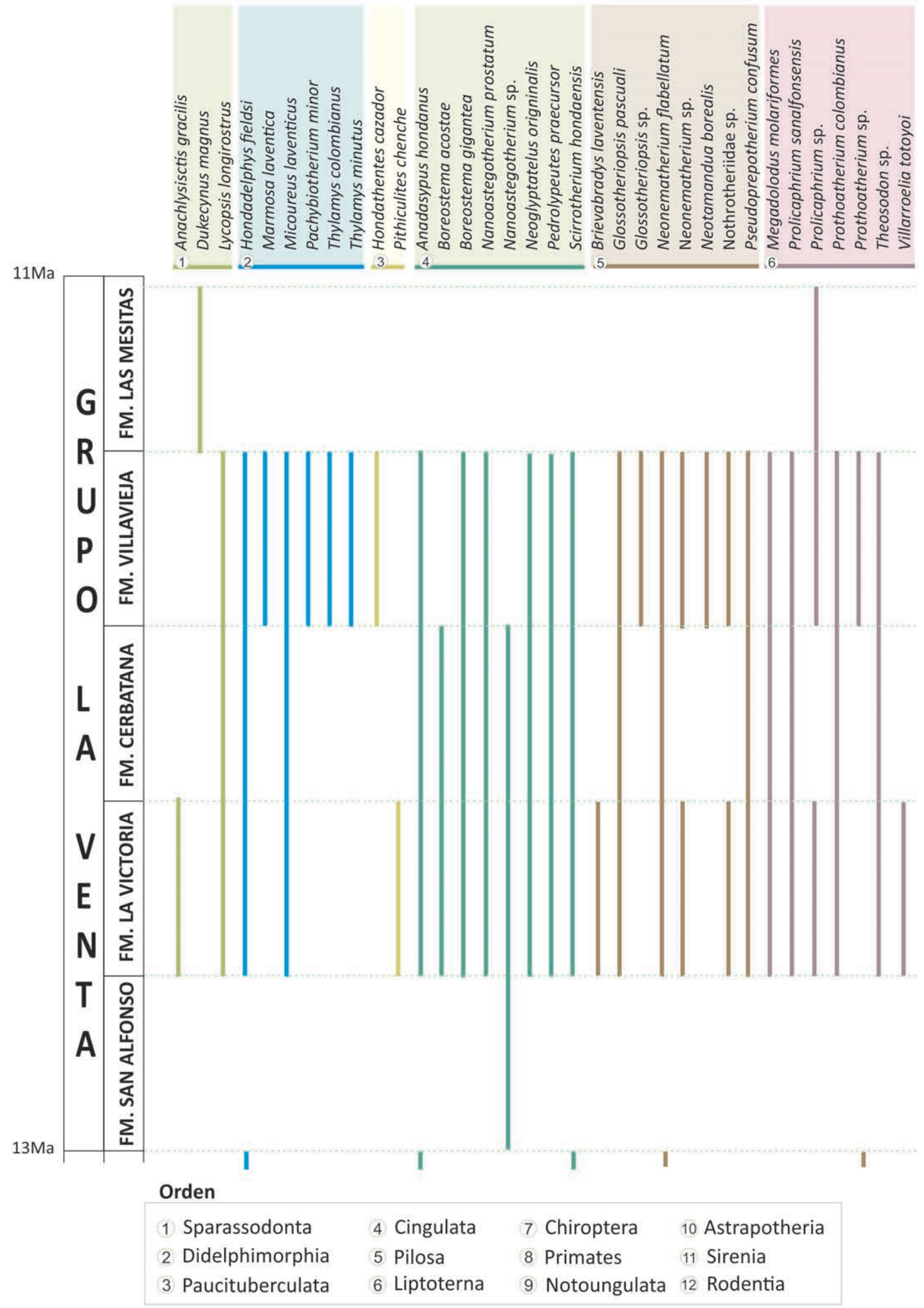



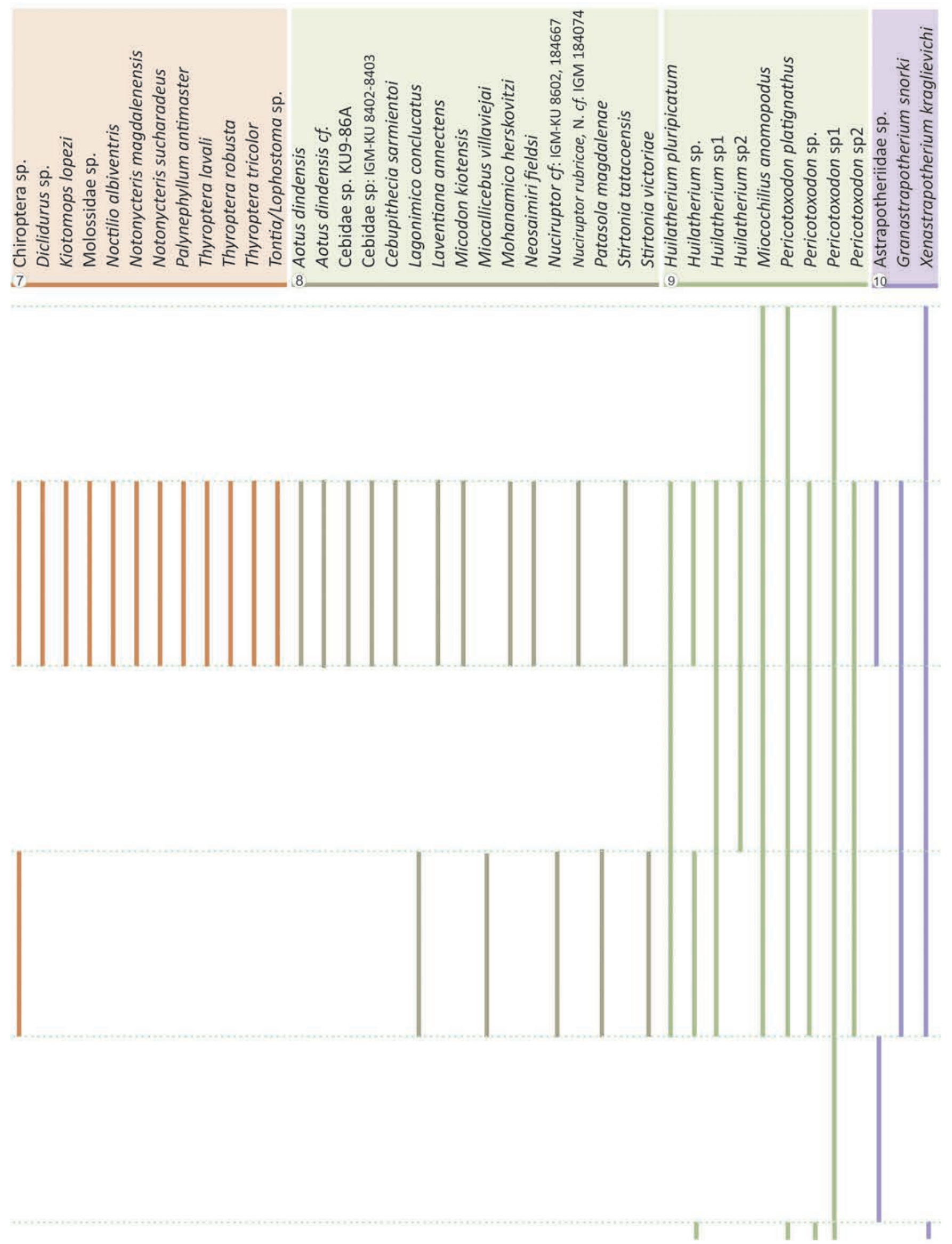

Anexo 27. Propuesta de la Fauna Laventense.

Compilado de: Muñoz - Saba 2017, Madden et al. 1997, Marshall et al. 1983, Hirschfeld \& Marshall 1976, Stirton 1953. 


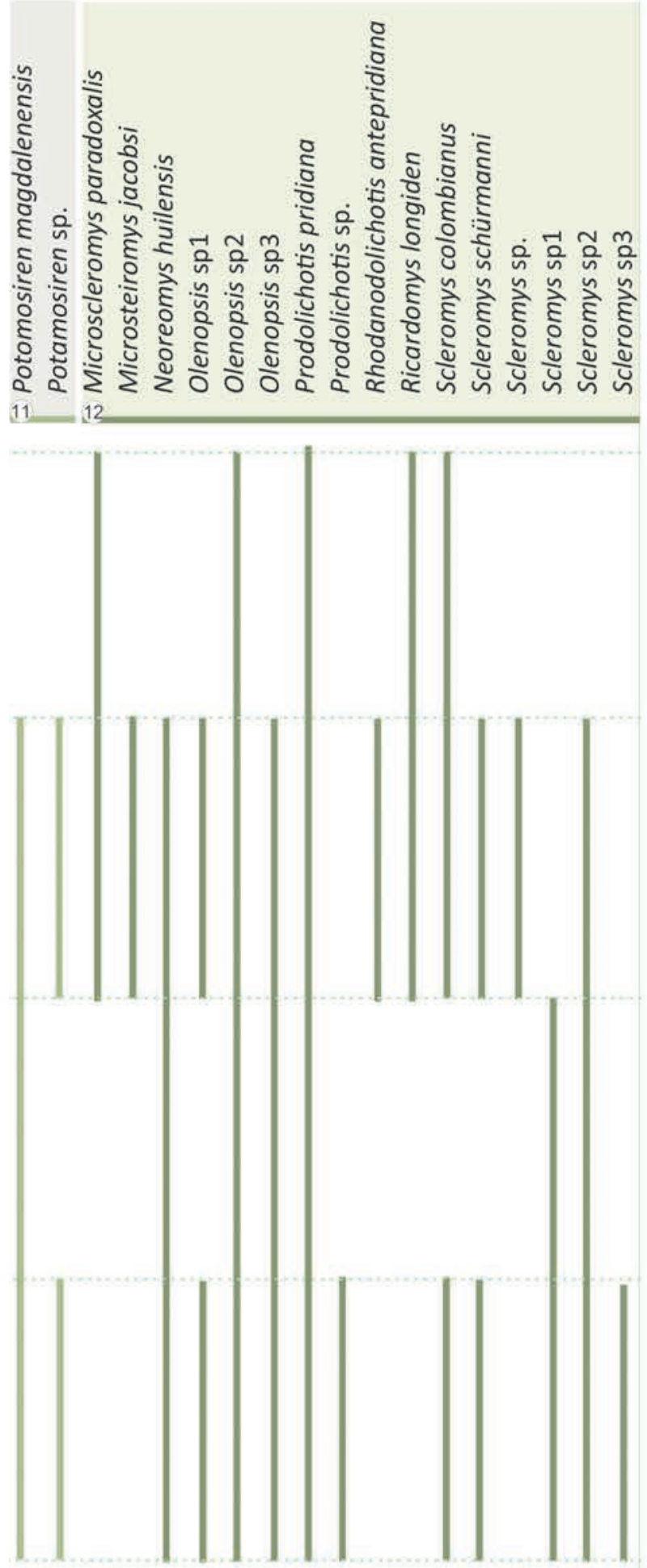

